\title{
REPORTS
}

\section{Migration and Irregular}

\section{Work in Austria}

A Case Study of the Structure and

Dynamics of Irregular Foreign

Employment in Europe at the

Beginning of the 2Ist Century

MICHAEL JANDL, CHRISTINA HOLLOMEY, SANDRA GENDERA, ANNA STEPIEN \& VERONIKA BILGER 
Migration and Irregular Work in Austria 


\section{IMISCOE (International Migration, Integration and Social Cohesion)}

IMISCOE is a Network of Excellence uniting over 500 researchers from various institutes that specialise in migration studies across Europe. Networks of Excellence are cooperative research ventures that were created by the European Commission to help overcome the fragmentation of international studies. They amass a crucial source of knowledge and expertise to help inform European leadership today.

Since its foundation in 2004, IMISCOE has advanced an integrated, multidisciplinary and globally comparative research programme to address the themes specified in its name, short for: International Migration, Integration and Social Cohesion in Europe. IMISCOE members come from all branches of the economic and social sciences, the humanities and law. The Network draws from existing studies and advances innovative lines of inquiry key to European policymaking and governance. Priority is placed on developing a theoretical design to promote new research and offer practical alternatives for sound policy.

The IMISCOE-Amsterdam University Press Series was created to make the Network's findings and results available to researchers, policymakers, the media and the public at large. High-quality manuscripts authored by IMISCOE members and cooperating partners are published in one of four distinct series.

Research

Reports

Dissertations

Textbooks

The RESEARCH series presents empirical and theoretical scholarship addressing issues of international migration, integration and social cohesion in Europe. Authored by experts in the field, the works provide a rich reference source for researchers and other concerned parties.

The REPORTS series responds to needs for knowledge within IMISCOE's mandated fields of migration research. Compiled by leading specialists, the works disseminate succinct and timely information for European policymakers, practitioners and other stakeholders.

The DISSERTATIONS series showcases select $\mathrm{PhD}$ monographs written by IMISCOE doctoral candidates. The works span an array of fields within studies of international migration, integration and social cohesion in Europe.

The TEXTBOOKS series produces manuals, handbooks and other didactic tools developed by specialists in migration studies. The works are used within the IMISCOE training programme and for educational purposes by academic institutes worldwide.

IMISCOE Policy Briefs and more information on the Network can be found at www.imiscoe.org. 


\section{Migration and Irregular Work in Austria}

A Case Study of the Structure and Dynamics of Irregular Foreign Employment in Europe at the Beginning of the $21^{\text {st }}$ Century

Michael Jandl, Christina Hollomey, Sandra Gendera, Anna Stepien and Veronika Bilger

IMISCOE Reports AMSTERDAM UNIVERSITY PRESS 
This study comes out of a larger European Collaborative Research Project entitled Migration and Irregular Work in Europe (MIGIWE), which was implemented on the initiative of the European Science Foundation (ESF) in cooperation with European research institutes in the period 2005-2008. The Austrian part of the research project was financed by the Austrian Science Foundation (FWF).

FWF Project number: P17721-G04

Project Leader: Michael Jandl

Researchers: Veronika Bilger, Sandra Gendera, Christina Hollomey, Michael Jandl, Anna Stepien

Cover design: Studio Jan de Boer BNO, Amsterdam Layout: The DocWorkers, Almere

$\begin{array}{ll}\text { ISBN } & 9789089640536 \\ \text { E-ISBN } & 9789048506385 \\ \text { NUR } & 741 / 763\end{array}$

(c) Michael Jandl, Christina Hollomey, Sandra Gendera, Anna Stepien and Veronika Bilger / Amsterdam University Press, Amsterdam 2009

All rights reserved. Without limiting the rights under copyright reserved above, no part of this book may be reproduced, stored in or introduced into a retrieval system, or transmitted, in any form or by any means (electronic, mechanical, photocopying, recording or otherwise) without the written permission of both the copyright owners and the authors of the book. 


\section{Table of contents}

\section{Acknowledgements}

I Theoretical background 9

I.I Introduction and background 9

$\begin{array}{lll}\text { I.2 Research topic and definitions } & 11\end{array}$

$\begin{array}{lll}\text { I.3 Methodology } & 13\end{array}$

$\begin{array}{lll}\text { I.4 Preliminary hypotheses and research questions } & 17\end{array}$

I.5 Theories on migration and the labour market 19

I.6 Theories on irregular labour migration 26

I.7 Research on migration and irregular work in Europe 33

I.8 Existing research and data on illegal foreign employment in Austria 44

I.9 The regulation of migration and foreign employment in Austria 51

I.Io Control of irregular migrant work at the workplace 56

2 The Delphi study 65

2.I Introduction 65

2.2 Methodology 65

2.3 A short definition $\quad 68$

$\begin{array}{lll}2.4 & \text { Forms of irregular migrant work } & 69\end{array}$

2.5 An assessment of the impact of irregular migrant work 74

2.6 Reasons and motives for employers to employ migrants irregularly $\quad 78$

2.7 Recruitment and social networks $\quad 81$

2.8 Social characteristics of irregularly working migrants in Austria $\quad 83$

2.9 Quantitative developments 86

2.IO Controls in the workplace 93

2.II Political measures against irregular migrant work $\quad 95$

2.I2 Prognoses and scenarios on the future development of irregular migrant work 101

2.13 Concluding remarks 106 
3 Empirical results from migrant interviews

3.I Methodology and sample description

3.2 Legal framework regarding access to employment of non-nationals

3.3 Actors involved in irregular employment networks

3.4 Motives to migrate and work abroad

Working life in specific sectors of irregular work

3.5 The construction sector

3.6 Catering and tourism

3.7 Agriculture

3.8 Domestic services

3.9 Sector-specific conclusions

3.Io Career planning in irregular versus regular work

3.II EU enlargement and its impact on irregular employment of migrants

\section{Conclusions}

4.I Integrating research approaches and results

4.2 Concluding remarks

Annex 


\section{Acknowledgements}

This research report presents the results of a three-year research project on migration and irregular work in Austria. To gain insight into irregular migrant work - a largely hidden phenomenon - we employed several complimentary research methods: document and literature analysis; a survey of expert knowledge through interviews and a systematic Delphi study; as well as narrative, biographical interviews with irregularly working migrants.

Having said this, it becomes immediately clear that our research project would not have been possible without the contributions of many individuals, above all the dedicated work of our multi-disciplinary research team (Veronika Bilger, Sandra Gendera, Christina Hollomey, Michael Jandl and Anna Stepien). In addition to these core members of our team, Martin Hofmann and Albert Kraler made significant contributions during earlier stages of the project. Special thanks go to our external interviewers Eva Huber and Daniela Rechling, who carried out part of our interviews with irregularly working migrants. We are also very grateful to all those experts who provided us with their expert knowledge on the subject, both during the interview phase and in the anonymous Delphi survey. Finally, our deep appreciation goes to the many courageous migrant workers who freely shared their experiences and insider knowledge with us. For understandable reasons, they remain unnamed and anonymous, though in a very real sense they are the true authors of this report.

While the main focus of our project was placed on researching irregular migrant work in Austria, from the outset, the international dimension of the project played an important part of our learning experience. Originally submitted as part of a larger international research consortium under the umbrella of the European Science Foundation (ESF), the Austrian part of the project was funded by the Austrian Science Foundation (FWF). Following some changes to the original structure, the original project was adapted to accommodate close collaboration with our research partners in the Czech Republic (led by Dušan Drbohlav of Charles University) and Hungary (led by Judit Juhász of Panta Rhei Research), both of whom had their national applications funded though are not formal members of the ESF. In a series of inter- 
national workshops and in regular exchanges and communications, this collaboration introduced a Central European dimension to the project, one in which each side could benefit from the insights and progress of the others. A common comparative publication is planned for the near future.

We would further like to thank our host, the International Centre for Migration Policy Development, who provided us with the necessary infrastructure to carry out this project on their premises.

Last but not least, we are grateful for the financial support of the Austrian Science Foundation (FWF), whose research grant enabled us to finance and carry out this project. We would also like to thank the European Network of Excellence IMISCOE for accepting our study for publication and covering the cost of editing. Special thanks goes to Karina Hof, managing editor of the IMISCOE Editorial Committee, and Jaap Wagenaar, our editor at AUP, for the able production of the manuscript in record time.

We are very appreciative of the support of all those named and unnamed individuals and institutions that helped to make this project a success. Needless to say, we take full responsibility for the results of our research. 


\section{Theoretical background}

\subsection{Introduction and background}

In many European countries, the relationship between migration and labour markets has become a hotly contested topic in both public and academic discourse. This is especially true when it comes to the interplay of migration and the irregular employment of foreigners. The precise content of the arguments may vary from one European country to the other, depending on national economic structures and migration patterns, but the debate generally revolves around two main questions. The first is the elusive nature of this hidden phenomenon that hinders our understanding of the true nature of the issue and opens the door to speculative and populist arguments. The second is the more practical issue of what should and could be done in terms of migration and labour market policies.

The problem with this two-pronged debate is that policymakers generally try to answer the second question without a minimally satisfying answer to the first. Both at the national levels and at the level of the European Union, sweeping policy proposals are put forward and swiftly translated into directives, ordinances and legislative instruments, with the intention to curb irregular (more often called 'illegal' or 'undeclared') employment through repressive means (usually a combination of higher sanctions and more controls). To give a striking example of such a wide-ranging policy plan that is based on rather scant evidence, a recent policy proposal of the European Commission (Commission of the European Communities 2007a) proposes sharply increased sanctions (including criminal sanctions for certain types of infringements) against employers of illegally residing third-country nationals, which would require EU Member States to ensure that at least Io per cent of companies per year are subject to inspections to control employment of illegally residing third-country nationals. While this policy proposal, if adopted, would require Member States to multiply their current control capacities and worksite inspections several times over and would likely cost billions of euros, the European Commission supplies no convincing evidence that sanctions and worksite inspections can indeed deliver the desired results. ${ }^{\mathrm{I}}$ 
The question as to whether it is sensible to address the complex relationship between irregular migration and irregular work solely through a package of increased sanctions and controls, and whether it is sensible to target exclusively third-country nationals in this context, will be taken up again in the conclusions to this study. For the moment we would simply like to note that the issue of irregular migrant work has become a familiar topic across Europe, which places this case study firmly at the centre of a European debate. Moreover, the mentioned policy proposal of the European Commission demonstrates two more points of interest - that all governments are facing the problem of reconciling their lack of knowledge on this hidden phenomenon with the need for rational, evidence-based policymaking, and that (partly for the same reason) some European states may be affected by regulations and policies that may not fit their particular circumstances. Both issues can and should be addressed with more in-depth research that is capable of indicating the differences in national circumstances as well as the common patterns that may be susceptible to common policy standards. As such, our own research is firmly linked to the contemporary theoretical and political debate in Europe, and will be interesting for both the Austrian as well as a wider European readership.

In fact, the state of knowledge about irregular migration and irregular foreign employment in Austria has been fairly underdeveloped up to the present. Surveying the literature, one finds very little systematic research on the topic, in contrast to the considerable level of interest these issues have attracted in the media, political discourse and public discussion. Perhaps this should not be surprising, as the phenomenon cannot, by its very nature, be precisely measured, and as primary sources are very hard to come by. In fact, aside from a limited number of scientific publications on irregular migration in Austria, most public knowledge on the subject up to now derives either from anecdotal stories or from evidence collected by law enforcement bodies.

From the perspective of social science, this lack of empirical and theoretical research is clearly unsatisfactory, as migration related to irregular foreign work constitutes an important aspect of social reality in the midst of our society with potentially wide-ranging social, economic and political consequences. Moreover, the growing complexity and dynamics of irregular labour markets call for substantial efforts towards an understanding of newly evolving irregular labour migration systems through rigorous scientific analysis.

Adding to the complex processes of migration and irregular work in Austria, as in other European countries, the 2004 expansion of the EU-I5 to the EU-25 had profound effects on migration patterns to and within the 25 countries of the enlarged EU. Aside from the much-discussed legal access to the labour markets of the EU-I5 countries for citi- 
zens of the new Member States, which at least in Austria and Germany will continue to be determined by national migration policies over the next couple of years, ${ }^{2}$ patterns of irregular foreign employment in Austria have seen significant changes in their structure and dynamics. With the latest $(2007)^{3}$ and future ${ }^{4}$ round of EU enlargement, new framework conditions will shape the dynamics of irregular foreign employment in many European States. To understand these processes, it is important to look at the underlying factors driving and sustaining irregular foreign work. Only by discerning fundamental patterns and structural reasons for irregular migrant work that lead to a holistic understanding of the phenomenon, can sensible policy interventions (either through migration policy or labour market policy both at the national and the European level) be designed, which are able to achieve their desired outcomes, while minimising their unintended consequences.

\subsection{Research topic and definitions}

The main focus of our study is the structure, dynamics and interplay of migration and irregular work in Austria. We understand 'migration' as the international movement and (at least temporary) settlement of a person (who is then called a 'migrant'): that is, the relocation of one's domicile, to Austria. We are furthermore interested in the migration of foreigners (non-nationals) only, thus excluding the migration of (returning) Austrians, but including both the migration of EU nationals and third-country nationals to Austria. We will refer to this group as 'migrants in Austria'.

We are, furthermore, not interested in all aspects of migration and all activities of migrants, but mainly in those aspects that relate to irregular work. 'Work' is conventionally defined as gainful economic activity (employment or self-employment), while the term 'irregular' needs further explanation. When talking about irregular economic activities of migrants, this is often referred to as 'illegal work', referring to illegal status of residence and/or illegal employment. In the course of this research project, it soon became clear, however, that this clear distinction between illegal and legal does not adequately account for the complexity of the phenomenon. Irregular work is increasingly taking place at the margins of legal regulations, often circumventing them, and it is thus not easily distinguishable from regular forms of economic activities. Additionally, irregular work is facilitated by new flexible working arrangements characterised by a blurry legal framework that can easily be misused. Consequently, irregularities are increasingly incorporated in precarious 'quasi-legal' forms of employment, regarding legality of 
residence and employment. Thus, to mark the boundaries of illegal migrant work is difficult. Consequently, the term 'irregular work' as it is used here comprises more than mere 'illegal work' (meaning persons who are either working without residence and/or work permits). For the purposes of this study, then, irregular migrant work is defined as follows:

Irregular migrant work comprises all paid work of foreigners (non-citizens), that conflicts with one or more of the following laws and regulations: foreign employment law (including residence law) social insurance laws, tax laws, labour legislation and trading regulations.

Thus in a legal sense, irregular work of foreigners is distinguished from irregular work of nationals (Austrian citizens) only insofar as currently only non-nationals (except EU-I5 Member States plus Malta and Cyprus) can violate the terms of foreign employment laws, and only third-country nationals can violate residence laws. This definition enables us to incorporate a variety of irregularities occurring on the Austrian labour market, including for example, work without a residence permit, non-registration at social insurance institutions or working as so-called 'pseudo-self-employed'. ${ }^{5}$

Having defined the terms 'migration' and 'irregular work', it becomes apparent that for the current research topic, it is of no specific significance $a$ priori whether or not the migrant worker has entered the country regularly or irregularly. (It is of course important for the opportunity structure of illegally resident migrant workers, as will be shown later). As we are interested only in the irregularity of work activities, the legality of a migrant's entry to Austria is not a pre-selecting factor in the choice of our research subjects. ${ }^{6}$ What matters for the status of the migrant worker, however, is whether his residence status is legal or illegal, whether his access to the labour market is restricted or unrestricted (in the same way as for nationals and EU-I5 citizens) according to migration and employment legislation, and whether his work is regular (for the purposes of social security contributions, taxes, trading regulations, etc.) or irregular. These three dimensions of the status of migrant workers logically result in eight theoretical categories of migrant work status, five of which fall within the domain of this study.

Of these eight theoretical categories, (I) and (3) are regular migrant work and are, hence, not the focus of this study. On the other hand, categories (5) and (6) do not exist, because unrestricted access to the labour market rules out the illegality of residence and (7) does not exist because the permission to work is subordinated to the permission to stay. This leaves categories (2), (4) and (8) as relevant status categories 
Table 1.1 Relevant categories of irregular migrant work status

\begin{tabular}{lll}
\hline & $\begin{array}{l}\text { Unrestricted access to } \\
\text { the labour market }\end{array}$ & $\begin{array}{l}\text { Restricted access to } \\
\text { the labour market }\end{array}$ \\
\hline Residence legal & (1) Work regular & (3) Work regular \\
Residence illegal & (2) Work irregular & (4) Work irregular \\
& (5) Work regular & (7) Work regular \\
& (6) Work irregular & (8) Work irregular \\
\hline
\end{tabular}

for our research. However, it is important to keep all possible categories of work status in mind, as our research has shown that both transitions from one status category to another (e.g. from (3) to (7)) as well as simultaneous combinations of work status for different activities (e.g. (3) and (4)) are a common phenomenon.

A final clarification on our research topic is needed. Our study is concerned with economic activities of migrants in Austria, which are, at least in principle, legal activities. Thus, criminal activities (e.g. cigarette smuggling, drug trafficking or illegal trading activities) are excluded from our research. Moreover, certain types of high-risk economic activities have not been the subject of our research, mainly due to the special difficulties of access to informants and for reasons of personal safety of our interviewers (this concerns mainly sex-work or prostitution).

\subsection{Methodology}

The study has been designed as a basic research project that hopes to provide a better theoretical understanding of the phenomenon of irregular migrant work in Austria through, mainly, qualitative research. Starting from relevant theoretical insights from the large body of migration theories and the rather scarce literature on irregular migration and informal work in Austria, the main challenge of the project was the design and implementation of methods suitable to produce empirical evidence on the structure, characteristics and dynamics of irregular migrant work in Austria. Overall, our project entails three compatible research approaches: secondary data analysis, expert interviews as well as qualitative interviews with irregularly employed migrant workers. This combined approach has been carefully structured in order to overcome a number of practical problems in empirical field research on 'hidden populations' (e.g. where to look for interviewees, how to gain access to them, etc.) and to validate our empirical results through triangulation (Flick 2007). Before these methods will be further discussed, 
it is necessary to say a few words on the suitability of such methods in the study of irregular migrant work.

Our research topic 'migration and irregular work' belongs to the category of research studies on 'hidden populations', which cannot be easily observed. Such populations are often also referred to as 'rare', 'elusive' or 'hard-to-count' populations and include, for example, illegal residents, male prostitutes or the homeless, as well as irregular workers (Chelimsky I99I; Schönwälder et al. 2004). Almost by definition, there are no official data on the whole group of research subjects under investigation, as irregular migrant workers and in our case also their employers have an incentive to hide their identity from the authorities. Therefore, there are no fully reliable quantitative methods to derive knowledge on the complete universe of the individuals in question, although there are several indirect estimation methods that can provide indications on the extent and characteristics of the phenomena under study (for an overview, see for example, Jandl 2004; Pinkterton et al. 2004; Sheldon 2002). Larger volumes of data are seldom available, except in rare circumstances where researchers have access to comprehensive police files and are able to carry out comprehensive surveys, or in countries with regularisation campaigns (see e.g. Engbersen I999a, 200I; Massey \& Zenteno 2000; Durand \& Massey 2004; Massey 2004). In most cases, however, the hidden character of the phenomenon prevents us from drawing a representative sample for quantitative studies (e.g. surveys or secondary data analysis), as the distribution of relevant characteristics (age, gender, nationality, economic sectors) is not known, and research is largely constrained to qualitative methods (Vogel 2003).

In recent years, a number of such studies on irregular foreign employment in other European countries have demonstrated the usefulness of qualitative empirical methods to the research subject in question (see e.g. Schönwälder et al. 2004 for a review of thirteen case studies on irregular migration). Due to their small sample sizes (normally between twenty and 40 interviews), it is hard to demonstrate the general validity of the conclusions (hard to replicate) with regard to irregular migration and informal labour markets. Still, they serve as an important source of information on a number of issues such as migrant motives, work-related strategies and types of organisation. It is thus widely agreed among international researchers that due to the sensitive and difficult nature of the underlying area of research, the use of qualitative empirical methods is essential (Lederer \& Nickel I997).

As we will see in Section I.7, in Austria there has been very little systematic research on irregular migrant work to date, despite the widely presumed significance of the phenomenon. The few studies that do exist take a limited qualitative approach (e.g. Behr 2003; Hofer I994; So- 
cial Impact 2000) or try to deduce the overall extent of informal work through indirect estimation methods (Biffl 200I; Schneider 2002, 2005, 2006). Aside from limited administrative data, there are no comprehensive data, large-scale surveys or regularisation campaigns. Due to these difficulties of obtaining reliable and suitable data on the quantitative dimension of irregular foreign employment, the qualitative aspects of irregular foreign employment are thus the main focus of our research, carried out mostly through qualitative research methods. Nevertheless, our study can also contribute to the debate on the quantitative dimensions of irregular foreign employment by gaining new insights into the organisation, structure and extent of the phenomenon in certain sectors and branches and thereby narrowing the range of plausible quantitative estimates.

In this study, we present results obtained through three complementary research methods. These should be briefly introduced here. A more elaborate description of the Delphi survey and the interview techniques for our migrant interviews will be presented at the beginning of Parts 2 and 3 of this report.

\section{Secondary data analysis}

In an initial phase, a topical review of the existing literature on the subject was carried out, which identified a number of empirical studies on the subject in other European countries but only few such studies on the Austrian situation. Nevertheless, many topical studies on other European countries, especially those on Germany, provide theoretical and empirical insights of relevance for the Austrian context as well. While irregular migration patterns and labour market structures may differ from case to case, insights into fundamental social processes elsewhere may still be valid for Austria as well. At the very least, these studies provide a starting point for formulating research questions and a valuable reference point for comparative analysis.

Parallel to the literature review available, administrative and statistical data relevant to the subject were identified and collected. Only few such data were identified in existing administrative records (e.g. police apprehensions of foreigners, entry-bans for foreigners based on preceding irregular foreign employment) and fewer still were considered relevant and suitable for the research topic (e.g. statistics on the detection of foreign workers on worksites by specialised units of the labour inspectorate or the customs office). 


\section{Expert knowledge}

One commonly pursued methodical approach in the study of irregular migration phenomena is the interviewing of selected key-informants or experts. 'Experts' are persons with specialist knowledge or special insights due to their role of producing information or having privileged access to information about certain groups of persons or of decisionmaking processes (Meuser \& Nagel 2002: 73). Therefore, unlike other forms of open interviews, in expert interviews it is not the biographical aspects of the interviewed persons, their orientations, attitudes or interpretations of their own lives that is of importance to the analysis, but rather the shared knowledge of experts on a certain phenomenon (ibid.: 72)

As access to data on irregular migrant work is very limited in Austria, our main aim in drawing on expert knowledge was to benefit from experts' 'head start' in terms of knowledge on various aspects of the field (Bogner \& Menz 2005). Therefore, in order to fully benefit from available expert knowledge on irregular migrant work in Austria, a twostage procedure was adopted. In the first stage, semi-structured interviews with 36 Austrian experts were conducted, transcribed and analysed. Experts were selected from a variety of fields and institutions, where their opinions and judgments were considered relevant to the research topic. These comprised, for example, labour market experts from chambers of commerce and labour, trade unions, ministries and academia; law enforcement experts; practitioners from charity and aid organisations, migrant organisations and migration researchers.

In the second stage, the so-called Delphi method (two rounds) was applied in carrying out and evaluating expert interviews. The design of the first Delphi questionnaire was guided by the preceding round of expert interviews as well as the literature review. The Delphi method involves a large number of independent experts in an interactive process of exchange through the use of written questionnaires, designed to foster convergence and consensus (see e.g. Linstone \& Murray I975; Rowe et al. I99I; Lachmanová \& Drbohlav 2004). Experts are given the opportunity to state their views on a given topic and react to the (anonymous and consolidated) views and assessments of other experts in the second round. Our Delphi survey involved the processing of two rounds of questionnaires, which were answered by 37 experts in the first round and 22 experts in the second round. More details on the Delphi method are presented in Part 2 of this report. 


\section{Migrant interviews}

To collect qualitative empirical data and to obtain an inside perspective on migration and irregular work, the main part of our research project consisted in the selection, identification and implementation of 50 Problem-Centred Interviews (Witzel 2000) with irregularly working migrants in Austria, i.e. face-to-face interviews with individuals who have first-hand knowledge of the subject themselves. As a qualitative interview technique, 'the principles guiding a Problem-Centred Interview aim to gather objective evidence on human behaviour as well as on subjective perceptions and ways of processing social reality' (Witzel 2000: I), viewing interviewees as agents in their decision-making processes and actions in a specific situation. The main aim therefore is the exploration and comprehensive description of processes and relevant aspects that can only be provided from 'insiders', in order to achieve a better understanding of social reality. In contrast with interviewing experts, who distance themselves from the subject in question but provide their expertise in a specific field of activity, affected persons can convey their very personal and subjective perspective of a process or a situation.

Over a period of more than a year, a total of 50 interviews with migrants, who were irregularly working in the most notorious branches and activity areas of the Austrian economy, were carried out. The sample selection (Schatzman \& Strauss I973; Sandelowski et al. I992) of interviewees was based on regions of employment, economic activities, gender and nationality, and was intended to be broadly representative of the branches, seasons, and activities in which particular irregularly working migrants are presumably concentrated, according to the preliminary results obtained in the Delphi survey. A detailed description of the interview sample, methods of analysis as well as further reflections on methodological problems in this type of research is provided in Part 3 of this report.

\subsection{Preliminary hypotheses and research questions}

Our research aims at contributing to improving the knowledge base in two disciplines: migration as well as labour market research. The main objectives of the project are to fill a major gap in Austrian migration research; to identify the main underlying factors driving and sustaining irregular foreign work; to discover fundamental patterns and structural characteristics of irregular migrant work; to identify shifts and changes in these patterns and characteristics that result in major socioeconomic trends; to determine the impact of (successive rounds) of EU enlargement on irregular migrant work in Austria; and to compare and con- 
trast our findings with the regulatory intentions of state policies and control mechanisms.

Based on a preliminary survey of the literature, a number of hypotheses were constructed to guide our theoretical interest and to be tested against empirical evidence:

I. Due to high income differentials, there is a large potential supply of regularly and irregularly working migrants in Austria from lowerincome countries in Central, Eastern and South-Eastern Europe.

2. In certain sectors and branches of the Austrian economy, there is a considerable demand for irregular foreign labour.

3. Irregular migrant work is in most cases accompanied by a de-qualification of the migrant workers accepting low-skilled work.

4. Irregular migrant workers in Austria strongly depend on the existence and functioning of social and family networks, and increasingly on professional networks of illegal job providers as well.

5. Access to irregular labour markets varies considerably according to the impact of specifically targeted policies (migration policy, labour market policy, enforcement measures, etc.) and the amount of administrative and 'social' control.

6. The 2004 enlargement of the EU had a profound impact on the structure and dynamics of irregular migrant work in Austria.

7. The ongoing process of EU enlargement has noticeable (substitution) effects on already established regularly and irregularly working migrants in Austria.

Based on these rather general hypotheses, more specific hypotheses and research questions were developed and operationalised in the formulation of the guidelines and questionnaires for the implementation of the expert interviews, the Delphi surveys and the migrant interviews. We will return to the above hypothesis in the concluding Part 4 of this report. 


\subsection{Theories on migration and the labour market}

As migration itself is a multifaceted social phenomenon that can be understood in its entirety only through a holistic approach, the study of migration tends to be multidisciplinary or it at least draws on a multitude of theoretical models from a number of social science disciplines (Hammar et al. 1997; Castles \& Miller 2003). This has resulted in a number of complementary - as well as competing - theoretical explanations of migration processes (cf. Arango 2004; Massey et al. I993; Lebhart 2002). Among the many theoretical approaches to migration, those emanating from the fields of economics and sociology stand out, both in their prominence and in their usefulness for the explanation of labour market-related phenomena such as irregular migrant work. We will therefore provide a short review of such disciplinary approaches, focusing on their potential contribution to our own research subject.

Sociological theories typically look at a broad spectrum of factors that can give rise to, shape and sustain migration flows. One of the oldest such models and one that has possibly contributed most in shaping theoretical thinking about migration is the push-pull model as proposed by Lee (1966). This model explains migration as the outcome of two complementary sets of factors impinging on the individual decision-maker, i.e. the (potential) migrant. First, there are the detrimental factors in the place of origin that make life hard and unpleasant for the individual in question (the 'push factors'); second, there are the desirable factors present in the place of destination that the individual perceives as a positive contribution to his well-being (the 'pull factors'). Between these two areas is a set of obstacles that has to be overcome if the migration decision is to be carried out (the 'intervening factors'). These last factors will increase the costs of migration and work against both push and pull factors. The decision to migrate for a given individual, then, is based on a comparison of the total value of the set of relevant factors at the place of origin (including the push factors) with the value of the set of relevant factors at the place of destination (including the pull factors), taking into consideration the intervening variables.

Although the model is rather general, it is attractive for a number of reasons. Factors such as distance of migration, migration costs and migration risks (particularly to irregular migrants) can all be potential variables in the model, as can labour demand, wages, unemployment and other economic factors. The greater the (perceived) difference in the net forces of attraction and repulsion at origin and destination, the more likely migration will take place. Moreover, Lee argues that migrants motivated primarily by pull factors would tend to be positively selected (by age and qualification), while those driven by push factors would tend to be negatively selected. Whether this is indeed the case, 
however, remains contested up to this day in the face of contradictory evidence (cf. the discussion on the human capital approach to migration later in this section).

While push-pull models offer some generally useful elements to explain migration processes, approaches that focus particularly on labour market and employment structures as key variables within such models are especially relevant for the current research subject (cf. Treibel I990; Steinbeck 1994). Some authors have drawn attention to the existence of 'global inequalities and differential opportunities' (Borowski et al. 1997: 44; see also Treibel 1990) and identify the unequal economic, demographic, political and cultural conditions as the 'root causes' of migration (Doomernik et al. I997: 62). However, despite the seeming plausibility of such aggregate, macro-sociological explanations, other authors have pointed out that they cannot fully account for the complexity of modern migration movements (cf. Borowski et al. I997; Müller-Schneider 2003).

Another major sociological contribution to migration theory focuses not so much on the individual but on his socially embedded nature, recognising that migrants often move together with their family and friends or join their relatives abroad who have moved first (Massey I988; Massey et al. I998; Portes \& Sensenbrenner 1993; Portes I995). The concept of a migration network, as 'sets of interpersonal ties that link migrants, former migrants and non-migrants in origin and destination areas through the bonds of kinship, friendship and shared community origin' (Massey I988) constitutes a form of social capital that migrants can draw upon for help, information, access to jobs, accommodation, social protection and much more.

Migration networks cannot explain why migration has been initiated in the first place, but they provide us with a powerful illustration why migration from particular locations, once initiated, tend to become selfsustaining and 'progressively independent' from their original conditions (Massey 1989). Thus, network theory has become extremely important in the study of migration and may be particularly relevant in the study of irregular migration and irregular migrant work. Several empirical studies have demonstrated that for irregular migrants, assistance in the process of migration, the provision of (irregular) accommodation and the avoidance of state controls will play even a larger role than for regular migrants (e.g. Alt I999a, 2003a; Lederer \& Nickel I997). In all these functions, networks can help to reduce the social, economic and emotional costs of migration, as argued by the proponents of migration network theory (Faist 1997; Light \& Bhachu I993; Massey I989).

Moreover, for access to irregular work, information about job opportunities is usually communicated within established networks, rather 
than advertised freely in front of law enforcement agencies (Doomernik et al. 1997). Besides informal networks of family, friends and ethnic compatriots, professional networks of labour brokers and people smugglers also act on the intermediary 'meso'-level of migration actors and have drawn the attention of the scientific community for over a decade now (cf. Faist 1995, I997; Heckmann 2004; Jandl 2007; Kyle \& Koslowski 200I; Mavris 2002; Salt \& Stein I997). In his monumental study on illegal migrants in Munich and other German cities, Alt (2003a) notes the parallel existence of private networks, characterised by strong ties of interpersonal relationships, ethnic networks based on weak ties of common heritage, commercial networks based on weak ties of common interest (such as those of irregular labour brokers) where illicit services can be bought on informal markets, as well as criminal networks that involve the exploitation and deceit of irregularly working and/or residing migrants. Alt (2003a) notes that there is no inherent contradiction between the existence and usage of these various types of networks and estimates that for irregular immigrants in Germany (the subject of his studies and interviews), non-criminal networks are dominant (330). Among other things, this conclusion is based on his observation that for certain forms of irregular migration (e.g. irregular circular migration from/to neighbouring countries to the east of Germany), the significance of professional networks has declined as migrants have accumulated their own migration-specific knowledge and personal contacts.

A relatively recent field of migration research has focused on the study of transnationalism, which is the simultaneous involvement or attachment of migrants both in their host and sending society (Vertovec 1999, 2004). The study of transnationalism rejects the notion of migration as a one-time process and recognises the (real or notional) involvement of migrants both 'here' and 'there'. It thus transcends theories that focus only on the initiating factors of migration and those that deal with the process of interaction (or integration) with the new host society (cf. Collyer 2005). In transnational approaches, migrants are conceptualised as acting in a transnational social space that 'stretches' the economic, political, social and cultural interactions in which migrants were involved before migration, so that they remain active following migration (Faist 2000). Writers on transnationalism have identified a number of different types of transnational involvement (cf. Bauböck I994; Itzigsohn et al. I999; Pries 1999), which has broadly divided the field into studies of economic transnationalism, political transnationalism and transnational identities (Tamas 2004). While the literature on economic transnationalism has not yet developed into a consistent theoretical approach that can guide our own research project, there are many important elements, such as the study 
of cross-border networks, which figure prominently in the study of irregular migrant work (cf. Faist, 2000).

Generally, we can expect transnational practices of migrants, regular and irregular, to become much more common than in the past. On one level, the "world-wide expansion of modern communication structures' (Müller-Schneider 2003: 20) and lower costs for travel and transport (Heckmann 1995) enable transnational ties to be maintained much more economically than in the past (Vertovec 2004)..$^{7}$ On another level, such increasing interactions are also suspected of reinforcing a 'global integration of values', at least as far as expectations of a 'good life' and economic and social aspirations are concerned (cf. Hoffmann-Nowotny 1993). Taken together, such 'globalisation' forces may account for both a higher willingness to migrate and a greater ability of many to do so. Moreover, such socioeconomic and technological trends also enable new forms of transnational mobility, such as more circular migration across greater distances. As we will see, when such enabling forces work together with national control policies (e.g. visas that limit length of stay), transnational practices and particularly circular migration patterns are especially likely to be relevant for irregular labour migration in Europe.

Economic theories of migration provide the second disciplinary strand of major relevance to our research subject. Economics has long treated migration in analogy to the movement of goods and capital in pursuit of profit. Thus, in macroeconomic theory the movement of people has come to be seen as the reallocation of scarce factors of production (labour and capital), whereby 'labour' should always 'flow' from low wage to high wage areas, while capital should flow the other way around (Heckscher-Ohlin theorem). Further, it has been argued that, given the general efficiency of free markets, this is a necessary and desirable process in the course of economic development (e.g. Lewis I954).

Later, in view of the presence of considerable unemployment and partly in reaction to Lewis's model, it has been pointed out that the assumption of full employment - underlying much of neoclassical economic theory - does not fit with reality, and that individuals therefore take the chance of being unemployed into account when making a migration decision. The expected income theory of migration (Harris \& Todaro I970; Todaro I976) essentially weighs prospective income (over a certain period) from a job in destination areas against the probability of getting such a job. The resulting 'expected income' is contrasted with the 'expected income' in the place of origin by the prospective migrant. The conclusion is straightforward: If the expected-income differential (net of migration costs) is positive, migration will occur. For an extension of this theory, whereby the migration decision is based on a 
rational cost risk-benefit calculation, is provided by the more generalised 'value-expectation theory' (Esser I999).

Common to both classical and neoclassical economic theories of migration is their fundamental assumption of rational individuals striving to maximise utility (cf. Djajic I989). Thus, migration is seen as the outcome of a rational individual choice, which will occur as long as the economic incentives (the differences in wage rates) are sufficiently high. A further extension of the economic approach to migration has been provided by human capital theory. Building on the work of Sjaastad (I962), this theory argues that a rational individual will base his decision to migrate on the present value of future income streams (his 'human capital') in any possible location net of migration costs (cf. Borjas I989; Massey et al. I993). In the simplest case, where income is the sole determinant of utility, the individual will choose to migrate to a location that maximises the net present value of his human capital.

The human capital approach to migration has a number of interesting implications. It provides some hypotheses on who the migrants are (in terms of their characteristics), as well as when migration would be most beneficial for them (i.e. at what stage in their life cycle). Probably the most widely known hypothesis of this theory is the so-called 'selfselection hypothesis': potential migrants will base their migration decision on the potential gain they can secure by transferring their existing human capital to a different location, thereby increasing their future real income stream. Because the gains in income will be higher for certain individuals than for others - owing to their specific endowment with human capital - and because direct migration costs are supposed to be the same for all, it follows that migration will preferably be undertaken by individuals with certain characteristics. In the "normal case' (implying 'positive self-selection'), the typical migrant is supposed to be young, well-educated, in possession of an above-average human capital endowment, and will therefore prove to have an above average earnings profile (e.g. Chiswick I979, I999). However, under certain circumstances, such as high unemployment in the country of origin, a 'negative self-selection' is possible as well (e.g. Borjas I989).

While traditional economic theories of migration have focused on the individual as the unit of decision-making and differences in wage and (expected) income levels as determining factors, the 'new economics of migration' (Stark \& Bloom I985; Stark \& Taylor I989; Stark I99I) have been celebrated for drawing attention to a new set of genuine motives determining migration processes. Key features of these elegantly formulated economic models are a shift from individuals to households as decision-making units; the introduction of additional factors in the utility functions (e.g. risk aversion, the distribution of income/wealth as relative deprivation); the conceptualising of migration 
as an ingenious strategy to overcome market failures and price distortions (e.g. in credit markets, insurance markets).

The new approaches demonstrate that, under certain assumptions, migration can be a rational strategy to pursue even in the absence of income differentials (though it does not deny that these can still be a powerful motivation for engaging in migration). The goal of diversifying risk, the attempt to switch to new technologies in the absence of sufficient capital, concern over one's relative ranking in the income distribution and other factors all constitute valid and sufficient motives for migrating (Stark I99I).

One of the most important deviations of the "new economics of migration' from conventional economic migration theories is certainly the redefinition of the ultimate decision-maker. Families or households make a joint decision that can result in the migration of one of their members (as in the case of risk-spreading). Individuals are said to abide by the decision since the institution of the family can secure 'economies of scale' as well as 'economies of scope', maximising family income and thus leaving everybody in the family better off. The links between family members manifest themselves through remittances between migrants and non-migrants and through individual action on behalf of the household. This new theoretical paradigm leads to several testable hypotheses as to who the migrants are (e.g. those individuals who can secure the maximum utility for their families through migration, persons from the lower end of the income distribution of their respective reference group) and how migration processes evolve over time. Once migration from a certain area has begun (innovation), the environment in which further migration takes place is altered, facilitating and stimulating further migration (imitation), eventually leading to the establishment of migration networks and transnational practices. In this sense, the new economics of migration can also be seen as a complementary model to network theories and transnational approaches.

In contrast to the classical and neoclassical economic theories discussed above, the so-called world systems theory draws on a fundamentally different (neo-Marxist) theoretical tradition. In this framework, the macrostructures are studied that give rise to worldwide migration streams. This approach has a lot in common with dependency theory in that its primary concern is with the expansion of the 'core' capitalist economies to the underdeveloped countries of the 'periphery'. Migration can then be linked to the institutional and socioeconomic inequalities between the core, the semi-periphery and the periphery (e.g. Wallerstein I974; Parnreiter I994). Other writers in this tradition have emphasised the importance of historical, cultural, linguistic and ex- 
colonial links for the emergence of migration systems (Portes I995; Sassen i988).

Finally, an important strand of economic theory for our research subject is the so-called dual labour market theory, as applied to migration (e.g. Piore 1979; Portes 1997). This theory focuses almost exclusively on the receiving end of migration, arguing that international migration is mainly caused by a permanent demand for cheap labour that results from specific characteristics of labour markets in highly developed industrial societies. Thus, international migration responds to the needs of modern industrial economies and serves and perpetuates the demand for cheap labour in industrial societies, which arises because labour markets are said to be fundamentally segmented. On the one hand, there are the permanent, high-paying jobs that demand considerable skills and training from their workforce and, on the other hand, there are the low-paying, labour-intensive, low-skilled, less permanent and often irregular jobs. These positions are less attractive to natives and are therefore increasingly filled by willing foreign workers. In this world, employers can avoid wage increases for low-paying - and therefore unattractive - jobs by importing cheap labour (which is often actively recruited) and/or by employing migrants irregularly. The basic tenet of this economic approach to migration is nicely summarised in the following quote: 'Contrary to widespread perceptions, immigrants come to the wealthier nations less because they want to than because they are needed' (Portes I997: 5).

In a modern interpretation of the dual labour market theory, economic globalisation does not only create opportunities for highly qualified labour but is also generating opportunities for poorly qualified and unskilled workers. Especially in the service industries, a wide range of job opportunities evolved that require no special training or qualification, while at the same time, social status and salaries connected with these jobs are not attractive enough for the domestic population (Arango 2004). The resident population has little or no motivation to accept the low wages, the unstable labour conditions and the few career prospects these jobs might offer. Thus employers turn to immigrants in order to satisfy shortfalls in this segment of the labour market. Due to the restrictive immigration and labour market policies imposed by most of the industrialised states, existing vacancies cannot always be filled by the use of legal immigration. As far as potential employees are concerned, there is a virtually inexhaustible potential supply of manpower on the international level. The wage and purchase power differentials between industrial and developing countries turn even the lowest wages in the West into an incentive for migrants to overcome all migration barriers. 
A specific hypothesis in this theoretical tradition is the Global City hypothesis as developed by Saskia Sassen (I99I). According to this argument, economic globalisation and the shift to a service economy in industrialised countries has led to a demand for highly skilled labour in large cities. However, the reproduction of these highly skilled workers requires the help of many unskilled and flexible workers at the bottom of the occupational hierarchy in the service economy, a demand that is mostly met by a constant supply of migrant workers, many of whom are employed irregularly (see also Section I.6). Whereas Sassen (I99I) focuses mostly on the demand side of immigration to large cities, other authors have combined this approach with network arguments to reinsert the supply side of migration. Light (2004) uses a two-stage model to explain current migration processes, whereby immigration in the first phase is demand-driven and in the second phase (through network effects) is supply-driven. Because migrants continue to arrive in large cities even after the saturation of the mainstream urban labour markets, but need employment and income to survive in their new host country, a process of 'over-urbanisation' takes place, that is the spreading of immigrants into the informal sector and the socalled ethnic economy, which act as a buffer (ibid.: $387 f$ ). According to Light, these 'ethnic economies and informal sectors enjoy an economic capacity for virtually unlimited expansion in response to self-propagating migration' (2004: 390). Thus, further immigration is not limited by the economic absorption capacity of the labour market, but by the political will and ability to control it.

\subsection{Theories on irregular labour migration}

Before turning directly to studies on the interlinkage of migration and irregular work, it is instructive to look at a more general perspective on informal economic activities. In their comprehensive study on informal employment in advanced economies, Williams and Windebank (I998) embed their analysis also in an assessment of wider changes in patterns of employment and labour market structures. The authors define informal employment as:

paid production and sale of goods and services that are unregistered by, or hidden from, the state for tax, social security and/or labour law purposes, but which are legal in all other respects. ${ }^{8}$

Evaluating various available quantitative approaches to the study of irregular employment (including indirect non-monetary methods, indirect monetary methods, income/expenditure discrepancy methods and 
direct survey methods), the authors conclude that each of these approaches has its own limitations, and that only a combination of different methods is likely to generate valid estimates. What is clear, however, is that in most advanced economies it is native citizens, rather than immigrants, who perform the bulk of underground activity, even if a significant share of immigrants can be involved in underground activity.

In their theoretical chapter, Williams and Windebank (I998) evaluate two major hypotheses that have been put forward to describe trends in informal employment: I) the formalisation thesis, closely connected with modernisation theory (as states modernise and develop, informal employment relationships all but disappear) and 2) the informalisation thesis (in advanced economies, employment is increasingly informalised as a response to 'over-regulation' of the labour market). Criticising their underlying assumptions, the authors dismiss both of these theses as fallacies and suggest that it may be better to look for more contextualised and geographically specific characteristics of informal employment, rather than try to establish universal trends for a globally diverse phenomenon.

As we will see, however, most theoretical concepts put forward as explanations of underlying trends in irregular migration and irregular migrant work do exactly that - they are not contextually embedded, often monocausal and apparently time insensitive. Such concepts can be roughly divided into demand, supply and regulatory arguments. ${ }^{9}$

One such structural demand-led explanation was already mentioned among the general migration theories, namely the Global City hypothesis, whereby the globalisation of the economy provoked the rise of a service industry, coupled with the decline of the old manufacturing industries, which drives the growth of the informal economy as a characteristic feature of post-industrial urban economies (Sassen I99I). ${ }^{\text {IO }}$ These processes take place either directly (through flexibilisation of labour and by contracting out specific tasks) or indirectly (by increasing income inequality and the demand for personnel in cleaning, care for children and the elderly). Such informal jobs in the service industry especially attract people with a disadvantaged position in the labour market, and natives are usually unwilling to take up such jobs because of their low status and wages. Moreover, governments have become more restrictive regarding the admission of low-skilled migrants hence the demand for irregular migrants. On the other hand, when the specific demand for low-skilled workers at the bottom of the occupational hierarchy cannot be filled, this may lead to 'structural inflation' (Joly 2000: 29). The Global City hypothesis has been widely debated in the literature but has also drawn much criticism for its simplistic as- 
sumption of ever-widening polarisation of income and occupational structures (see e.g. Samers 2002).

A more general hypothesis referring to globalisation argues that due to increasing global competition, employers (especially small- and medium-sized firms) are forced to cut wage (and non-wage) costs and ensure flexibility by resorting to informal (migrant) workers (Overbeek 2002). Part of this flexibilisation takes place through outsourcing and subcontracting of production processes that result in precarious employment relationships and violations of labour regulations (Mingione I999). However, as has been pointed out elsewhere (Samers 2005), while certain sectors may indeed face severe cost-cutting pressures due to global competition and thus rely heavily on migrants working irregularly, the need for flexibilisation does not necessarily lead to more demand for irregular migrants and may even mean the opposite. As Iskander (2000) points out in her study of the Parisian garment industry, the share of workers in an irregular work situation in this sector is apparently fairly low, while so-called 'hybrid arrangements' of formal/informal work through ever more complex forms of subcontracting seem to be increasing. She thus argues that:

...as these hybridised forms of informality become more widespread, undocumented immigrant workers lose their competitive edge of offering firms 'no-strings-attached employment.' [...] As a result, being an undocumented immigrant is no longer an advantage. In fact, it has even become something of a liability because it means that they cannot work under semi-formal employment arrangements with one or more facets that are declared and above board. (2000: 46)

Another demand-side perspective focuses on the industrial structure of an economy, arguing that in economies dominated by smaller firms, there would be a higher demand for informal work than in economies made up of fewer, but larger, corporate firms. Smaller firms tend to be less unionised and rely more on subcontractors (see also Williams \& Windebank I998). Building on this analysis, Samers (2003) argues that the massive decline of migrant workers in industry and the concomitant increase of new service jobs also led to a rise of irregular work (or informal employment, in his terminology). However, he also sees no reason to believe that a growth in informal employment will inexorably lead to a rise in the number of undocumented immigrants working in such jobs. Quoting Iskander (2000), Samers (2003) hypothesises that the alternative labour supply of EEA citizens (mainly Portuguese unskilled workers) working in informal and semi-formal work may have been important in reducing the demand for undocumented 
migrant labour in the French case. At the same time, the French state's massively expanded policing of undocumented migrants - coupled with the fact that the advantages associated with the employment of undocumented migrant labour were gradually eroding - contributed to the decline of irregular employment of undocumented migrants. Samers concludes that 'undocumented immigration is intimately bound up with capital accumulation and the nature and regulation of labour markets' (2003: 575). Thus, by implication, an exclusive focus on normative categories like 'undocumented migrants' or migrants in an irregular situation is bound to miss the really fundamental points - the changing structures and power relations effective on labour markets and changing state and employer strategies of regulating employment.

Another demand-side argument holds that the degree of affluence experienced in many industrialised countries creates a demand for informal work. In this view, formal and informal activities are complements rather than substitutes, and an increase in the former will lead to an increase in the latter (e.g. Marcelli 2004). While this argument may be more valid in certain contexts (e.g. for domestic workers in cleaning and care) and at specific times and locations than in others, in its generalised form, this 'affluence thesis' is certainly not supported by available comparative data (see e.g. Reyneri 200I on the relatively high levels of informal economies in southern European countries, compared to their more affluent northern European neighbours).

A related demand-led perspective refers to the demographic, socioeconomic and lifestyle developments that lead to a higher demand for migrant workers, particularly female migrants irregularly working in private households (e.g. Anderson 2000, 200I). According to this view, demographic aging increases the demand for old-age care across Europe, while a rising female labour force participation leads to higher demand for (irregular) domestic services (childcare, care for the elderly, cooking, cleaning, etc.).

Regarding supply-side arguments on migration and irregular work, the most prominent argument holds that the large (and apparently increasing) volume of unsolicited migration experienced by high-income countries is fostering the growth of informal or irregular economic activities (cf. Light 2004). As we have seen in the previous section, migration is often explained by differential conditions in the country of origin and destination that give rise to migration flows. The same arguments can be applied to irregular migration and migration and irregular migrant work. For example, Jahn and Straubhaar (I998) argue that 'if the utility difference between host and receiving society is large enough, for some people the net present value of migration minus regular transaction and transportation costs of moving [...] minus the expected risk of being caught and punished remains positive. This means 
they will offer their work in a host country even if this is only possible irregularly. So we will have a supply of illegal foreign workers' (I998: Io). While Jahn and Straubhaar continue by emphasising the important role of the demand for irregular labour in this equation, others are less balanced. In many cases, the arguments quickly take on a controlcentred view, according to which more irregular migration means more irregular migrant work, driving down wages, constituting tax fraud and leading to unfair competition between immigrants and natives, and should therefore be prevented (cf. Bundesregierung 2000). Alternatively, the argument can also take on a human rights perspective, according to which a larger pool of both legal and illegal immigrants constitutes a 'reserve army of labour' that is easily exploited in irregular work. The most serious cases of labour exploitation, in fact, constitute trafficking in forced labour, for which only little empirical evidence exists in Europe but which is given increasing attention by international organisations and NGOs (cf. Andrees 2004). Another rights-based approach holds that the presence of foreigners allowed to reside in a given state but not allowed to work legally (such as (rejected) asylum seekers or family members of established migrant workers), forces these migrants to accept irregular work, thus 'illegalising' them (e.g. Fronek 2000).

Many supply-side arguments relate back to the general migration theories discussed above, according to which network factors lead to sustained, 'progressively independent' immigration flows, whether the state tries to prevent further migration or not (Massey 1989). According to this perspective, the presence of a significantly large immigrant community will foster irregular migration when new migration opportunities are restricted by state control (e.g. Doomernik et al. I997). Increasingly, migration researchers have also drawn attention to a sophisticated migration industry that facilitates migrants in overcoming state regulations and physical barriers to migration (e.g. Bilger et al. 2006; Kyle \& Koslowski 200I; Mavris 2002; Salt \& Stein 1997). A more optimistic view looks at the potential significance of informal economic activities for the social and economic integration of irregular and marginalised migrants, who are often employed by other (formal and informal) immigrant entrepreneurs (Rath I999). ${ }^{\text {II }}$

In a comprehensive survey of such demand-side and supply-side theories of the underground economy, Samers (2005) explores some of these theoretical constructs further by asking what they can contribute to explaining the apparent growth (which he, however, does not accept as a given) of underground economies and particularly of the alleged growth in the irregular employment of immigrants. After reviewing the arguments for both demand-side and supply-side theories, he concludes that neither of them offers a sufficient explanation for the ap- 
parent growth of irregular migrant work. Consequently, he turns to the examination of regulation as a causal factor driving informal employment. Samers distinguishes between three approaches that focus on regulation: The globalisation, the de-/re-regulation and the over-regulation arguments. According to him, the globalisation argument stresses the unwillingness or inability of national states to control (illegal) immigration, thus implicating states in the growth of underground employment. While Samers dismisses this thesis by noting that the supply of labour willing to work in the underground economy is not determined by state migration policies alone, the argument that states are unwilling to control irregular migration should not be dismissed prematurely. In fact, it may be more or less valid in particular national contexts, and may be particularly salient in the case of the southern European countries with frequent regularisation schemes, where states seemingly tolerate a large informal economy with only minimal control of the labour market (see e.g. Reyneri I998; Abella 2002; Pastore 2008). However, when the globalisation thesis stresses the inability of states to control (illegal) immigration - due, for example, to strong network effects - the thesis becomes, in effect, a supply-side argument. According to this argument, even strong mechanisms of control fail when the incentives are strong and the social preconditions for migration are fulfilled (e.g. Massey et al. I998). Located somewhere in between the assumptions that states are unwilling and/or unable to control irregular migration is an argument focusing on the nature of state controls. Sciortino (2004b) argues that under modern conditions of expanded opportunities for travel and communications, most internal control measures aiming to prevent long-term settlement of irregular migrants will fail to control the actual circular migration behaviour of many irregular migrants. Under these conditions, circular irregular migration and restrictive migration policies may coexist for a long time and even reinforce each other. To this we could add that national migration control policies are constantly negotiated among a number of competing actors and demands, and are also subject to limitations imposed by international regimes (Cornelius et al. 2004; Brochmann I999).

The second approach focusing on regulation is the de-/re-regulation argument, whereby states tolerate the expansion of underground activities as a substitute for the progressive erosion of welfare entitlements and to allow firms to remain competitive in increasingly globalised markets (cf. Talbot 2004). However, while some states indeed seem to be complacent about informal economic activities, many others are going to great lengths to suppress them, precisely to prevent financial losses to the social welfare system. What seems to be crucial in many 
cases, however, is the lack of enforcement of employment regulations and employer sanctions (Martin \& Miller 2000; OECD 2000).

The third regulatory argument examined by Samers (2005) is the socalled over-regulation thesis, according to which employers are induced to resort to irregular work due to the high levels of wages and nonwage costs that come with regular employment (minimum wages, taxes, social security payments and other benefits and restrictions on regular employment). While Samers criticises several aspects of this view, others remain less sceptical. Schneider and Enste (I999), for example, conclude that their results:

show that the increasing burden of taxation and social security payments, combined with rising state regulatory activities, are the major driving forces behind the size and growth of the shadow economy (I999: 44).

It is clear that this line of argumentation brings us back to the 'informalisation' hypothesis examined by Williams and Windebank (I998; see beginning of Section I.6). The high level of indirect costs drives a wedge between net earnings and wage plus non-wage costs for employers, creating a strong incentive for them to hire workers informally. In principle, this should apply equally to native and foreign workers alike, provided they are willing to accept work under these conditions.

The over-regulation thesis provides a strong argument for the explanation of irregular work and it is likely that it also plays a role in the employment of irregularly working migrants. Economic theory argues that under certain conditions, over-regulation can lead to a demand for irregularly working migrants, when employers see that the benefits of employing workers irregularly outweigh the costs of doing so. In the case of migrants working irregularly, this may simply be the expected cost savings (presumably weighted by the risk of detection and the extent of expected fines, cf. Boswell \& Straubhaar 2004). Thus, both the level of regulation and non-wage costs as well as the strength of enforcement play a role. However, neither the demand nor the regulation arguments alone can suffice to fully explain irregular migrant work. The existence of any market (even a market in irregular migrant work) requires both supply and demand, and neither of them is effective without the presence of the other (Jandl I994). Markets left alone (i.e. without any regulation and in the absence of market failures and externalities) would tend to clear on their own and, almost by definition, there would be no 'irregular' market emerging. However, both from theoretical insights and empirical observations, we can conclude that there is a strong demand for irregular work in certain sectors of many European 
economies, and we can also observe that this demand is often filled through irregular migrant workers.

In reviewing the theoretical explanations for irregular migrant work, we have thus come full circle. All of the above arguments have some explanatory power to contribute and neither of them alone can provide a self-sufficient explanation. In weighing the strengths of each theoretical argument for the concrete case of irregular migrant work in Austria, we need to apply a context-specific, empirically rich approach. Before doing so, however, we will review the existing empirical literature on irregular migrant work in other European countries.

\subsection{Research on migration and irregular work in Europe}

Research on irregular migrant work has started only relatively recently in European countries, reflecting the relatively recent concern with irregular migration and irregular foreign employment in Europe. Up until the mid-I970s and throughout the so-called guest-worker period, irregular migration was not entirely absent in Europe, and it was often possible for unsolicited migrants to regularise their status after entering the labour markets, thanks to the booming economy and widespread shortages of workers (see e.g. Castles \& Miller 2003). It was only during the I970s and I980 that policymakers in European countries changed their perceptions and started to introduce specific sanctions for irregular employment of migrant workers (Doomernik \& Jandl 2008).

In the I990s, a number of research studies on illegal/irregular migration and the illegal/irregular employment of foreigners in Europe were produced (for a brief overview, see Düvell 2005: 34-39). With the progressive transfer of responsibilities in the fields of migration and asylum - and in particular in the field of illegal migration - to the level of the European Union, there is also a greater interest in comprehensive Europe-wide or at least European comparative studies on illegal migration (cf. Angenendt 2002; Boswell \& Straubhaar 2004; Chahrokh et al. 2005; Commission of the European Communities 2006). Many of these and other studies, however, remain on a theoretical, legal or policy level, while few have gone to the trouble of collecting primary empirical data. Those that do engage in primary research are typically characterised by a regional focus, the use of qualitative methods in research and relatively small sample sizes. A thematic focus of these studies is the living and working conditions of the migrants. In the past two decades, feminist migration researchers have made a great effort to investigate the global trend of outsourcing unpaid family work to paid migrant domestic workers (see e.g. Anderson 2000 and Lutz 
2008 for Europe; Caixeta et al. 2004 for Austria), caregivers and nurses (Gendera 2007; Lazaridis 2007; Yeates 2006). Studies, investigating the international division of reproductive labour (Parreñas 200I) generally look at intersections of gender, ethnicity and class, migration and welfare policies (Sciortino 2004a) in structuring the feminisation of migration. Research on labour market structures (demand, segmentation, etc.), however, is mostly lacking. While on their own, such studies often reflect regional, national or group particularities and are hardly representative for the overall European situation (with the partial exception of studies on domestic work), taken together this body of research does provide important insights into reasons, characteristics, patterns and trends of irregular migration and irregular migrant work. In the following, we will give a brief overview of studies focusing on irregular migrant work (rather than irregular migration in general), and, in particular, cases involving Germany and comparative European studies that are considered most relevant for the Austrian case.

First of all, what emerges from the available literature is a very diverse picture that reflects the very heterogeneity of life situations and survival strategies of irregular immigrants in European countries (see e.g. Schönwälder et al. 2004 for a review of the recent German literature). What many studies do agree on, however, is the centrality of irregular labour markets for irregular migration systems in general and for the sustainability of their livelihood for irregular migrants in particular. It is clear that not all illegally residing migrants also work illegally. Many can rely on their networks of family and friends, while on the other hand there is only little evidence of systematic engagement in criminal activities to generate income (see Anderson 1999 for the United King-

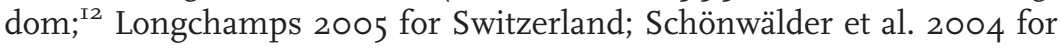
Germany). Nevertheless, it is widely assumed that a majority of illegal residents is in fact engaged in irregular work activities. According to Boswell and Straubhaar (2004), some 70 per cent of illegal residents in the EU countries are estimated to be engaged in illegal labour. Alt (2003b) estimates that around 50 per cent of undocumented migrants reside in Germany for the purposes of work, while another IO-I5 per cent work in the sex industry. While such estimates clearly illustrate the importance of irregular work in the lives of irregular migrants, the same conclusion cannot be made the other way around. Indeed, there is a wide consensus that the bulk of irregular work (or informal, undocumented economic activities in general) is carried out by natives, rather than by foreigners. For example, Schneider estimates that only a small share of the net value added in the informal economies of the three German-speaking countries in 2003 has been produced by foreigners (Germany: II.5 per cent; Austria: I2.7 per cent; Switzerland: I3.7 per cent) (2003: I2). 
However, both such precise estimations and such general statements about irregularity always need to be treated with caution, as irregularity as such is extremely context-specific and changes over time. Irregularity in migrant work is defined and conditioned by differing and constantly changing national laws and regulations on residence rights, access to work, employment laws, etc. To provide just one example: Since 2004, all citizens of the ten new EU Member States have enjoyed unlimited freedom of movement in all EU-I5 Member States, while their access to the labour market has been partly restricted in some countries but not in others. Over a seven-year transition period (2004-20II), all restrictions on labour market access will be gradually lifted, albeit at various speeds in the various EU-I5 countries. This does not mean, however, that all migrant work will automatically become regular, as employment will still be subject to different national laws and regulations such as tax and social security laws.

As mentioned before, many studies focus on the conditions of life, the situations and survival strategies of irregular migrants and emphasise the very diverse living experiences that irregular migrants go through, ranging from people in poverty and need (even in exploitation) to those using opportunities to improve their life (Alscher et al. 200I; Alt 2003, 2004; Jordan \& Düvell 2002; Vogel 2003). The same diversity is attributed to the social characteristics of irregular migrants: While most authors see a preponderance of low-skilled migrants working in jobs that are characterised by a high rate of 'exchangeability' (Bundesregierung 2005: 40) and that require little or no formal qualifications (the so-called ' $3 \mathrm{D}$ jobs': dirty, difficult and dangerous) in the informal economy (cf. Lederer \& Nickel I997; Stobbe 2004), others identify the typical irregular migrant as being exceptionally self-reliant, resourceful, entrepreneurial and in possession of above-average skills. For example, in his study entitled Entrepreneurial Illegal Migrants [own translation], Elwert (2002) focuses on the demand side of irregular (long-distance) migration in Berlin. According to his findings, the majority of long-distance migrants came to the industrialised countries of the West because of existing earning possibilities rather than because of persecution or poverty in their home countries. The majority of his interviewees ${ }^{\mathrm{I} 3}$ were well-educated, had excellent knowledge about job opportunities and had come to Germany only after they had been given the assurance that a job would be provided for them. That is to say, they moved in reaction to a specific demand for their irregular work. Regarding social characteristics, Elwert indicates that his interviewees comprised individuals with middle and lower upper-class backgrounds rather than members of the lower class of the population in their countries of origin. Many were 'overqualified' for the jobs they were doing (ibid.: I7). 
The sample selection of Elwert's study may prevent a generalisation about other migrant groups and host countries. Moreover, the countries of origin are likely to matter in the self-selection of irregular migrants even more than in the case of regular migrants, as irregular migrants from distant countries have to invest more funds to overcome migration barriers (for example, by paying smugglers or obtaining documents). Depending on the specific context, the status of unauthorised migrants, as well as that of irregularly working migrants, can be an option determined by choice or by compulsion to varying degrees (cf. Anderson 1999 for the UK). Thus, the qualification structure of irregular migrants in various countries remains an open question subject to empirical testing. However, an important observation in this context is that many irregular migrants may be well-qualified and even highly skilled, but they have to accept unskilled work out of necessity. Such a de-qualification process in irregular migrant work is confirmed in qualitative interviews in Berlin and London by Jordan and Vogel (1997). The majority of their interviewees had above-average educational qualifications, though they were doing unskilled work. Unpleasant, menial and insecure working conditions were accepted as part of the sacrifices irregular migrants were willing to make in order to achieve a higher living standard or for their long-term benefits: to return to the countries of origin with some savings and to build a better future there. Cyrus refers to this process of de-qualification as 'brain waste', which occurs when illegally-employed foreign workers are routinely overqualified for their jobs (2004: 37). In this context, an interesting observation has been made in a study of irregularly working migrants in Geneva (Chimienti et al. 2003). Based on an analysis of 400 administrative cases against illegally employed foreigners as well as interviews with migrants and employers, the authors conclude that while all migrants were employed in less qualified jobs in Geneva, a disproportionate percentage of them had university degrees. Moreover, irregular migrants from more distant countries (in Latin America and Africa) had a higher share of university graduates than European countries, indicating some form of self-selection mechanism referred to above. ${ }^{\mathrm{I}}$

Moreover, most authors agree that due to the lack of legal protections as a consequence of illegality, irregular migrants often find themselves in a vulnerable position regarding economic and social security (e.g. Anderson 1999 and Kofman et al. 2000 for the UK; Schönwälder et al. 2004 and Cyrus 2008 for Germany). Due to their 'exchangeability' on the informal labour market, they find themselves in precarious employment conditions, as they usually lack any power and status and are in a very weak position when they have to negotiate working conditions and payment with their employers (Sinn et al. 2005; cf. also Anderson 2000). On the whole, irregularly working migrants have little 
incentives and opportunities to challenge employers, since legal challenges will often automatically result in the termination of their stay, while personal challenges often lead to the loss of the job (see Cyrus 2004 for Germany). Negotiating entitlements is especially difficult when the employer-employee relationship is characterised by intimacy and a web of affective bonds, as this generally is the case in paid domestic and care work (Rodriguez 2007). Lederer and Nickel refer to this as a 'structurally-founded vulnerability to be blackmailed' (I997: 29), a situation that in extreme cases may expose them to the risk of forced labour, characterised by exploitation and enforcement through the use of force (or the threat thereof) or the restriction of the freedom of movement (see also Cyrus 2005: 29 and Anderson \& Rogaly 2005 for a study on forced labour in the UK) and, in rare cases, even sexual violence (Rodriguez 2007). However, the illegal employment of foreigners should neither be principally equated with exploitation and forced labour, as there is a wide range of mutually beneficial working conditions (Cyrus 2005: I4), nor should the migrants be perceived as powerless victims, as they organise themselves in transnational networks. These networks provide them assistance in difficult situations and constitute a useful tool in finding alternative employment (Gendera forthcoming).

Most authors see illegality in residence status as a difficult situation to cope with, although to different degrees in different countries depending on the concrete legal, administrative and control regimes. Sometimes, it can prove useful to compare the migration and control regimes irregular migrants are subject to in different countries. For example, Jordan and Vogel (I997) compare the influence of national policies on migrants' decisions based on qualitative interviews with irregular Brazilian migrants in London and Berlin. While emphasising the importance of social and family networks for the migrants' decision to choose a specific country as their destination, they note that the significance of these networks is closely tied to the existing labour market regulations and controls. Whereas irregular migrants in London were able to provide themselves with a job or a new accommodation soon after their arrival, irregular migrants in Berlin (which is apparently subject to a higher degree of legal and social control) heavily relied on the assistance of established networks (legally resident friends or relatives) to find access to the irregular labour market. Generalising these findings for Germany and the UK, Cyrus, Düvell and Vogel (2004) conclude that, once inside the country, irregular migrants are subject to fewer controls in the UK and have easier access to social services than in Germany, which is heavily oriented towards internal controls. A similar conclusion is drawn by Stobbe (2004), who finds the 'room 
for manoeuvre' much wider and access to the labour market much easier in the US than in Germany.

Related to the severity of controls and the 'room for manoeuvre' that individual migrants may have is also the periodicity of irregular migration. As a general feature and from the perspective of individual migrants, illegality is often perceived as a temporal and transient state (even though it may last for several years), while from the perspective of the host society, illegality may be a structural phenomenon. Thus, in many European countries, the circularity of irregular labour migration may play an important role, especially in countries and regions where irregular migrants from Central and Eastern Europe make up the largest share of the undocumented workforce. This has been argued for Germany (Cyrus 2004; Morokvasic 2003; Hess 200I; Schönwälder et al. $2004^{15}$ ) and is also valid in the Austrian case (see e.g. Gendera \& Haidinger 2007). These general observations are supported by much anecdotal and some systematic empirical evidence. For example, in his study on the life situation of irregular migrants in Leipzig, Alt (I999a, I999b) confirms the hypothesis of the growing importance of circular migration for irregular foreign employment. His interviewees, mainly from Central, Eastern and South-Eastern European countries, stated that the focal point in their lives remained in the countries of origin and that they commuted between their places of origin and places of work as often as possible.

The duration and periodicity of irregular migration is likely to be closely connected with the individual's life choice and personal circumstances, as well as his or her opportunities for legalisation. However, ways into illegality are as manifold as its motives and available options are. Illegal entry could be the result of legal entry as a student, an au pair, a tourist, etc., with subsequent overstaying, or it could result from illegal entry, in which case circularity may not be a viable option at all. Across these various cases, however, there generally seems to be a significant link between legal and illegal migration, as irregular migrants often rely on the assistance of already legally established migrant populations for access to jobs and accommodation (cf. Jandl \& Kraler 2006). Thus, it has been argued that for Germany, besides geographic proximity, existing legal migrant populations are likely to account for relatively large irregular migrant populations from the same source countries such as Turkey, the Western Balkan states, Vietnam, China and India (Schönwälder et al. 2004). Social capital - in the form of already established migrant populations - has also been identified as the most important factor for the decision to come to the Netherlands (Engbersen 200I; Engbersen et al. 2006). Likewise, Chimienti et al. (2003) find that the decision of irregular migrants to come to Switzer- 
land is usually related to the existence of social and familial networks with already established migrant populations.

In this context, an interesting study drawing attention to the close relationship between legal and illegal seasonal migration has been carried out in Poland, the main source country of seasonal workers in Germany (Lukowski 2004). Based on a survey of 800 seasonal migrant workers as well as 27 interviews, the authors conclude that the structural conditions of the German labour market (high demand for seasonal unqualified workers especially in agriculture) create a demand that is supplied by young, energetic (and often overqualified) Polish workers, who view the wages earned as additional income outside their normal employment back in Poland (e.g. during teachers' school holidays). In fact, the vast majority of their sample of migrant workers had some sort of employment in Poland and 85 per cent of the money earned in Germany was spent in Poland. Moreover, the authors found that the expansion of seasonal legal work opportunities in Germany during the I990s (special quotas for seasonal workers) has resulted in the movement of many Polish workers from illegal to legal employment.

Another interesting study on Poland (Kindler 2005) draws attention to the fact that migrant-sending countries are often significant destination countries for irregularly working migrants as well. Based on qualitative interviews and participant observation methods, Kindler describes the significance of temporary irregular migration from Ukraine to Poland, much of which has been transformed to pendular shortterm migration after the introduction of visa requirements for Ukrainian nationals in Poland in 2003. While in the course of Poland's integration to the EU the government had enhanced worksite inspections, domestic workers (cleaning, day care, health care) who are not subject to such inspections have little fear of detection and can establish work contacts relatively easily (e.g. through newspaper ads). Despite significantly lower wages for these workers in Poland, Kindler argues that this temporary migration system has not become a springboard for moving on to other countries for the particular migrants engaged in it, the vast majority of whom are women. They are comparatively older, less risk-taking and less qualified than other migrant groups, and have to fulfil particular needs of their families back home, a situation which has kept many of them in a state of 'lasting temporariness' (of their temporary migration projects) for many years (2005: 6). Claire Wallace's research on migration patterns between Ukraine, Bulgaria and Romania to Central and Eastern European countries comes to a similar conclusion. Wallace draws attention to the fact that circular migration patterns in the Central European region differ from migration between poorer developing nations and developed ones. Migrants in Central Europe tend to return to their countries of origin on a regular basis to 
make use of, respectively stay entitled to, welfare services: for health care, educational or pension purposes (2002: 6I6).

A major question for this research project is which branches are most affected by irregular migrant work, and what characterises these branches and the type of work migrants are doing irregularly. On the most general level, it is often stated that virtually all branches of the economy are affected by the illegal employment of foreigners. For example, in the regular reports of the German Federal Government on the impacts of the 'Law on the Combat of Illegal Employment' (Bundesregierung 2000, 2005), the following areas are mentioned as significant for the illegal employment of foreigners: construction business and associated businesses, hotels and restaurants, cleaning of industrial facilities and buildings, agriculture and forestry, food, beverage and tobacco industry, transportation of persons and goods, metal processing industries and businesses in the entertainment sector (bars, nightclubs, amusement arcades). Also in private households and on private building sites, it is considered particularly likely that illegally employed labour is used (Sinn et al. 2005).

Generally, there are good reasons to assume that the extent of irregular migrant work is linked to the extent of domestic irregular work in the 'shadow economy', of which foreigners make up only a minor part (cf. Biffl 200I; Schneider 2002, 2005, 2006). However, starting from estimations provided by Schneider, namely that the share of irregular employment of migrants in the total informal economy of Germany is some I3 per cent, Cyrus (2004) indicates that this share is generally larger in specific industries such as construction, agriculture, tourism and domestic services. Similarly, in a 2003 workshop on migration and illegality in Germany, the following branches and areas were mentioned as those being 'most affected' by irregular migrant work: the building sector, work in private households, agriculture and the sex industry (AKI 2003). ${ }^{\mathrm{I}}$ Turning to other countries, Cyrus et al. (2004) mention the same sectors as the most notorious ones for irregular migrant work in the UK. Similarly, Anderson (I999) lists the construction industry, agriculture, hotels and catering, household jobs and cleaning as well as courier services, small enterprise trades and the textile industry as the main sectors where migrants work informally in the UK. For Switzerland, Longchamp (2005) identifies the same sectors yet again, namely households, construction, catering, cleaning, agriculture and prostitution.

Going to the level of occupations and economic activities, Alt (2003a) mentions the following activities and branches in which irregularly working migrants are particularly active in Germany: as assistants, bricklayers and foremen in the construction business, in landscaping and as gardeners, in window cleaning and cleaning of buildings, in the 
field of domestic services, car repair, as workers in agriculture, restaurants and catering, sales assistants, newsagents and in prostitution. In addition, irregular migrants may also work as self-employed, for example, as traders, hawkers or musicians (Alt 1999). Similarly, Lederer and Nickel (I997) see the access to job opportunities mainly limited to the following sectors and occupations: domestic help (maids, nursery, cleaning, renovation), construction trade, catering industry, tourism, harvesters, seasonal workers, peddlers, 'professional' beggars, prostitution or transnational trade. Moreover, they point out that such informal labour markets are highly segmented. In reality, specific ethnic groups often control certain sectors of the informal labour market (e.g. Pakistani nationals selling flowers in restaurants). Similarly, Elwert (2002) describes irregular labour markets as highly fragmented, as they have to be sealed off from outsiders and depend on specific forms of organisation. In this situation, the existence of social and family networks is of crucial importance. These networks not only provide information on job opportunities, but also the necessary contacts with irregular job providers, which are decisive for the actual choice of occupation.

For the UK, Anderson (I999) points to the importance of social and ethnic networks in the access to specific job opportunities and as a means of familiarity and protection, which is visible in the textile industry (notably, the Bangladeshi and Turkish communities) or in certain self-reliant structures (such as restaurants and small business). At the same time, however, ethnic networks can also serve as a means of exploitation of a lasting dependency that frequently devalue their own people's qualifications by 'trapping' them in low-skilled jobs in their communities (I999: I74).

Given these many branches and economic activities that are routinely mentioned as important for illegal employment, can certain characteristics be identified that make these areas particularly susceptible to irregular migrant work? According to the literature, the following factors seem to be most relevant: a standardised qualification profile (lowskilled jobs), seasonal or generally high fluctuation of workers, labour intensive jobs that are hard to mechanise and a relatively low risk of detection. Moreover, it has been argued that - besides private households - it is mainly small- and medium-sized businesses that use the services of irregular migrants in Germany, that is businesses whose production methods are labour-intensive and that are not able to outsource production to low-wage countries (cf. Alscher et al. 200I; AKI 2003, 2003a). Accordingly, we would expect irregular migrant work to be higher in branches that have some or all of these characteristic features (agriculture, construction, domestic services) but lower in other branches (e.g. in industrial production, where firms are often larger, 
unionised, subject to a high level of control and can either mechanise nor outsource their labour-intensive production).

Which of these factors predominates and structures irregular migrant work cannot be established a priori. Cyrus (2004), for example, argues that the employment of undocumented migrants in Germany is limited to a few industries in which the risk to be controlled is also relatively low, with the risk in domestic services being lowest. Because of the nature of work in construction (many short-term tasks contracted out) and the large number of construction sites, the risks to be controlled in construction are also relatively low, even though law enforcement is to some degree focused on construction. In the agriculture, catering and restaurant sectors, on the other hand, irregularity occurs mainly in terms of 'breach of wage and work condition regulations' rather than in breach of immigration regulations (ibid.: 34).

The last observation refers to an important development that has been observed and described in some recent studies on irregular migrant work: the increasing proliferation of legal statuses, which blur the lines between legal and illegal. This development has been linked to the recent round of EU enlargements that created complex regulations and restrictions in access to the labour markets of the EU-I5 for citizens of the new EU countries (cf. Favell 2006), but has also become visible in those countries where no such restrictions were introduced. For the UK, Anderson and Ruhs (2006) argue that the very flexibility of the British economy has produced a flourishing demand for irregular work that is increasingly filled by irregular or semi-legal means, for example, in the form of subcontractors or short-term fragmented irregular work. In a study on the impact of EU enlargement on legal status in the UK, based on a large survey with over 500 migrants from Central and Eastern European countries as well as interviews with migrants, employers and host families, they introduce the concept of 'semi-compliance' in the UK labour market and divide the legal status of migrants into compliant (both in terms of residence and work rights), non-compliant (migrants without residence rights) and semicompliant (legally resident but not complying with work regulations; this was the largest group in the sample). Relevant examples of the latter are students working over twenty hours per week, au pairs working and earning more than allowed, etc. In this view, immigrant status becomes a spectrum and not a dichotomy, which raises important questions on how the state can and should act on semi-compliance in the migrant labour market.

Another set of important studies and data on irregular work stems from NGOs that defend the rights of undocumented migrants. The European Civic Forum focuses on the European dimension of labour migration and irregular work and has done extensive studies on the life 
and work situation of seasonal workers in the region of Almeria, Spain, a European centre of agricultural production (EBF/CEDRI 2004; Bolyos \& Behr 2007; Hahn, Behr \& Dinhof 2007). Another NGO that defends the rights of irregular migrant workers on a European level is the Platform for International Cooperation on Undocumented Migrants (PICUM), which publishes regular reports on the living situation of undocumented migrants, as well as on the respective policy framework. The report 'Undocumented migrant workers in Europe' (LeVoy, Verbruggen \& Wets 2003) analyses the EU policy framework with regard to irregular work, but also presents working conditions of migrant workers in different economic branches. A current report by PICUM focuses on access to health care for irregular migrants in several European countries, also including a chapter on the Austrian situation (PICUM 2007).

Finally, we should say a few words on issues that have not been touched upon in this comparative literature review, focusing on general patterns and characteristics of irregular migrant work. Generalisations are always hard to make in a field as diversified as our current research topic, while the higher the level of abstraction of a statement or hypothesis on the nature of irregular migrant work, the more likely it is that it will be contradicted by place-specific and context-specific particularities. A good example is provided by residence patterns of irregularly/ illegally residing migrants and irregularly working migrants. One argument why irregularly/illegally residing migrants are thought to prefer to live in larger cities rather than smaller ones (or even the countryside) is that the anonymity of the city offers a form of protection against detection - living in bigger cities minimises the risk of apprehension by enforcement authorities (Engbersen I999b). Another argument is provided by the higher availability of irregular work opportunities in larger cities, which is thought to contribute to a concentration of irregularly/illegally residing migrants mainly in urban areas (cf. AKI 2003 for Germany). Others, however, have pointed out that irregular migrants are seen to be present in rural areas as well, insofar as employment opportunities (mostly of a seasonal nature, in agriculture or related industries) exist there (Cyrus 2004).

On a general level, then, the distribution of irregularly working migrants cannot be sensibly predicted as long as we do not know enough about the causal factors of irregularly working migrants' spatial distribution, and the distribution of job opportunities for irregular migrants (e.g. in the catering and the tourist sectors, in childcare and elderly care, in 'ethnic' businesses, etc.) in any given country or region. Based on an empirical study on the spatial distribution of irregular migrants in the The Hague, Engbersen et al. (2006) identify four important factors for the observed residential patterns of irregular migrants in this 
city: I) existing social capital and network effects through legally established co-ethnic migrants; 2) economic opportunities for irregular migrants, which are partially provided in migrant-specific facilities (mosques, shops, hairdressers, coffee houses, etc.); 3) the availability of cheap and safe accommodation; and 4) patterns of relationships with the native population (e.g. as spouses, partners, servants, cleaners). Which of these factors predominates is subject to empirical observation.

Similarly, the gender distribution of irregular migrants cannot be established a priori and depends mainly on the opportunities present in various sectors. For Germany, for example, Schönwälder et al. (2004) refer to police statistics for 2002 that show that around 75 per cent of apprehended illegal migrants were male, but caution that this could reflect a bias in identification. They conclude that it is safer to say that at least 25 per cent were female.

Other factors that are often treated in studies on irregular migration in European countries are likely to be even more context specific, especially when they are tied to the concrete rules, regulations and implementation practices of national labour markets and welfare systems. In the aforementioned review study of Schönwälder et al. (2004), the authors indicate that for Germany, the overall impact of irregular migrant work on wages and unemployment of nationals is likely to be small, but there are likely to be sector-specific exceptions in which illegal workers may be in competition with indigenous workers, mainly in construction and private household services (but not in agriculture anymore, as there is now easy access for seasonal workers). Likewise, the impact on the German welfare system is seen as likely to be small, as irregular migrants are mostly excluded from public services. While the same is in principle true for other countries as well, the specific implementation practices of health and welfare agencies may lead to different results in different countries. The easy availability of National Insurance Numbers in the UK, for example, is known to significantly facilitate the access of irregular migrants to free universal health care services (Jordan \& Düvell 2002; Düvell 2005).

\subsection{Existing research and data on illegal foreign employment in Austria}

In contrast to the significant number of research projects on irregular migrant work (usually referred to as illegal foreign employment) that have been carried out in other European countries, little attention has been devoted to the subject by researchers in Austria. Studies and reports referring to migration and labour markets have mainly focused 
on regular foreign employment, while irregular migration and informal work is mentioned only in passing, if at all (cf. Biffl 2003, 2005; Bock-Schappelwein 2004; Demel et al. 200I; Fassmann \& Stacher 2003). Other studies that do address irregular migration in Austria remain on a legal or theoretical level without going into the structure of irregular labour markets in Austria (cf. Çinar et al. 2000; Fronek 2000; Riedel 2000). A specific issue that has received much attention in the recent literature on labour migration to Austria is EU enlargement and its effects on Austrian labour markets (cf. Commission of the European Communities 2003; Fassmann \& Münz 2002). In this context, the potential for an increase in irregular migrant work by new EU citizens due to the immediate validity of freedom of movement and residence from May 2004 onwards, in connection with continued restrictions in the access to the labour market, has been squarely predicted (Huber \& Brücker 2003; Jandl \& Hofmann 2004) without, however, providing much empirical evidence for these claims.

A partial exception to the widespread omission of irregular activities in studies on the effects of the 2004 EU enlargement is provided by a project of the Paul Lazarsfeld Society for Social Research. In this project, a group of researchers developed an instrument for a continuous labour market monitoring in the border regions around Eastern Austria (including the greater Vienna region) and empirically tested their approach. Based on extensive surveys of potential migrants within commuting distance in the Czech Republic, Slovakia and Hungary, the study concluded that there is a considerable general migration potential within the region, but that the current 'active migration potential' (that is, persons with language skills who had already taken concrete steps to work in Austria) was rather low (0.7 per cent, I.2 per cent and 0.5 per cent of the respective samples in Hungary, Slovakia and the Czech Republic). Moreover, the future development of actual labour migration from Austria's neighbouring regions is seen as highly dependent on the extent of economic growth and development and continued regional wage differentials between the regions (Hudler-Seitzberger \& Bittner 2005: 93). However, an analysis of 90 expert interviews carried out in the same region in 2004 as part of the same project predicted a potential increase in the amount of illegal employment as well as in the number of self-employed migrants following EU enlargement. More concretely, construction, agriculture, catering and domestic services were identified as the main attraction points for irregularly working migrants. According to the expert interviews, the share of irregular migrant workers among the regular stream of commuters to Austria was already relatively high before 2004, especially for migrants from Hungary and Slovakia. Many of these commuters are 
young and well-qualified, but most are employed in jobs below their qualifications (Paul Lazarsfeld Gesellschaft für Sozialforschung 2004).

A recent study on the quantitative effects of EU enlargement on the labour markets in the EU-I5 shows that labour migration from the EU8 (the ten new EU Member States minus Cyprus and Malta) has considerably increased in Austria despite the restrictions imposed by the transitional rules for access to the labour market (Tamas \& Münz 2006). Between 2003 and the end of 2005, the share of EU-8 workers increased from I.2 per cent to I.5 per cent (or 45,000) of the total labour force in Austria (while it remained more or less stable in Germany at 0.7 per cent). This increase was partly due a growing number of EU-8 citizens with free access to the labour market (year end 2005: I5,700) and partly due to a flexible handling of short-term permits for EU-8 workers (2003: 48,000; 2005: 56,000), in which EU citizens receive preferential treatment in the allocation of short-term permits (see Section I.9). At the same time, the number of EU-8 citizens who have registered as self-employed service providers has tripled (2003: 2,000; 2005: 6,000), a development which, according to the authors, can at least partly be interpreted as a way of circumventing transitional restrictions.

Apart from the few studies on general labour migration and/or the effects of EU enlargement on migration to Austria that also address irregular migrant work, there are only very few studies that specifically deal with illegal/irregular employment of migrants as such. One early exception is a study carried out by Hofer (I993), which relies mainly on participant observation (Hofer himself worked irregularly in the informal economy), as well as qualitative interviews with irregular Polish migrants in Vienna conducted over the course of one year. At that time (I992 - shortly after the fall of the Iron Curtain), Polish workers in Austria were a rather new class of immigrants, with few established networks. Consequently, most had to rely on finding work by standing by the roadside (Arbeiterstrich), where workers offer their labour directly to potential employers passing by. In the early I990s, most of the workers on the well-known Arbeiterstrich Herbsstrasse were Polish and male. They were selected for their strong physical appearance and their manual skills and had to endure hard and unpleasant work for little money. Irregular migrants were hired for construction sites or for private building sites, and sometimes the work was organised by workers coming to Austria to fulfil specific tasks. Moreover, Hofer notes that construction enterprises used migrant networks to keep their own enterprise as ethnically 'clean' as possible, to avoid conflicts and competition between different migrant communities. Generally, migrant workers were used for unskilled work that needed to be done by assistants to the - mostly Austrian - skilled workers. However, because they were 
less expensive to hire, they were also in competition with unskilled and older migrant workers whose job opportunities decreased. In Hofer's opinion, the continued employment of irregular workers decreased the ability - and the desire - of enterprises to expand the employment of regular workers, and undermined labour and income standards on the labour market.

The latter argument is also put forward in a Master's thesis by Staudinger (I992), who adds another important reason for employers to pay their workers 'off the books', namely the existence of so-called 'black money'. This is undeclared income that businesses receive without providing a receipt, and it can be used to pay undeclared wages without raising further suspicions by the tax authorities.

All over Europe, a growing number of migrants - generally female and in many cases undocumented - are employed by private households as caregivers and cleaners. It was only in recent years that the international discourse on domestic work and care-giving was picked up by Austrian researchers. In 2004, two qualitative studies were published by Caixeta et al. and Rechling, examining the living and working conditions of the so-called live-out domestic workers (migrant women generally employed on an hourly basis). Many of the interviewed women from diverse ethnic and linguistic backgrounds faced de-qualification. As a consequence, it is not surprising that most of them assessed their working situation as a temporary and transitory stage in their work cycle. This fact is also connected to the low social status of domestic and care-giving work. In a further publication, by Haidinger (2004), the Austrian sector for domestic services is analysed from an economic perspective. In her work, Haidinger collects, analyses and compares quantitative data from various statistical sources and provides a good overview of existing data on the formal sector for domestic services, as well as estimations on persons engaged in this sector of the informal economy.

Another study carried out by a group of social scientists in I999 examined the situation of illegally resident or illegally employed (foreign) cleaning ladies in Austria (Social Impact 2000). The project resulted from the cooperation of sociologists and artists in order to achieve a combination of scientific rational and emotional subjective understanding. The goal of the project was thus not only to study the living conditions of irregularly working migrant women working as cleaning ladies, but also to contribute concretely to the improvement of their situation. The empirical part of the project relied on a limited number (fifteen) of problem-centred qualitative interviews with migrant women, as well as with some of their employers. The interviews reflect the main concerns of the respondents, which include the fear of getting sick (which can lead to being fired) or getting caught and deported 
by the police, as well as worries about their children. Most of the interviewees were overqualified for their jobs as cleaning ladies and wished they could start to work in their own occupational field as they used to do in their home country. This means that they wished to recover the social identity they used to have in their country of origin. Finally, the study draws attention to the crucial role of networks in the lives of irregularly working migrant women. Similar to the findings of qualitative studies in other European countries (e.g. Hofer 1993), social networks seemed to play a much more important role than institutional or professional help for finding a job or a flat.

An interesting study that sheds light on the conditions of production in Austrian industrial agriculture and its relationship to irregular migrant work is the Master's thesis of Behr (2003). Though not restricted to irregular work per se, this empirical study of seven different agricultural enterprises in Marchfeld in Lower Austria demonstrates the poor working and living conditions of seasonal migrant workers in vegetable and fruit gardening. While the author argues that outright illegal employment (i.e. non-registration) of migrant workers in agriculture has diminished due to the easy availability of work permits for seasonal workers (up to six months) and harvesters (up to six weeks), the interviews with migrant workers and their employers show that minimum employment conditions (work hours, rest periods, safety standards) are systematically violated, which results in extreme work conditions and exploitative work situations. While regular minimum wages are already extremely low for seasonal agricultural workers (around 3.30 euro per hour), most employers still save on taxes and social security contributions by registering workers as only part-time (e.g. twenty hours a week, while actual working hours can amount to twelve hours a day or more) and paying the rest informally in cash. Moreover, the particular organisation of harvest work (foremen giving work orders, piece work, accommodation with employer, food onsite, etc.) structures work relations and often leads to a high degree of dependency of the workers on their employers and/or recruitment agencies. Even if seasonal migrant workers are registered with the labour market services, they do not have the opportunity to protest against their poor working conditions or even to organise in trade unions. As the study shows, however, much depends on the personal relationship of the migrant workers with their particular employer and the way of recruitment. Sometimes there is a privileged core group of workers that comes every year, while others are recruited through specialised agencies. New (and more motivated) workers may be hired as 'competitors' in order to mobilise returning (already experienced but less motivated) workers to work more efficiently. Proven and reliable workers are often employed as 'control- 
lers' and are given a privileged position in comparison to other workers (better pay, cell phones, etc.).

Several of the agricultural enterprises studied by Behr (2003) were 'specialised' in hiring workers of some specific ethnic or national background, and farmers often consciously admitted they are not employing some specific groups that would differ in mentality (e.g. Romanians, Serbs). Nevertheless, the author also notes a growing competition between workers from various countries of origin and predicts that seasonal workers and harvesters from the (former) accession countries (Poland, Hungary, etc.) will be replaced by workers from more distant East European countries (e.g. Ukraine, Belarus), simply on the basis of wage differentials and the motivation to do hard and unpleasant work for very low wages.

The project 'Undocumented Worker Transitions', which will be completed in 2009, researches the status transitions in the broader nexus between labour and regular/irregular migration flows to Europe and involves qualitative migrant interviews as well as legal analyses in five European countries, one of them being Austria (FORBA 2007).

Besides these limited qualitative studies, very little research has been done on the structure and processes of irregular foreign employment in Austria. Some researchers have, however, attempted to provide estimates on the quantitative extent of irregular foreign employment on the Austrian labour market. An early figure (now somewhat dated) was provided by Pichelmann (I994), who estimated that in the early I990s, between 80,000 and I00,000 foreigners were illegally employed in Austria. Pichelmann based his figures on statistics from the Inspectorate of Labour and extrapolated from a sample of illegally employed foreign workers found to be present at worksites during routine controls.

In a comprehensive study on the economic integration of foreigners in Austria by Biffl (200I), the leading labour market economist in Austria devotes a section to informal foreign employment in the 'black' economy and provides an excellent overview of the difficulties one may encounter when: I) attempting to estimate the actual quantitative size of illegal foreign employment in a country and 2) trying to identify and define different categories of illegal foreign employment as such. According to Biffl, the main reason for the growing significance of the black economy - and of the illegal employment of foreigners in particular - lies in economic change and the resulting changes in forms of labour organisation (growth of the service sector, new technologies, flexibilisation, informalisation, etc.). In addition to such favourable factors on the demand side, there is also a growing number of individuals willing or forced to engage in illegal employment on the supply side. Among the latter category, migrants represent an increasingly impor- 
tant group - though by far not the only one. The wage differentials between Austria and its eastern neighbours provide clear incentives for migrants from these countries to engage in irregular circular labour migration. However, the very heterogeneity of illegal foreign employment often prevents the application of clear definitions and concepts in research on the phenomenon, which further hampers the gathering of representative and systematic data.

Given these caveats, Biffl then presents her own estimation method on the extent of illegal foreign employment in Austria. Based on the assumption that the black economy contributes about 8.7 per cent to total value creation in Austria (a figure included in official GDP estimates), and given the fact that typical areas of illegal employment are the more labour-intense sectors of the economy, it is estimated that the actual labour force deployed to the black economy corresponds to io per cent of the total labour force in Austria.

It is further assumed that both Austrian nationals and migrants engage in illegal employment. While it is often stated that migrants are over-represented in this group (due to existing restrictions in their legal access to the labour market), Biffl argues that this effect may be neutralised by the fact that Austrian nationals are likely to have a broader range of opportunities for irregular work at their disposal (e.g. freelance jobs), whereas illegal employment can be observed frequently. Thus, while 'domestic' and 'foreign' illegal employment might appear differently, the relative total extent is not likely to vary that much. As foreigners represent an average of Io per cent of the labour force, the total extent of illegal foreign employment would then comprise 35,000 persons (in full-time equivalents), though the actual number of foreigners engaged in (full-time and part-time) illegal foreign employment is likely to be significantly higher (between 50,000-70,000). Biffl further estimates that between 80 and 90 per cent of the illegal foreign employees are migrants residing in Austria, while I0-20 per cent (or up to Io,००० persons) engage in 'labour tourism' (irregular labour commuting) every year. Ten to 20 per cent of the illegal foreign employees are estimated to be officially registered in 'minor employment' (geringfügige Beschäftigung). Ten to 20 per cent are estimated to be foreign students. Another Io-20 per cent are believed to be foreigners legally residing in Austria, who for various reasons do not have legal access to the labour market. Only about 10,000 (again Io-20 per cent) are estimated to fall under the category 'illegal residence/illegal employment'.

These estimations on the extent of illegal foreign employment in Austria differ quite significantly from those made by economist Friedrich Schneider for about the same period. In his estimations on the sizes of the shadow economies (defined as 'all unregistered economic 
activities that contribute to the officially calculated GDP'; see Schneider \& Klinglmaier 2004: 4), Schneider uses econometric models that attempt to estimate unobserved variables (GDP, output) with the help of observed variables (e.g. cash in circulation). The so-called currency-demand approach is based on the idea that services in the shadow economy are usually paid in cash and that the size of such transactions can be estimated with properly specified currency-demand equations, while the so-called DYMIMIC (dynamic multiple-indicators multiple-causes) model links the unobserved variable (the size of the shadow economy) with a set of indicators through a number of structural equations (cf. Schneider \& Enste I999, 2000).

Schneider (2002) estimates that the absolute and relative size of the shadow economy in Austria has grown considerably over the past 30 years. While it was only I.89 per cent of the official GDP in I970, it grew to 2.69 per cent in I980, 5.47 per cent in I990 and 10.69 per cent of the official GDP in 2002. However, later estimates (Schneider 2005) indicate that after the year 2000, the shadow economy in Austria has stabilised at IO-II per cent, with a provisional estimate of I0.27 per cent for the year 2005. For 2006, a decrease to 9.70 per cent has been estimated (Schneider 2006). This aggregate estimate for 2006 can be further refined by sectors of economic activity: construction and handicraft 39 per cent, other trade and industry I6 per cent, service industry such as hotel and catering 16 per cent, leisure and entertainment I2 per cent and household services and other I7 per cent. Based on the estimations of the shadow economy output, estimates on the extent of 'black labour' involved are provided. For 2006, these are estimated to involve 716,000 native Austrians (full-time equivalents, thus a highly fictional number of a much larger number of Austrians involved part-time) and 98,000 illegal foreign workers (full-time equivalents; ibid.: I8).

\subsection{The regulation of migration and foreign employment in Austria}

Although Austria has a long history of immigration, it has never officially defined itself as an immigration country. In the ig6os, Austria introduced a guest-worker model along the lines of the Swiss and German model to temporarily fill low-skilled jobs that could not otherwise be filled by natives. This system of temporary labour migration officially ended with the advent of the first oil crisis in I973. While many of the foreign workers did return home in subsequent years, many also stayed and brought their families with them. During the I980s, even more migrants settled in Austria on family reunification or humanitar- 
ian (asylum) grounds, until a new economic boom at the beginning of the I990s led to a short-lived liberalisation of the labour migration regime, again boosting foreign employment in Austria. It was also during this time of extraordinarily high migration that Austria instituted its only-ever 'legalisation' campaign in I990, when foreign workers were able to regularise their status after very brief periods of residence with no questions asked (around 35,000 persons took advantage of such special administrative procedures). In addition to this new wave of labour migration and the ensuing family reunification, Austria admitted around 95,000 war refugees from Bosnia and Herzegovina between I992 and I995. As a consequence of all these developments, the number of foreigners in Austria almost doubled from 344,000 in 1988 to 690,000 in 1993 (or around 9 per cent of the population), a level at which it has since more or less stabilised. The two largest immigrant groups today are still people coming from the traditional 'recruiting' countries: former Yugoslavia and Turkey (Jandl \& Kraler 2003). ${ }^{\text {.7 }}$

At the beginning of the I990s, Austria started to restrict further immigration through the introduction of a dual quota system. Already in I990, a quota for the employment of foreigners (as an upper percentage of total employment) was introduced, and in 1993 a new Residence Act established quotas for different categories of migrants, limiting the number of new residence permits to be issued each year. These laws have since been revised several times (most recently by the new Aliens' Act 2005) but have retained the dual quota system. Currently, three major laws regulate migration and access to the labour market for foreigners in Austria: the Aliens' Act (Fremdengesetz - FrG) with the Residence and Settlement Act (Niederlassungs- und Aufenthaltsgesetz - NAG) and the Employment of Foreign Nationals Act (Ausländerbeschäftigungsgesetz - AuslBG). The Aliens' Act regulates the entrance, residence and settlement of foreigners (non-EU citizens only) in Austria and distinguishes between those who reside temporarily (e.g. students, temporary employed persons, commuters) and those who want to settle permanently in Austria. The latter group enjoys special treatment such as the consolidation of residence status but also has to fulfil special obligations: since 2003 , they have had to fulfil the so-called 'integration agreement' (Integrationsvereinbarung), involving language courses for those with insufficient German language skills. ${ }^{18}$

In principle, then, new immigrants who are non-EU nationals and are not otherwise exempted from immigration restrictions are subject to an annual immigration quota. This quota is fixed each year by the federal government after consultations with the relevant parliamentary committee and the social partners. The Austrian-wide quota is then divided into sub-quotas for the federal states, which are further divided into subcategories according to the purpose of residence (family reuni- 
fication, 'key personnel', private and others). In addition, a special quota for seasonal workers and (since 200I) 'harvest helpers' has been introduced. The annual quotas for the years I998-2006 are given in Table I.2.

In reality, however, actual immigration is much higher than the annual immigration quota would indicate because so many categories of immigrants in Austria are not subject to the quota. As Table I.3 indicates, less than ro per cent of all new immigrants are subject to the established quota.

From the more than 100,000 immigrants registered in 2004, most fall outside any quota restrictions due to international commitments (EU nationals and their family members, asylum seekers, diplomats and their personnel, etc.) or because they have otherwise managed to evade restrictions (e.g. through illegal entry with subsequent registra-

Table 1.2 Annual migration quotas in Austria

\begin{tabular}{llllr}
\hline & Total quota & \multicolumn{2}{l}{ of which: } & Others* \\
\cline { 3 - 5 } & & $\begin{array}{l}\text { Family } \\
\text { reunification }\end{array}$ & $\begin{array}{l}\text { Key } \\
\text { personnel }\end{array}$ & \\
\hline 1998 & $\mathbf{8 , 5 4 0}$ & 4,550 & 1,860 & 4,500 \\
1999 & $\mathbf{9 , 5 6 5}$ & 5,210 & 1,130 & 5,500 \\
2000 & $\mathbf{7 , 8 6 0}$ & 5,000 & 1,010 & 5,500 \\
2001 & 8,338 & 5,490 & 1,613 & 15,000 \\
2002 & $\mathbf{8 , 2 8 0}$ & 5,490 & 1,905 & 15,000 \\
2003 & 8,070 & 5,490 & 2,405 & 15,000 \\
2004 & $\mathbf{8 , 0 5 0}$ & 5,490 & 2,200 & 15,000 \\
2005 & $\mathbf{7 , 5 0 0}$ & 5,460 & 1,600 & 15,000 \\
2006 & $\mathbf{7 , 0 0 0}$ & 4,480 & 1,125 & 15,000 \\
\hline
\end{tabular}

* Seasonal workers and harvesters

Source: Ministry of Interior

Table 1.3 Immigration and emigration of non-nationals to Austria

\begin{tabular}{lcll}
\hline & Immigration & Emigration & Net migration \\
\hline 1998 & 59,229 & 44,865 & 14,364 \\
1999 & 72,379 & 47,279 & 25,100 \\
2000 & 65,954 & 44,367 & 21,587 \\
2001 & 74,786 & 51,010 & $45,372 *$ \\
2002 & 92,567 & 38,777 & 53,790 \\
2003 & 97,164 & 46,065 & 51,099 \\
2004 & 108,947 & 48,326 & 60,621 \\
2005 & 101,455 & 47,480 & 53,975 \\
2006 *** & 85,384 & 52,904 & 32,480 \\
\hline
\end{tabular}

* Statistical break in series

** Provisional numbers

Source: Statistics Austria 
tion). In 2004, people who were exempt from the quota included 36,198 citizens from the EU-24, of whom I6,310 were from the ten new EU Member States and I3,I79 from Germany. After EU nationals, the second largest group of quota-exempt immigrants was made up of family members of Austrian and other EU citizens, including 23,308 third-country nationals who received a residence permit as a family member of an Austrian citizen and 559 family members of nationals of EU/EEA citizens (König \& Perchinig 2005: 2).

It has already been mentioned that in addition to the entry, residence and settlement of foreigners governed by the Aliens' Act, the employment of foreigners in Austria is regulated under the Foreign Employment Law (Ausländerbeschäftigungsgesetz - AuslBG). In principle, a foreigner may only be employed if he or she has been granted an employment permit by the Employment Service (Arbeitsmarktservice AMS); if he or she possesses another entitlement to work (work permit - Arbeitserlaubnis; certificate of exemption - Befreiungsschein, etc.); a long-term residence permit (either an unlimited residence permit, a settlement permit - unlimited or an entitlement 'permanent stay EC'); or if he or she is otherwise exempted from the Foreign Employment Law. Among the latter, the major groups who do not require a special work permit are family members of Austrian citizens, convention refugees, diplomats and all 'old' EU and EEA citizens. However, with the accession of ten new Member States to the EU in 2004, a new law (EU Expansion Adjustment Law) codified that nationals of the 'new' Member States (except for Malta and Cyprus) still remain subject to the Foreign Employment Law for a transition period. ${ }^{\text {I9 }}$

To simplify, the Aliens' Act and the Foreign Employment Law restrict new labour immigration of non-EU citizens to a) 'highly qualified personnel' and b) so-called 'seasonal workers' and 'harvesters' (König \& Perchinig 2003: 6). These restrictions have been extended under transition rules to nationals of the ten new EU Member States (minus Malta and Cyprus) who joined the EU in 2004, first until 2006 and then until 2009. A further extension (up to 20II) is only possible in case of 'grave disturbances' on the labour market and has to be agreed to by the European Commission. In 2006, the transition rules have also been extended to nationals of the new EU Member States Bulgaria and Romania (in a first phase from 2007 to 2009). While these transition rules prevent unrestricted access to the labour market for citizens of the new EU Member States for the time being, these individuals nevertheless receive preferential treatment in access to employment permits over third-country nationals (BMWA 2006).

The requirements for the issuing of an employment permit (Beschäftigungsbewilligung) to new immigrants from outside the EU or from the new EU countries subject to transitional rules are such that lower qua- 
lified migrants may only enter Austria as 'seasonal workers', 'harvesters' or under very limited cross-border commuter schemes (in place only with Hungary and the Czech Republic). Otherwise, in order to qualify as 'key personnel' under the annual immigration quota, the prospective immigrant has to demonstrate to the Employment Service earnings of at least 60 per cent of the upper threshold for social security contributions, which in 2007 amounts to a 2,304 euro gross monthly salary, fourteen times a year (Beratungszentrum 2007). Employment permits for seasonal workers are issued for a maximum of six months by the Employment Service within the quotas for seasonal workers (employment permits for harvesters are issued for a maximum of six weeks within the quota for harvesters). Citizens from the new EU Member States again receive preferential access to seasonal work permits and harvesting, which are normally issued for temporary employment in tourism and agriculture but are in principle no longer restricted to these sectors.

To alleviate labour shortages in the health and care sector, in 2004 the minimum income threshold for key personnel in this sector was lowered to 40 per cent of the upper threshold for social security contributions (2007: I,536 euro) for health care workers and caregivers from the new EU Member States only. Foreign students may obtain an employment permit outside the quota, if the work to be performed does not distract them from their studies, which is normally assumed for work paying less than the threshold for so-called 'minor employment' (2007: 34I euro). Top managers and top researchers (2007 income threshold: 4,6o8 euro) are exempted from the Foreign Employment Law altogether. Foreign au pairs are also exempted from the requirement to obtain an employment permit, but their certificate has to be renewed after six months, provided that they fulfil the conditions ${ }^{20}$ of their status (BMWA 2006).

In addition to these regulations on the access to the labour market for dependent employees from third countries and from the EU-8 countries (under transitional regulations), there is a complex set of highly differentiated regulations on self-employment that restricts nonnationals' access of to self-employment in Austria. Generally, these trade regulations (mainly the Austrian Industrial Code (Gewerbeordnung) and the EU Service Directive that includes the Posting of Workers Directive enable EU citizens to freely register a trade and to offer their services in Austria. However, for new EU-8 citizens, self-employment in many economic sectors such as construction and many construction-related activities is also subject to restrictions under transitional regulations. As we will see in the following chapters, this complicated set of regulations has given rise to a sophisticated system of circumventing existing restrictions through quasi-regular forms of self- 
employment. A more detailed description of the rules and the ways they are circumvented is provided in Section 2 of Part 3 in this report.

\subsection{Control of irregular migrant work at the workplace}

As the preceding section shows, foreigners in Austria are subject to a wide range of rules and regulations specific to their status as non-nationals (e.g. in regard to their entry and residence, but also in access to work). Compliance with these rules is also divided across a range of authorities, most importantly the Aliens Police but also the Employment Service, the Border Police or the magistrates. Moreover, to control the seemingly growing illegal employment of foreigners, a special unit was established within the Ministry of Economy and Labour (MEL) in the early I990s: the Control Unit for Illegal Foreign Employment (Kontrolle der Illegalen Ausländerbeschäftigung, KIAB).

In recent years, however, it has become clear that irregular (illegal) foreign employment is no longer primarily a problem of the illegal residence of foreigners, but of a wider range of irregularities that may occur alongside a legal residence status of foreigners. At the same time, more attention has been paid to the irregular work of natives, which often occurs alongside that of foreigners in the workplace. As a consequence, the focus of controls has been shifted towards detecting and preventing all forms of irregular employment (that is, all employment in contravention to labour, tax and social security regulations) by natives and foreigners, as well as employment in contravention to foreign employment regulations.

In July 2002, the KIAB first came under the supervision of the custom authorities in the Ministry of Finance (MoF). In 2004, the unit was renamed from the Control Unit for Illegal Foreign Employment to the Control Unit for Illegal Employment, though still maintained its German acronym KIAB. Over the past few years, the control unit has quickly expanded from a staff of 39 in 2000 to a staff of 93 in mid2002 , to a staff of I86 in May 2004 (conforming to the date of EU enlargement and the expected increase in irregular employment from new EU nationals). From 2006 onwards, the unit is supposed to be supplemented by another 300 staff members.

Conforming to this increase in control staff, the number of worksite inspections (sometimes small workplaces, sometimes large construction sites involving dozens of worksite inspectors and including tax authorities, Aliens Police and others) has grown enormously in recent years. Consequently, after decreasing in the second half of the I990s, the number of foreigners detected in illegal employment has also grown over the past five years (see Table I.4). 
Table 1.4 Apprehended illegally employed foreigners in Austria

\begin{tabular}{lccc}
\hline Year & $\begin{array}{l}\text { 1) Number of worksite } \\
\text { inspections }\end{array}$ & $\begin{array}{l}\text { 2) Number of apprehended } \\
\text { illegally employed foreigners }\end{array}$ & 2) / 1) \\
\hline 1995 & 11,513 & 4,210 & 0.37 \\
1996 & 14,363 & 4,083 & 0.28 \\
1997 & 14,452 & 3,858 & 0.27 \\
1998 & 15,537 & 2,999 & 0.19 \\
1999 & 14,027 & 2,550 & 0.18 \\
2000 & 13,211 & 2,881 & 0.22 \\
2001 & 12,765 & 3,010 & 0.24 \\
$2002 *$ & 6,602 & 1,293 & 0.20 \\
2003 & 21,140 & 5,690 & 0.27 \\
2004 & 23,222 & 6,201 & 0.27 \\
2005 & 18,579 & 7,641 & 0.41 \\
2006 & 22,367 & 8,206 & 0.37
\end{tabular}

* Second half only

Source: Ministry of Economy and Labour (up to 2001); Ministry of Finance (from second half of 2002)

If we divide the number of foreigners detected in irregular employment at Austrian worksites by the number of inspections, we can see that the average number of detected foreigners per worksite fell to 0.24 in $200 \mathrm{I}$ and further to 0.20 in the second half of $2002 .{ }^{21}$ Since 2003 , however, this indicator steadily increased to $0.4 \mathrm{I}$ in 2005 and was 0.37 in 2006 . It would be too easy, however, to attribute this increase in the efficiency of inspections (almost a doubling in the 'success' of inspections) solely to an increase in illegal foreign employment, as the worksite inspections are not performed randomly across all Austrian worksites. Rather, most inspections are carried out on the basis of certain prior information received by the control bodies. Such tip-offs can come from private individuals (e.g. neighbours of employers hiring irregular workers) or from regular employees of firms that also employ irregular workers. Other hints are provided by unsuccessful bidders in tender (e.g. for big construction projects that were won by employers of low-cost workers working irregularly) or from other public authorities (e.g. health or sanitary inspectors). In addition to worksite inspections based on such cues, the KIAB devises its own control strategy. For example, they might control all firms of a certain branch in a predefined district and time period. Therefore, an increased success rate may also indicate more denunciations or a better organisation and higher level of training of the inspection staff.

Looking more closely at the raw data on foreigners apprehended for irregularities in their employment status, it must be noted that there is indeed a growing disconnection between irregularity of work and illegal residence. As mentioned, this has been anticipated by the transfor- 
mation of the KIAB into an outfit of the Ministry of Finance responsible for all kinds of irregularities on the labour market. As already outlined, since May 2004, foreigners from the Central and Eastern European countries that joined the EU cannot (by definition) be illegal residents in Austria any longer, yet they still face restrictions in their access to legal employment for the time of the transition periods (at least until 2009 and possibly longer). According to the KIAB, the majority of apprehended foreigners on worksites are from Central, Eastern and South-Eastern European countries.

If we look at a breakdown of apprehended foreigners illegally employed at worksites in the three regions this study focuses on, we can see that generally the most notorious branches are, as in other European countries, construction and related industries and catering and tourism. This is true both before and after EU enlargement in 2004, as can be seen from the following three tables (Tables I.5, I.6 and I.7).

In interpreting these data, we should ask two main questions. First, does the recorded distribution of apprehended illegally employed foreigners across sectors conform to the actual distribution of irregular migrant work across these sectors and, second, how can we interpret changes in the recorded distribution over time? Both questions are clo-

Table 1.5 Apprehended illegally employed foreigners in Austria, 2003

\begin{tabular}{lllllllll}
\hline & $\begin{array}{l}\text { Construction } \\
\text { and related } \\
\text { industries }\end{array}$ & $\begin{array}{l}\text { Catering } \\
\text { and } \\
\text { tourism }\end{array}$ & Transport & Agriculture & $\begin{array}{l}\text { Service } \\
\text { industry }\end{array}$ & $\begin{array}{l}\text { Trade and } \\
\text { industry }\end{array}$ & & \\
\hline Vienna & 891 & 476 & 98 & 12 & 73 & 22 & 73 & 1,645 \\
$\%$ & $54 \%$ & $29 \%$ & $6 \%$ & $1 \%$ & $4 \%$ & $1 \%$ & $4 \%$ & $100 \%$ \\
Burgenland & 129 & 50 & 9 & 66 & 31 & 5 & 36 & 326 \\
$\%$ & $40 \%$ & $15 \%$ & $3 \%$ & $20 \%$ & $10 \%$ & $2 \%$ & $11 \%$ & $100 \%$ \\
Tirol & 163 & 123 & 11 & 19 & 17 & 2 & 5 & 340 \\
$\%$ & $48 \%$ & $36 \%$ & $3 \%$ & $6 \%$ & $5 \%$ & $1 \%$ & $1 \%$ & $100 \%$ \\
\hline
\end{tabular}

Source: BMF-KIAB

Table 1.6 Apprehended illegally employed foreigners in Austria, 2005

\begin{tabular}{|c|c|c|c|c|c|c|c|c|}
\hline & $\begin{array}{l}\text { Construction } \\
\text { and related } \\
\text { industries }\end{array}$ & $\begin{array}{l}\text { Catering } \\
\text { and } \\
\text { tourism }\end{array}$ & Transport & Agriculture & $\begin{array}{l}\text { Service } \\
\text { industry }\end{array}$ & $\begin{array}{l}\text { Trade and } \\
\text { industry }\end{array}$ & Other & Total \\
\hline Vienna & 241 & 658 & 21 & 4 & 61 & 110 & 89 & 1,184 \\
\hline$\%$ & $20 \%$ & $56 \%$ & $2 \%$ & $0 \%$ & $5 \%$ & $9 \%$ & $8 \%$ & $100 \%$ \\
\hline Burgenland & 126 & 85 & 12 & 53 & 167 & 64 & 190 & 697 \\
\hline$\%$ & $18 \%$ & $12 \%$ & $2 \%$ & $8 \%$ & $24 \%$ & $9 \%$ & $27 \%$ & $100 \%$ \\
\hline Tirol & 116 & 133 & 15 & 4 & 28 & 29 & 75 & 400 \\
\hline$\%$ & $29 \%$ & $33 \%$ & $4 \%$ & $1 \%$ & $7 \%$ & $7 \%$ & $19 \%$ & $100 \%$ \\
\hline
\end{tabular}

Source: BMF-KIAB 
Table 1.7 Apprehended illegally employed foreigners in Austria, 2006

\begin{tabular}{lllllllll}
\hline & $\begin{array}{l}\text { Construction } \\
\text { and related } \\
\text { industries }\end{array}$ & $\begin{array}{l}\text { Catering } \\
\text { and } \\
\text { tourism }\end{array}$ & Transport & Agriculture & $\begin{array}{l}\text { Service } \\
\text { industry }\end{array}$ & $\begin{array}{l}\text { Trade and } \\
\text { industry }\end{array}$ & Other Total \\
\hline Vienna & 464 & 596 & 52 & 13 & 119 & 138 & 125 & 1,507 \\
$\%$ & $31 \%$ & $40 \%$ & $3 \%$ & $1 \%$ & $8 \%$ & $9 \%$ & $8 \%$ & $100 \%$ \\
Burgenland & 129 & 32 & 5 & 19 & 201 & 25 & 77 & 488 \\
$\%$ & $26 \%$ & $7 \%$ & $1 \%$ & $4 \%$ & $41 \%$ & $5 \%$ & $16 \%$ & $100 \%$ \\
Tirol & 151 & 172 & 12 & 8 & 27 & 37 & 58 & 465 \\
$\%$ & $32 \%$ & $37 \%$ & $3 \%$ & $2 \%$ & $6 \%$ & $8 \%$ & $12 \%$ & $100 \%$ \\
\hline
\end{tabular}

Source: BMF-KIAB

sely related to the intensity and the success of controls in each region and sector. To simplify, putting more (human) resources into the control of a certain sector will yield more detections of irregularities. Tables I.8 and I.9 reflect the number of worksite inspections per sector and region in 2005 and 2006.

As can be seen from these tables, the intensity of worksite inspections varied widely between sectors, regions and years, and this can be linked to the numbers and shares of apprehended illegally employed

Table 1.8 Number of worksite inspections, 2005

\begin{tabular}{lllllllll}
\hline & $\begin{array}{l}\text { Construction } \\
\text { and related } \\
\text { industries }\end{array}$ & $\begin{array}{l}\text { Catering } \\
\text { and } \\
\text { tourism }\end{array}$ & & Transport & $\begin{array}{l}\text { Agriculture } \\
\text { Service } \\
\text { industry }\end{array}$ & $\begin{array}{l}\text { Trade and } \\
\text { industry }\end{array}$ & & \\
\hline Vienna & 290 & 1.157 & 69 & 8 & 121 & 181 & 95 & 1.921 \\
$\%$ & $15 \%$ & $60 \%$ & $4 \%$ & $0 \%$ & $6 \%$ & $9 \%$ & $5 \%$ & $100 \%$ \\
Burgenland & 965 & 279 & 110 & 59 & 114 & 281 & 217 & 2.025 \\
$\%$ & $48 \%$ & $14 \%$ & $5 \%$ & $3 \%$ & $6 \%$ & $14 \%$ & $11 \%$ & $100 \%$ \\
Tirol & 358 & 277 & 91 & 13 & 35 & 112 & 98 & 984 \\
$\%$ & $36 \%$ & $28 \%$ & $9 \%$ & $1 \%$ & $4 \%$ & $11 \%$ & $10 \%$ & $100 \%$ \\
\hline
\end{tabular}

Source: BMF-KIAB

Table 1.9 Number of worksite inspections, 2006

\begin{tabular}{lllllllll}
\hline & $\begin{array}{l}\text { Construction } \\
\text { and related } \\
\text { industries }\end{array}$ & $\begin{array}{l}\text { Catering } \\
\text { and } \\
\text { tourism }\end{array}$ & & Transport & $\begin{array}{l}\text { Agriculture } \\
\text { Service } \\
\text { industry }\end{array}$ & $\begin{array}{l}\text { Trade and } \\
\text { industry }\end{array}$ & & \\
\hline Vienna & 1.011 & 1.576 & 580 & 30 & 233 & 595 & 359 & 4.384 \\
$\%$ & $23 \%$ & $36 \%$ & $13 \%$ & $1 \%$ & $5 \%$ & $14 \%$ & $8 \%$ & $100 \%$ \\
Burgenland & 658 & 107 & 70 & 36 & 153 & 163 & 143 & 1.330 \\
$\%$ & $49 \%$ & $8 \%$ & $5 \%$ & $3 \%$ & $12 \%$ & $12 \%$ & $11 \%$ & $100 \%$ \\
Tirol & 682 & 579 & 298 & 9 & 113 & 221 & 355 & 2.257 \\
$\%$ & $30 \%$ & $26 \%$ & $13 \%$ & $0 \%$ & $5 \%$ & $10 \%$ & $16 \%$ & $100 \%$ \\
\hline
\end{tabular}

Source: BMF-KIAB 
foreigners recorded in Tables I.6 and I.7. For example, the number of worksite inspections in the construction industry in Vienna increased more than three-fold in absolute numbers (or from 15 per cent to 23 per cent in relative terms), resulting in almost a doubling of apprehensions in absolute numbers (an increase from 20 per cent to 3I per cent of all apprehensions in Vienna). The number of inspections in catering and tourism also increased in absolute terms (but decreased in relative terms from 60 per cent to 36 per cent), resulting in a somewhat lower absolute number of apprehensions in that sector (and a relative decrease from 56 per cent to 40 per cent of all apprehensions in Vienna). We could thus conclude that the absolute numbers of apprehensions of illegally employed foreigners, as well as their relative distribution, is a simple reflection of control intensities, which varies erratically over time.

Although this is a valid argument, it is also not the whole story. As the distribution of worksite inspections (where the control body KIAB concentrates its resources) is not completely random but is guided by some prior knowledge and tip-offs on likely irregularities in certain sectors and enterprises, we may assume that the control intensities do in fact follow some real developments in irregular migrant work. While such targeted controls can never be completely efficient (as reflected in the varying 'success rates' of controls), by and large we may assume that a consistently high number of controls and apprehensions in a certain sector also indicates a relatively high intensity of irregular activity in that sector.

Given these caveats and reflections, we can now attempt to provide some careful interpretation of some regional patterns reflected in the above data. While the share of detected irregularities in construction and related industries is high in all three regions, catering and tourism are clearly more important in Vienna and Tirol (both with a large tourist industry) than in Burgenland. On the other hand, there are more detected irregularities in agriculture in Burgenland (a border region to Hungary with many agricultural enterprises) and Tirol (with a strong horticulture) than in Vienna.

An interesting case is provided by the service industry: while apprehensions in this area (mainly in private households) are relatively low in Vienna and Tirol, they are relatively high in Burgenland. However, data on the service sector are likely to suffer from an especially severe data bias, namely the fact that irregular work in private households (e.g. cleaning, babysitting and caretaking) is generally not subject to worksite inspections, as KIAB inspectors do not usually have access to private homes. Moreover, as the recent (2006) discussion on the irregular care sector in Austria has shown, there has long been a widespread (political) consensus that irregular work in the care sector should not be subject to controls and legal proceedings, as that would 
interfere with other social policy goals (most obviously in the area of caregivers for elderly persons, who mostly come from neighbouring countries and provide care-giving services far below Austrian wage levels). Worksite inspections in the care sector included in the above statistics thus refer exclusively to controls of the (presumably irregular) placement agencies, but not to controls in private households.

Finally, statistics and reports of the KIAB indicate that the detected irregularities at the worksites take on various forms in different branches. Common forms of irregularities in the construction sector are tax and social security fraud through the use of subcontractors and sub-subcontractors (who quickly file for bankruptcy before paying their employees and the tax authorities) and employment as pseudo-self-employed. In catering and tourism (bars, hotels, restaurants), there are many cases of underreporting of the extent of employment, in care-giving it is paid employment through membership associations, while in other industries it is often simple non-registration for social insurance and tax purposes (BMF 2004a, 2004b). In Part 2 of this report, we will provide a systematic typology of the various forms of irregular migrant work as seen by a group of experts in the field.

\section{Notes}

I Such convincing evidence is also conspicuously lacking in the accompanying background paper to the policy proposal. See Commission of the European Communities (2007b).

2 In the accession negotiations, a transitional period of up to seven years was agreed upon, during which time the 'old' Member States individually may still regulate access to their labour markets for citizens of eight new Member States (the AC-Io except Malta and Cyprus, often referred to as the AC-8). Between 2004 and 2006, all countries of the EU-I5 except Ireland, the United Kingdom and Sweden had made use of transition periods for the free access to their labour markets for the AC-8. From 2007 onwards, only Austria and Germany continue to apply the same restrictions on citizens from the AC-8, while all other 'old' EU Member States have fully or partially lifted them.

3 When Romania and Bulgaria joined the EU in 2007, all EU-I5 countries except Finland and Sweden (but including Ireland and the UK) announced they would make use of transition periods for the free access to their labour markets. Italy and Hungary announced they would partially open their labour markets, while the 'new' EU Member States Poland, the Czech Republic, Estonia, Cyprus, Latvia, Lithuania, Slovenia and Slovakia opened their labour markets immediately to Romanians and Bulgarians.

4 Croatia and Turkey formally started membership negotiations in 2006. Macedonia received candidate status in December 2005, but has not yet formally started membership negotiations.

5 For a more extensive typology of types of irregular migrant work, see Part 2 of this report. From this discussion of frequently encountered types and forms of irregular migrant work, it should also become clear why we have chosen not to use some of 
the other terms that are commonly used in the literature. For example, the terms 'undocumented work' and 'undeclared work' are not used because they would exclude work that is, in fact, declared (or at least partly declared) yet irregular in some other important dimension of the definition provided above.

6 For a classification according to legal/illegal entry, residence and work, see Tapinos (I999: 23I), who details six important categories of clandestine status.

7 On the contrary, the report 'Transnational involvement and social integration' (Snel, Engbersen \& Leerkes 2006) argues that while transnational identity increases the social and economic position of a migrant, this does not directly correspond to actual transnational involvement, as such may be very cost-intensive.

8 According to this definition, informal employment is characterised by one or more of the following: evasion of taxes, social security fraud, and violation of labour legislation. Adding a fourth dimension, the violation of aliens legislation, results in a definition that is close to the one adopted for irregular migrant work above.

9 A fourth line of argumentation, the so-called 'cultural acceptance' argument, is not further explored here (cf. Samers 2005).

Io Still, this demand is not the only factor that 'drives' migration in this model, as migration to rich countries is seen as interlinked with capital flows to poor countries (Sassen I99I).

II However, it should be noted that Rath focuses specifically on self-employed immigrants, a subject that has traditionally received only scant attention by migration research. In much of the literature on economic activities of migrants, regular (and even more so, irregular) migrants are mainly perceived as being 'workers' only, while immigrant entrepreneurs have long remained 'unsung heroes' (Klosterman \& Rath 2003: I).

I2 While Anderson finds little or no evidence for involvement of irregular migrants in the UK in organised crime, he finds some indications of involvement in petty crime (small-scale drug dealing, prostitution, social security fraud (I999: I76). Engbersen et al. (2006) find evidence for a rise in subsistence crime among irregular migrants in The Hague.

I3 It has to be stated that Elwert's study comprised only a small sample size and migrants with specific social characteristics and a specific migration strategy.

I4 However, Chimienti et al. (2003) also report that their sample is likely to suffer from a serious selection bias, as certain sectors that also employ irregular workers (albeit more qualified ones such as IT, banking and insurance) are usually excluded from official control strategies. In this case, qualified irregular workers would be underrepresented in their sample, but the extent of de-qualification would be overestimated.

I5 Police statistics show that the majority of apprehended illegal migrants in Germany were from Poland, Central and Eastern Europe, Turkey, former Yugoslavia, Iraq, Vietnam, China and India (Schönwälder et al. 2004).

I6 In the AKI report, it is pointed out that migrant sex workers in Germany may be either illegally residing women or women who live here as tourists, wives or with a tolerated status (AKI 2003: 9).

I7 Annual net immigration to Austria at the beginning of the I990s was approximately 80,000 , while it was only around 20,000 during the second half of the I990s. At the same time, 20,000-40,000 foreigners were naturalised annually during the I990S. In the early years of the 2Ist century, net migration again increased to around 40,000-60,000 annually.

I8 EU citizens are exempted from this requirement.

I9 However, immediate free access to the labour market has been granted to those new EU nationals who have been working legally in Austria for at least twelve months, have been settled in Austria for five years or have fulfilled the requirements to receive 
a long-term work permit according to the Foreign Employment Law before I May 2004 .

$20 \mathrm{Au}$ pairs are foreign students between eighteen and 28 years of age who are allowed to work in households up to 25 hours a week, performing childcare and light housekeeping duties. They are provided with free room and board and receive spending money of at least 60 euro a week.

2I However, the year 2002 is an exception, as the responsibility for inspections was transferred from the Ministry of Economy and Labour to the Ministry of Finance, with an organisational restructuring of the responsible unit (KIAB). 



\section{The Delphi study}

\subsection{Introduction}

This chapter summarises the results of a multi-round Delphi study on migration and irregular work in Austria, carried out between 2005 and 2006. '. The goal of this survey was to provide in-depth expert assessments of the structure and dynamics of irregular foreign employment in Austria following the fifth enlargement of the EU in 2004. As one of several methods employed in the overall research project, the structured use of expert opinions by way of a Delphi study can provide valuable insights into irregular labour markets, the effectiveness of current or planned policy measures towards irregular foreign employment and can also serve as a qualified means of forecasting future developments with regard to irregular labour migration (especially regarding further rounds of EU enlargement).

\subsection{Methodology}

To learn more about irregular economic activities of foreigners in Austria and particularly about recent developments in this area after the latest rounds of EU enlargement, we employed a method that is different from those employed in earlier studies of the subject - the so-called Delphi method. In general, this method involves a larger number of independent experts in an interactive process of exchange through the use of written questionnaires, designed to foster convergence and consensus. ${ }^{2}$ The Delphi method is particularly valuable when confronted with complex social and economic phenomena where only little wellestablished knowledge is available, or where such knowledge is dispersed across a wide range of experts whose subjective evaluation can enrich the understanding and analysis of the research subject. Furthermore, the evaluation of policy measures (Policy Delphi) and the prognosis of future developments (Prognostic Delphi) are two main applications of the method. ${ }^{3}$ The goal is to bring together existing but fragmented knowledge and expertise in an interactive process. Experts are given the opportunity to state their views on a given topic and react to 
the (anonymous and consolidated) views and assessments of other experts in a second (and possibly third) round. The primary value of a Delphi survey is not in the (quantitative) representativeness of its findings, but in the qualitative input of a diverse collection of experts that helps to elucidate a broad view of the research subject.

The following characteristics of the Delphi method are important conditions for the achievement of relevant results: a multi-stage process, a balanced composition of the group of participating experts and anonymity. In order to allow for exchange, revision or refinement of opinions expressed by experts, the survey must include valid feedback mechanisms. Therefore, the Delphi method includes several consecutive stages (a minimum of two rounds of written questionnaires). In this process, the role of the researcher is to summarise the points made by the experts and to communicate both the contested and the consensus views back to the participants, who are then called upon either to adjust their views in light of the new arguments or to better justify their own opinions.

Our Delphi study involved the administration and processing of two rounds of Delphi questionnaires, which were answered by 37 experts in the first round and (out of this group) by 22 experts in the second round. However, the first questionnaire was guided by a preceding round of in-depth interviews with 37 experts in the same field. The results of this preceding interview phase were reflected in the first round Delphi questionnaire. Therefore, we can designate the current Delphi survey as a 'two-and-a-half-round' Delphi Study. All these stages of the Delphi study were implemented between October 2005 and September 2006.

When choosing the participating experts for a Delphi survey, researchers should strive to achieve large heterogeneity within the group of experts in order to cover as many aspects of the research subject as possible. On the other hand, once the interactive process is started, the group has to remain closed. No new experts may participate as they have not been involved in previous feedback rounds, even if some participants will drop out of the process. For valid results, however, the number of participating individuals should not fall below fifteen (Gordon 1994).

The institutional background of the participating experts in our Delphi survey are reflected in Table 2.I. In both rounds, there was a good distribution of experts regarding their institutional affiliation. The importance of such heterogeneity became apparent in the analysis of the responses - an example was when experts from a certain professional or institutional background often expressed similar opinions towards a certain topic, or when certain subgroups as a whole differed in their assessments from other subgroups. 
Table 2.1 Institutional background of participating experts

\begin{tabular}{llc}
\hline & $\begin{array}{l}\text { Number of } \\
\text { respondents } \\
\text { in Delphi 1 }\end{array}$ & $\begin{array}{c}\text { Number of } \\
\text { respondents } \\
\text { in Delphi 2 }\end{array}$ \\
\hline $\begin{array}{l}\text { Governmental } \\
\text { (ministries, labour market service, worksite inspectors, } \\
\text { social security bodies) }\end{array}$ & 12 & 8 \\
$\begin{array}{l}\text { Non-Governmental } \\
\text { (charitable organisations, migrant organisations, aid and }\end{array}$ & 8 & 5 \\
$\begin{array}{l}\text { advice bodies) } \\
\text { Special interest groups } \\
\text { (Chamber of Commerce, Chamber of Labour, trade } \\
\text { unions) }\end{array}$ & 7 & 3 \\
$\begin{array}{l}\text { Research } \\
\text { (labour market researchers, migration researchers, other } \\
\text { researchers) }\end{array}$ & 10 & 6 \\
Total & 37 & 22 \\
\hline
\end{tabular}

Finally, it is important that the participating experts remain anonymous before, during and after the Delphi survey in order to allow an even-levelled process of communication across institutional and status barriers. This is especially important for sensitive research topics like irregular migrant work, where institutional affiliations may otherwise impede the free expression of personal opinions. In our Delphi study, the anonymity of participating experts remained safeguarded during all stages of the research process.

Taken together, these methodological principles can maximise the explanatory power of Delphi studies. Nevertheless, there are also significant constraints in the use and interpretation of Delphi surveys. The main constraint is the fact that the Delphi survey can only reflect the opinions, however well-argued and justified, of the participating experts and cannot deliver representative or quantifiable results. Nevertheless, the main achievement of our Delphi survey is a well-grounded assessment of the theoretical, political, structural and economic dimensions of the subject under study. In addition, the prognosis of likely future developments and the assessments of more than twenty current and planned policy measures meant to address irregular migrant work will be particularly interesting for policymakers looking for effective means for tackling this complex issue. 


\subsection{A short definition}

The subject matter of our research is the irregular work of migrants (or irregular migrant work - IMW), a term that has not been commonly used so far and requires some explanation. Traditionally, irregular economic activities of immigrants have been referred to as 'illegal foreign employment' (Illegale Ausländerbeschäftigung), and this is also the legal term commonly used in Austria and other German-speaking countries. However, already at an early stage of research, it became clear that this traditional terminology fails to capture essential elements of the phenomenon. Today, irregular income-generating activities of immigrants increasingly take place between legality and illegality and encompass various forms of irregularity, both with regard to the legality of residence status and employment status. As has been noted elsewhere, a simple dichotomy of legality-illegality of employment and residence status is no longer sufficient, particularly after the latest rounds of EU enlargement have created various levels of access to the labour market for foreigners (cf. Anderson \& Ruhs 2006).

For the purposes of this Delphi study, the definition of the term 'irregular migrant work' (IMW) was deduced from the expert interviews carried out at the beginning of the research process. In the first place, we are interested in the economic activities of migrants (defined here as foreigners or non-nationals) only, thus excluding economic activities of Austrians, but including both those of EU nationals and third-country nationals. Furthermore, we are not interested in all aspects of migration and all activities of migrants, but mainly in those aspects that relate to irregular work. 'Work' is conventionally defined as gainful economic activity (employment or self-employment), while the irregularity in such activities can include many forms of semi-legal, quasi-legal or grey areas of employment relationships of migrants. Such arrangements often take place at the margins of legal regulations or try to circumvent them in various disguised forms. For the purposes of this study, irregular migrant work has been defined as follows:

Irregular migrant work comprises all paid work of foreigners (non-citizens) that conflicts with one or more of the following laws and regulations: foreign employment law (including residence law), social insurance laws, tax laws, labour legislation and trade regulations.

Thus, in a legal sense, irregular work of foreigners is distinguished from irregular work of nationals (Austrian citizens) only insofar as currently only non-nationals (except EU-I5 Member States plus Malta and 
Cyprus) can violate the terms of foreign employment law, and only third-country nationals can violate residence law.

\subsection{Forms of irregular migrant work}

The definition of irregular migrant work used in this study enables us to incorporate a variety of irregularities occurring on the Austrian labour market. And the legal or illegal residence status of economically active migrants is but one aspect that assumes ever less importance for irregular migrant work in Austria. Based on information gathered during the initial interview phase of the project, our expert panel was asked in Round I to identify and describe the most important forms of IMW prevalent in Austria and to link them to certain notorious sectors and branches (construction, agriculture, catering and tourism, domestic services and industry). In Round 2, the information gathered previously was evaluated by the experts and was supplemented with additional information. All together, the experts described ten 'typical' forms of irregular migrant work, which often occur in combination with each other and clearly show the complexity of the concept of IMW, which is increasingly characterised by the blurring of legal boundaries.

\section{Working without a work and/or residence permit}

According to current immigration and employment laws, ${ }^{4}$ all employed non-nationals, except EU citizens of the EU-I5 plus Cyprus and Malta, have to get a work permit; third-country nationals must also get a residence permit before being able to get a regular job in Austria. Working without the required work permit generally also implies the migrants' non- registration at social insurance and tax institutions as will be explained later, while the same is not necessarily true the other way around.

According to most experts, this form of irregular migrant work is especially dominant in private households (both in cleaning and care-giving), where traditional household structures have led to a widespread public attitude according to which housework as such is perceived as 'traditionally unpaid work'. Accordingly, the outsourcing of household duties (to cleaning ladies, for childcare or elderly care) to unregistered migrant workers is perceived as almost normal or in any case only a minor irregularity. Moreover, the special protection of the private sphere of households (with no worksite inspections) renders this particular form of IMW relatively 'risk-free' for both employers and employees. In addition to work in private households, this form of IMW was 
also seen as important in construction and industry, but not so much in agriculture and in catering and tourism.

\section{Non-registration at social insurance institutions}

The registration of the employee at one of the social insurance institutions is the duty of the employer, except for self-employed persons. Interestingly, this registration at a social insurance institution is decoupled from the possession of a work permit. That means that even persons who are irregularly employed in terms of not having a work permit theoretically have the right to social insurance payments by their employers (and can theoretically even claim this right after the fact before labour courts, something that is almost Utopian for people without a secure residence or employment status and almost never happens in practice).

As already mentioned, this form of IMW is seen by our experts as closely related to the first form (not having a work and/or residence permit), therefore the same sectors and branches were considered as important in this context. In addition, it was argued that non-registration at social insurance institutions often occurs in 'short seasonal jobs' in agriculture, where employers may simply not bother to overcome the few 'bureaucratic hurdles' for registration.

\section{Non-registration at tax institutions}

Registration for tax purposes is also the duty of the employer, who has to shoulder part of the non-wage labour costs, except for self-employed persons. However, registration with tax authorities requires a valid work permit for all foreigners not exempt from this obligation.

This form of IMW will occur mostly in combination with other forms of IMW, usually with non-registration at social insurance institutions. For persons working without a valid work permit but who require one, the combination occurs automatically. On the other hand, even persons who have a valid work permit will often not be registered for tax purposes. Consequently, our experts have rated this form of IMW as relatively common in all branches except tourism and industry, where the dominant form is seen to be 'under-registration' of the hours worked (rather than complete non-registration). The reason for this apparent difference could be in the relative risk of detection faced in each sector: migrants working irregularly in service provision in bars, restaurants or hotels are presumably more exposed to this risk than migrants working in occupations that do not involve direct contact with customers. 


\section{Violation of workers' rights}

Although it can be argued that a violation of workers' rights lies in the nature of all irregular work, we have chosen to include it as a separate form of IMW when the systematic occurrence of such violations is an inherent characteristic of the migrants' work. Thus, even if a specific job of a migrant is 'regular' in all other aspects of residence and employment laws (including registration with residence and work permit), a systematic violation of workers' rights (labour law) can still justify its classification as irregular.

The statements of our expert panel reveal that such systematic violations are particularly widespread in temporary and seasonal work in the catering and tourism sector. Examples are extremely long working hours, unpaid overtime, unpaid holidays, no holidays at all, payment below minimum wage, excessive deductions for room and board, etc. While such violations were also attributed to other sectors (agriculture, construction and, partly, industry), it is interesting to note that they were hardly mentioned for work in the private sphere (cleaning, caregiving). Apparently, our experts already assumed that labour standards are generally not enforceable (and thus of little relevance) when it comes to work in private households.

\section{Insufficient registration of employment contract}

In these cases, the migrant worker may be officially registered as only part-time or minimally employed (and will thus be able to produce official documents during inspections), but in fact works much longer hours than the official timeframe of the contract. In many such cases, a regular work permit exists but social insurance contributions and taxes are paid only for part of the total income. The difference in income is paid out informally in cash.

Our experts judge this specific form of IMW to be far more common in the catering and tourism sector than in other sectors, again indicating the apparent use of a legal cover for the irregular employment of migrant workers in this sector. As a special case within this form of IMW, foreign students were mentioned. Foreign students are exempted from employment laws if their work is only part-time, does not interfere with their normal course of studies and is not their primary source of subsistence. Using these special provisions, many foreign students are apparently registered as part-time employees, but are in fact working full-time. 


\section{Irregular extension of a regular work permit}

Our experts mentioned this as a specific form of IMW, whereby the time limits on temporary work permits for foreign employees are exceeded after their expiration. In the case of third-country nationals, this often affects not only the legality of employment, but also their residence status, which is usually tied to legal employment.

This form of IMW has been mentioned most often for seasonal employment in agriculture but also in catering and tourism. For these sectors, work permits for seasonal workers are issued for a maximum period of six months, and several experts indicated that such periods of regular employment are often followed by periods of irregular work, at least until the next (temporary) work permit again legalises the employment relationship. A special case is provided by short-term seasonal workers in agriculture (harvesters) who are granted work permits for a maximum of six weeks only during the harvesting season.

\section{7. 'Pseudo-self-employed' ('Scheinselbstständigkeit')}

This form of IMW constitutes an irregular evasion of foreign employment law, but also implies the non-payment of social security contributions by employers. It makes use of the fact that self-employed foreigners are generally not subject to foreign employment laws (no quota restrictions) and can practice their trade with relative ease by obtaining a trade licence for certain (restricted) occupations. In many cases, however, such work does not constitute genuine self-employment but rather a disguised form of employment involving dependency on an employer. The latter then orders the work to be done, provides the necessary materials and 'buys' the services of the 'self-employed' subcontractor. While this constitutes a breach of foreign employment legislation, such disguised forms of dependent employment can be hard to prove in legal proceedings.

Besides circumventing foreign employment law and other labour standards, this form of IMW is very advantageous for employers, who additionally save on the employer's share of social security contributions. Our experts mentioned this relatively new phenomenon in relation to the May 2004 EU enlargement in particular, which has since been followed by the registration of several thousand newly 'self-employed' citizens of the new EU-8 Member States in Austria, mostly in certain construction-related activities. The fact that dubious subcontractors are most often used in the construction sector (see also form 9 below) makes this form of IMW particularly notorious in that sector. According to several experts, however, this form of IMW is becoming increas- 
ingly common in certain branches of trade and industry, as well as in other areas.

\section{Violation of trade regulations}

The fact that genuine self-employment by foreigners outside foreign employment law (that is without a work permit) is permitted in certain trades but not in others (such as mainstream construction work) can also give rise to another form of IMW. In this case, the foreigner is a genuine self-employed person with a trade licence for one of the permitted trades, but works in another (restricted) trade and thus violates trade regulations. The foreigner might also work as a self-employed person without any trade licence at all.

There was again widespread agreement among our experts that this form of IMW is mainly present in construction and construction-related areas, and became more frequent after the latest round of EU enlargement.

\section{9. 'Pseudo-companies' ('Scheinunternehmen')}

This category actually refers to a specific form of organisation of irregular work in which irregular migrant work is often involved. Pseudocompanies are companies that are specifically set up with the intention of committing tax and social security payment fraud. Such companies often officially register and employ migrant workers but very quickly (within a few months) declare bankruptcy and disappear before ever paying regular wages and non-wage labour costs. In such cases, the migrant workers may or may not be implicated in this fraudulent scheme and often fall victim to the withholding of promised wages.

According to several experts and official enforcement data, 'pseudocompanies' appear almost exclusively in the construction sector. This sector is characterised by complicated subcontracting and sub-subcontracting arrangements for the fulfilment of larger building projects, making it difficult to trace and apportion the responsibilities for irregularities and fraud when the company 'disappears'. ${ }^{5}$ Legal matters can become even more complicated when 'pseudo-companies' themselves subcontract work to 'pseudo-self-employed' migrants as subcontractors.

\section{Organisation in membership associations}

This form of IMW has been designed to shift completely irregular employment situations (no work permit, no registration, etc.) in the private sector to a less obvious 'grey area', where the employment relationship is disguised as social work within charitable associations. The very moderate payments for long working hours are designated as 'pocket 
money', and there is no official registration, tax or social security contributions.

According to our experts, this form of IMW has been specifically 'invented' to link supply and demand for irregular care services in private households. Care personnel and patients are registered as members in (usually transnational) membership associations with branches in the countries of origin and in Austria. Officially such associations claim to provide a simple referral mechanism for 'neighbourhood help', but the fact that both the migrant workers (usually qualified female nurses from Austria's neighbouring countries) and the patients (usually elderly handicapped persons who receive special financial assistance for their needs from the state) have to pay significant fees to these associations suggests a predominant profit motive on the part of the organisers.

To summarise, our experts have listed and described a number of different forms and manifestations of IMW and have also provided us with their assessments of sector-specific patterns and structures. The various forms of IMW are reflected here as ten 'ideal types' for the purpose of clarity, but in reality they are likely to occur in various combinations and with considerable overlaps. In fact, the findings of our Delphi survey suggest that IMW occurs in greater heterogeneity today than it did only a few years ago. Moreover, we found that both irregularly working migrants and their employers are constantly looking for ways to circumvent existing laws and regulations by using available loopholes, and that, consequently, the 'grey area' between regular and irregular migrant work has become larger if not more blurred.

\subsection{An assessment of the impact of irregular migrant work}

One of the questions we asked our experts in the Delphi survey concerned the overall impact of irregular migrant work. In particular, we asked about the likely impact of IMW on the national economy and on national finances. Furthermore, they should assess the effects of IMW on employers and regular employees. The options given ranged from 'strongly positive' and 'positive' to 'neutral', 'negative' and 'strongly negative'.

Not surprisingly, the analysis of the answers shows that there are both winners and losers where irregular migrant work is concerned. According to some comments received, IMW leads to replacement processes, which have a negative impact on native-born workers, migrants already integrated into the labour market and, especially, those who are low-skilled. Additionally, the social financial system is said to be hol- 
lowed out by diminishing the tax base for the provision of public infrastructure such as public education, health care, security and means of transport. This, in turn, reduces the demand for these goods and services and the possibility of future investments. Thus, most experts agreed that there are strongly negative effects of irregular migrant work on national economic development.

However, some experts also saw positive impacts of irregular migrant work on the national economy. Here, experts stressed economic growth, investments of the 'saved' capital, a higher national income in Austria and a more cost-effective production. A common argument made was that irregular migrant work plays a significant role in the national economy because some sectors simply could not exist without it. Others have pointed out that such perceived positive effects are overestimated and in most cases would only benefit employers.

Concerning the impact of irregular migrant work on public finances, experts assessed it as strongly negative or negative (26 out of 37 experts). Several respondents pointed out that this concerns also irregularly employed Austrians. The most important effects were seen in the defrauding on income taxes, value added tax and social insurance dues.

In regard to the effects of irregular migrant work on employers, a relative majority of experts (sixteen out of 37) agreed on its positive impact. The following advantages for employers were particularly stressed: high profits without taxes and a high dependency of employees on employers, without having to provide employees with legal protections. Lower wages were mentioned as one further advantage. However, it was also mentioned that for all honest employers, the distortion of normal trade conditions has negative effects on their businesses (e. g. when they cannot win a bid due to their higher prices).

When it comes to the impact of IMW on regular employees, a large majority of respondents (29 out of 37 ) agreed that it is negative or strongly negative. They referred mostly to wage dumping on the level of unskilled workers and displacement competition. In the view of several experts, the cheaper labour supply by irregularly working migrants generally depresses the level of wages and the competitiveness of regular workers.

In the second round of our Delphi survey, our experts were confronted with a reformulation of the above theses. The new statement to be evaluated now read: 'The general impact of irregular migrant work is negative, especially for economic development, public finances and for regular employees in Austria'.

The overwhelming majority of experts agreed with this statement. From the additional comments provided, we may conclude that our respondents mainly saw the distortion of fair competition, the defrauding of taxes and social security payments and wage dumping as the 
main problems. However, it was also stated that these general negative effects should not be overestimated, as there are also many actors who profit from irregular migrant work. These are not only enterprises, but also private households, for example, those in need of elderly care and home health care. As one of the experts claims: 'The competition [there] is not distorted, as some occupations are simply not offered on the regular market in a sufficient volume, as for example, in the care sector.'

As this is an important issue, we will now take a better look at the question of unfair competition through irregularly working migrants.

\subsubsection{Competition on the labour market}

In the first round of our Delphi survey, experts were asked to assess four theses concerning competition on the labour market through irregular migrant work. In the second round, these theses were reformulated and again submitted to the experts for a re-evaluation of their responses. The first thesis concerned the assertion that migrants already integrated on the labour market are pushed into the irregular sphere by the arrival of new EU-8 citizens. The evaluation of the first round of questionnaires showed disagreement on this point among experts. A narrow majority agreed with this thesis, among them most representatives of trade unions and NGOs. The opinion of experts oscillated between two positions. On the one hand, new EU-8 citizens were not perceived as competitive as they would not yet enjoy automatic access to the Austrian labour market because of the transitional rules. They would first have to muddle through the long and complicated system to get a work permit. On the other hand, they were seen as favoured due to the 'community preference' principle and because they enjoy freedom of residence (and, additionally, because they often have a better education). Some experts thus thought that they could be at least potentially competitive. However, they also noted that there was no significant displacement within the foreign labour force, with the exception of specific sectors, where there was a demand for unqualified and cheaper labour and where the aim was to avoid official labour standards, taxes and social insurance contributions. Significantly, the second Delphi round yielded a similar result. 'Displacement' was portrayed as a continuous process that happens within the irregular labour market. The transitional rules also provided some exceptions for the new EU-8 citizens. Thus, it was argued that both groups (established third-country nationals and new EU-8 migrants) sometimes covered similar labour market segments and would thus be in direct competition with each other. For example, the seasonal quotas for catering and tour- 
ism prior to 2004 were covered mostly by third-country nationals, while since EU enlargement migrant workers from the new EU Member States have received preferential access to seasonal work permits. In 2006 , no new seasonal work permits were issued to first-time seasonal workers from third countries and the number of regularly returning third-country seasonal workers ('core workers') was cut by 50 per cent.

The second thesis - that the supply of low-cost, irregularly working migrants makes the job placement of unemployed persons more difficult - was supported by nineteen of 37 experts (among them many representatives of NGOs, public administration and representatives of employees). Eleven experts rejected this assumption. The main argument presented was that only part of the tasks of irregularly working migrants could be occupied by unemployed persons, as they are not as motivated and flexible as the former. In addition, the very 'advantage' of irregular employment was seen in the resulting irregularity, whereas a regular job placement would lead to regular employment. It was also noted that in the most notorious sectors (such as in catering) employers would hardly be willing to pay higher wages and offer better working conditions to make them more attractive for the unemployed. In practice, some of the unattractive professions are almost never filled through the AMS, as there is the experience that it is extremely difficult to motivate unemployed persons to take them. To test this thesis in the second round of the Delphi survey, our experts were confronted with a new formulation of the above thesis. We now asked whether some specific unattractive professions are not offered to unemployed persons due to their lack of motivation and flexibility. In their reactions, some experts argued that this situation is attributable not to the lack of motivation or flexibility of unemployed persons per se, but to the specific characteristics of the unemployed (often persons over 50 years old with health problems) and to the nature of the unattractive jobs.

The third thesis, that long-term employees who already make higher demands to their employers are replaced in certain branches through newly arriving EU-8 citizens, was approved by a large majority of experts in both Delphi rounds. This was seen to be especially valid for low-skilled migrants from the new EU countries. Some experts related this to a general trend of 'outsourcing' tasks previously performed by employees to borrowed staff from personnel companies (who often subcontract) and to self-employed migrants. At the same time, doubts were raised by migration and labour market researchers. They were of the opinion that the thesis was not valid in those branches where longterm employees already possessed specific valuable knowledge, skills 
and experience, making them less likely to be easily replaced by new workers.

With regard to the fourth thesis - that employers favour irregularly employed Austrians over irregularly employed migrants - almost half of our experts did not take a position. Representatives of NGOs, migration and labour market researchers were especially sceptical about it, with the partial exception for fields and occupations where German language skills are of importance. Generally, it was argued that the weaker position of migrants and their higher dependency rate seems to favour irregular migrant employment rather than that of Austrians. The second round of the survey found a significant majority of experts (77 per cent) agreeing to this position. Moreover, it was argued that it depends more on the capacity, motivation and the personal reputation of reliable workers.

\subsection{Reasons and motives for employers to employ migrants irregularly}

In the first round of the Delphi survey, our experts were asked about their assessments and comments in regard to the reasons for irregular employment of migrant workers. The analysis of the results shows a clear consensus among experts. The consensus view is that the main motive behind irregularly employing migrants is to save on additional wage costs (taxes, social security contributions and other dues) and, to some degree, on generally lower wages. However, some experts stressed that the 'cost argument' is not the only one that is relevant. According to them, it is more an interplay of many different motives, such as 'a flight from labour legislation' and a general non-compliance with employees' rights.

Furthermore, there was wide agreement among our respondents that for persons in need of 24-hour-a-day home care, there is currently no other option than to employ a migrant worker irregularly. Thus, experts demanded a restructured official framework for those in need of health and elderly care (see also Section 2.II).

Experts were asked if the large number of foreign workers available influences the decision of employers to hire migrants irregularly. The analysis shows that the easy availability of foreign manpower is seen as a main precondition for irregular migrant work, as the irregular labour market is shaped by both demand and supply. As far as the role of ethnic businesses in urban centres and their influence on the size of irregular employment is concerned, a majority of experts agreed that there is a connection. It was pointed out that just as native businesses, also ethnic businesses often use the helping hands of their family members 
(sometimes irregularly), but that for foreign business owners, the restrictive regulations on labour migration often lead to a breach of immigration legislation.

There was more disagreement among experts concerning the arguments of flexible working conditions and administrative barriers, which are often said to influence the decision of employers to hire irregularly. Some experts mentioned the missing job security of irregularly working migrants as a central motive, giving employers a free hand in employing someone without any obligatory contractual obligations in hiring and firing. However, it was also pointed out that some flexibility is also in the interest of irregularly employed migrants, as it gives them the possibility to earn more money and furthermore, to plan their travels to their country of origin in a flexible manner.

As far as the administrative obstacles are concerned, there was no agreement among experts about their influence on employers' motives to hire irregularly. Generally, representatives of NGOs were of the opinion that administrative obstacles promote irregular migrant work. On the contrary, representatives of trade unions were of the opinion that there are enough possibilities for regular employment of migrants, and that a majority of them actually had official access to the Austrian labour market, if only they would use it.

We also wanted to know whether a general labour scarcity in specific sectors may lead employers to hire migrants irregularly, as had been argued in the preceding round of oral interviews by several experts. Such labour scarcities may be rooted in the unattractiveness and low prestige of certain occupations, in inconvenient working hours, hard working conditions and other factors. However, several experts argued that it was mainly the low wages in certain occupations that were to blame and that, moreover, these wages would have to rise in the absence of irregularly working migrants. A typical argument is provided by the following expert statement: 'When the payment is good and the working conditions fair, also hard and "dirty" jobs are attractive.'

In the second round of the Delphi survey, we asked our experts to refine their positions by attaching the mentioned motives to specific labour market sectors. According to the respondents, the main motive in the construction sector, which is particularly characterised by high competition, is clearly the saving of labour costs. In the catering and tourism sector as well as in agriculture, an additional motive seems to be the avoidance of labour market regulations and a higher flexibility of irregularly working migrants willing to work long hours, especially for smaller enterprises. For private households (care and cleaning) it was argued that, apart from the cost-saving, it is the easy availability of migrant manpower that induces employers to hire migrant workers irregularly. In this area, a high and rising private demand (due to demo- 
graphic and socioeconomic developments) was said to be met by an ample supply of irregularly working migrants.

Overall, the results of the first Delphi round were confirmed in the second round. Thus, according to our expert panel, the main motives for employers to hire migrants irregularly are:

I The saving of costs through lower hourly wages and the non-payment of payroll taxes and social insurance premiums $(85$ per cent agreement in the first round and 82 per cent in the second round).

2 The easy availability of irregularly working migrants (68 per cent agreement in the first round, 64 per cent in the second round).

3 The higher flexibility, lower social protection and greater dependency of irregularly working migrants compared to regular employees.

On the other hand, restrictive labour immigration policies and administrative obstacles were not seen as a main motive for employers to hire irregularly (49 per cent agreement in the first round and only 30 per cent agreement in the second round).

Apart from these general motives and reasons for irregularly employing migrant workers, we also wanted to learn more about the impact of broader developments on the labour market on IMW. The results are summarised in the next paragraphs.

\subsubsection{Deregulation, flexibilisation, liberalisation and globalisation}

As our economies, societies and labour markets are undergoing profound changes, some of these developments are likely to have significant effects on the structure and extent of irregular labour markets as well. To gain insight into the impact of such changes, we presented our expert panel with a number of hypotheses and asked them to answer and comment on them. One such thesis, which found almost universal approval in the first Delphi round ( 89 per cent), was the claim that de-regulation and outsourcing to sub-enterprises promote and enable more irregular migrant work. Similarly, the thesis that flexibilisation of employment relationships facilitates IMW was approved by a growing majority of respondents (54 per cent in Delphi I and 73 per cent in Delphi 2). A third thesis, namely that the ongoing liberalisation of the labour market increases the extent of IMW, was also agreed upon by a growing majority of respondents $(57$ per cent in Delphi I and 64 per cent in Delphi 2), while the thesis that globalisation (in the form of higher competition) pressures employers into irregularly hiring more migrants was met with a high but decreasing share of positive answers ( 67 per cent in Delphi I and 50 per cent in Delphi 2). 
Against these four theses that found significant approval among our expert panel are several other theses that found little consensus, many abstentions or even sharply opposing viewpoints. For example, there was little agreement on the impact of general demographic developments (aging, population decline, labour scarcities, etc.) on IMW, on the influence of growing incomes and wealth, on the relationship with the business cycle and the level of unemployment in Austria. Our respondents put forward a range of arguments in favour of, or against, these propositions, but the overall picture remains inclusive. ${ }^{6}$

\subsection{Recruitment and social networks}

In order to get a better understanding of recruitment processes and the functioning of social networks, experts were asked to evaluate different search strategies of migrants when looking for irregular work. By far the most important strategy mentioned here was referral by family and colleagues (also colloquially referred to as 'word of mouth'). Our experts drew attention to this form of search strategy especially for private households and personal services (home nursing, home health and elderly care, babysitting, cleaning) as well as in agriculture. However, it was also suggested to play a significant role in the construction and catering sectors.

In a ranking of the most frequently named search strategies, the second place is occupied by recruitment agencies. Our experts pointed out that these play an important role especially when looking for a job in the care sector. In addition, this search strategy was also seen to be increasingly prevalent in the construction sector, but less so when it comes to agriculture and seasonal jobs.

Contacts from previous employment in Austria were seen by our experts as the third most important strategy when looking for a job. This form of direct access to irregular jobs was considered particularly valid for the tourism sector and for jobseekers from the new EU-8 countries.

The fourth important form of recruitment mentioned by experts was subcontractors. This should be true especially for IMW in construction and related industries.

The fifth place in the ranking is occupied by the ethnic community. One respondent adds that several empirical studies have already proven that networks play a central role when looking for a job. However, as another expert pointed out, ethnic communities are often limited to specific regions and urban centres where such structures can develop.

Most respondents assigned only a minor role to digital and print med$i a$ in the countries of origin, when looking for irregular work in Austria. According to one expert, only a minority makes use of this strat- 
egy, as jobs found through newspaper advertisements later often turn out to be non-existent. Others pointed out that it could still be a popular strategy in the recruitment of personal services (e.g. au pairs) as well as in tourism and agriculture.

Finally, other search and recruitment strategies have been assigned only limited roles by our expert panel. This concerns both the street market (Arbeiterstrich) for irregularly working migrants that used to be an almost ubiquitous phenomenon in the early I990s but is reportedly less frequented these days, and the strategy of 'going from door to door'. Anecdotal evidence shows that the latter sometimes still occurs in agriculture, catering and construction but is limited geographically or to specific groups such as asylum seekers. Finally, finding a job through offering their services in advertisements in newspapers is seen to be of little relevance, mainly because other options are available.

To sum up, on the basis of our expert assessments, we can distinguish three major recruitment strategies. They are as follows: contacts through social and family networks (at the core), professional contacts and recruitment and searching for work by means of one's own initiative or advertisements in the media.

Particular search and recruitment strategies of irregularly working migrants have an obvious and logical relationship to the observed presence of specific nationalities in particular segments of the irregular labour market. Therefore, our experts were asked to relate this phenomenon to either professionally organised recruitment or informal networks of irregularly working migrants.

The majority of our experts shared the opinion that the 'clustering' of specific migrant groups in specific segments of irregular labour markets is clearly connected to the existence and functioning of informal networks. Experts pointed to the well-known phenomenon of 'chain migration' through contacts with long-established migrants in Austria, who are themselves employed in specific sectors of the labour market. Others referred to the role of language within informal migrant networks. A significant deviation from this view is noticeable in the answers from representatives of public control bodies, who believed that the clustering phenomenon is mostly connected to professionally organised recruitment in the country of origin, particularly for irregular work in construction, agriculture and care work. Overall, the arguments brought forward indicate that there is often no clear difference between organised recruitment and recruitment through informal networks, as both exist close to each other and often intersect and overlap.

Finally, the majority of respondents argued that especially the socalled 'ethnic businesses' (as present, for example, in the catering and service sectors) draw upon existing ethnic networks (specific groups mentioned were migrants from Turkey, former Yugoslavia, China and 
Asia in general). In the next section, we will take a more detailed look at the social characteristics of irregularly working migrants in Austria.

\subsection{Social characteristics of irregularly working migrants in Austria}

Important points in the discussion of irregularly working migrants in Austria are often their gender ratios, their qualification and work profiles and their countries of origin. We will examine each of these one by one.

\subsubsection{Gender ratios}

In regard to the sex ratio, the results of our Delphi survey indicate that this is seen as highly sector-specific and, moreover, that the situation in the most important sectors in not much different than that in regular employment. Generally, experts pointed out that the labour market is divided along gender lines and used labels such as 'classical role images', 'traditional educational domains' or simply 'sexual discrimination', which would lead to gender segregation on the labour market. One expert mentioned the historical development of migration to Austria, which was traditionally dominated by men and was related to the dominance of the male workers in specific sectors. This would be especially true for the traditional countries of origin of the guest workers and asylum seekers in Austria and sectors such as construction and industry, which are dominated by a high proportion of migrants from former Yugoslavia and Turkey. On the contrary, the care sector is dominated mainly by caregivers from Slovakia, the Czech Republic, Poland and Hungary, where 97 per cent of respondents judged this sector to be female-dominated. A similar situation is assumed for the cleaning sector, with a high proportion of women from the successor states of former Yugoslavia.

According to another view, however, the prevailing gender ratio is related more to the traditional role images for certain occupations than the history of labour migration to Austria. It was also mentioned that the various ethnic groups have different images of the gender role and tasks, and that the connection between gender and country of origin in irregular migrant work would therefore be only indirect.

On the whole, more than 70 per cent of experts assessed the gender ratio for all sectors together as balanced, while 28 per cent judged it to be male-dominated. There was no one who evaluated the overall gender balance as female-dominated. At the same time, our experts tended to the following sector-specific assessments: 
- Construction is explicitly dominated by men.

- Care is explicitly dominated by women.

- Cleaning is explicitly dominated by women.

- Trade and industry is gender-balanced though with a tendency to male dominance.

- Agriculture is gender-balanced though with a tendency to male dominance.

- Catering and tourism is gender-balanced though with a tendency to female dominance.

These tendencies are furthermore accentuated or qualified depending on the region and the various activities within specific sectors.

\subsubsection{Qualifications and work profiles}

Another important question on the social characteristics of irregularly working migrants concerns their qualifications and their work profiles.

In the first round, experts were asked to present their assessments of the qualification profiles of irregularly working migrants and to compare these to their work profiles. Questions asked were: 'Is the education level of the irregularly working migrants in ... [the particular sector] low, middle or higher?' and 'Is the nature of their work skilled or unskilled?' Additionally, experts were asked to differentiate between EU-8 citizens and other migrants.

Our experts assessed the qualification profile of irregularly working migrants to be generally higher than the nature of the work done by irregularly working migrants (their work profiles) in all sectors apart from private home care. The strongest contrasts in this relationship were assigned to agriculture, household/cleaning and catering and tourism, where the nature of the work performed was almost universally judged to be 'unskilled', yet many experts assessed the qualification level of workers in these sectors to be at least 'middle' or 'higher', suggesting a strong 'de-qualification effect' when migrants accept irregular work. The only exception was seen to occur in private home care, where qualified care personnel (trained nurses) perform skilled work even when their employment relationship is irregular.

Moreover, irregularly working migrants from the EU-8 countries were generally seen to be more qualified than other migrants working irregularly across all sectors. At the same time, the nature of their work tasks were also seen to require a higher skill level in all sectors except household/cleaning, which suggests the same type of 'de-qualification effect' albeit at a higher level.

Responding to several questions and arguments in both the first and second Delphi rounds, our experts came up with several explanations 
for this apparent 'de-qualification effect'. One argument links this effect to labour migration in general, irrespective of whether it is regular or irregular - for example, language difficulties or the non-recognition of foreign education and diplomas may compel migrants to accept jobs below their qualification levels. Another argument relates to the nature of irregular jobs on offer: mostly unskilled, hard, unpleasant and requiring manual labour (the $3 \mathrm{D}$ jobs: dirty, difficult and dangerous). A third line points to current immigration regulations, which provide only limited options for very highly qualified non EU-I5 workers (socalled 'key-employees') to come to Austria for work purposes. Thus, even middle-qualified workers would have no other option but to accept any irregular work options on offer. Finally, it was pointed out that accepting work below one's educational level is often pursued as a necessary entry-level strategy by irregularly working migrants. Over time, when migrants learn the language and the ways and means of the country, they would gradually move up the skill ladder through a change in occupation - either within the same sector or by moving to a different sector.

\subsubsection{Countries of origin}

Asked about the major countries of origin of irregularly working migrants in Austria, our experts listed (in order of frequency of their mentioning) citizens of Poland, former Yugoslavia ${ }^{7}$, Slovakia, Hungary, Turkey and Romania as the most numerous. This overall ranking was further differentiated according to specific sectors.

In the construction sector, Poland and former Yugoslavia were mentioned as the two most important countries of origin by far. Next came Turkey, Slovakia and Hungary and, with far fewer listings, the Czech Republic, the CIS countries, Romania and Bulgaria. (The latter two countries were believed to assume an increasingly important role in IMW over the coming years). Some regional specificities were also distinguished. For Vienna and Tyrol, experts mentioned workers from former Yugoslavia; for Burgenland, they cited workers from neighbouring Hungary.

In agriculture, Poles were mentioned most often as well, followed by workers from Hungary, Slovakia and Romania. In the view of our experts, catering and tourism are dominated by workers from former Yugoslavia, Slovakia and Hungary. Irregularly working migrants from Poland, the Czech Republic, Romania and Turkey received far fewer listings. In ethnic businesses, persons from China and Egypt as well as Germany were also mentioned. In the case of workers from Germany, this could, however, be a simple reflection of recent developments in that sector (a large inflow of seasonal workers from eastern Germany 
to seasonal jobs in catering and tourism). Moreover, for bars and night clubs, women from the CIS countries, Hungary, Romania and Bulgaria were mentioned.

For household/cleaning, our experts listed Poland, former Yugoslavia and Slovakia as the most important countries of origin followed (by a large margin) by Hungary, the Czech Republic and Romania.

An interesting case is provided by the household/care sector, which according to our experts should be mostly covered by persons from EU-8 countries, mainly Slovakia and the Czech Republic (in the north, centre and west of Austria), Poland and Hungary (in the eastern part of Austria). With far fewer listings, Romania and the Philippines were also mentioned.

Finally, our experts were quite unsure concerning the main countries of origin in trade and industry. Despite many abstentions, their listings indicate that irregularly working migrants from former Yugoslavia play an important role, followed by workers from Poland, Turkey, Hungary, Slovakia, Czech Republic and Romania. The higher proportions of former Yugoslavians and Turks were sometimes justified with the importance of ethnic businesses and food shops, where family members of foreign owners may find easy, if unofficial and irregular, employment.

\subsection{Quantitative developments}

\subsubsection{Assessments of trends over time}

To gain insight into what our expert panel thought about recent changes in the extent of irregular migrant work (IMW), we asked them to provide assessments of recent quantitative developments in IMW. ${ }^{8}$ In Delphi I, the experts were asked whether they thought that IMW has 'strongly increased, increased, stagnated (stayed about the same), decreased or strongly decreased' in each five-year period since I990. In addition, they were asked to answer the same question about the shorter time period since EU enlargement in May 2004. The cumulative results are reflected in Table 2.2.

Generally, most of our experts were of the opinion that IMW has increased across all five-year periods since I990 - though with important qualifications and in various intensities. A significant majority thought that IMW increased or strongly increased between 1990 and 1995 (after the fall of the Iron Curtain to the east of Austria) and again after EU enlargement in 2004; only a small minority thought that it has actually decreased or strongly decreased during these periods. ${ }^{9}$ A smaller majority also thought that IMW increased or strongly increased in the period I995-2000. There was less consensus on the period 2000- 
Table 2.2 The development of irregular migrant work in Austria over time: Expert assessments (Delphi 1)

\begin{tabular}{llllllll}
\hline $\begin{array}{l}\text { Period/ } \\
\text { assessment }\end{array}$ & $\begin{array}{l}\text { Strongly } \\
\text { increased }\end{array}$ & $\begin{array}{l}\text { Increased } \\
\text { Stagnated } \\
\text { staped about } \\
\text { the same) }\end{array}$ & Decreased & $\begin{array}{l}\text { Strongly } \\
\text { decreased }\end{array}$ & $\begin{array}{l}\text { Don't } \\
\text { know }\end{array}$ & Total \\
\hline $1990-1995$ & 6 & 12 & 4 & 1 & 2 & 12 & 37 \\
$1995-2000$ & 2 & 12 & 8 & 1 & 1 & 13 & 37 \\
$2000-2005$ & 2 & 13 & 13 & 1 & 0 & 8 & 37 \\
Since May 2004 & 3 & 17 & 9 & 2 & 0 & 6 & 37 \\
\hline
\end{tabular}

2005, for which equal numbers of experts said it increased and stayed the same.

It is interesting to compare the opinions and the supporting argumentation of our experts by their institutional affiliation. Experts from public administration and control bodies argued that the assumed increase in IMW since 2004 is mainly due to the decreased risk for new EU citizens to live and stay in Austria while at the same time working irregularly. These experts also pointed to a recent increase in irregular employment relationships designed to circumvent existing regulations and in particular the transitional rules on the labour market. The group of migration researchers largely concurred with this assessment, but as an additional argument, several respondents from this group emphasised the importance of a generally higher demand for IMW. Respondents from NGOs showed a surprising amount of variation in their answers. In contrast, respondents from special interest groups displayed more familiar patterns of argumentation: while our experts from trade unions saw alarming increases in IMW, those affiliated with employer interests saw decreases or stagnation in irregular dependent employment, but a noticeable increase in irregular self-employment.

\subsubsection{Quantitative assessments of trends by economic sectors and branches}

To gauge recent quantitative developments of irregular migrant work in certain sectors and branches, we asked our expert panel to assess whether they thought IMW had increased, decreased or stayed about the same in selected economic branches over the past five years. The selection of sectors and branches was based on the previous round of expert interviews, in which our respondents indicated the most notorious branches for IMW.

The first round yielded 132 substantive answers (all answers without 'don't know' responses) from 37 returned questionnaires, out of 222 possible answers to our questions (59 per cent). Out of these, 74 answers $(56$ per cent) indicated increases, while 34 answers ( 29 per cent) 
indicated stagnation (no change) and only twenty answers (I5 per cent) indicated sector-specific decreases. While these trends are clearly influenced by the selection of branches, on the whole they support the general assessments on the development of IMW in the period 2000-2005 reflected in the previous section. The aggregated answers by sectors/ branches of Delphi I are summarised in Table 2.3.

The aggregate results and the supporting argumentation of the first Delphi round were summarised and the experts were asked in the second round to reassess their statements in light of the arguments of their colleagues. The second round yielded relatively more substantive answers than the first round (IO2 substantive answers from 22 returned questionnaires out of $\mathrm{I} 32$ possible answers, or 77 per cent). Out of these, 56 answers (55 per cent) indicated increases, while 36 answers (35 per cent) indicated stagnation (no change) and only ten answers (Iо per cent) indicated sector-specific decreases. The results are summarised in Table 2.4.

The overall assessment of our expert panel on quantitative developments of IMW in selected sectors and branches can thus be summarised as follows (see also Figure I): an overwhelming majority of substantive answers indicated an increase in IMW in private households (care) (89 per cent in Delphi 2 against 92 per cent in Delphi I) and in private households (cleaning) (78 per cent in Delphi 2 against

Table 2.3 The development of irregular migrant work in Austria over the last five years: Branch-specific expert assessments (Delphi 1)

\begin{tabular}{llllll}
\hline & Increased & Stayed the same & Decreased & Don't know & Totals \\
\hline Private households (care) & 23 & 2 & 0 & 12 & 37 \\
Private households (cleaning) & 14 & 8 & 1 & 14 & 37 \\
Construction & 13 & 6 & 3 & 15 & 37 \\
Catering and tourism & 11 & 8 & 5 & 13 & 37 \\
Agriculture & 8 & 8 & 5 & 16 & 37 \\
Trade and industry & 5 & 6 & 6 & 20 & 37 \\
\hline
\end{tabular}

Table 2.4 The development of irregular migrant work in Austria over the last five years: Branch-specific expert assessments (Delphi 2)

\begin{tabular}{llllll}
\hline & Increased & Staped the same & Decreased & Don't know & Totals \\
\hline Private households (care) & 16 & 2 & 0 & 4 & 22 \\
Private households (cleaning) & 14 & 4 & 0 & 4 & 22 \\
Construction & 11 & 5 & 2 & 4 & 22 \\
Catering and tourism & 9 & 6 & 2 & 5 & 22 \\
Agriculture & 3 & 12 & 1 & 6 & 22 \\
Trade and industry & 3 & 7 & 5 & 7 & 22 \\
\hline
\end{tabular}


62 per cent in Delphi I). An absolute majority also stated an increase in construction (6I per cent in Delphi 2 against 59 per cent in Delphi I) and in catering and tourism (53 per cent in Delphi 2 against 46 per cent in Delphi I). In the remaining two sectors, there were significant shifts in the relative answer patterns between Delphi I and 2: reacting to the arguments of their colleagues, in Delphi 2 only is per cent of respondents saw an increase of IMW in agriculture, while 75 per cent saw no changes and 6 per cent saw decreases (compare to Delphi I: 38 per cent; 38 per cent; 24 per cent). For trade and industry, only 20 per cent saw increases, while 47 per cent saw no changes and a substantial 33 per cent share even saw decreases (against 29 per cent, 35 per cent and 35 per cent in Delphi I).

The intuitive impression gained from a simple comparison of the results of Delphi I and Delphi 2 is that of a much clearer picture on sector-specific quantitative developments as seen by our experts. This intuition is confirmed by a statistical analysis of the answer patterns in Delphi I and 2. Standardising the answers 'increased', 'stayed the same' and 'decreased' with the numerical values +I, $\mathrm{O}$ and $-\mathrm{I}$, and multiplying the frequency of the respective answers by these values, the statements for most sectors become on average more pronounced. ${ }^{\text {IO }}$ At the same time, the standard deviation of the aggregate answers thus quantified decreases for all sectors and branches except private households (care), where it increases slightly but remains at the lowest level of all sectors and branches. ${ }^{\text {II }}$ There is thus more consensus and less

Figure 1 The development of irregular migrant work in Austria over the last five years: Branch-specific expert assessments (Delphi 1 Q 2)

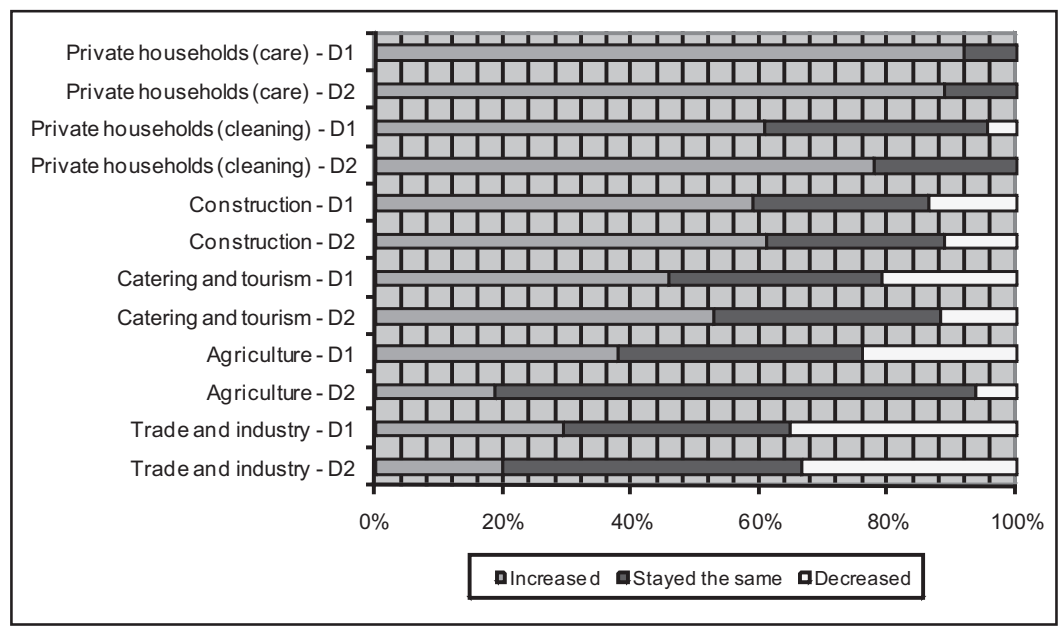


heterogeneity on the subject among the experts. Moreover, as noted above, there were relatively more substantive answers given and fewer abstentions on the part of the respondents.

\subsubsection{Expert estimations on the extent of irregular migrant work}

Given the difficulties of producing qualified estimates on the extent of IMW in various sectors and branches, experts are usually quite hesitant to come forward with their own estimates. To collect a broad sample of opinions, insights and relevant statistical indicators, we asked our experts in the first Delphi round to give their opinions on a predefined set of estimates on the extent of IMW in various sectors and branches (these were based on estimates gleaned from the literature and our preceding expert interviews), and to justify their judgements in free text answers. While around half of all respondents abstained from any substantive answers to these questions, there were also a number of relevant opinions and insights that were then analysed and provided as feedback in the second round. In addition, we asked our respondents in Delphi 2 to provide numerical estimations on the extent of IMW (as a percentage of total employment) in selected sectors and branches.

As can be seen from Table 2.5, only about half of the respondents provided their own detailed estimates in the second round of the Delphi study. ${ }^{\mathrm{I} 2}$ On average, our expert panel estimated the extent of IMW as a percentage of total employment to be highest in construction and in catering and tourism (around I5 per cent, in both cases with a large range from I0-30 per cent). Next comes agriculture (I3 per cent), with a range from 3-20 per cent. The average estimate for trade and industry was substantially lower (5.2 per cent), while the range of estimates for this sector was surprisingly narrow (5-7 per cent). Finally, the estimated share of IMW in total employment in Austria comes out at 5 per cent, with a large range from 2.5-7 per cent. ${ }^{\mathrm{I3}}$

Besides the arguments reviewed elsewhere in this paper on the forms and developments in IMW in Austria, some experts put forward

Table 2.5 Estimated share of irregular migrant work in total employment by branches: Expert estimations (Delphi 2)

\begin{tabular}{lllllll}
\hline & Minimum & Average* & Maximum & $\begin{array}{l}\text { Number } \\
\text { of estimates }\end{array}$ & $\begin{array}{l}\text { No } \\
\text { estimates }\end{array}$ & $\begin{array}{l}\text { Total } \\
\text { respondents }\end{array}$ \\
\hline Construction & 10 & 15.4 & 30 & 13 & 9 & 22 \\
Catering and tourism & 10 & 15.0 & 30 & 13 & 9 & 22 \\
Agriculture & 3 & 13.3 & 20 & 10 & 12 & 22 \\
Trade and industry & 5 & 5.2 & 7 & 10 & 12 & 22 \\
Whole economy & 2.5 & 5.0 & 7 & 10 & 12 & 22 \\
\hline
\end{tabular}

* If a range was given, the average of the range was taken. 
new justifications for estimations strongly deviating from the average. For example, one relatively high (25 per cent) estimate for IMW in construction was justified by the plausible argument that there is a great amount of irregular construction activity in private homes (renovation work, gardens and parks, swimming pools), especially in the sprawling suburbs of Vienna and other cities, and that this would be indicated by the booming business of home improvement stores (home depots, doit-yourself stores, etc.). Another interesting observation relates to the large variability in the estimations for agriculture and catering and tourism: as these sectors have high seasonal variations, much of IMW is likely to be of a seasonal nature (e.g. during tourist seasons or at harvest time), followed by periods with less IMW.

In addition to the quantitative estimates (see Table 2.5.), our experts were asked to provide estimates on the absolute numbers of irregularly employed foreigners in care and cleaning in private households. Within a broad range of I5,000-50,000, the average estimate of IMW in the care sector in private households was around 29,000. In a more narrow range of $20,000-40,000$ for cleaning in private households, it was around 24,000. Around half of all respondents in Delphi 2 abstained from giving any estimates (Table 2.6).

Many experts again provided elaborate justifications for their estimations. These are especially interesting for widely deviating estimates. For the household sector, for example, estimates on the high end were backed up with evidence from surveys on household expenditures, which allegedly indicate some 60,000 illegally employed household helpers (cleaners, cooks, etc.). However, these totals cannot be broken down by nationality, and many irregular workers in private households would be nationals and non-migrants. ${ }^{\mathrm{I}}{ }^{2}$ For IMW in private home care, many estimates were based on the number of persons receiving special disability and care allowance from the state. This comes in the form of cash benefits, with the amount varying on the extent of the disability and care needs (divided in seven steps). The number of beneficiaries in steps five, six and seven (basically those in need of intensive care

Table 2.6 Estimated number of irregular migrant workers in private households (Delphi 2)

\begin{tabular}{lllllll}
\hline & Minimum & Average* & Maximum & $\begin{array}{l}\text { Number } \\
\text { of estimates }\end{array}$ & $\begin{array}{l}\text { No } \\
\text { estimates }\end{array}$ & $\begin{array}{l}\text { Total } \\
\text { respondents }\end{array}$ \\
\hline $\begin{array}{c}\text { Private households } \\
\quad \text { (care) }\end{array}$ & 15.000 & 28.636 & 50.000 & 11 & 11 & 22 \\
$\begin{array}{c}\text { Private households } \\
\text { (cleaning) }\end{array}$ & 20.000 & 24.444 & 40.000 & 9 & 13 & 22 \\
\hline
\end{tabular}

* If a range was given, the average of the range was taken. 
around the clock) amounts already to over 30,000 persons, most of whom would employ irregular foreign care workers. Added to these should be a substantial part of beneficiaries at step four $(42,000$ persons) and below. Another indication comes from evidence on the socalled membership associations that link care workers and their patients. One expert stated that there are currently 50,000-70,000 irregular care workers 'parked' in these associations.

To conclude this section, a few final observations are in order. First, rather than accepting or rejecting any of the quantitative assessments made by our experts a priori, it is instructive to view them in their totality and to describe them objectively in statistical terms as a range of estimates with a certain mean value. There is no inherent reason why that calculated mean estimate should be closer to the 'real' value of the unknown quantity other than the fact that it reflects not one particular point of view, but the whole range of opinions by our panel of experts. The mean thus reduces the weight of the more 'extreme' estimates on the high and low end. Second, such 'extreme' estimates may still be valid estimates, but due to their deviation from the consensus view are likely to be in particular need of argumentation of how they came about. Third, such justifications provided by our experts often indicated their reasoning or 'estimation methods', and sometimes brought forward new data on which certain estimates were based. In many cases, insights on the methods of estimation are at least as interesting as the estimates themselves, particularly when they lead to results that strongly deviate from the mean.

Finally, we may ask ourselves how the numerical results of our mean expert estimations compare to other figures put forward in the literature. As indicated above, there are only two quantitative estimates given in the recent relevant literature that are serious enough to provide their estimation methods with them. Biffl (200I) estimated 35,000 and Schneider (2006) estimated 98,000 full-time equivalent foreign workers working illegally in Austria. ${ }^{15}$ While we may note that our mean estimate for the share of IMW in Austria would be considerably higher than either of these estimates ( 5 per cent of total employment would be equal to some 150,000 irregularly working migrants), we should be aware that we employed a particularly broad definition of IMW that goes well beyond the one used by Biffl (200I); it may also be broader than that of Scheider (2006). At the same time, we consider this broad definition to be particularly valid under current circumstances as explained above. 


\subsection{Controls in the workplace}

As all of our experts have many years of experience in the area of migration or irregular work, we asked them to provide us with their assessments on the effectiveness of repressive measures - in particular on enforcement measures through border controls and controls at the workplace. In Delphi I, we asked for an evaluation of a list of predefined statements regarding controls. The aggregate responses can be grouped into three relevant types. The first group contains statements in which a strong majority either accepted or rejected the statement and a certain 'consensus view' emerged from the supporting arguments. The second group concerns two statements that received widely diverging or unclear answers. These were reformulated and - together with additional feedback - included in Delphi 2 for clarification. The statements and answers in these two groups are briefly described in this section. The third group concerns statements in which the answers lead to much more comprehensive strategies and options against IMW than only repressive control measures. These options were further explored in the second Delphi round and are recounted in the next section on political measures against IMW.

First, there was wide consensus that 'the effectiveness of controls (at the workplace) is limited by the fact that controls are selective' (eighteen agree, seven disagree and twelve abstentions). However, it was also pointed out that comprehensive (Ioo per cent sample) controls are neither feasible nor desirable, and that the efficiency of current control measures is largely sufficient in view of their cost.

Second, the statement that the 'effectiveness of controls is limited by the fact that fines for irregular employment are too low in comparison to the level of payroll taxes and social security payments for regular employment' was overwhelmingly approved by our experts (2I agree, eight disagree and eight abstentions). At the same time, one dissenting expert pointed to the deterrent effect of non-monetary sanctions for employers (e.g. exclusion from public tenders).

Third, the statement that 'the effectiveness of controls is limited by the fact that certain criminal entrepreneurs will always employ irregularly' was approved by an overwhelming majority of respondents (twenty agree, five disagree and twelve abstentions). It was also pointed out that such criminal employers are often short-lived (and then dissolve and disappear) or work in transnational legal arrangements, which further limits the effectiveness of sanctions.

Fourth, the statement that 'the effectiveness of controls is limited by the fact that economic interests (e.g. home improvement stores) prevent a sufficiently high density of controls' was agreed to by a majority of respondents (thirteen agree, eight disagree). At the same time, this statement 
drew the largest number of abstentions (sixteen out of 37 returned questionnaires) and strongly contradictory comments. While some experts pointed to the economic interests of many employers in irregular migrant work, others emphasised that it is precisely in the interest of firms to have rigid controls to prevent unfair competition from employers hiring irregularly.

Fifth, the statement that 'the effectiveness of controls is limited by the fact that border controls have no influence on the irregular employment of migrants' was largely approved by our respondents (22 (59 per cent) agree, eight (22 per cent) disagree and seven (I9 per cent) abstentions). Several experts pointed to the effects of EU enlargement in 2004: since then, new EU citizens have had freedom of travel and residence and cannot be rejected at the borders any longer, but they still face restrictions in their access to the labour market under transitional rules. Others, however, pointed to the deterrent effect of border controls for non-EU citizens that would effectively limit irregular migration and therefore also the potential pool of irregularly working migrants. To clarify the issue, we asked the same question again in Delphi 2 and provided the comments made in the first round. As a result, an even greater percentage of respondents agreed on the limitation of border controls for the suppression of IMW: sixteen (73 per cent) agree, five (23 per cent) disagree and only one (4 per cent) abstention.

Sixth, the statement that 'the effectiveness of controls is limited by the fact that the KIAB (Control Unit for Illegal Employment) has no access to private homes' was answered affirmatively by a large majority of respondents (eighteen agree, six disagree and twelve abstention). Finally, seventh, the parallel statement that 'the effectiveness of controls is limited by the fact that there are certain areas that are for political reasons "off-limit" for control measures' received the highest degree of approval (26 agree, one disagree and ten abstentions). Despite the high level of approval to both questions, the comments indicated that experts disagreed on whether or not this represented a satisfying situation or not and what should be done about it. While some saw the dawn of a new age of "private servants' and advocated stronger controls, others were concerned about the protection of privacy and felt that the possible extent of misbehaviour against the law by employing irregularly in private homes would not justify a erosion of that principle. To learn more about what our expert panel actually thought about such opposing views, we followed up in Delphi 2 (after providing feedback on the comments from other experts) with the following direct statement: 'The private area should be more controlled'. In line with their previous reactions to the statements concerning the private area, our respondents overwhelmingly rejected that statement (seventeen disagree, four agree and one abstentions). Interestingly, however, there was a shift in the argumen- 
tation brought forward to justify these opinions. Rather than the protection of the private sphere, several experts now questioned the very feasibility of efficiently controlling the private sector and, given limited resources, called for prioritising controls of business employers.

To shortly summarise our discussion of control measures, there was a widespread tendency among our experts to argue that, for a variety of reasons, sheer control measures have only a limited impact on irregular migrant work in Austria. Moreover, among our expert panel, the opinion predominated that effective solutions for addressing IMW cannot be found in more controls and a higher control density alone, but that other, more comprehensive political measures must be found. The options and limits of such wider measures are the subject of our next section.

\subsection{Political measures against irregular migrant work}

In the first Delphi round, we asked experts to evaluate four measures that were recently introduced or were already decided upon by political authorities with the aim of reducing irregular migrant work in Austria. The results brought few surprises but a number of interesting comments that were integrated into the questionnaire of the second Delphi round. Thus, between two-thirds and three-quarters of all respondents in Delphi I agreed that the following four measures were 'sensible' or 'highly sensible' instruments for reducing IMW in Austria: I) further increasing the staff of the KIAB (control unit for illegal employment) by 200 persons; 2) enlarging the scope of current trainee programmes with Austria's neighbouring countries ${ }^{16}$;3) strengthening the controls of the so-called 'pseudo-self-employed' (see Section I.Io); and 4) increasing the maximum penalties for the irregular employment of migrants.

While any single one of these recently established measures found broad support among our expert panel in Delphi I, many respondents voiced their doubts and concerns in additional comments. Several saw the overall impact of these measures as fairly limited or, in the words of one respondent, as a 'cure of the symptoms' rather than a comprehensive strategy. Many experts followed our request and outlined their own suggestions for dealing with irregular migrant work.

Out of these ideas, demands and suggestions, we compiled a list of 24 possible measures that go beyond simple short-term control measures but have a wider scope and timeframe that requires discussions and decisions at the political level (e.g. through the passing of new laws or ministerial ordinances). These political options were then put to the vote by our expert panel in the second Delphi round. Following 
a well-established procedure in past applications of the so-called PolicyDelphi (see Section 2.2), we asked our experts whether they judged any particular measure to be 'desirable' (yes/no/don't know) and 'feasible' (yes/no/don't know). ${ }^{17}$ Of the 22 respondents in Delphi 2, most answered at least some of the questions on political options for dealing with IMW, and many added further verbal comments. In the next section, we will provide a short overview and description of the results. A summary table of the expert evaluations is provided in Annex A.

\subsubsection{Expert assessments of political measures}

\section{Opening of the labour market}

I) The opening of the labour market for certain occupations for which there is a particularly high labour demand was seen by our experts predominantly as desirable (fifteen) and even more so as feasible (sixteen). Nevertheless, dissenting opinions pointed to certain areas (e.g. private care) where existing problems could not be solved by a simple opening to foreign labour.

2) An even higher level of consensus found the suggested option of opening the labour market for certain groups of third-country citizens, who already have a long-term residence permit in Austria but face restrictions in their access to the labour market (e.g. family members of established foreign residents, students). ${ }^{\mathrm{I}}{ }^{8}$ Twenty-one respondents saw this option as feasible and sixteen as desirable.

3) While a majority of respondents judged a regionally limited opening of the labour market for certain branches and occupations as feasible (fourteen yes against six no), there was wide disagreement on the desirability of this option (ten yes against eleven no). Experts noted that much would depend on how such a policy would be designed and implemented concretely, and that there would be the danger of a premature opening of the labour market with many negative effects.

4) There was a particularly high level of disagreement in the evaluation of a possible early phasing out of the transitional rules on the access to the labour market for EU-8 citizens. Nine respondents judged this option as politically feasible but twelve did not. Similarly, ten experts welcomed this step as desirable, while twelve found it undesirable. Those in favour of an early abolition pointed to the experiences with the EU accession of Spain and Portugal, among other things, while those renouncing it argued, for example, that the 'labour supply shock' would come too early. 


\section{Labour standards and foreign employment law}

5) A clear majority of fourteen respondents thought that a liberalisation of current labour standards (e.g. facilitating the hiring and firing of employees, more flexibility in work-hours, etc.) was feasible and some pointed to recent examples in other countries (the Netherlands, France). At the same time, such a policy was highly unpopular among our expert panel, with seventeen respondents judging the option as undesirable (and only five as desirable).

6) Even more than the previous suggestion, the option of adjusting the current levels of minimum wages downwards was met by unanimous opposition by our expert panel. Out of the 22 respondents, twenty deemed this option undesirable (with two abstentions) and a majority did not consider it feasible (thirteen not feasible against six feasible).

7) Similar to option 2, but going beyond it in its scope, a general merging of the right to reside and the right to work in Austria ${ }^{\mathrm{I} 9}$ was predominantly seen as desirable (sixteen yes against four no) and also as feasible by our experts (eighteen yes against four no). While some comments added that this should not automatically be the case for shortterm residents, others explicitly included asylum seekers in their considerations (by granting access to the labour market after a certain period of stay, e.g. one year).

\section{Measures for addressing irregular private home care}

8) In view of the current debate on irregular care work in private households, ${ }^{20}$ our expert panel largely agreed that a considerable increase of the state-funded disability and care allowances (to enable the regular financing of 24-hour-per-day care services for patients) would be desirable (seventeen yes against three no). At the same time (reflecting the current dilemma of policy in this area), a clear majority of fourteen respondents judged this option as not feasible (against seven feasible).

9) On the other hand, the chances to realise an alternative option for private home care were seen to be more favourable: to establish a legal right for persons receiving public care allowances to receive certain services in kind rather than in cash (e.g. short-term care services, care substitutes) was seen as a feasible option by a clear majority (fourteen yes against seven no). Moreover, this idea was almost universally welcomed by our expert panel as desirable (twenty yes against two no). 
Io) To remedy current labour shortages in the care sector, there was also a clear vote for providing access to the labour market for foreign household helpers in households with persons in need of care (following the German example of 38.5 hours per week). This option was seen as desirable by seventeen respondents (one against and four abstentions) and also as feasible by fourteen experts (three against and five abstentions).

\section{Incentive systems, sanctions and support mechanisms}

II) There was little agreement among our panel on the establishment of special incentive models for the creation of regular low-wage jobs (combination wage that would partly be subsidised by the state). While a clear majority of respondents considered such a model as principally feasible (fifteen yes against four no), only eight assessed it also as desirable while eleven thought it was not desirable. Against familiar arguments that low-wage jobs should not be supported, proponents of the scheme stated that it would at least allow the transformation of irregular to regular jobs.

I2) There was a clear vote on the suggestion of introducing sanctions or fines against irregularly working migrants. ${ }^{2 \mathrm{I}}$ While a clear majority of sixteen respondents deemed this measure as feasible (sixteen yes against four no), an equally clear majority considered such an option as not desirable (sixteen no against five yes).

I3) On the other hand, an overwhelming majority of respondents saw the strengthening of legal support services for irregularly working migrants in court cases against their employers as a desirable measure (eighteen yes against three no). Almost as many (sixteen yes against five no) considered this option also as a feasible one.

I4) In a similar vein, the creation of specialised advisory services for irregularly working persons (e.g. a 'service hotline') was strongly favoured by eighteen experts as desirable (two said not desirable) and also as feasible (eighteen yes against three no). One commentator pointed out that this would especially be a task for the trade unions.

I5) The majority of respondents (fifteen desirable against six not desirable) would further welcome a mandatory representation of the Chamber of Labour or the Austrian Confederation of Trade Unions in legal proceedings. However, regarding the feasibility of this option, only around half of the respondents were optimistic (eleven yes against ten no). 
i6) Another suggestion that has recently drawn some attention was equally viewed sceptically by our expert panel. The 'skimming off' of profits (by employers) gained through irregularly employing workers was seen as desirable by a large majority of our experts (seventeen yes against three no), and yet, the chances for implementing this policy were doubted by many (twelve not feasible against nine feasible). One commentator pointed out that in theory, irregularly gained profits should already now be skimmed off in the form of back-payments of taxes and social security contributions, but that in many cases such payroll taxes and duties turn out to be irretrievable in practice.

I7) The suggestion to make more use of sanctions in the form of excluding perpetrators from public tenders and public work contracts rather than levying fines was seen as both desirable and feasible by the majority of respondents (in both cases fourteen yes against four no). However, a number of commentators qualified their approval by noting that such exclusionary sanctions should be used in addition rather than in lieu of fines. A combination of both sanctioning instruments would be necessary especially 'for those irregularly employing who never receive (or tender for) public contracts'.

\section{EU-wide regulations}

I8) The overwhelming majority of respondents found a common legal EU framework for the cooperation of institutions tasked with combating irregular work desirable (sixteen yes against three no), but only a smaller majority deemed the implementation of such a framework also feasible (twelve yes against six no). One expert noted critically that 'the discussion for many years on the EU Service Directive clearly shows the complexity of establishing such an EU-wide legal framework'.

I9) Our experts were even more hesitant in the evaluation of a possible EU-wide approximation of economic framework conditions (e.g. for taxes, social security contributions, etc.). While such approximation was seen as desirable by a large majority (fourteen yes against six no), among other reasons to 'prevent wage dumping', opponents warned that this could lead to a 'significant worsening of Austrian living standards'. In any case, only around half of the respondents judged an EU-wide regulation in this area to be feasible (ten yes against nine no).

\section{Other political measures}

20) Measures designed to raise the awareness of employers hiring irregularly to change their behaviour are seen as desirable by a large ma- 
jority of our panel (sixteen yes against three no). At the same time, only eleven respondents thought awareness-raising a feasible strategy (against seven who did not), indicating widespread doubts about the effectiveness of such measures.

2I) Also assessed as feasible by a relative majority of respondents were measures to strengthen control systems through the use of modern technologies such as the use of biometric data (twelve yes against seven no). However, an overwhelmingly large majority of eighteen respondents judged such measures as not desirable (against three who deemed them desirable).

22) A large majority of our experts advocated a faster and less bureaucratic recognition of foreign training certificates and diplomas (sixteen yes against five no). An even larger share of respondents regarded such measures as feasible (eighteen yes against two no).

23) The suggested option of using legalisation of irregularly working migrants as a policy measure to reduce irregular migrant work in Austria produced some contradictory statements by our experts. While on the whole such measures were viewed as both feasible (fourteen yes against seven no) and desirable (fourteen yes against six no), both advocates and opponents of such schemes pointed to the additional pulleffects created by collective regularisations and noted that legalisations would be only desirable when certain criteria are met (e.g. discretionary case-by-case regularisations).

24) Finally, the list of policy options evaluated by our experts is completed with a proposal that found broad consensus among respondents. A better networking and information exchange among responsible labour market institutions (social security institutions, labour market service and others) was mostly seen as feasible (eighteen yes against one no) as well as desirable (eighteen yes against two no). One commentator added that this should concern mainly the linking up of existing databases, rather than the creation of new control systems.

\subsubsection{EU enlargement and the end of transition periods on the labour market}

As already noted, our experts were divided when it came to the foreseeable end of the transition periods for access to the Austrian labour market for new EU citizens (for the EU-8 in 2009 or 20II, and at a later stage for citizens of Bulgaria and Romania. In Delphi I, only a small majority of respondents (52 per cent) were in favour of ending the tran- 
sition periods before 20Ir. Some of these proponents justified their position with a rising demand for additional migrant workers over the coming decade and the resulting chance for migrants already working irregularly in Austria to move to a regular job. Others supported only a gradual opening of the labour market as a preparation to the free movement of workers later on. On the other hand, opponents argued that over the coming years, the high wage differentials between Austria and its neighbouring countries will continue to exist, leading to extreme pressure on the labour market with substantial substitution processes, especially in low-skilled occupations.

To learn more about the likely impact of the end of transition periods (which will come sooner or later, irrespective of the political will in Austria), we asked our expert panel whether they think that the extent of irregular migrant work will increase after the end of the transitional regulations or not. It is interesting to note that when confronted with the above arguments made by their colleagues in response to that question in Delphi I, relatively more experts thought that this would be the case: the rate of agreement rose from 44 per cent in Delphi I to 60 per cent in Delphi 2. Some of the experts justified their change in position by arguing that the migration-supporting factors - at least in the short run - would prevail. The demographic and development factors would only become important in the longer run (after 2020). A detailed look at possible future scenarios of irregular migrant work in Austria is provided in the next section.

\subsection{Prognoses and scenarios on the future development of irregular migrant work}

\subsubsection{Sector-specific prognoses of irregular migrant work}

Prompted for a prognosis about the future development of IMW in the most notorious sectors and branches over the next ten years, our expert panel made the following predictions: an overwhelming majority projected further growth of IMW in the private care sector, and a majority also foresaw further growth of IMW in cleaning in private households and (relatively fewer) in catering and tourism. Interestingly, IMW in construction and agriculture was largely predicted to remain stagnant (albeit at a high level). Finally, IMW in trade and industry was forecast to remain stagnant or on be on the decline. Generally, IMW as a share of total employment in Austria was predicted to grow further by a substantial majority of respondents (nine out of fifteen) (Table 2.7).

It is interesting to review some of the arguments made by our respondents to justify their branch-specific and sector-specific prognoses. For both care and cleaning tasks in private households, several experts 
Table 2.7 Will the extent of irregular migrant work in Austria increase, stay the same or decrease over the coming ten years in the following branches? Branchspecific expert prognoses in Delphi 2 (in absolute numbers)

\begin{tabular}{lcccccc}
\hline & Increase & Stay the same & Decrease & Subtotal & Don't know & Total \\
\hline Private households (care) & 14 & 0 & 1 & 15 & 7 & 22 \\
Private households (cleaning) & 9 & 6 & 0 & 15 & 7 & 22 \\
Catering and tourism & 7 & 5 & 2 & 14 & 8 & 22 \\
Construction & 5 & 9 & 1 & 15 & 7 & 22 \\
Agriculture & 4 & 10 & 1 & 15 & 7 & 22 \\
Trade and industry & 1 & 9 & 4 & 14 & 8 & 22 \\
Total employment & 9 & 5 & 1 & 15 & 7 & 22 \\
\hline
\end{tabular}

pointed to a continuously rising demand due to demographic developments (more old people in need of care and a higher labour force participation of women, who 'outsource' household tasks to irregular migrants). And yet, the predicted stagnation of IMW in both construction and in trade and industry was related to a generally lower employment dynamic in these sectors, due to the possibilities to mechanise and rationalise low-skilled tasks and to relocate labour-intensive production processes to low-wage countries abroad. ${ }^{22}$ The same argument was repeatedly made for agricultural production as well; however, several experts argued that mechanisation in this sector would be limited by the need for manual work in the production of high-quality food products.

As indicated by this brief discussion, our experts based their sectorspecific prognoses of IMW in Austria generally on considerations of demand-side factors and their future development. Among these, demographic and technological factors figured most prominently.

\subsubsection{Future scenarios of irregular migrant work}

At the end of the questionnaire in Delphi 2, our expert panel was asked to briefly sketch the one scenario that in their opinion reflects the most likely development of irregular migrant work in Austria over the coming decade. Seventeen out of 22 respondents outlined such a scenario, formulated in free text. While the very openness of the question invited a broad range of possible forecasts, there were several key predictions that were shared among several experts.

First of all, it is interesting to notice that, contrary to the sector-specific prognoses summarised above, the general focus of the outlined scenarios was on the supply side of irregular labour markets. The following prospects were the most important factors in the deliberations on future developments: 
- The projected end of current transition periods on the Austrian labour market for EU-8 citizens (2009 or 20II) and the resulting 'supply shock' on the regular labour market.

- The timing and duration of transition periods for Bulgarians and Romanians on the Austrian labour market.

- The possible lifting of entry and residence restrictions for citizens of other EU-candidate countries (especially South-Eastern European countries and Turkey).

- The economic development (projected income convergence and job creation) of Central, Eastern and South-Eastern European countries over the coming decade.

- 'Crowding-out' processes of various groups of labour migrants from different origins on the regular and irregular labour market in Austria.

- The possible return of irregularly working migrants from Austria to their newly prosperous countries of origin.

Various combinations of the strength and possible effects of each of these factors on irregular migrant work, then, resulted in diverging scenarios on the future of IMW in Austria.

The following quote is typical for those forecasting strong disturbances from a labour supply shock:

The end of the transition periods will lead to more competition between workers, an effect that will be exacerbated by the lifting of residence restrictions for citizens of the Western Balkan states and possibly Turkey. The resulting oversupply of labour will lead to wage pressures and a higher willingness of workers to enter into and to accept irregular employment opportunities (for example, part-time jobs with unpaid overtime, et cetera).

On the other hand, the following scenario illustrates the position of those projecting a decrease of supply pressures due to a rapid economic convergence process of new EU members and candidate countries:

The end of transition periods...will surely create new incentives for workers from neighbouring countries to search employment in Austria and other European countries. However, with favourable economic growth across Europe, the labour market will be able to absorb additional workers; especially in the new EU Member States themselves, with growth rates of 5 per cent to 6 per cent per year, new jobs will become available. 
However, such optimistic prognoses are regularly followed up with comments on a suggested 'crowding-out' effect by new groups of labour migrants, as in the following quotes:

There will be a shift of irregular employment to [citizens of] Bulgaria and Romania, and additionally to Moldova and Ukraine, resulting in a crowding-out of current irregularly working migrants, who will return to Poland.

For [citizens of] the new EU Member States, there will be opportunities to change from illegal to legal employment. On their behalf, [citizens of] Romania and Bulgaria will follow as they will face long transition periods. In the new EU Member States, there is a large segment of illegal work carried out by Russians, Belarusians and Ukrainians. The lifting of border controls could then result in a movement of these irregularly working persons to the 'old' EU Member States.

The extent of irregular migrant work will remain about the same, if Turkey does not accede [to the EU]: the mobility of workers from Central and Eastern Europe will decline due to demographic shifts, but irregular migration from the rest of the world will keep the share [of IMW] about stable. However, if Turkey accedes [to the EU], there will be a migration wave that can no longer be socially integrated.

Generally, then, we can conclude that the supply-side arguments show a strong tendency towards predicting a continuously high pressure on the Austrian labour market, accompanied by a shift to irregularly working persons from ever more remote countries of origin, with clear consequences for irregular migrant work in Austria.

On the demand side, however, there are two opposing views that can be attributed to differences in the experts' position on the underlying reasons of IMW. The first, optimistic forecast is illustrated by the following quote:

With the end of transition periods, many migrant workers will leave their status of illegality. Demographic changes will lead to labour scarcities and hence an increase in regular employment.

This optimistic scenario runs counter to several forecasts that base their assessments on the underlying structural reasons of IMW: 
Irregular migrant work will continue to increase slowly. Efforts of legalisation will be able to transform only some irregular employment relationships into regular ones, while the additional costs related to regular employment will still favour irregular employment on the whole.

The liberalisation of labour laws and standards (in regard to part-time or 'minor' employment, for example) has created the basis for irregular employment. Therefore, irregular employment will by no means decline over the coming ten years. Those migrants, who [then] have the opportunity to access regular work and who are economically integrated, will follow the model of many native workers - a combination of [unemployment] benefits and irregular work [...].

[There will be] few changes, except that for citizens of certain [EU Member] States, there will be no more need for work permits under foreign employment laws; but this will only make it easier for dubious employers (especially from abroad) to pay wages below the minimum standards; there will be a strong expansion of the 'grey area'! Consequences: wage levels will fall, legitimate firms (small- and medium-sized enterprises) will not be able to compete and will find it difficult to survive.

\subsubsection{And the world goes round...}

Generally speaking, the suggested scenarios of our expert panel, give us little confidence to predict a general decrease in irregular migrant work in Austria. However, the prognoses of several experts point to significant shifts in the countries of origin of irregularly working migrants, coupled with a 'crowding-out' between migrant groups at the lower ends of the labour market. At the end of this section, we would therefore like to quote one elaborate scenario that pointedly combines many of the above-mentioned elements:

Following its long-term trend, irregular employment will continue to increase, parallel to the shadow economy as a share of GDP. The end of transition periods for citizens of the EU-8 will bring a supply shock on the labour market that will stimulate growth but at the same time increase unemployment of both native and foreign workers [...]. The labour market will become even more segmented according to qualifications and ethnic/religious background. One way out will be an increase in self-employment (bazaar capitalism). With the end of the transition per- 
iods, migrant workers from the EU-8 will shift from the irregular to the regular labour market and workers from the new EU accession countries will take their places as irregulars. And the world goes round...

\subsection{Concluding remarks}

As this study demonstrates, research on difficult issues (such as irregular migrant work) can clearly benefit through the use of the Delphi method. Experts from various backgrounds and institutional affiliations often possess a lot of insight and information that would otherwise be unavailable to the researcher and can offer a wealth of knowledge for further analysis. At the same time, the very divergence of expert opinions points to the main shortcomings of the method: experts may have only partial insights into a complex and multi-faceted phenomenon and may mistakenly base general conclusions on partial or invalid indicators. The Delphi method is designed to overcome some of these problems by involving a larger number of independent experts in an interactive process of exchange through the use of written questionnaires. By fostering convergence and consensus, the method should result in an overall picture of a hidden phenomenon that is a better reflection of reality than simply the sum of the individual opinions.

Against this background - and keeping in mind the strengths and weaknesses of the research method employed - our Delphi survey has produced a number of interesting results on the most important aspects of irregular migrant work. Our experts provided their assessments on: the most important forms of IMW, the effects on various parts of the economy, the main motives of employers to engage irregularly working migrants, search and recruitment strategies, countries of origin, gender and educational levels of workers, the most notorious branches and their developments with regard to IMW, the extent of IMW, a scenario forecasting of future developments, an evaluation of control strategies and political measures against IMW and much else.

As the analysis of these issues is laid out in detail in the preceding sections and is taken up again in Part 4 of this report, they will not be repeated here. Rather, we would like to point to one particular feature of our Delphi survey, which is likely to be a valid characteristic of expert-based research in general: the great majority of participating experts in our survey are not only 'knowledge carriers' for the purposes of this particular research, but are actively involved in shaping or implementing policies and regulations that in turn will have an effect on the research subject as such - as officials in public administration or enforcement bodies, activists in NGOs, professionals in special interest 
organisations, policy advisors, authors of influential reports or, simply, as experts asked for special advice on the subject by the government, administration or the media.

It is for this reason that the sections on control strategies and policy measures assume a special weight in our Delphi study. And while the effectiveness of controls (at the workplace) and sanctions is predominantly seen as limited, there is much less agreement on which alternative policy measures could or should be taken to address irregular migrant work. By dividing the evaluation of policy measures into two dimensions - what is (politically) feasible and what is (generally) desirable in the eyes of our experts - we gained a picture of what could and should be done about irregular migrant work that is sometimes clearcut and in other cases strongly contested. This should not be surprising. Insofar as our experts are opinion leaders and/or attached to institutions that represent certain interests and positions, their views are likely to reflect the contested standpoints on irregular migrant work currently prevalent in Austrian society. Luckily, this is not the end of the story. By specifying, justifying and revising their views in the course of this Delphi survey, our experts have helped to sharpen a blurred picture and to clarify the desirability and feasibility of available policy options. This in itself is no mean achievement, and we wholeheartedly thank all our participating experts for their contributions.

\section{Notes}

I Parts of this chapter have been published as a working paper of the International Labour Office and are reproduced with the ILO's kind permission; see Jandl, Hollomey and Stepien (2007).

2 General information on the Delphi Method is provided in Linstone and Turoff (I975). A good overview is provided in Masser and Foley (1987).

3 See, for example, Rowe et al. (I99I). For a recent application of the method, see Lachmanová and Drbohlav (2004).

4 Mainly, the Foreign Employment Law (Ausländerbeschäftigungsgesetz - AuslBG) and the Aliens' Act (Fremdengesetz - FrG), which includes the Residence and Settlement Act (Niederlassungs- und Aufenthaltsgesetz - NAG).

5 To increase the chances of successfully prosecuting such cases, organised tax and social security fraud has been made a criminal offence (rather than an administrative offence with fewer powers of investigation) by the new Social Security Fraud Act of 2005 (Sozialbetrugsgesetz 2005).

6 For example, a common argument made with regard to demographic developments (aging and more need for elderly care) and socioeconomic developments (higher employment rates of women and more need for childcare) is vigorously opposed by those arguing that the relative need for these services (currently often supplied by irregular migrant workers) should be satisfied by accommodating social policies (more childcare facilities, retirement homes, etc.). Demographic developments will also lead 
to scarcities on the labour market, which can either be filled by more regular or more irregular workers. And so on.

7 The designation 'former Yugoslavia' was generally used by our respondents when referring to the successor states of the former Yugoslavia. Although no longer a 'state' or a 'country', we use this term as a regional designation.

8 In addition, for all assessments of quantitative developments, we also asked our experts to justify their statements with qualitative arguments. These arguments formed an important part of the feedback we provided to the respondents of the first Delphi round and which led experts in many cases to reconsider their earlier assessments in the second Delphi round. For clarity, and to avoid duplication, such qualitative arguments have been integrated in other sections of this report and will not be repeated here.

9 An interesting justification of the latter opinion is provided by the observation that the one-time legalisation campaign of some 30,000 irregular migrants in I990 led to a momentary decrease in the number of illegally employed foreigners.

Io The resulting average values for Delphi 2 (Delphi I) are as follows: for private households (care) 0.89 (0.92); for private households (cleaning) 0.78 ( 0.57$)$; for construction 0.50 (0.45); for catering and tourism 0.4I (0.25); for agriculture 0.I3 (0.I4); for trade and industry -0.13 (-0.06).

II Using the above-listed numerical values for the three answer categories, the standard deviation for the aggregate answers in Delphi I and Delphi 2 decreases for private households (care) from 0.59 to 0.43 ; for construction from 0.74 to $0.7 \mathrm{I}$; for catering and tourism from 0.79 to $0.7 \mathrm{I}$; for agriculture from 0.79 to 0.50 ; for trade and industry from 0.83 to 0.74 . For private households (care), it increases from a low 0.28 to a still relatively low 0.32 .

I2 Out of I54 possible estimates from 22 respondents in seven sectors/branches, $78 \mathrm{nu}$ merical estimates were made. Experts from NGOs and from public administration abstained relatively more often than others.

I3 One expert pointed out that a share of 5 per cent in total employment would amount to some 150,000 migrants in irregular employment in Austria, and that this would thus certainly be too high. However, no justification as to why this would be too high was given. Another expert, providing a relatively high estimate, argued that IMW takes place also in many other sectors and branches than those listed in the questionnaire, and that 5 per cent could thus be substantially too low. Again, no further justification was provided.

I4 The comment pointed out that there are some 3.2 million households in Austria, many of which employ household helpers. At the same time, regularly employed cleaners and gardeners are still the exception rather than the norm.

I5 Both authors point out that the actual (non-full-time) number of illegal foreign workers is likely to be considerably higher than these figures.

I6 Such trainee programmes are currently agreed upon with Hungary and the Czech Republic in the form of trainee and border commuter agreements only, and comprise several thousand persons per year. For 2007 , the quota for Hungary was fixed at I,800 trainees and 2,350 border commuters. For the Czech Republic, the quota for 2007 (the first year in which the agreement was applied) was set at 300 trainees and 500 border commuters (BMWA 2006).

I7 The following definitions were provided: 'Feasibility means the high probability that this measure can be politically implemented' and 'Desirability is taken to reflect your personal evaluation of whether this measure should be implemented in order to reduce irregular migrant work, taking into account all positive and negative effects this measure could have (effectiveness and costs of measure, ethic criteria and effects on higher-level goals)'. 
I8 It was also pointed out that this issue has by and large already been addressed by recent changes in foreign employment law required by existing EU regulations. However, some groups with residence rights still face certain restrictions in the access to the labour market.

I9 Currently, these two rights are not fully aligned, as can be seen in the existence of two separate permits for residence and work purposes. A full merging of these rights would abolish all work permits needed under foreign employment law and grant the right to work to anyone with a residence permit, thus going beyond recent approximations in the two sets of rights.

20 At the time of carrying out this study, the issue of irregular migrant workers in private home care became a hotly debated political topic, especially in the run-up to the elections in October 2006. With few realistic solutions for establishing affordable home care in sight, it was eventually decided in a typical political move to establish a commission that would study the issue and suggest solutions. To allow time for this, a general amnesty until 30 June 2007 for irregular care workers and their employers (that is, the patients) was announced by the Minister for the Economy and Labour. After months of bitter negotiations and political bickering, however, no politically acceptable solution was in sight that would allow both upholding labour standards and regularising irregular care workers. Therefore, in mid-June 2007 , the government extended the amnesty until the end of the year.

2I Under current legislation, only the employers of irregular migrant workers are subject to sanctions and fines but not the irregular workers themselves. However, for third-country citizens, the fact of being apprehended for irregular work will in most cases lead to expulsion from Austria.

22 However, a counter-argument fielded by some experts was that in the medium term, higher competition in international product markets would lead to more cost pressures in certain industries, and thus more demand for irregular (low-cost) migrant workers. This argument was sometimes also related to irregular migrant work in socalled 'ethnic businesses' (e.g. family members of migrant entrepreneurs). For construction, a common counter-argument against a future decrease in demand for irregular migrant workers was a perceived boom in construction and renovation activities in private households. 



\section{Empirical results from migrant interviews}

\subsection{Methodology and sample description}

In order to get a broader picture of the meaning of irregular migrant work in Austria from an insight perspective and to get in-depth knowledge on the evolvement of labour market strategies and the impact of legal admission schemes in the context of EU enlargement, we decided to carry out problem-centred qualitative interviews (Witzel 2000) with individuals who have first-hand knowledge themselves: migrants working irregularly. Qualitative interviews are based on the assumption that, in contrast to experts who are able to distance themselves from the subject in question, affected persons can convey their very personal and subjective perspective of a process or a situation and can thus be considered as 'experts' for their individual situations (Gläser \& Laudel 2004). Personal experiences bring new aspects to the research topic and can shed light on aspects otherwise underrepresented.

\subsubsection{General sample description}

As our research interest was to gain in-depth knowledge on a phenomenon in a certain geographical and temporal context, namely irregular migrant employment in the context of EU enlargement in Austria, we decided for selective sampling (Schatzman \& Strauss I973; Sandelowski et. al. I992) and therefore to sample subjects 'according to a preconceived, but reasonable initial set of dimensions [we had] worked out in advance for the study' (Glaser 1978: 37).

We carried out qualitative interviews with 50 migrants working irregularly in the most notorious branches and activity areas, in times of high and low seasons and in various geographical regions where irregular migrant work is deemed to be concentrated: construction and related industries, catering and tourism, agriculture and domestic services.

In addition, interviews were conducted in three regions: the Federal State of Burgenland as a region that borders the relevant states of Slovakia and Hungary and serves as an important agricultural region; the Federal State of Tyrol as a region that borders only 'old' EU Member 
States and depends heavily on tourism; and the capital city of Vienna, which provides urban structures and anonymity.

The objective of our research was to explore the impact of EU enlargement on irregular foreign employment in Austria. Therefore, respondents originated mainly from new EU Member States. Only in cases where it seemed to be relevant for our research did we include thirdcountry nationals originating from countries bordering the EU (Ukraine and, before 2007 , Romania and Bulgaria), but also individuals from other states who, due to their long-term involvement, could draw on comprehensive knowledge about irregular foreign employment in Austria. In order to gain insight into changing strategies, most selected individuals had already started to work in Austria before the May 2004 enlargement and could therefore reveal a great deal on changing strategies associated with their changed legal status under EU residency rights. Those who arrived after the enlargement were generally younger and had decided to come to Austria to work or study after having finished school or some other educational training. Of the 50 persons interviewed, 23 were male and 27 were female (see Table 3.I).

Most of the persons interviewed were aged between twenty and 29 years at the time of the interview. Only four were older than 50, while twenty persons were aged between 30 and 49. No one was younger than twenty, as interviewed persons generally came to Austria only after having finished school or a professional education.

Of the 50 persons we interviewed, many were engaged in several activities and some across various sectors at the time of the interview, as the earnings from one job alone would usually not be sufficient to

Table 3.1 Composition of interview sample by nationality, gender and time of first arrival

\begin{tabular}{lrrrll}
\hline & Male & Female & Total & $\begin{array}{l}\text { First arrival } \\
\text { before 2004 } \\
\text { EU enlargement }\end{array}$ & $\begin{array}{l}\text { First arrival } \\
\text { after 2004 } \\
\text { EU enlargement }\end{array}$ \\
\hline Poland & 12 & 12 & 24 & 19 & 5 \\
Slovakia & 2 & 3 & 5 & 4 & 1 \\
Ukraine & 1 & 3 & 4 & 2 & 2 \\
Czech Republic & 1 & 2 & 3 & 2 & 1 \\
Former Yugoslavia & 1 & 2 & 3 & 2 & 1 \\
Hungary & 1 & 1 & 2 & 2 & \\
Romania & 1 & 1 & 2 & 2 & 1 \\
Bulgaria & 1 & & 1 & 1 & 1 \\
Belarus & 3 & 2 & 5 & 4 & 12 \\
Other & 23 & 27 & 50 & 38 & \\
\hline Total & & & & &
\end{tabular}


make a living. In addition, most respondents could look back on a good deal of 'careering' in various sectors and therefore could provide information on several branches and several types of job arrangements.

As the assignment of accurate numbers of interviewees according to sectors and branches would simply be inaccurate (due to the involvement of many migrants in several branches simultaneously or over time), the following table (Table 3.2) provides only an indicative overview on the extent our sample was distributed according to branches and activities, ascending from - (no one) to xxx (many).

\subsubsection{Interviewing and analysis}

We applied a combination of problem-centred interviews (Witzel 2000) and expert interviews as outlined by Gläser and Laudel (2004), who advocate a very broad concept of who is an expert and who possesses expert knowledge. In accordance with Gläser and Laudel (2004), the participating narrators were not only 'objects' to the research but, at the same time, they were viewed as experts in the sense that they are not only personally involved but witnesses of certain processes and structures (Gläser \& Laudel 2004: IO). In this case, they were witnesses to irregular migrant work in various sectors and over time. In addition, we chose the problem-centred interview as it allows for the revealing of biographical evidence such as specific conditions, types of interactions, emotions, personal assessments, strategies and consequences. At the same time, the semi-structured prompts allow for better comparison and embedding the biographical evidence in the bigger context of structure, dynamics and changes in irregular migrant work in the most notorious sectors in Austria (cf. Witzel 2000).

This research technique is characterised by face-to-face encounters between the researcher and his or her respondents, but in contrast to other face-to-face interviews that follow a pre-determined structure, allows respondents to put their own emphasis on particular aspects they want to highlight. The goal is the examination of specific events and how these are interpreted by persons who are themselves part of the

Table 3.2 Composition of interview sample, according to regions and sectors

\begin{tabular}{llll}
\hline Region & Vienna & Tyrol & Burgenland \\
Sector & & & \\
\hline Construction & $\mathrm{xxx}$ & $\mathrm{xx}$ & $\mathrm{x}$ \\
Catering and tourism & $\mathrm{xxx}$ & $\mathrm{xx}$ & - \\
Agriculture & $\mathrm{x}$ & $\mathrm{xxx}$ & $\mathrm{xx}$ \\
Domestic services & $\mathrm{xxx}$ & $\mathrm{xx}$ & - \\
\hline
\end{tabular}


(social) context in question. Therefore, we used an interview manual containing specific problem-centred subtopics, and narrators were not confronted with a standardised list of questions, but were invited to speak freely about their experiences.

Combining these two approaches served to get insight into the general structure of irregular migrant work, but also to explore the impact of irregular work on living and working conditions of migrants. It also looked into how workers make sense of their irregular situation and what coping strategies they develop.

All interviews were carried out by researchers who had pertinent experience with the interview technique applied. The research team was fully transparent in its aims and procedures and obtained the informed consent of all research participants prior to the interview. Respondents' anonymity and confidentiality were respected throughout the entire research process - from the point of first contact to dissemination of research results. Participation in the research was voluntary and respondents received fifteen euro as compensation for their time and effort. Duration of the interviews varied between one and three hours.

Interviews were carried out in the narrators' first language or in German, if the language skills of the person allowed for it. The written or taped records were then transposed to German or English and analysed using thematic coding as developed by Flick (I995). We chose thematic coding because it seemed the most appropriate means to achieve our aim of addressing already defined themes and questions prior to conducting the research, while at the same time being flexible enough to identify new aspects. Although based on Grounded Theory (Glaser \& Strauss I967), thematic coding foresees the interplay of inductive and deductive category acquisition and therefore allows for case comparison and for the analysis of responses from predefined groups.

Thematic coding foresees several analytical steps:

- A brief summary of each case was produced containing background information on the person interviewed (age, sex, legal status, time of arrival, sector, type of employment, country and region of origin, etc.), as well as basic characteristics specific to this particular case.

- In several steps, categories were developed by applying open as well as selective coding. Those interviews that had appeared to be most representative of the group were analysed paragraph by paragraph, first in order to identify all the possible codes that may be relevant for answering the research questions. As a next step, these codes were grouped together in so-called thematic fields that were derived from both the interview material and from pre-existing theories and earlier research findings already used to compile the interview manual. In this way, the thematic structure of the interview emerged, 
which was then applied to all interviews. Applying this thematic structure to all interviews enabled constant comparisons between the different cases and allowed the modification and complementation of emerging new aspects and themes to the original thematic structure.

By implementing thematic coding, it was possible to identify, analyse and compare differences and similarities between groups along criteria such as gender, age, ethnicity or nationality. At the same time, this mode of analysis remains sensitive to the individual case.

\subsubsection{Methodological challenges and possible sample biases}

When designing the research, it was decided that the samples drawn would aim to be broadly representative according to sectors, seasons and regions in which potential interviewees are likely to be concentrated. ${ }^{\mathrm{I}}$

However, gaining access to possible interviewees proved to be the most difficult part of our fieldwork, as the building up of trust, a prerequisite of every successful qualitative interview, was extremely difficult on such a sensitive topic of semi-legality or complete illegality. On the respondent's side, this concerned potential interviewees who were in an irregular situation or even residing illegally. In addition, they were often closely associated with their employers and therefore feared putting themselves and their job opportunities at risk by talking about the difficulties they face with their jobs and their employers. This explains why access to EU nationals turned out to be much easier than to thirdcountry nationals, which became most obvious when trying to access persons through one of the established ways of accessing 'hidden' populations: 'snowballing' (narrators were asked to name other potential participants, e.g. colleagues, friends).

Mistrust and apprehension did not only play a role with the migrants interviewed, but also, and maybe even more so, with the other actors involved. Getting at interviewees through the use of 'gatekeepers' - individuals who provide access to interviewees and reduce mistrust when associated with the researcher - turned out to be extremely difficult. Possible biases that may arise from the gatekeepers' side means that the use of gatekeepers must be viewed critically. Often, gatekeepers will only refer interviewers to those interviewees they think would fit the profile best or those who are generally outspoken. In our research, the challenge was to find gatekeepers who would be ready to help in accessing possibly reluctant interviewees. Possible gatekeepers from local NGOs and migrant organisations were uneasy about providing contacts, as they feared losing their clients' trust. Therefore, only 
few contacts were established by means of local gatekeepers from NGOs, migrant associations or labour market monitoring institutions.

Even more difficult was the fact that, in some cases, employers themselves attempted to function as gatekeepers. Especially in sectors where workers get accommodation from the employer and spend their free time - if any is available - in the closest surroundings of the workplace, employers hoped to act as gatekeepers and exercise control over the selection of persons to be interviewed. In some cases, we even had to get the employers' permission to do interviews with some of their personnel. This was especially the case for au pairs and other domestic workers in private households, and in areas of seasonal work, most significantly in agriculture. Here, workers live with their employer or in compounds near the farm and have very little spare time. There is also no secluded place that would ensure the privacy needed to talk freely and openly about possible grievances. We therefore tried to minimise this influence by directly approaching workers on their worksites. But even there - and especially where employers work together with their workers - we knew that the employers' permission would be needed and that interviews would have to be done directly at the workplace. This did not only affect the sample selection, but strongly affected the quality of the information retrieved in such situations. (In the case of agriculture, some farmers even insisted on being present during the interviews. As a result, narrations were significantly biased, as the most crucial topics could simply not be discussed).

However, in many cases, the narrators' accordance with their employers not so much derived from a direct fear of getting in trouble or being severely punished by their employers, but rather represented a certain type of loyalty towards them. As (especially in the case of EU nationals) it is the employers who would be penalised if any information on irregularities were to go public, workers would act in favour of the employer as long as they still had an interest in upholding a possible work relationship for a longer period of time or over several seasons.

On the other hand, employers were very cautious about making interviewees available. This derived from their own fear of being consciously or unconsciously denounced by their workers. Consequently, if any delicate information were made public, they would lose their entitlement for seasonal quotas, which in the end would not only cause difficulties on the employers' side, but would affect their workers' job security and future job arrangements. This strong fear on the side of the employers became obvious by the fact that in some cases, even the local chairman of the farmers' association was consulted and had to approve the interview. 
Therefore, we decided that the third potential source of contact was to be the research team itself. The researchers and/or bilingual or multilingual interviewers engaged for this study used their personal contacts for potential respondents, appealing to friends, relatives and acquaintances who fell under the selection criteria or who could establish direct contacts with individuals in the target group. Although the information collected in this manner turned out to be the most comprehensive, this also explains a certain bias of the sample composition (for example, in favour of younger migrants, students or Polish nationals).

\subsection{Legal framework regarding access to employment of non-nationals}

The legal framework regulating access to employment and the informal strategies of migrants and employers to circumvent it are interconnected and mutually influence each other. Regulations on immigration and labour in Austria are defined through regulations and legislation on a national, bilateral and EU level. National regulations on the employment of non-nationals in Austria are in general determined by two laws: the Foreign Employment Law regulating access of non-nationals to the labour market, and the Aliens' Law that regulates entry to Austria and the right to stay. In addition to the Foreign Employment Law, which concerns only dependent employment, regulations on self-employment define the access to certain trades. Next to this general framework on a national level, there are additional regulations for certain groups of people, e.g. students or au pairs. The model of seasonal employment allows for specific access regulations in seasonal branches.

In addition to laws on the national level, EU regulations gain more and more importance in the structuring of employment possibilities. In this respect, the transitional regulations introduced in 2004, which restrict the access to the domestic labour market for citizens of new EU Member States, can be seen as an attempt to postpone the influence of EU legislation and retain the influence of national regulations. Transitional regulations restrict access to dependent employment almost entirely, while self-employment is only partially restricted. Together, national and EU-wide regulations shape the environment in which regular and irregular employment of non-nationals takes place.

\subsubsection{Regulations on self-employment and transitional regulations}

Access to the labour market for the self-employed is regulated by trade regulations, the so-called Austrian Industrial Code (Gewerbeordnung), 
as well as by the EU Service Directive that includes the Posting of Workers Directive. Both generally enable EU citizens to register a trade and perform their services in Austria. For new EU citizens, however, especially activities in the construction sector have been largely excluded from free access during the application of transitional regulations since 2004. Getting a trade licence for most construction activities and performing specific construction services is thus restricted by transitional regulations, and is also bound up with additional obligations for the foreign entrepreneur. In order to get access to such restricted branches, EU-8 citizens are obliged to submit a certificate that proves their skills were obtained by education and experience (Befähigungsnachweis).

Registering a trade in Austria as a self-employed person is one way to get access to the Austrian labour market outside of Foreign Employment Law. In order to get a licence, one has to pay a monthly fee and organise social insurance on one's own. On the other hand, due to regulations of the EU Service Directive, owning a company in the country of origin principally enables foreign entrepreneurs to accept temporary jobs as self-employed persons in Austria. Foreign entrepreneurs are also allowed to use their own workers to carry out a limited specific order in Austria. Due to transition periods, foreign entrepreneurs have to prove their qualifications for most construction activities and, according to the Foreign Employment Law, their workers additionally need a work permit for the duration of the job. As only national employers can obtain one, the foreign entrepreneur has to cooperate with an Austrian enterprise in order to get work permits for his or her own workers. As an additional requirement, the need to employ a foreigner instead of a domestic worker to carry out the respective job has to be declared (preferential treatment of native workers).

While self-employment is possible in almost all branches of the economy, it plays a significant role mainly within the construction sector, where a number of restrictions apply due to transitional regulations after EU enlargement.

\subsubsection{Regulations on seasonal employment}

In addition to the regulations on highly qualified workers, ${ }^{2}$ seasonal employment is another limited possibility for foreigners to get access to the Austrian labour market. Two sectors, namely agriculture and catering and tourism, are considered seasonal and thus mainly affected by this regulation. While key personnel are per definition highly qualified and well-paid, seasonal labour covers the demand for cheap foreign labour in low-skilled sectors. The system of seasonal work is construed as an additional access possibility to the labour market outside 
the framework of the Austrian Foreign Employment Law. In addition, the limited duration of seasonal work permits guarantees that seasonal employees do not achieve further access to the labour market. Consequently, seasonal work permits do not lead to integration on the Austrian labour market in the long run, but only allow access for the duration of the permit. Even migrants who have worked as seasonal employees for years do not acquire any labour market status and have to start from scratch time and time again.

Seasonal work permits are temporary work permits. Every year, the Ministry for Economy and Labour defines a quota for the number of 'seasonal work permits' to be issued for specific sectors, occupational groups or regions, especially covering occupations in seasonal tourism and agriculture. Seasonal work contracts are usually issued for the limited period of six month only but can, upon application, be prolonged for another six months. If, in this case, a person is temporarily employed for one year, a reapplication under the same conditions is only possible after suspending the work for two months. Seasonal work permits include health and pension insurance, as well as unemployment insurance. However, due to the temporary restricted character of seasonal employment, seasonal workers do not have the possibility to claim those accumulated rights on pension and unemployment benefits. In agriculture, a work permit for so-called harvesters (work permit and visa for only six weeks) was introduced to cover peaks at harvest times. This work permit only includes social insurance. Minimum wages are currently 4.80 euro per hour net income for seasonal workers; harvesters earn even less.

EU citizens, including Romanians and Bulgarians since accession in 2007 , are guaranteed preferential access to seasonal employment. As a result, third-country nationals are not issued a seasonal work permit anymore, unless they belong to the so-called 'core workforce' of employers, having worked at one and the same farm for some years. But recently, even the number of this non-EU core workforce has been reduced by half.

In the agricultural sector, this poses a problem to those farmers who have in the past mainly relied on workers coming from third countries. They have to hire new workers who must be newly incorporated and trained in the business. Another potential problem of the seasonal employment system is the non-compliance of seasons with the duration of seasonal work permits. As the season is slightly longer than the permit, there has to be a shift of the workforce within the season, the main season lasting from March to October. The unpredictability concerning the yearly-defined quotas of seasonal workers keeps farmers in suspense as to whether they will be able to harvest as much as they did the previous year. 
As the legal and administrative regime of seasonal employment does not seem to be adequately tailored to the actual needs in these specific branches, it may play a part in facilitating irregular employment, informally 'adjusting' work contracts to seasonal realities.

\subsubsection{Regulations on the employment of students}

Regulations on the employment of students also play a major role in shaping irregular employment, as the employment of students underlies restrictions. Foreign students are able to access the Austrian labour market as long as they are registered at an Austrian university. Since January 2003, non-national students are obliged to prove sufficient financial means every year (a capital of 7,000 euro). ${ }^{3}$ In addition, for non-EEC students, the university fee is twice as much as for nationals and EU citizens (around 720 euro). At the same time, these students have only very limited, but not clearly defined access to the Austrian labour market, leaving room for discretion. By law, non-EEC students' income 'gained by work on the Austrian Labour market must not be the primary source of subsistence to cover the larger part of living costs'. Generally, working hours are limited to approximately ten hours per week, and the salary has to be below the threshold for the payment of social insurance premiums (Geringfügigkeitsgrenze), which was 333.I6 euro per month in 2006). Besides this limitation, students holding a residence permit are allowed to work on the basis of service contracts and can apply for a work permit to enter seasonal work.

However, as the legal provision is not specific on the definition of what the 'larger part of living costs' entails, a number of students actually work at the margins of the law in order to be able to finance their living expenses, or they prefer to work irregularly so as to prevent the eventual loss of their residence permit.

As students holding Austrian or any EEC citizenship usually have social insurance coverage by other means (e.g. parents, second petty employment, student health insurance), employers might to a certain extent feel exonerated from responsibilities, choosing not to register them or registering them below the social security threshold (333 euro). In addition, Austrian students who receive a scholarship are only allowed to work a certain number of hours per year and therefore may also have an interest in non-registration.

In the sectors we analysed, the employment of students primarily plays a role in catering and tourism, as kitchen help, waiters, waitresses or 'barmen', as well as in domestic services such as au pairs. Working in a restaurant, a bar or in childcare is a common practice for students overall. For many students, such sectors provide conditions more easily compatible with the need for studying and working at the 
same time: flexible working hours and salaries and/or tips that are paid in cash after the respective shift.

\subsubsection{Regulations on employment in the private sector: Childcare, care for the elderly and care for people with a disability}

As in many other European countries, Austrian households tend to employ migrant workers as a means of dealing with the declining capacity and willingness of traditional networks to provide services such as housekeeping, child and elderly care, on the one hand, and the steady increase in demand for these services, on the other. In order to grasp the widespread phenomenon of outsourcing formerly unpaid family work to paid domestic workers, certain socioeconomic and demographic factors have to be taken into account. These include the increased participation of women in the paid labour market, the emergence of the dual-career family, the unchanged sharing of household tasks between the members of a household and demographic developments such as aging populations and changing household and family structures (e.g. increase of one-person households). Nonetheless, the structure of the welfare state and the manner in which childcare and the provision of long-term care are organised and social responsibilities are divided among households, the public and the market sector can influence the households' decision to employ a migrant caregiver.

The liberalisation of the au pair law can be seen as a political recognition of the rising demand for migrant domestic workers in Austria. Although, the au pair programme was initially designed as a culture and language exchange programme for foreign young women and men, it has gradually developed into a migration policy, supplying Austrian households in need of care with affordable labour. In April 200I, the law regulating the residence and employment status of au pairs, predominantly women aged eighteen to 28 and originating from Central and Eastern European countries, was changed to facilitate the employment of caregivers. Since then, households in need of childcare can employ an au pair for one year without needing to apply for a work permit under the quota system regulating the access of foreigners to the national labour market (König \& Stadler 2003: 236). The host family's sole obligation is to register the au pair at the AMS two weeks prior to the commencement of the work relationship. Following a successful registration, the au pair is entitled to a temporary residence permit. The host family is obliged to provide room and board as well as 60 euro per week in pocket money. The contract between the host family and the au pair defines basic working conditions, such as the amount of working hours per week (which is limited to 25) and the duties performed, including childcare and simple household chores. 
In the case of elderly domiciliary care, the Austrian government launched a policy package regulating the informal sector for long-term care. In the autumn of 2006 , a broad public discourse on the irregular employment of migrant caregivers resulted in a general amnesty that offered employers and caregivers impunity until the completion of the policy measures. In July 2007 , the government implemented two sponsorship models as an incentive to employ live-in migrant caregivers on a regular basis. People in need of long-term care who were receiving care allowances were given the opportunity to either hire a self-employed migrant caregiver or employ a dependent foreign caregiver. Depending on the kind of care relationship established between the allowance receiver and the migrant caregiver, the state funds part of the additional expenses associated with regular employment. Estimates on the overall monthly costs for compliant live-in domiciliary care range from 1,500 euro to 2,000 euro in the case of self-employed caregivers, and from 2,600 euro to 2,850 euro in the case of subordinate employees, of which the government's financial support covers anywhere from 225 euro to a maximum of 800 euro. Because of considerably lower costs in the self-employed model, experts assume that it will be more widely accepted. In effect since July 2007, the two sponsorship models have not been very effective in stimulating the regular employment of migrant caregivers. Of the 40,000 migrant caregivers estimated to be working irregularly, only a couple hundred had registered as of February 2008 .

\subsection{Actors involved in irregular employment networks}

In order to meet the very different and often changing needs of migrants in working and social life, networks of migrants have to be very flexible and versatile. Every network provides different kinds of access to various 'services' appropriate for a variety of purposes. Thus, migrants navigate within various networks, create them, try to get access to them, activate and reactivate them and sustain them. Having access to different kinds of networks can both create or limit possibilities, influence decisions and define whether or not people can benefit from or improve their current situation.

Recruitment and employment agencies, employers, the ethnic community, family, friends and colleagues are different actors in the networks within which migrants move. The ability to incorporate sectorspecific key individuals into one's networks determines the sustainability and effectiveness of the networks at hand. The following part describes those actors that are most crucial in networks of irregularly em- 
ployed migrants, including both organised and informal networks and the different kinds of possibilities they can open up.

\subsubsection{Family, friends and colleagues}

Social networks comprising family, friends and colleagues, ethnic and linguistic community organisations, etc. are almost invariably considered to be the most important actors. Family, friends and colleagues, in Austria and in the country of origin, have an impact on the initial decision to migrate to Austria, often open doors to work and social life in Austria, are key in emergency situations and are also crucial for return perspectives to the country of origin. Networks of family, friends and colleagues define the scope of possibilities and thus the working and social position of migrants at the time of entry, and they are fundamental to further establishing social contacts. This was most comprehensively expressed by a Serbian student: 'You don't go anywhere where you would end up in the street, but somewhere where you have family and friends who can help you' Social networks are the core resource for managing accommodation and employment in the region of immigration; they provide assistance in legal, financial and personal matters, and stretch beyond national borders. Nevertheless, there are also limitations to these social networks. It was also stated that, especially under conditions of geographical vicinity and free movement, some people just take a sum of money and start a trip into the blue in order to find work. But sometimes they would spend all the money in travel and don't have any money left to come back home'.

\subsubsection{Ethnic and linguistic community}

In addition to familial and friendship networks, the ethnic and linguistic community with all its institutions and resources may provide additional help to organise social and working life abroad, either in a formalised or informal way. While the general importance of familial and friendship networks results in the tendency that job mediation mainly takes place within one's own ethnic and linguistic community, there are also more formalised actors that evolved differently in respect to their migration history in Austria. As one that has grown and established itself over a longer period of time, the Polish community played a crucial role for our Polish interviewees.

The Polish church, in particular, was mentioned as an important meeting and contact point for irregularly employed migrants of Polish origin, providing information about housing, working and migration, as well as a place for recruitment by employers of the same ethnic origin. ${ }^{4}$ In addition, a Polish-language magazine has been complement- 
ing this role for a few years now as an informal meeting point, in which everybody can advertise apartments (for free) or services (five euro) in Polish.

However, ethnic and linguistic networks and their resources are not equally available in all regions of Austria, but concentrate in bigger agglomerations as in Vienna. This again results in the tendency of ethnic communities to reproduce themselves there, because migrants prefer to come to a place where there are already some established networks in place. Thus, to recruit people in Vienna for work in other areas of Austria (e.g. Tyrol) is conceived as difficult. But even employment in specific sectors seems to be structured along ethnic lines. As mentioned above, migration abroad and recruitment is mainly built upon informal networks of family members, friends and colleagues. To cover additional demand, employers as well as labourers fall back on the available informal recruitment structures. These informal structures are steadily multiplying, creating specific 'territories' for specific ethnicities.

Each nationality has its own territory. For many years it has evolved like this, and as everyone was satisfied, it continued along those lines. Exactly such a chain is here: first, a cousin came, then an aunt, etc. I think, when somebody has done his or her work well, then people are again looking for similar nationalities. If this definite person isn't available anymore, then one is looking for somebody coming from the same country because one thinks that they are similar regarding their character and capabilities: diligent, fast, honest, accurate. (Male respondent, Poland, construction)

Over the course of time, each ethnicity has acquired a certain reputation. These reputations again contribute to the maintenance of ethnic structures in the irregular employment of non-nationals. Thus, Polish workers rely on their reputation to be 'hardworking, able and flexible'. This reputation is seen as a decisive advantage in looking for work and is said to differentiate Polish workers from, for example, Austrians, who are generally considered to be 'lazy'.

We [Polish] are taken very readily, because we're working very well. Everybody tells us this, also my friends tell me the same: that their employers say that we're really performing well. (Male respondent, Poland, construction)

Ethnic companies and their recruitment networks are another factor in upholding ethnic structures within the construction sector. Ethnic employers are the most important employers for co-ethnics. Without 
being highly skilled, contacts within the ethnic community are crucial to succeeding abroad. However, it has to be kept in mind that people are not constrained to those ethnic networks and that these limitations can be overcome with time.

... either one is coming with someone who already knows the place, or to a Polish enterprise. This is okay, but otherwise it makes no sense. (Male respondent, Poland, construction)

\subsubsection{Employers}

In our sample, the role of employers was perceived somewhat ambiguously. In several cases, employers would promise to 'take care of the regularisation and organise the relevant documents' (Female respondent, Poland). It is exactly this powerful position and the trust they gain that employers can exploit. At the mercy of their employers, respondents reported they were intentionally misinformed about their current legal possibilities or status, or they were cheated out of their salaries, as the following story of a Serbian woman shows:

Then a Turkish guy in a pizzeria hired me as a waitress. The guy cheated me. He said he'd help me stay in Austria, so I signed this contract. I didn't know what I was actually signing, but after this I was self-employed! I would never do this again! By signing it, I was the boss and he was employed by me. I had to pay his social insurance fees and other things. (Female respondent, Serbia)

The following quote also shows that several respondents clearly distinguish between 'immigrant employers' and 'Austrian employers' as performing differently when employing irregularly.

Foreign employers like Yugoslavs or Turks will not register you at all. At these pizzerias, bars, et cetera (at least all those I worked for), you work for two or three months and then he should pay, and instead he would tell you he doesn't need you anymore and you would miss out. Austrian employers don't like to employ fully unregistered people, they get nervous and are scared of being punished. (Female respondent, Serbia)

While migrant workers consider contacts and information provided by social networks, family, colleagues and the ethnic community as being of key importance when trying to find a job on the informal labour market, actually being employed by a co-ethnic is not viewed as the 
most desirable option. In many cases, however, the fact that both employer and employee are embedded in the context of informal foreign labour markets works to the disadvantage of migrant workers. The employer exploits these employees and even goes so far as to use intimidation and threats, as reported by the same Serbian woman:

I will never work with a Yugoslav employer, or with any foreigner. Now that I'm in Austria, I want to work with Austrian employers. If an Austrian doesn't pay me, fine, I can go to the Chamber of Labour and lodge a complaint. Theoretically I can also do this with a Yugoslav employer, but then I would most probably have problems of a different kind: my car would be scratched, problems for my family. My daughter is there, at home. I don't even want to think about what could happen. (Female respondent, Serbia)

Despite stories of unfair treatment, underpayment or cheating employees out of their money, employers were seen much more strategically: even in cases of unfair treatment, only short employment or fully unregistered employment, it can be worthwhile to perform well and to stay on good terms with the employer. In the future, one could always come back and, already familiar with the employer, could get full and legal employment or would at least be recommended to someone else in need of irregular labour.

Aside from the perception as a potential source of legal employment, 'Austrian' employers were generally portrayed as an important source of information on legal and administrative matters, if not as persons who would themselves enable a regularisation.

Apart from informal networks, formal job agencies (recruitment and national employment agencies) are viewed as important for accessing jobs especially to those persons who have legal residence status and access to the Austrian labour market, such as persons holding a work permit, persons working under seasonal contracts, self-employed individuals and students.

\subsection{Motives to migrate and work abroad}

Motives to leave the country of origin and come to Austria to work are very diverse and vary among people of different age, gender and family status. It should be stressed that no one comes to Austria with the aim to work irregularly, but with the intention to work, study or live here. Subsequently, available job opportunities, labour market regulations 
and individual networks are responsible for the entry of migrants into irregularity.

Generally, migrants leave their countries of origin due to a bad economic situation, a high unemployment rate, little or no state support and minimal prospects for the future. Especially for those with families, a sense of responsibility and the wish to provide a better education and prospects to one's children are factors that lead to migration. As one live-in caregiver states,

I came to Austria to earn some money, to be able to survive in Poland, to pay the rent and the bills. [...] And when I first came here my daughter was still at the university, so we needed to support her as well. (Female respondent, Poland)

In the case of women, it is often divorce or separation and the related need to care for one or more children alone that result in the decision to work abroad. Furthermore, it is also the wish to emancipate, to earn one's 'own' money, which causes people to migrate.

In comparison to migrants with children and/or families, younger persons mentioned an even greater mix of reasons. They emphasised curiosity of going abroad, learning German and starting or continuing a university education as well as earning some money. This is especially true for young women engaged as au pairs or working in catering and tourism: 'I work more or less because I want to study' (Female respondent, 24, Czech Republic). While the au pairs consciously chose care-giving as a strategy to work, learn and live abroad: '[being an] au pair is the best and cheapest way to learn a language and go abroad' (Female respondent, 22, Czech Republic), the live-in caregivers who were aged at least 30 to 50 stressed that they had not consciously chosen this type of work, but it was the only one available.

I didn't choose this kind of work. Before I started working here, I didn't even think about doing care work - it was just the only possibility I had. Back in my home country, I was unemployed and here I could earn a lot more than in Slovakia. (Male caregiver, Slovakia)

Coming to Austria for educational reasons was only mentioned by respondents in sectors that allow for a combination of working and studying, such as serving as an au pair or catering. Employment in other sectors does not allow for parallel education. While employment in the construction or agricultural sector allows students to earn some extra money during occasional stays (e.g. visiting a relative living in Austria) or their holidays, these time-intensive and physically demand- 
ing jobs make it impossible to follow educational aims parallel to employment. This is also true for live-in caregivers, who have hardly any free time to pursue anything but monetary aims.

The reasons why Austria was chosen as a destination country were often rather by chance. Some migrants originally planned to go to another country using Austria as a transit country, yet ultimately ended up staying. The major part of respondents chose Austria due to prior established contacts and connections through family, friends and colleagues. But also German as a second language in school or learned during prior stays in Germany or Switzerland played a significant role.

\section{Working life in specific sectors of irregular work}

\subsection{The construction sector}

\subsubsection{Construction: Sample description}

At the time of the interviews, twelve out of 50 migrants were employed irregularly in construction or construction-related activities, including work on construction sites, renovations in private households, but also landscaping and garden renovations. All of the interviewed migrants were male, the majority of them coming from Poland (see 3.I), but also including interviewees from Hungary and former Yugoslavia.

The age of interviewees varied widely, the youngest being 23 and the oldest 55. About half of the interviewees were over 40. While the youngest ones were single without children, most of the migrants had one to four children and lived in a partnership, whereas some had gotten divorced during the course of their employment abroad.

Regarding the legal status of migrants, all of them had the right to stay in Austria as EU citizens, refugees or asylum seekers. In contrast to this, most of them had no access to the labour market at the time of interviews, three held a trade licence, and only one, a refugee, had a regular work permit.

The majority of interviewees had a vocational training in construction or construction-related activities (engineer, plumber, carpenter), or had previous work experience in the construction sector in their country of origin or abroad. Some qualifications, however, had nothing in common with construction work, including completed trainings as cook, mechanic or caster. Only one refugee had not been able to complete his education before coming to Austria.

Prior to their work in Austria, five men had also worked construction in Germany, Ireland or another Central or Eastern European country. Only two came to Austria after EU enlargement in 2004. Most of the 
interviewees had over ten years of work experience in irregular work in Austria.

\subsubsection{Construction: Structural features and specific actors involved}

Reasons for irregularity

Respondents identified the legal framework as the most decisive reason for irregular employment in the construction sector. Especially the transitional regulations and their restrictions on dependent employment were said to result in 'pseudo-self-employment':

Yes, you still can't operate a 'white' firm [in compliance with the regulations] because you can't employ Polish workers, that's just impossible. They only can work as self-employed people, everyone opens up a single business on his or her own. Because the Poles are not allowed to work here legally. (Male respondent, Poland)

Interviewees also mentioned that the possibility to work with trade licences facilitates the irregular employment of non-nationals. The 'ordinary' registration of employees is unattractive because 'employment' by means of trade licences is much cheaper and means fewer responsibilities for employers.

I think everybody knows this, also the Austrians: the non-wage labour costs are so high. So many Austrians have told me, 'I pay you roo Schillings [about seven euro], and then I have to pay Ioo to the revenue office. That's simply too much.' (Male respondent, Poland)

Generally, jobs in the irregular economy in Austria are restricted. While interviewees agreed that there is a demand for irregular jobs in the construction sector, working possibilities are restricted to those tasks people with access to the labour market do not want to do. Therefore, irregular migrant work is considered 'the worst jobs that Austrians don't want to do' (Male respondent, Poland): mainly badly paid, hard, unattractive and low-skilled:

Regarding irregular employment, in general it means hard work, transport, carrying things in old houses that don't have an elevator. Work in the garden, cleaning, and agriculture outside of Vienna. For women it's cleaning, because not all Austrian women want to do that. For Polish people, it's construction sites. Turks don't like that, only if they have to, otherwise they are 
more engaged in small-scale catering and trade. Poles and Slovaks are easier to find for hard work. (Male respondent, Poland)

In addition to this, irregular work is most often found where the chances to detect irregularities by inspectors are limited. In the construction sector, this is said to be in the countryside and at big construction sites, as the following quote exemplifies: 'Most of the jobs are outside of Vienna. Often, I also worked on very big construction sites' (Male respondent, Poland).

\section{Actors involved}

The organisation of work and the involvement of various actors are very complex in the construction sector. Generally, one can distinguish between small-scale, informal jobs, often in private households or for one private employer, and large-scale, official construction projects. For the latter, projects are assigned in the course of official competitions the lowest bid gets the job. Competitors are mostly big construction companies. Afterwards, projects are commissioned to a number of smaller companies, so-called subcontractors. Those subcontractors redistribute work to other subcontractors, going down to so-called 'single-person enterprises', consisting of only one self-employed person as the name suggests. Consequently, projects are divided into smaller units, in the end leaving one company or even one self-employed person for one specific task on the construction site (e.g. plastering walls, installing floors).

Whether or not the work is performed in compliance with the law is no longer the responsibility of the principal. From a legal point of view, he or she is not responsible for any irregularities that take place on the level of hired subcontractors, although at the time of writing there were discussions of changing the law in this respect. The delegating and redelegating of projects to a long chain of actors, who are again distributing and redistributing different tasks, makes it difficult to identify the responsible employers involved in the case of fiscal or worksite inspections. In this environment, the door for circumventions of, and noncompliance with, legal regulations is wide open.

Due to the allotment of projects along a chain from principal to ordinary employee, so-called 'mediators's become key persons in the mediation of work by serving as intermediaries between employers and workers. Mediators are persons who organise work for themselves and others for money. The scope of their activity ranges from mediating work for colleagues and organising labourers for an employer to serving their own labour needs as employers and carrying out projects directly. The difference between mediators and reciprocal mediation of work between colleagues and friends is that mediators demand a 
monetary compensation for their mediation. In contrast to transnational mediation services such as care agencies, mediators in our interviews almost exclusively acted on the national, mostly even on the local level of the labour market.

For the most part, mediators themselves are acting as a 'single-person-company', directly taking the money for the projects from the principal employer and then redistributing it to 'their' workers, keeping about one-third of the money for themselves. Working for a mediator offers a significant advantage because the mediator takes over the permanent need to look for work and thus disburdens the single worker. In contrast to that, working for a mediator can also mean losing control over one's autonomy. Thus, some workers prefer to organise their own work, provided that they already have enough contacts to employers on their own, be it private persons or company owners.

\subsubsection{Construction: Recruitment structures}

As was shown above, not only informal players such as family members and friends are essential in finding a job, but one also needs to gain access to more formal players, such as employers or mediators. The following persons can thus be key in successful job seeking: I) family members and colleagues who have already been working in Austria for some time in a given enterprise, with more information about working possibilities; 2) employers; and 3) mediators who refer work for others and for themselves. At the time of entry, migrants only have access to limited networks. Those 'starting points' have a decisive impact on how recruitment networks can be further developed and extended over time.

\subsubsection{Initial recruitment strategies}

Some migrants already have contacts to key persons before coming to Austria, either because they were recruited by an employer directly in their country of origin, one of their colleagues happens to be a mediator or, as is most often the case, a job was organised via family members before arrival. On the other hand, job prospects, mostly made by colleagues before migration, often turn out to be not as reliable as expected, so that migrants may face a situation without a job or accommodation upon arrival in Austria. In such a situation, knowing people who know where to look for a job is also very crucial.

Colleagues and friends are an important resource to find a job in the initial period of employment, in 'hard times', and also as help for one's occupational career. The mediation of jobs between colleagues is usually free and based on reciprocity: first you help your colleague, and the 
next time he will help you. Often, colleagues share bigger projects that cannot be done alone with others, expecting they will then do the same for you.

There are places and strategies to find work in the construction sector that are especially important for 'newcomers' on the labour market persons who have not yet established contact with key individuals. In big cities, there are special places for recruitment along roadsides (the so-called Arbeiterstrich) where employers pass by to recruit workers, mostly for jobs in private homes. These places are found in front of the branches of the Austrian labour market service, home improvement stores or refugee camps (e.g. Traiskirchen). Many workers gather in such places especially in the morning, waiting for potential employers to come. The chance of finding a job there according to interviewees lies at an average of 50 per cent, and decreases as the day goes by.

Those who are looking for work on the roadsides are either new in Austria, low-skilled (in regard to previous experience in the construction sector) or have little knowledge of German. Mediators also use the roadsides to recruit labourers, but stress that it is the wrong place for hiring craftsmen, as mostly inexperienced migrants gather there. Consequently, the hourly rate that is paid there is lower than for other jobs. Jobs that are offered there are mostly very small, short tasks for informal employers in private households, ranging from work for a few hours to some months. An irregular Polish construction worker remembers his first time in Austria on the roadsides:

It was not that easy, completely without German of course, but it worked. To pay the rent, the weekly metro ticket, food, I had enough in the beginning. Employers pass by there and ask whether one wants to do this work. I could say a few words. (...). There are those people who only know very little German. But to get a job, that's enough. (Male respondent, Poland)

Due to the low efficiency of newcomers' recruitment strategy, looking for work on the roadside must be complemented by other plans of attack. In addition to advertising services in newspapers (a strategy that was reported to be totally unsuccessful for those without a work permit), establishing contacts at ethnic meeting points like the Polish church or mass dwellings, people make use of another search/recruitment strategy that was labelled 'Von Tür zu Tür gehen' ('going from door to door') in our Delphi survey. Migrants just walk or drive around to construction sites (or private houses with construction material lying in front), and they ask if there is any work to be done. Another Polish worker tells about his experiences: 
Sometimes we were just driving around and when we saw construction material lying in front of the door, we just asked for work. No matter if it was a private house or a business, we just asked. Once we asked for work at a villa and then we spent the night in our car in front of the house, and the next day we worked there. We got something to eat there and we built a garage. (Male respondent, Poland)

\subsubsection{Modifying recruitment strategies}

Since the jobs found through these recruitment strategies are of low prestige ('unskilled', 'inexperienced') and are miserably paid, migrants try to widen their social contacts with every project they get in order to climb the occupational ladder. The possibilities to find work increase with an increasing number of contacts. Telephone numbers of colleagues and employers are collected continuously. The most important strategy in widening one's working possibilities is getting recommendations from colleagues or former employers. As one migrant confirms: 'People have relatives, acquaintances and family. If you have done well once, word-of-mouth recommendations are the best propaganda' (Male respondent, Poland).

Still, establishing as many contacts with employers as possible is especially important for those workers who work 'on their own' - this means that they are not working for a company or one specific employer, but are continuously organising new private small-scale jobs. In this case, one does not depend on an intermediary and has a lot of autonomy, but the mostly short-term character of the jobs means that one has to keep looking for new jobs. Hence, looking for work and adapting one's recruitment networks takes a considerable amount of the migrants' time and energy.

As also in other sectors, at the beginning of working life in Austria, recruitment contacts are by and large made up of co-ethnics. Also employers are often looking for workers of the same origin, and are also establishing recruitment networks with their country of origin. By means of advertisements in Polish newspapers or the cooperation with somebody who organises workers directly in Poland, they try to hire craftsmen or other workers, often under the precondition or with the prior knowledge that the employment will be irregular.

There are certain resources that strengthen the position of employees in the eyes of their employers. This can be language or other specific skills needed in the given sector. Although 'one can always find something' in order to facilitate job seeking and get access to better jobs (bet- 
ter working conditions, better payment, more security, etc.), one needs some key resources.

In addition to language, sector-relevant qualifications facilitate job seeking. Most of the construction jobs performed by irregularly working persons are low-skilled activities that can be learned quickly. Work is mostly restricted to manual and physically demanding occupations. Therefore, formal qualifications such as education and certifications count less than capabilities in determining one's career - experience, flexibility and versatility are key qualifications. When looking for work, people are not asked about their formal qualifications, but about their capabilities. Knowing how to plaster a wall or install a floor determines whether they get the job or not.

It's difficult to find work here, especially if you only know how to do one thing. Me, for example, I'm very versatile: I know how to tile a floor, I'm an electrician, and I know so many other things. That's why I always find a job here, but if somebody only knows how to do one thing, then he won't make it here. You have to be extremely versatile. It is very difficult. (Male respondent, Poland)

Most of the workers told us that they had no idea of the tasks they had to perform when they first came to Austria, but they all acquired specific skills in the course of their employment and thus became 'experts with time'. Migrant workers assess the acquisition of know-how very positively. 'Learning by doing' does not only refer to the tasks performed, but also to language, which is mostly learned when talking to colleagues. Increased experience also improves the bargaining position of workers towards their employers. Thus, a man who has been working in Austria since I990 can gradually make demands and enforce them as well:

He only wanted to pay me eight euro an hour. I said I don't work for less than ten euro because I already have a lot of experience, and he should stop the car and let me out. And then he accepted the ten euro, but the others have to work for eight euro. (Male respondent, Poland)

\subsection{Construction: Forms of irregularity and working conditions}

As a general feature for all sectors and at all levels of occupation, ranging from ordinary workers to self-employed individuals, there are only oral contracts, if not pseudo-contracts that do not give an account of all activities actually carried out. Oral contracts cannot be checked by any- 
body from outside and thus do not give any guarantee of compliance with workers' rights or working standards. This means that nothing can be taken for granted. Irregular working conditions can thus imply irregularity in all respects, ranging from lack of insurance and other benefits to violation of workers' rights to insecurities concerning payment, accidents, etc. Not having a written contract results in great pressure on irregularly working migrants who have to put a lot of effort in keeping their jobs.

Our illegal construction workers have to work much more accurately, because we only have oral agreements over working conditions. If the principal employer has any complaints, he can afford not to pay. (Male respondent, Hungarian entrepreneur)

Aside from this general characteristic, irregular employment in the construction sector takes on various specific forms. First, there are people who are working without any permit (neither work permit nor residence permit). Migrants without any permit are mostly working 'indoors', either in private homes or on bigger construction sites as soon as the doors are installed.

On open construction sites, only those people worked who were already legal. When work was advanced so far that the doors were already there, we could work there enclosed. (Male respondent, Poland)

In the last few years (according to migrants' assessments since about 2000), there has been a shift from being employed completely irregularly to being employed pseudo-regularly or semi- regularly. As many migrants claim, companies are employing workers without any permits less and less because of an increase in worksite inspections. This development could not stop irregular work of migrants, but has resulted in an increase of circumventions of legal regulations. Those circumventions are often hardly traceable legally speaking, as was described above. 'Pseudo-regular' forms of employment aim at circumventing regulations on taxes, non-wage labour costs and social insurance dues, and try to keep employers' responsibilities and duties as minimal as possible. The main characteristic of pseudo-regular or semi-regular forms of employment is that employees have some kind of access to the labour market (as self-employed persons, part-time employees, etc.), but their actual working conditions do not comply with the respective legal regulations.

The first of these pseudo-forms is the insufficient registration of employees, meaning employment in a company and possession of a con- 
tract that falls short of indicating the extent to which one is actually working (e.g. having a part-time contract but working full-time). Part of the money is thus paid according to tax and social insurance regulations; the other, much larger, part is paid in cash. This practice of insufficient registration is not only restricted to the employment of nonnationals, but seems to be a general feature of construction work.

I have never met somebody who was registered for I,500 euro and also got this amount. That simply does not exist. It is like this in the entire construction sector. And I really have a lot of experience, really! (Male respondent, Poland)

Another young migrant does not seem sufficiently informed about the compliance of his working situation with the officially registered working hours. As long as there are no problems, he's also not interested in it: 'Eh...nine hours I am allowed to work, but how many hours I am registered I really don't know. But I am registered, I think, for 30 hours. In any event, anything goes' (Male respondent, Kosovo).

Circumventions of regulations on self-employment are the other considerable part of irregular work in the construction sector. To circumvent regulations on self-employment under the transitional regulations (see Section I.9), employees and their employers often use trade licences. Often, such trade licences are registered for another trade as the one actually practised. Another very common way to circumvent the Foreign Employment Law is to subcontract to 'self-employed' migrants, although the character of their work as employees would still fall under the regulations of the Foreign Employment Law. In the case of inspections, employers and 'employees' are able to produce official documents. Lately, media has reported intensely on such forms of employment in the construction sector, generally referred to as "pseudoself-employment' (Scheinselbstständigkeit).

In addition, despite restrictions on the 'posting of workers' (see Section I.9), foreign entrepreneurs equip their employees with trade licences in order to circumvent registration procedures dictated by the Foreign Employment Law.

Thus, in whatever way, employers try to find the cheapest way to employ their workers quasi-regularly:

I have a trade licence for cutting wood, because when I want to get a trade licence as a carpenter I would need an official master's examination certificate. The fees are also cheaper this way. That's why I have the trade licence for cutting wood. The boss always finds the cheapest alternatives for minimal costs. (Male respondent, carpenter from Poland) 
Another worker got a trade licence upon his boss' suggestion, so that he would be protected in case of worksite inspections: 'We have it in case we get inspected. One-third of the bills get billed on the trade licence, it is only a matter of form. It was our boss who proposed this possibility to us.' (Male respondent, Poland).

While equipping employees with trade licences protects employers in case of inspection, gives their companies the appearance of 'legality' and does not produce many responsibilities for them, this strategy is far less advantageous for employees. A substantial disadvantage for migrants is that the monthly administrative costs of about I70 euro for registering a trade license have to be covered exclusively by the workers themselves, while their salary does not increase. Their legal status is not improved, either. Workers with trade licences often do not know that having a trade licence does not automatically regularise their work when working for an employer, as this statement indicates:

Everything is legal, only the small worker in the lowest position has to pay the I7o euro out of his own pocket. That's a minus the only plus is that it is legal. (Male respondent, Poland)

\subsubsection{Payment: Amount, form and time of payment}

Irregularities concerning payment are another major problem irregularly employed migrants have to face in the construction sector on a daily basis. Irregular work does not offer any guarantee in terms of amount and time of payment or even in terms of being paid at all. Most of our interviewed workers did not get paid on time and were not paid as much as had been agreed upon before. While the amount of payment is generally agreed upon in advance, one has no guarantee that this agreement will ultimately be adhered to.

Another problem is that people who work illegally to 95 per cent don't get their money as was agreed. Either much later, or only part of what was agreed on. (Male respondent, Poland, 'mediator')

Payment is generally agreed upon before the job starts, often not leaving the worker much room for negotiation. Not only the amount is determined, but also whether the worker will be paid per hour or per unit of production. Being paid per unit of production was considered preferable by interviewees, as the work performed can be demonstrated to the employer exactly, reducing his chances of defrauding the worker. The unit of production rate varies according to the kind of occupation (easy and fast or difficult and slow) and on the individual speed of the worker himself: 
When I am working per unit of production, I get two euro per square metre for plastering and nine euro per square metre for installations. For this first job, I had to do the plastering of I2O square metres in two days, and for that I got over 200 euro. That was a good job. (Male respondent, Poland)

Generally speaking, the amount of payment depends on a lot of factors. Experience and capabilities define which kind of work one can get: for those looking for work on the Arbeiterstrich, payment per hour only rarely exceeds five euro. In case of recruitment by an employer or mediator, hourly wages are usually a bit higher, around eight to ten euro. This is due to the fact that such people are mostly hired because of their skills and thus have a better negotiating position. In addition to learned trades, formal qualifications also influence the price of a worker. Craftsmen get paid better than unskilled labourers, although there is no guarantee for that in irregular construction activities. In spite of capabilities and qualifications, the payment for newcomers is generally lower in the beginning, even when they possess certain qualifications: 'In Austria, as bricklayer you get seven or eight euro per hour, in the beginning, six euro' (Male respondent, Poland, construction and agriculture). Another worker states:

In the beginning, I got 50 Schillings [about 3.50 euro], today you maybe get around four euro. But it hasn't changed much; when somebody starts working now, he won't get more than five euro. (Male respondent, Poland)

As a result, experience is not only decisive in regard to capabilities, but also in regard to knowing how much one's work is 'worth'. The bargaining position of workers towards their employers thus improves over time. Nevertheless, an increase of payment over time is not assured for irregularly employed migrants. Even when working for the same employer for a long time, they almost always have to fight for better payment. When they finally achieve their goal, they have to put more effort into their work, as higher payment means higher expectations on the part of their employers:

Payment has increased very slowly. We therefore had to beg our boss, force him, threaten him to leave the firm. If he then paid a bit more, we at the same time had to work more efficiently or to pay for our work clothes on our own. (Male respondent, Poland) 
In general, employers can do what they like with the salaries of their employees. Automatic deduction of pre-payments from future salaries is a very common practice among mediators, for example, to cover food or accommodation costs.

In the beginning, he just deducted I,000 Schillings [about 700 euro] for the flat. You could not do anything about it, because he threatened us with the other thousands of people who are standing in line for our job. (Male respondent, Poland)

Nevertheless, lower income is accepted when the employer provides additional services like lunch, housing (needed when the job is out of town) or sanitary facilities. Such services are an important indicator as to whether the employer cares about his employees' working conditions, something that is very much appreciated, even if it occurs only rarely.

\subsubsection{From unpaid wages to 'pseudo-companies'}

Due to frequent job changes, especially for those who organise work on their own, migrants cannot count on a fixed amount of money per month. Unforeseen interruptions of working activities mean an interruption of income. While regular workers continue to receive their wages even in cases of illness or accident, irregularly employed workers simply cannot afford to get ill, go on holidays or visit their families for too long. What's more, withheld payment is another major problem for construction workers. The calculations of one worker who does odd jobs demonstrate the unpredictability and insecurity of payments in an irregular working situation as such:

First week 70 hours, second week 70 hours, third week 44 hours, fourth week 44 hours for one and the same employer. In sum, for seven euro per hour, this would make I,750 euro for one month of work. First I got paid roo euro, then ten, twenty, fifteen and again twenty euro, then 300 euro. In sum, only 700 euro. This was an Austrian, you should really make a black list of those employers who treat you this way. (Male respondent, Poland)

This account exemplifies another big problem in irregular construction work: irregularities in payment are not only due to frequently changing jobs, but also to inconsistencies and fraud on the part of employers. Being cheated in one's wages far exceeds late payments. Cheating in wages ranges from occasional cheating on a small scale to criminal 
and planned fraud by companies, also known as 'pseudo-companies'. The extent of cheating can range from not paying part of the income to entire monthly wages.

The timing of payment is agreed upon in advance between workers and employers. Irregular workers are usually paid weekly, every two weeks, monthly or when a given job is finished. Generally speaking, migrants explain that the later they are paid, the more uncertain they are to get paid at all. As a result, migrants mostly reject monthly payment plans:

Monthly payment is okay only when you're employed regularly, not when work is irregular, because if something happens to him [the employer], I will never see my money. (Male respondent, Poland)

Due to the very short duration of daily jobs on the Arbeiterstrich, labourers and employers cannot develop a relationship of mutual trust. As a result, one has to be paid daily: otherwise, 'you will never see your money'. However, the above-mentioned example suggests that payment generally is divided into very small sums, leaving some claims partly open. Consequently, most workers demand a partial payment after one week of work to check the employer's reliability. But this strategy cannot prevent cases in which employers pay out only part of the money, never the whole sum that was agreed upon, as in the example above. Inexperienced, young workers are especially in danger of being exploited by fraudulent employers.

He [the employer] takes young people, agrees on I,500 euro but only pays them 300 euro, promising to pay the rest in two weeks. But then he says that he has no work for them anymore. And they never receive their money, and he finds himself some new idiots. (Male respondent, Poland)

The more intermediaries there are between the worker and the principal employer, the higher the risk is of being cheated. When doing informal jobs for private persons, the risk of being cheated is relatively low, while it is higher when working for a mediator or for an employer who is involved in bigger public projects. While subcontractors are dependent on regular payments by their principals, workers are the weakest link in the chain as they are dependent on the reliability of all other parties before them. If the first principal does not pay because of bankruptcy, etc., subcontractors and workers may lose great sums of money, while in the case of cheating by subcontractors and sub-subcontractors, only workers have to bear the costs. This cheating in wages can extend 
into organised criminal activities. So-called 'pseudo-companies' (Scheinunternehmen) accept projects from bigger companies, money for their services is transferred to them, but they disappear, declare bankruptcy, etc., before paying out the money to their employees:

...he is a cheater. He takes on projects from big companies, has us do the work and then does not pay the workers. And we are left out in the rain. (Male respondent, Poland)

Some migrants state that cheating in wages generally has increased in the last few years, making irregular employment less and less profitable for them. While migrant workers generally consider the risk of cheating in payments to be very high, they see the highest risk when working for ethnic employers. This does not mean that Austrians are not involved in fraud, but it seems that the number of ethnic subcontractors in the construction business is at least as significant.

I would never work for a Pole again, also not for a Yugoslavian. That was for free. Never again! They did not pay at all, or only Io per cent. That happened a lot of times. (Male respondent, Poland)

\subsubsection{Working hours and worker-employer relations}

Generally, construction activities do not imply fixed or regular working hours and overtime seems to be standard. However, such irregularities are not only restricted to irregular migrant work, but are rather common in construction work as a whole. Projects have to be finished under time pressure and factors like weather influence possible working hours. The difference from regular work lies in the fact that those working irregularly always have to be at their employer's disposal regardless of whether it is weekend, evening, etc. The closer the relationship between employer and worker is, the more enhanced this 'being available' becomes. As links between employer and worker increase, so does the worker's dependence on his or her employer. When the employer is not only the provider of a job, but also the proprietor of the worker's accommodation, possibilities of affecting the migrant's life increase. Some employers in the construction sector are also active on the real estate market, buying old buildings, renovating and reselling them. To make additional profit, they house their workers in buildings that are very much in need of renovation. Consequently, the dependency of workers on their employers increases, as now employers are needed for both work and housing. In such situations, the fine line between work duties and voluntary help grows increasingly blurry. The 
boss can come by at any given moment just to say that he needs somebody to 'drive a nail into the wall'. It is very difficult to reject such requests. Some employers even make use of their powerful position and deliberately hassle their workers:

Sometimes, the boss comes by exactly when we want to go home. Then he comes and checks our work and we have to stay for another half an hour. No questions asked, and unpaid. (Male respondent, Poland)

Another difference from regular work is the range of instability and unpredictability regarding working hours. While some days are filled up with projects, others are totally free. This especially applies to those who organise informal jobs on their own. However, sometimes such flexibility regarding working hours is also assessed positively. In contrast to rigid regular working hours, irregular employment enables migrants to allot their time more autonomously. Nevertheless, this apparent autonomy must also be put into perspective:

When I want to go home, I go. I don't have to be at work from 8 a.m. to 5 p.m. I work about ten hours a day. And when I don't want to work anymore, I say, 'I'm going now.' The employer can say, 'No, you have to keep working.' Okay, then I have to stay. But I haven't had any problems for a few years now. (Male respondent, Poland)

The dependency on employers as providers of work and money dominates an irregular working situation. A conflict between employer and worker can mean the loss of one's job. This is true even for conflicts about workers' rights that are otherwise taken for granted, like the right to holidays or protection against random dismissals, not to mention paid leave. As most of the workers are 'replaceable', the employer can treat them as he wishes.

With holidays it is problematic - we can only go on holidays when the boss goes, too. You cannot make any plans. Apart from this, he only rarely accepts requests for holidays. If somebody demands a holiday, he can even fire him. Holidays are of course unpaid. (Male respondent, Poland)

For workers who have no fixed employer and are free to manage their own time, taking holidays or working less means an interruption of income for the period of time that they are free. Holidays are a luxury 
and, in almost all cases, involve visits to the home country, to see the family or deal with things that need to be done there.

\subsection{Catering and tourism}

\subsubsection{Catering and tourism: Sample description}

At the time of the interviews, twelve persons (nine women and three men) out of 50 were working in a hotel, restaurant or a bar either fulltime or as a side occupation for some hours only. Respondents mainly originated from Ukraine, Poland, Slovakia, former Yugoslavia and the Czech Republic.

Of these individuals, six had entered Austria prior to the EU enlargement of 2004 and the six others had followed sometime between 2004 and 2006, mostly with the idea to stay in Austria for a longer period of time and/or to find work. Only four of the interviewees were older than 30. The youngest person interviewed in this group was a $2 \mathrm{I}-$ year-old woman.

By the time of the interviews, only three interviewees had all rights to access the Austrian labour market, while nine others either enjoyed EU mobility rights, were holding tourist visas or were in the asylum system and therefore did not have access to the Austrian labour market.

The sample did not include persons currently working on the basis of a seasonal contract. We therefore had to rely on respondents' experiences living and working in Vienna and in the federal state of Tyrol. Tyrol is one of the more touristy areas of Austria, so seasonal work is consequently of major importance.

Generally, the respondents' educational level was above average (e.g. higher education certificate, university degree, trained librarian), or they had sophisticated skills as generally required for careers in the branch, such as training in catering and confection, a diploma from a private school for tourism and hostelry or training as a waiter. Only one had dropped out of nursing school and another stayed in school only as long as was required by law.

Accordingly, those who had finished their educational training had already started to work in their countries of origin and/or other countries as an educational psychologist, translator, a secretary in a large company, a tailor, a retail salesperson, a cook or a waiter in a big hotel.

From my region, not so many people go abroad, but a lot come from Western Ukraine. I know a lot of people here in Vienna from there. This is a bit sad because many high-skilled people like engineers or doctors are coming here illegally. For the most 
part, they are working on construction sites or as cleaning ladies. This is a bit sad. (Female respondent, Ukraine)

\subsubsection{Catering and tourism: Structural features and specific actors involved}

Tourism, hostelry and catering possess certain characteristics that can be identified as facilitating irregular employment. They involve activities of a temporary nature, require only a low qualification profile and secondary knowledge of the German language and do not call for intense initial training, so a high rate of labour turnover is easily possible (Lederer \& Nickel I997). In addition, businesses exclusively run by certain ethnic groups (e.g. restaurants) are under strong suspicion for systematically violating working standards and the non-registration of their workforce.

Besides the enormous number of potential employment locations, the major characteristic of the branch is that apart from seasonal work arrangements, working in restaurants or bars is more easily compatible with other jobs, obligations or interests as demonstrated by our sample (e.g. studying). Working hours are usually flexible and organised in shifts with a tendency towards night work, which makes it easier for employees to adjust other obligations and interests to their working hours.

\subsubsection{Catering and tourism: Recruitment structures}

Particular social networks that migrants usually rely on include family and friends, current or former colleagues or the ethnic community. In one way or the other, all respondents used these networks to identify possible employers. The complexity and roundabout ways of finding work are well explained by the following examples:

I always found my jobs through colleagues and friends. And there is my family. My uncle, my mother's sister, my cousin they are all here. And they all work in the same place. So they would ask around: do you need a waitress or dishwasher, et cetera? Unregistered work, of course. This is how it goes, the contact between people and employers. (Female respondent, Serbia)

It was very difficult for me to find something by myself. It was always easy when I knew someone who knew the employers. When I tried to get in touch with employers on my own, it was very difficult. Only in one case did I find a job by myself, but this was just luck. All other jobs came through friends. (Female respondent, Slovakia) 
Respondents noticeably pointed to the importance of colleagues. Colleagues become friends. Colleagues not only know someone who might be in need of a worker, but former colleagues would sometimes open up their own business after some time and attract others to work for them.

Some of the respondents, mostly those who already had contacts, broader experience or better knowledge of the German language, highlighted that they themselves act as intermediaries and help others to get a job. However, recommending someone to a familiar employer also harbours certain risks. If the recommended person does not perform well, it would also reflect on the mediating person and could tarnish their relationship. For potential career opportunities, this is definitely not helpful.

First, my acquaintance didn't want to give me the employer's number, as we didn't know each other so well. She had already recommended someone who ended up performing badly. And, you know, this reflects on you. (Female respondent, Poland)

As already mentioned above, in irregular employment - even more than in regular employment - building up a good reputation and staying on an employer's good side are indeed of specific importance. Even in cases of unfair treatment, short-term employment or fully unregistered employment, it may be worthwhile to perform well and to keep in touch with the employer. One day, when a migrant's status is fully legal, he or she can always come back. Already familiar with the employer, the migrant may then get full and legal employment or would at least be recommended to someone else in need of irregular labour.

In all work arrangements, the employer should be satisfied with my performance. And wherever I have worked unregistered, now that I have documents I can go there and everybody welcomes me. For me, it's really easy to find work. Unregistered, registered, I don't have any problems. Also with the company I'm currently working with, I had worked unregistered before for some time. (Female respondent, Serbia)

Formal job agencies such as recruitment agencies and national and regional employment agencies are of importance for accessing jobs especially to those persons who have a legal residence status and access to the Austrian labour market, such as those holding a work permit, those working under seasonal contracts, self-employed individuals, asylum seekers and students. 
In our sample, recruitment agencies did not play a decisive role in accessing irregular employment in catering and tourism, but this does not mean that they are of no importance at all. Personnel are often formally recruited for seasonal employment, especially in the important tourist regions.

But also in cases in which the AMS may not be able to directly help or assist due to the lack of a residence permit or work permit, potential workers would at least use the infrastructure of its regional branches, as the example of a Czech worker illustrates. Already some time ago, when he had a job in the agricultural sector in Burgenland, he had established contact with the regional branch of the national employment agency. Now jobless and lacking a work permit, he would nevertheless use this connection. As he stated, he had called regularly and asked whether it would be possible for him to get a seasonal work permit: "They said, "Mister, you have to do this yourself. We cannot help you. Go back to the Czech Republic. You have to work." Knowing that friends and family had worked in Tyrol, he decided to also try his chances there, nevertheless using the infrastructure and the connection to this regional agency:

At the regional AMS, I collected job offers for Tyrol. Going through the offers, I finally decided to go there, just like this, without discussing or reviewing much, to just go there and try by myself. I used the computer advertisements in the regional employment agency. Since the I990s, they have established a computer system that would display job offers everywhere in Austria. I would then call every single employer from a telephone booth myself, that's the story. [...] After 40 or 50 calls in hotels and restaurants, the fiftieth employer would say, 'Come, we need someone, let's try.' It was interesting. After two minutes of talking, they would decide. You don't need to negotiate much. (Male respondent, Czech Republic)

In this and other narratives, calling a potential employer was presented as a very effective strategy, especially for seasonal work, regardless of whether a potential employer was identified by means of the Internet, newspaper ads, family, friends, colleagues or former employers. Especially in cases where the necessary preconditions for regular employment are missing, direct and personal communication was regarded as the best way to sound out potential employment.

Without a work permit, however, it is very difficult to find an employer who takes the risk of employing someone totally without registration, as employers can also employ students or seasonal workers 
with a formal contract (but not necessarily according to the agreed working conditions).

If you have a job interview, they ask you about your documents and you have to tell the truth. And by the time you start explaining why you don't have documents and how they can help you in organising a permit, the whole story is already finished because no employer wants to take the risk, even if they really want you to work for them. Even if they start arranging it, it is not clear if you'll get it. The whole procedure simply takes too long. (Female respondent, Poland)

The often only temporary nature of irregular employment and the need to have several jobs at the same time demands a high level of flexibility. Finally, in irregular employment, one cannot be too selective: 'It always worked out, but only temporarily. One should not be too picky' (Male respondent, Czech Republic). Some respondents explained that looking for a job requires at least as much time as they actually spend working. Therefore, working and looking for a job often have to be performed simultaneously.
Although I'm really experienced in finding jobs - I have so many friends, the labour agency, the Internet, the newspapers, et cetera. - you spend the same amount of time looking for a job as you do actually working. In the morning I'd look for jobs, and in the afternoon and evening I went to work. And it goes on like this. (Male respondent, Czech Republic)

In this context, it was also highlighted that it is much easier for women to access irregular employment in tourist regions than for men. According to a Serbian woman: 'For women, it is always easier, for men it is much harder. In a hotel they need several nannies: two, three, six, seven. But they only need one dishwasher.'

Looking for work becomes easier over the course of time, as respondents improve their knowledge of German. Without German, however, they are more reliant on friends and family, as well as on ethnic employers. As mentioned above, however, working in ethnic businesses is often only considered as a temporary alternative:

It took quite some time until I found a job, most probably because of my bad German. Then I found a Polish pub on the Internet. I called and had the interview, presented myself, and it went fine. (Female respondent, Poland) 


\subsubsection{Catering and tourism: Working conditions}

\section{Forms of irregularity}

As in other sectors, employers in catering and tourism may also draw on certain sector-specific 'traditions' when employing irregularly. Documented cases confirm the violations of regulations for temporary work (seasonal employment contracts), part-time employment and the systematic violation of general labour standards.

In catering and tourism, one of the most established practices to circumvent regulations and standards is the non-registration or the registration of workers below the social security (and tax) threshold. ${ }^{6}$ In this scenario, the contracts of employed personnel state they receive the minimum income only. In reality, however, much more is disbursed in cash and therefore remains also untaxed. As the following example of a Slovak woman shows: 'Payment was okay. Once a month, I got my money transferred to my account, and the non-registered hours I got in cash.'

Besides tax evasion, systematic violations of regulations for seasonal workers seem to be very common. Employment contracts are 'adjusted' to seasonal reality, which means that workers overstay the time of their official registration, are employed between seasons without a contract or have to work significantly more than agreed upon in tourist peak times.

In our sample, for those respondents who were not registered at all, working and payment conditions were agreed upon verbally. In the best case, non-registered employees would get net salaries equal to those of registered employees: 'Just cash in hand logically. Employers don't want the cash flow tracked. Everything was in limbo. But I had a room, food, work and a monthly income' (Male respondent, Czech Republic).

As mentioned above, one established way to register someone below the social security threshold is the registration of workers as students (provided the concerned employees are registered at an Austrian university) for a maximum of ten hours a week and a maximum income of 333.16 euro a month (2006 level). In this arrangement, social security payments are in the hands of the respective student him or herself. A Polish female student who reflected on the registration practice in her workplace provided a very good example:

The waiters aren't registered either, or only as students - below the social security threshold. Me, I'm not registered at all, just like the other foreigners she employs. Of seven employees, only are registered. They're registered as students and they're Austrians. If she was inspected, she would just say she's trying them out and they started today, or something like that. That's it. And 
we also think she has connections and knows when someone would come to inspect, as normally she would not get away with something like this, right? And she earns a fortune by not paying any tax or social security contributions for all these people. (Female respondent, Poland)

\subsubsection{Irregularities concerning working hours and payment}

Although irregular working arrangements equally apply to the native workforce, immigrants are much more affected by these practices. Foreign employees either have to work harder than their Austrian colleagues for the same wages, or their wages are significantly lower. In addition, especially non-EEC nationals risk getting cheated or even physically attacked by their employers.

And then I had all these problems with payment! When you work unregistered, you can't do anything about it! I don't want to work in a kitchen anymore, maybe I just worked in the wrong hotel, but he beat me with the ladle, here on my leg! (Female respondent, Serbia)

Respondents reported that especially those employees who got their salary on a monthly basis worked much more than agreed upon (more hours or up to seven days a week) and without any kind of compensation. In a monthly payment arrangement, the lowest rate reported was 200 euro per month for a part-time job (which equals an hourly rate of approximately 2.50 euro). Nevertheless, if compensation was provided (either compensatory payment or compensatory time off), respondents perceived their working arrangements as rather fair by stating that due to their irregular situation, they are not entitled to health, social or pension insurance anyway.

In hourly payment arrangements, the rates ranged from five to ten euro per hour, and waiters would have their tips as well. Nevertheless, employees were cheated in the hours they had worked, which ultimately reduced their hourly payment rate.

They just calculated less than the actual hours I had worked. On their monthly salary confirmation sheet, they wouldn't write the hours to be paid. One day, I said that there must be something wrong, because I had carefully written down my actual working hours. Every month I got less and less. In the beginning when it was around ten or twenty hours, I didn't say anything. But then I decided to quit. It was really getting to be too much. I had 
worked 70 to 80 hours without being paid! (Female respondent, Serbia)

The same person also explained why employees might have good reason to be against hourly payment: 'Better I get a monthly salary. If you get 40 euro every day, you spend it easily. So she wrote down the days she didn't pay me and I got all the money at the end of the month' (Female respondent, Serbia).

\subsubsection{Several jobs at one time}

Irregular work demands a high level of flexibility on the part of workers. Irregular employment is usually of a temporary nature. Especially in certain seasonal work arrangements, it is mostly temporary and often only part-time. In order to make a living, workers therefore often need to be engaged in several jobs at the same time. Besides being highly seasonal, work in catering and tourism already provides a structure that may allow for several jobs. 'Part-time employment' gets a different meaning, as individuals may work at night and keep their days free, either to 'look for another job' or to do some 'small jobs' on the side. In our sample, all interviewees working in this field had at least two jobs or were trying to find a second or third job.

In the morning, I work in the hotel, unregistered. In the afternoon, I work in a private household, and on Sundays, in another restaurant. I'm commuting a lot. Before, I used to work eight hours in a hotel; that was easier. Now I do a minimum of twelve hours every single day. (Female respondent, Serbia)

Managing and organising several jobs at the same time was perceived as specifically difficult in cases where irregular employment is on a daily or even an hourly basis. Employers would call for work one day and cancel the next, so establishing a daily routine is difficult. Nevertheless, if such arrangements were 'small side-jobs', respondents did not see much problem with it, especially students who may have other sources of income or other priorities: 'I only do this when I can take time off. It's not worth the effort to neglect my university classes for an extra 60 or 70 euro a month, as I also have another job' (Female student, Poland).

Especially women reported that they were made into 'jacks of all trades' by the same employer: 'My job was to clean the rooms, but also to help in the restaurant and in the kitchen. And on Sundays, also in the restaurant bussing tables.' (Female respondent, Serbia). 
Furthermore, some employees would also take additional work on weekends. For the bigger hotels, this meant working as a chambermaid, helping in the kitchen and sometimes also as a waiter.

Respondents involved in seasonal employment and with one employer appreciated the usual practice of providing accommodation and food. One Czech respondent consciously looked only for those jobs also including a room, as he could save on the cost of living this way: 'You get a room, food and work!' (Male respondent, Czech Republic).

\subsection{Agriculture}

\subsubsection{Agriculture: Sample description}

Out of the entire sample of 50 interviewees, only seven (six men and one woman) were working in the agricultural sector at the time of the interviews. In addition to those, other interviewees had previous work experience in agriculture and could also provide valuable insights. Interviewees originated from Poland, Romania, Ukraine and Bulgaria.

At the time of the interviews, half of the respondents had the right to reside in Austria independent from their seasonal work permit, while the others only had a visa bound to the seasonal work contract. As agricultural work is mostly seasonal work, half of the migrants worked in the construction sector between seasons, while the other half returned home. While all workers were employed legally during the season (seasonal contracts as seasonal workers or harvesters), they mostly worked without contracts off-season.

Because of the difficult access to interviewees, who were almost all accommodated in a dwelling close to the farmhouse (see also Section 3.I), we could only reach migrants who had a seasonal work permit. Nevertheless, all interviewees were affected by irregularities in regard to registration, workers' rights and/or compliance to agreements in their contract.

All of the interviewees were between 30 and 40 years of age and, with the exception of one, all were either married or divorced as well as had one or two children in the country of origin. Most of the interviewees came to Austria after 2000 , but still before the accession of the EU-8 Member States in 2004. Most of the interviewed third-country nationals already belonged to the core workforce of their employers and were thus still able to get a seasonal work permit, a situation that was aggravated after 2004 due to the preferential treatment for EU citizens. Some of the men had previous work experience in the construction or industrial sector abroad, e.g. in Germany or Turkey.

All of the interviewees had vocational training, ranging from cook or baker to mechanic, carpenter and teacher. One even attended an agri- 
cultural school. Due to seasonality, seasonal work is also attractive for students who come to earn money during their holidays. In reference to his colleagues, a Polish carpenter said: 'Some people are in school, some do agricultural work, some work on construction sites as electricians, tile setters - specialists' (Male respondent, Poland).

\subsubsection{Agriculture: Structural features and specific actors involved}

Even more than in other sectors, the family seems to be the most important 'actor' in agriculture. As recruitment structures evolved mainly via mediation between relatives, those private networks continue to play a crucial role in the mediation of jobs. The informal development of mediation structures also leads to recruitment chains. If farmers need more workers, they often charge their employees with the responsibility to get new people from their village the next season.

Often it works like this: you start with two or three people, and they mediate the work among their family. You just take the brother, or the neighbours with you. That's how it has developed. (Farmer, Tyrol)

Seasonal work is most attractive to those who cannot afford to be absent from home for too long. Mothers or students thus often work as harvesters for some weeks, which enables them a small supplementary income.

Due to the provision of accommodation and social insurance by the employers, family networks are less needed for the organisation of social life in the region of immigration (e.g. housing, contacts to doctors in case of an accident). This situation clearly differs from the scenario of those in mediating jobs.

Because seasonal labourers do not change their employers as often as workers in the construction sector, for instance, having as many contacts to employers as possible is not considered important. Having contacts to employers is only important if someone wants to change his job.

There are indications in our interviews that also organised recruitment is taking place in the country of origin. Nevertheless, who those professional recruiters are and whether they require monetary compensation for their services remained unanswered questions.

\subsubsection{Agriculture: Recruitment structures}

Job seeking in agriculture follows very similar structures as in the other sectors. Family, friends and colleagues are crucial in getting infor- 
mation about and recommendations for jobs. The difference from other sectors is that recruitment for seasonal labour mostly happens in the country of origin, as visa and work permit are then issued in one. However, this has changed with EU enlargement, as EU citizens can stay in Austria as long as they wish, and thus can look for other jobs directly in Austria before or after their seasonal employment. Before enlargement, migrants needed a tourist visa to look for work, just as third-country nationals still do: 'I just came and found something, at first moonlighting' (Male respondent, Bulgaria). One Polish worker and his son also came to Austria at random. They had information from colleagues about regions with a high demand for agricultural workers, so they drove from one Austrian farm to another and asked everybody for work.

The first time I came together with my son. My son already knew some German and we looked for work. [...] This first time we only worked for two months, a little bit in the tree nursery, a little bit harvesting apples, but we had the telephone numbers for the next year. It was no problem to call and say that we would come again. (Male respondent, Poland)

Due to the importance of family networks in recruiting workers, it is often whole families working on one farm. A Romanian seasonal worker managed to organise a job for his wife as well. 'My wife is here, too. It's her first year here' (Male respondent, Romania).

Due to the unpredictability connected to harvests and weather conditions, recruitment takes place on very short notice. This is true for initial employment, but also for the core workforce, as employers can never make a binding promise of when work will start and whether they will get a work permit for their employees the next year. Thus, migrants often have to decide within days or a few weeks whether they will come to Austria or not. For example, one interviewee got the number of a local farmer from a colleague, called and came.

Another colleague says, 'Good firm, good work, do you also want to work here?' I call the enterprise, they say they need a chauffeur [to bring the vegetables to the supermarkets], and I come. (Male respondent, Poland)

Often, reliable workers are responsible for bringing additional employees the next season. This mediation is mostly done without asking for a return service, for it is more based on a system of mutual help. While one case showed how the employer of a Romanian worker, a small farmer, asked him whether he knew somebody else who would also 
like to be a seasonal worker and then take the employee with him, another interviewee described organising harvesting jobs for almost his entire village:

Those, who now come in the fall are twenty, 30 persons from me, from my village. [...] They are coming through me. For the lettuce and apple harvest. (Male respondent, Poland)

In addition to these informal recruitment structures, organised recruitment of workers directly in the country of origin also takes place. Indeed, a Romanian woman was told about a job at a Tyrolean farm by a friend of hers. This friend then knew another man who always would come to Romania to hire people for work abroad. Transport from Romania to Austria and back would be organised by bus. Another worker from Bulgaria has also heard about such organised recruitment structures: 'I know that there are such people who organise work, but me myself, I don't know anybody' (Male respondent, Bulgaria). Overall, informal recruitment structures seem to play a more decisive role in Austrian agriculture than organised ones, as the interviews indicate.

Over the course of time, migrants also get to know other working possibilities and other employers, and have the opportunity to change their job or even change to another sector. However, for seasonal workers who are in the country for only six months, have to work all day and live at the farmhouse, it is not that easy to look for other jobs. This is easier for those who remain in Austria after their seasonal employment, as the following example shows. Here, the important role of employers as a resource of jobs and the importance of making a good impression are stressed:

The work as bricklayer emerged later. I started with trimming trees and harvesting apples and then it got around that I could also work as a bricklayer. Now I have many contacts and it's good. And when people are content, then everything is okay. (Male respondent, Poland)

\subsubsection{Agriculture: Forms of irregularity and working conditions}

It seems that registration-related irregularities in agriculture have diminished in the last years, due to enlarged and professionalised company structures and also increased worksite inspections. In addition, seasonal labour arrangements were created to meet the demand for flexible, cheap labour anyway, which are considered to be one of the most important motives for employing irregularly (see Part 2 on the Delphi study in this report). Consequently, irregularities largely take 
place within the seasonal labour model and can be considered as an inherent part of it.

While interviewees indicated that they or their colleagues worked without any registration some years ago and are now registered as seasonal workers, there are indications that working without registration also occurs now, even if on a smaller scale. However, working without registration mostly seems to be limited to some days, while the employer is waiting for approval of the work permit by the labour market service or when work is continued after the official end of the employment contract. While it is not very risky for farmers in the eastern part of Austria to employ someone without a contract (and thus without social security) for several days, this seems to be too dangerous in the western part, as geographical conditions there are much more likely to lead to accidents.

Another difference in the handling of seasonal work resulting from the geographical situation is that farmers in the east of the country can make more use of the shortest-term contract for harvesters, as many of their workers are commuters from Hungary. The close distance renders flexible and short-term arrangements more acceptable than for workers who have to travel long distances every time they are hired.

There are also migrants who remain in Austria after the end of their seasonal employment contract and continue to work for the same employer or change to another sector in between seasons. In this manner, the legal or illegal status of employment is not fixed but is rendered interchangeable. For EU citizens, overstaying does not exist anymore; for third-country nationals, overstaying can have significant consequences, as one interviewee states. (At the time of the interview, Romania was not a member of the EU.)

If you stay longer than six months, you get problems at the border for not having a valid stamp. Some people also stay in Austria after those six months and work irregularly. I heard about a woman who worked irregularly in a hotel, was caught and prohibited from coming to Austria for the next five years. You don't have problems at the border except when you're working irregularly - then you have no chance. If you get caught, of course. (Female respondent, Romania)

On the contrary, EU citizens can come and go as they please without fearing severe consequences. One Polish citizen works six weeks a year as a harvester, gets social insurance, etc., and then returns to his irregular work in the construction sector. 
For six weeks legally [work and stay], then you have to return to Poland for two or three days and then you can come back again to work irregularly. (Male respondent, Poland)

Pseudo-self-employment as another means of circumventing registration was mentioned in reference to Germany. Self-employed 'lettuce pickers' or 'carrot packers' are reported to occur there in order to get around the limit of six-month employment, while such cases were not reported for Austria so far.

For those who have a seasonal work contract, accidents do not pose a problem as health and accident insurance are covered. For the time between seasons, however, all workers have to arrange for extra insurance, regardless of whether they stay in Austria or return to their country of origin.

\section{Q: What if you have an accident here?}

A: If it happens while I'm working irregularly, I have to return to Poland. When I'm here for the apple harvest, then I'm insured, but only for the time of harvest. That's short. This is my Austrian insurance. Otherwise, my insurance is in Poland. In Austria or Germany, the insurance also costs so much. (Male respondent, Poland)

Most irregularities occur in regard to working conditions. While regular access to the labour market is provided and social insurance is covered, violations of workers' rights and especially of working hours are very common, even if registered according to the rules. Generally speaking, the agricultural sector is characterised by flexibility in all respects. Working hours and workload depend on the weather and the time of the season, both of which cannot be predicted in advance.

Q: Did you agree on the maximum number of hours you were supposed to work?

A: No, because you cannot say how much is necessary for that kind of work on a farm. It varied. Sometimes you know: when it was raining during the week, then you have to finish some things on the weekend, also when it's raining. (Male respondent, Poland)

This indispensable flexibility results in the difficulty to check the compliance with working hours. All interviewees stated that there are times where they have a lot of work, while other days are nearly work-free. In 
sum, however, most of the interviewees work more than they are obliged to. While one interviewee is registered for 40 hours, he actually works 60 hours on average per week. The following man collected a lot of unpaid overtime while working for a winegrower in Burgenland:

I got 4.50 euro per hour. Ten hours per day, 6o hours per week. We worked each day except for Sunday. On Sunday, we could rest. (Male respondent, Poland)

Despite what this interviewee said about having Sundays off, most farms will not interrupt production flow for all workers on Sundays. Generally, seasonal workers have one day per week off, but they are not guaranteed a free weekend.

For those workers who come from countries that are further away, it is not possible to return on weekends or to see their family during the six months of employment. Getting holidays, whether that is one or two weeks off, depends on the good will of the farmer. While some workers are granted one week of holidays, others remain at their place of employment non-stop.

Agricultural work as such is assessed to be really hard work. Work in the field is considered to be exhausting and dirty, particularly for women. While women at horticultural farms are mostly employed for cleaning and preparing vegetables to be sold, in their initial phase of employment, women often have to work the fields as well. Interviewees very much appreciated the opportunity to shift to other in-house occupations such as the processing of vegetables or cleaning the house, and considered such moves a sign of occupational mobility. Thus, occupational mobility within the agricultural sector does not refer to an increase in income or an improvement of the contract, but just to an improvement of activities performed. As one interviewee stated, 'Work here isn't hard, except for work in the field'.

There also seems to be a decisive difference between working conditions on large and small farms. The latter is defined as one family employing one to ten workers. On large farms, occupations are exclusively piecework or paid per unit produced or action performed: 'On large farms, there is always only one kind of work to be done. I only picked strawberries or radishes', a Romanian seasonal worker recounted. On large farms, employers also have much less regard for their workers and their needs. Their only concern is to keep up the production flow.

The last few years, she was on Farm X. That was a bit, well... For example, work started at 4 a.m. Or to pick strawberries, she slept in the field for three hours. Everything was piecework. She got about six euro for one day. And when she came home, at 
about Io p.m., she cried and said, 'No, tomorrow I won't go there anymore.' (Female respondent, Poland, about her sister-inlaw working in Austria during her children's holidays)

Conversely, small farms help migrants to acquire know-how in agricultural production, as their skills improve every year.

In the beginning I only picked apples, no more. Then I learned how to trim trees for winter, and this and that. Now I can almost run a fruit farm - no problem, I can do everything. (Male respondent, Poland)

Working conditions on small farms are considered to be much more familial and fair. This is also due to the fact that employers and employees have to work together very closely. Even the employer works the field and everyone lives together in one farmhouse, so they must all get along with each other. Nevertheless, this also raises the degree of dependency of the labourer on his or her employer.

Whether small or large, farmers provide accommodation for their employees, as most migrants have no other accommodation in Austria and could not afford it with the income of seasonal labour alone. Due to the situation of farms on the border in the east of the country, they are again an exception to this practice, as many employees return home each day or have organised private accommodation in Hungary. For all others, accommodation is organised directly on the farm. For large farms, this involves mass dwellings with two to four persons sharing one room and only one toilet or shower per floor, as one Romanian woman reported - this all for a six-month period. Accommodation is not free: workers must pay between 50 euro and roo euro per month - no small price, considering their hourly income of around four euro.

There you only have very small rooms [about IO-I5 m], half as big as this one. In a group of four, two double beds. And you have to pay iıo euro per person. You have one bathroom with three showers and one toilet. About roo people live there. (Female respondent, Poland)

At small farms or family businesses, employees sometimes do not have to pay for accommodation. The lack of a monetary return service blurs boundaries between duties and help. One is always available and feels obliged to lend a hand in return. One of our respondents preferred paying rent to informal arrangements: 
I said like this: 'I don't want to live there for free, I want to do something for it.' I always did something additional, even when I worked for him. I couldn't help it. I feel better, when... Now I pay my rent and I am left in peace. (Male respondent, Poland)

Seasonal work in agriculture also extends to work in the vegetable processing industry. In those cases, most of the workers are settled in Austria, most are refugees, and they have to cover their cost of living on their own. This leads to the very low level of payment in seasonal work. Payment follows the collective bargaining wages for seasonal workers, currently set at 4.80 euro net hourly income for seasonal labourers, and a little more than three euro for harvesters. While employers are always free to pay more than this minimum wage, only few actually do so. Experience and specific know-how may qualify some workers for a higher salary.

A Bulgarian seasonal worker recalls a time when he was not yet registered as a seasonal worker. Firstly, working hours were not at all regulated, and secondly, only the work that was actually done was compensated.

The same as here: 3.60 euro per hour. I worked from 8 a.m. to 4 p.m. And if there was more work to do, we worked more, up to eleven hours. And if there was less work, we worked less. On rainy days we couldn't work in the field, so for those days we didn't earn any money. (Male respondent, Bulgaria)

Nevertheless, being cheated out of payment does not seem to be as frequent as in the construction sector, as one Ukrainian interviewee with experience in both sectors indicated. In his opinion, the close relationship with the employer and the already very low rate hourly income prevents employers from cheating in their employees' wages.

\subsection{Domestic services}

\subsubsection{Domestic services: Sample description}

Of the 50 migrants we interviewed, nineteen (seventeen women and two men) were currently working in private households. The respondents mainly originated from Poland, Slovakia, the Czech Republic and four came from Ukraine. Thirteen people had entered Austria prior to the EU enlargement in 2004 and six persons since May 2004. The bulk of our domestic workers were in their mid-twenties; seven respondents were 30 or older, three of them in their fifties. The younger women generally cared for children or worked as housekeepers; male 
and older caregivers generally cared for older people or people with a disability.

Given the underlying age structure, the marital status of the younger respondents was single with no children; only one young woman was married. Three of the migrants aged around 50 had children and were also married or in one case divorced. Two caregivers lived with their spouses in Austria.

Concerning the educational level of the six women and men caring for elderly or handicapped people, two had a high school diploma, another had finished nursing school in Slovakia and had his diploma recognised in Austria and the others had a lower education and no experience in health care before starting work in Austria. By contrast, all the young domestic workers had completed high school at least, some had already gotten a university degree in their home countries and most were attending university in Austria at the time of the interviews.

As for their residence and work status in Austria, university studies meant that the young women either, as students, had limited access to the labour market and a residence permit, or they had entered the country on an au pair contract. Concerning the domestic workers over thirty, one had married an Austrian and therefore had also gained access to the labour market, while another had a trade licence for a 'cleaning company'. In some cases, the women and two men also entered Austria on a tourist visa. Of the six caregivers primarily taking care of elderly or handicapped people, two had full access to the Austrian labour market, while the others worked without any working papers or registration.

The given age and educational structure in our sample is mainly a consequence of access to student networks and dormitories; it is not implicitly representative of the domestic sector. The high proportion of young, female migrants in childcare also reflects the persisting legal au pair framework that is directed towards this group of migrants. Women coming from Central and Eastern Europe, particularly Poland, who work in domestic services generally have an above-average educational background, as has been noted elsewhere (Fassmann et al. 2004).

\subsubsection{Domestic services: Structural features and specific actors involved}

\section{Reasons for irregularity}

One of the reasons for employing migrant domestic workers on an irregular basis is low labour costs. Public and private domiciliary health care services often extend the care recipients' and their families' ability or willingness to pay for care. This is especially true for 24-hour care provided in private homes. Employing a migrant caregiver on an irre- 
gular basis can resolve the tension between the need for care and the unaffordability or unavailability of services.

When you think that we [live-in caregivers] earn 50 euro per day, that's not much. A regular service provider would take 300 to 500 euro per day for a 24 -hour job. But the people, they can't afford this. (Male respondent, Slovakia)

Other factors include the limited possibilities to employ migrant domestic workers regularly, due to restrictive foreign employment laws. However, employers can benefit from this situation, as it enables them to set the working conditions at their discretion.

Due to existing income differentials between Austria and its neighbouring countries, many migrants are willing to work in the informal sector for far below minimum wage, often having no other employment options in Austria. Providing care and domestic work in the private domain can also ensure the migrant with a sense of security, as private households are not accessible to the public.

\section{Sector-specific characteristics}

It seems to be rather difficult to distinguish between different tasks performed in paid domestic labour. As Bridget Anderson (2000) stated, domestic workers do 'everything' and 'classify their employment, not by type of work done [...], but by whether it is live-in or live-out' (2000: 28). 'Live-in' is in general associated with caring for children, older people or people with a disability. The caregivers work for one employer and live in their employers' home. By contrast, live-out domestic workers do not share the same living space with their employers. 'Live-out' can mean working for a single family, but more often it means working for several employers and is generally more task-orientated.

In this study, it was not always easy to uphold the clear distinction between live-in and live-out domestic work, because the respondents were in many cases involved in both types of work. Also, some women worked as live-out but at the same time lived in apartments their employers had organised for them or that were owned by them, generally just five minutes away from their workplace. In these cases, their working situation was quite similar to that of live-in domestic workers. Nevertheless, we kept the distinction line between live-in and live-out domestic work in those cases where we detected obvious differences in working or living conditions of the workers. 


\section{Specific actors involved}

In the domestic sector, recruitment strategies for live-out domestic workers are exclusively based on informal actors. In the first place, they include other migrants and Austrians - friends, colleges and family many of them already working in this sector. A decisive role is played by Austrian employers as they recommend their domestic worker to friends and relatives.

Although these structures play an important role in live-in recruitment as well, formalised actors such as commercial placement agencies play an important role in bringing together families in need of long-term care and women and men looking for employment in this sector. Generally, they provide live-in domestic workers such as au pairs or caregivers for elderly and disabled people.

The au pair agency provides information about duties and rights of the involved parties and establishes the contact between the family and the au pair. For their services, the agency is paid a one-time fee by the host family and, in some cases, also by the migrant caregiver. Although most au pair agencies support their clients during their stay abroad, one interviewee from Ukraine complained that she had not received any help from the agency when she ran into conflicts with her host family and wanted to be placed elsewhere.

In the case of domiciliary care, recruitment agencies and associations play a crucial role in structuring the informal market for care-related services. Since the beginning of the I990s, these organisations (many of them situated in neighbouring countries, others situated in Austria) have been set up as 'charitable associations'. They work on a transnational basis and place live-in care workers from CEE countries predominantly in Austria and other German-speaking countries. The rising demand for home care services has not been efficiently satisfied by public structures, the market, the non-profit sector or family care arrangements. Therefore, these formalised actors, as well as informal networks organised by the migrants themselves, have stepped in to get the job done.

The agency or association situated in the neighbouring country recruits locals searching for temporary employment and willing to live and work in Austria for several weeks at a time, in general for a period of two weeks. The association based in Austria recruits migrant caregivers, mainly in the Czech Republic and Slovakia, and finds them a job in an Austrian household. In general, the caregivers are on call 24 hours a day and reside in the same house as their elderly employer. After a fourteen-day 'shift', they can return home as they are replaced by another caregiver (in many cases someone from the same country of origin) during their two weeks 'off'. 
Regional differences exist between the eastern part of Austria and Tyrol. A longer travel distance between the country of origin and the workplace in Austria, as in the case of Tyrol, has prolonged the working stay up to as much as three months in a row, as one migrant from Slovakia reported.

This organisational pattern has several advantages: first, before EU enlargement in May 2004, the system secured the migrant care worker a legal residence status in Austria according to the visa regulations for tourists; second, the care workers have the opportunity to relax after a physically and emotionally draining work shift and take care of their own family; third, to circumvent employment laws, the agencies defined the migrant workers as 'guests' performing charitable activities and not work, and therefore they only receive pocket money.

In contrast to the au pair agencies, these commercial actors always charge both the care workers as well as their employers for their services, either on a regular annual or monthly basis. Both clients pay a substantial fee regardless of how long a given care relationship lasts. In one of the most prominent agencies, the annual mediation fees for the host families range from I,IOO euro in Austria to I,300 euro in Switzerland. The migrant care workers pay a smaller amount, approximately 667 euro per year (Leibetseder 2004).

In some agencies, a contract for long-term care is signed between the agency and the family in need, defining further rights and duties between the two parties, e.g. the right of the family to substitute a caregiver in case of dissatisfaction. But the care workers themselves do not enter into a contract with the host family or the agency, and they must rely exclusively on oral arrangements. Some migrants reported that language tests and work experience had been requested upon application, although this is handled very differently by the various placement agencies. Some also organise the transportation for the caregivers, but even here no general statements can be made.

In the case of providing care to older people or people with a disability, not only placement agencies play a decisive role, but certain gatekeepers might also pave the way to potential employers. They can consist of doctors, medical staff or nurses working in the health care sector (hospitals or professional home care services). These professionals working in the formal labour market come into contact with caregivers working irregularly in a private household during their daily routine, for example, when taking care of a patient at home. Under these circumstances, they do not only get to know the caregiver working irregularly, but they get the chance to evaluate job performance and ask for contact details. At the same time, the gatekeepers are connected to potential people in need of long-term care. Sometimes they mediate a care relationship between the caregiver and the care recipient. Such 
gatekeepers play an important role in distributing information and connecting potential caregivers and care recipients (Gendera 2007; Schmid \& Prochazkova 2004: I8f).

Although none of the respondents in our sample organised jobs in elderly care for other colleagues in return for money, but rather on the basis of reciprocity and trust, mediators, as they are known in the construction sector, also exist in domestic services. But here the monetary return is paid once only on a lump-sum basis (e.g. 400 euro for a long-term care-giving job that, depending on the health of the patient, might last for several years). In contrast to the construction sector, the recruitment of the care workers takes place on a transnational level. The mediator does not simply offer a job to the care worker but also assumes some responsibility, providing substantial information on how the job should be done, negotiating the salary and other benefits, such as a private bedroom for the caregiver or mediating in conflict situations (Gendera 2007).

\subsubsection{Domestic services: Recruitment structures}

Agencies play a major role in providing migrants with initial access to live-in employment opportunities, especially when the migrant does not have any references from family, friends or former employers. Most of the interviewed women who entered the country as au pairs had used an agency the first time they were looking for employment abroad. The au pair agency is not only helpful in finding a host family, but it offers migrants a certain amount of security: working and living conditions are determined in advance, and the arrangement includes legal working and residence status in the host country. Because of the regular status it offers, au pair migration is especially interesting for female third-country nationals. In our study, several au pairs came from Ukraine. Besides through obtaining a student visa, au pair migration is one of the few possibilities for non-EU citizens to enter the country legally. Therefore, it is not surprising that the majority of registered au pairs in Austria are Ukrainian women (Gendera \& Haidinger 2007).

The job-seeking strategies our au pairs implemented after their au pair contracts had ended differed considerably depending on future plans and further job opportunities. For some, the next stage was to contact the agency once again and migrate to another German-speaking country.

Because I already spoke German, I thought it might not be so bad to try Austria. So I went to the au pair agency again and I paid them 4,500 Czech crowns (approximately I50 euro). Three months later, the agency informed me that they had finally found 
me a family who would contact me as soon as possible. And so they did. The agency already told me that as an au pair, I'm not supposed to work more than 25 hours a week plus twice babysitting in the evening, that all for 60 euro. (Female respondent, 24, Czech Republic)

Four interviewees, two of whom came from Ukraine, had been working as au pairs in Germany prior to coming to Austria. By entering Austria on an au pair visa, they gained residence and working rights for another year. The women who migrated directly to Austria had either visited the country before on a tourist visa, they had family and/ or friends whom they could rely on or they had completed or started a university degree in German language. Whether the women entered the country as tourists and relied on informal contacts or whether they arrived with the help of formalised actors (an agency), informal actors played an increasingly important role in the second phase of their migratory project. As in other sectors, enlarging their social network helps migrants gain access to information and improve their chances of finding a better job. With the exception of one case, further work opportunities in domestic services had all developed through personal contacts the women had met in their language course, in a public parks or through already established contacts via family and friends. Several of the young women working as live-in help switched to live-out work as soon as they had the opportunity to do so.

When the au pair contract ended, I found a new job by chance. In the beginning, my host mother offered for me to stay with them and I agreed. But I wasn't satisfied with that solution because I wanted to study at university, and how was I supposed to study with two crying babies? But then I got lucky, because a Polish friend I'd met on the playground was pregnant and I could take over her jobs. And this was a great opportunity for me. She passed on three families to me and all I had to do was baby-sit for seven or eight euro per hour. (Female respondent, 23, Ukraine)

Some women also tried to find work - whether this was live-in or liveout work - through ads in newspapers, notice boards in supermarkets or via the Internet. Either they posted ads themselves or they called potential employers. Although this recruitment strategy works in some cases, several women mentioned sexual harassment when they posted their phone number. They said that they were very cautious when they took a job in this manner because no one they knew had recommended the employer to them. Nevertheless, one young Hungarian 
woman who found a job posted in the newspaper stated to have worked with the 'best employer' ever.

In the case of elderly care - generally live-in work - we detected the same recruitment pattern as in childcare: commercial agencies are only important in the beginning of the migratory project when the caregivers have no further references in the country of destination.

I was searching for work on the Internet and I found the phone number of the agency organising 24-hour care services in private households. There are a lot of these agencies - I know of about five in Slovakia and the Czech Republic. They are organised a bit like Caritas, but I don't know if it's legal. [...] I think it's somewhere in between - neither black nor white work [neither illegal nor legal work]. (Male respondent, 35, Slovakia)

In fact, only two of our six respondents who worked with elderly or disabled people made use of an agency, while the others either contacted friends and family in Austria or were recruited by them transnationally for a specific job. In the second phase of the migratory project of the live-in caregivers working with the elderly, informal and personal contacts dominate the recruitment strategy as well.

You only need the agency in the beginning. They serve as a kind of 'promotion ladder'. Once you've got the contacts here, the agency is useless. (Male respondent, 35, Slovakia)

Generally, caregivers prefer to work without any formalised actor (agency), in the first place because the migrants can save the annual mediation fee. At the same time, it implies that the migrants' informal contacts and networks are extensive, including as many potential Austrian employers, fellow migrants working in the informal sector and gatekeepers (such as medical staff) as possible. The agency is a good way to enter the informal market (to get a 'foot in the door', as interviewees put it), but it can only provide live-in work. For the migrants, this means that problems with employment and housing are solved at the same time. Live-out jobs seem to be more difficult to find especially in the beginning, although those who want to stay in Austria longer prefer those arrangements. A female respondent from Ukraine worked as a live-in caregiver for two families in a small village in Lower Austria. She felt socially isolated there and finally decided to quit her job and find live-out work in a major city. But not everything turned out to be as easy as she had imagined in the beginning. 
That small village, it was quite boring there and I had to work a lot as well. So I thought, why not go to Vienna - you can live a good life there, you earn a lot when you are paid by the hour, you really have good income possibilities there. But at that time, I didn't know about all the problems you have to cope with: you have to find a place to stay and you also have to find work...and that is not always an easy thing to do even if your friends help you. [...] So after my first jobs, I wasn't so optimistic anymore. (Female respondent, Ukraine)

The difficulty concerning live-out domestic work is to find several employers. Those working on an hourly basis need many households to make a living. It seems that the longer the women work in the live-out domestic sector, the easier it becomes for them to find new employers due to their already developed informal networks.

Austrian employers play a central role in recruitment, whether searching for live-in or live-out domestic work. These informal actors are most likely in contact with other Austrian families searching for a caregiver or domestic worker. Often they recommend the migrant worker to friends or family, or ask their domestic worker to find someone 'trustworthy' for those dear to them. This mechanism is also connected to the characteristic of domestic work, which takes place in the private sphere. At first it takes some time to gain the trust of the employers, but as soon as they trust the worker and are satisfied with the work performed, they act as informal 'job agents'.

I also found work for my father. A friend of my current employer - also a disabled man - was looking for a caregiver. And then my employer asked me if I knew anyone who could do the job and I recommended my father. (Male respondent, Slovakia)

This kind of 'direct hire' works very efficiently. Potential employers prefer to hire caregivers formerly employed by their friends or relatives or recommended by them instead of contacting an agency and paying a high mediation fee for this service.

\subsubsection{Domestic services: Forms of irregularity and working conditions}

\section{Forms of irregularity}

Although the au pairs in many cases had a contract in their first year that limits them to a maximum of 25 hours per week, and one woman providing elderly care had a part-time contract as well, live-in caregivers generally work much more than officially laid down in their arrangement. 
Besides working more hours in spite of a limited live-in contract, a major irregularity in the private sector is the complete lack of registration. After the au pair contract had expired, none of the interviewed women had working papers, although most of them had a work permit as students.

A comparable situation can be observed in the case of caring for the elderly and the sick. With the exception of one Polish woman, none of the respondents had an official work permit or were registered at an Austrian social insurance agency. A Polish female caregiver with a work permit had a part-time contract. Her employers registered her in the social security system for only 25 hours per week, although she was on duty 24 hours a day. A further irregularity concerned her unemployment insurance. She had assumed that her working contract included social insurance (pension and health) as well as unemployment insurance. But after caring for an elderly woman for a period of ten years, she discovered that her employers had not paid the unemployment insurance for her. When the elderly woman died, the caregiver became unemployed and decided to leave for Poland. After several years, once she had used up all her savings, she returned and searched for work in domestic services again. Although her work permit was still valid, she did not search for work in the official labour market service due to her poor language skills.

In another case, that of a male nurse from Slovakia who had his diploma approved in Austria and started a career in home care, the caregiver continued to take care of his elderly landlady on an irregular basis, while also working for an official home care service. This man was the second respondent caring for an elderly or disabled person who had full access to the formal labour market and still worked part-time on an irregular basis.

Of those women working in the live-out domestic sector, none of them were registered at their workplace as a domestic worker or a childcaregiver. Only one Polish woman had found a way to 'semi-legalise' her working status by registering a trade licence for a 'cleaning company' shortly after the 2004 EU enlargement. Although her working situation did not change substantially, her self-employment allowed her and her husband access to social security. Because the woman had a trade licence, she could also accept cleaning jobs from offices or companies who needed an invoice. Although her duties did not change at all, she acted as an official company at least towards some of her clients.

The completely or semi-irregular working situation of most interviewed women and some men working in domestic services included all kinds of insecurities: no protection in case of unemployment, sickness, violation of workers' rights, problems with payment, no paid holi- 
day leave and, most notably, no fixed working hours, breaks or defined duties.

\subsubsection{Live-in domestic work: Working hours and employer-employee relationship}

Different kinds of live-in domestic work - whether caring for children or for older people and people with a disability- are subject to similar mechanisms. Because the women and men work where they live, their working hours and duties are not clearly defined and tasks in a household can be endless. The tasks the domestic workers performed ranged from preparing the meals, doing the shopping, personal hygiene, changing nappies, playing with the children or entertaining the elderly, cleaning the house, doing the laundry, bringing the kids to school or taking the sick to the doctor - just to mention some of the most important. But the list of duties also included medical care and rehabilitation in the case of elderly care-giving (irrespective of the professional qualifications of the caregivers), gardening or accompanying the family on holidays (especially for au pairs). Live-in domestic work in many cases means being on call even at night. When the care recipient suffered a major illness or the children cried, the caregivers had to look after them regularly at night and calm them or dispense medication. One interviewee working with an Alzheimer's patient could hardly sleep for several months because her employer screamed at night. In such cases, she got up in the middle of the night and tried to calm the elderly woman.

The main problem live-in domestic workers are confronted with is the disregard for basic workers' rights. Although some have a contract limiting working hours to 25 per week, all live-in caregivers complained about having to work much longer than what they had arranged for in the beginning. Sharing their living space with the care recipients and in many cases also the employers (family members) makes it virtually impossible to maintain a clear time framework, as one woman highlights in the following statement:

So the parents know very well that they can ask me for help anytime, since I am at home anyway. That means that even when I have fixed working hours, I think I always work a bit more. (Female respondent, 24, Czech Republic)

Furthermore, it is even more difficult to explain to children why one is 'available' (at work) in the afternoon but not in the evenings or on weekends: 


\begin{abstract}
Also, what sometimes disturbs me is that when I am 'off' but want to stay in the house, the boys sometimes come to my room and want something from me, and of course I can't just tell them to get out. They don't understand it really that I am there to 'work' with them, if you know what I mean. (Female respondent, 22, Czech Republic)
\end{abstract}

The lack of control over working hours and leisure time has further consequences. In some cases, the domestic workers felt restricted to the employer's household because they didn't know when they were supposed to 'work' and when they were 'free' to leave the house - and in a household, there is always work to be done. Being available at both the beginning and the end of the day can lead to exploitation and a lack of self-determination. For these reasons, it was difficult for the following respondent to organise her time or even find an extra job in the live-out sector:

I wouldn't mind finding an extra job, maybe in cleaning or babysitting for another family. But as I said, I can't because I don't have fixed working hours. (Female respondent, 24 Czech Republic)

Usually the live-ins had some free time in the afternoon,when the family members took care of the elderly person, or even a full day off on the weekends, as in the case of most au pairs. But the live-in situation also means that this arrangement can be changed anytime, for example, when the employer has some additional work to do. In situations where the elderly person is mentally ill and cannot be left alone for even an hour, the caregiver has to stay at work all day long. In the case of one Ukraine au pair, after some time, her employer complained about her going out on weekends and wanted her to stay at home even on her days 'off'.

Several months before my contract was supposed to end, we argued about my going out on weekends. But the weekend is meant for going out, meeting friends or travelling, isn't it? When you do this type of work, you need a private life as well. But she told me, 'No, it's not okay for you to go out on weekends. I like the way you perform your tasks and take care of the children. I want you to stay with us, but I don't want you to go out every weekend.' But staying at home on the weekends for me means work, nothing but work. (Female respondent, 25, Ukraine) 
Conflicts between employers and employees were rarely carried out as openly as in this case. Disputes arose about different attitudes of performing housework tasks or disciplining the children. In general, the domestic workers did not complain about substantial problems like their working conditions or low payment. This situation can be described as the 'part-of-the-family' dilemma. In domestic services whether this is live-in or live-out work - the employer-employee relationship is characterised by a strong personal relationship that is shaped by power and friendship at the same time. The relationship between employer and domestic worker is never exclusively governed by the intimate setting and friendship or by civic relations - it is always a mix of both. As Bridget Anderson stated, the division of society in two separate spheres, a private and a public, is the ground where

the employer consolidates much of her power: the worker may be treated as 'part of the family' (governed by customary relations) when it is a matter of hours and flexibility, and as a worker (governed by civic relations) if she becomes too sick to work. (2000: 4f)

The dependency of the worker on the employer's goodwill - especially in those cases where the migrants have an undocumented or insecure residence status - and the complex relationship between the employer and the domestic worker can help to explain why another young woman never addressed her dissatisfaction about her poor income. When she was asked in the interview why she had never spoken about her problems to her employers, she explained with the following:

No, I never dared to talk about money and such. I don't know why...I feared that talking about money always changes the relationship between people, and I didn't want our relationship to change. We really had a very good relationship. I didn't want anything to change just because of a couple of euros. But if I were to work as an au pair in the future, I would set up clear rules. And if the family didn't live by them, then I would say, 'Sorry, but not this isn't okay.' (Female respondent, 23, Ukraine)

Although this woman had a very good relationship with her employer, she feared addressing sensitive issues such as payment and working conditions. A general characteristic of domestic work is that the employer-employee relationship is not recognised as such but is defined in terms of personal friendship. Therefore, it is obvious why this au pair had to 'protect' her 'good relationship' with her employer: a change in the attitude towards the domestic worker might lead to a deteriora- 
tion of her working conditions and, in the worst case, even the loss of her job. Another feature of domestic work is that many caregivers speak of their work as being 'part of the family'. But feeling like part of the family can obscure the asymmetrical work situation that is governed by the migrants' dependence on the employers' goodwill and their lack of rights.

I always worked a bit more. [...] But I didn't mind it so much, because they were always very kind to me and I really like their children. (Female respondent, 24, Czech Republic)

This tension between the affective relations of the private and the normative relations of employment is a structural aspect of domestic work in general, although it seems to be more prominent in live-in working arrangements. Although the 'being part of the family' rhetoric obscures the unequal power relations between employers and migrant workers, it also has an impact on the migrants' overall work satisfaction.

Building up a complex and emotional relationship or even feeling 'love' for the care recipients is a reality for this type of work. A 48-yearold woman from Poland who had spent more than ten years caring for an older and disabled woman expressed her deep attachment to her employer. She wanted to stay with her 'until the end', although in the meantime she had received working papers and could have searched for a less demanding and better paid job elsewhere. The same reason feeling emotionally bound up - was mentioned by another caregiver. A central feature of caring work is bringing feelings and subjectivity into the caring relationship. In this sense, it is understandable why this caregiver preferred to stay with 'her' care recipient instead of searching for a live-out job or employment in the formal labour market.

A further aspect of live-in domestic work is social isolation. Working in the house in the case of elderly care, often 'around the clock', makes it difficult to socialise with people outside the household. At the same time, the lack of privacy and not being able to invite friends over or working in isolated, rural areas means restricted social contacts.

I don't have many friends here, either. The family lives in a big house in a village near Vienna, and I didn't have the opportunity to meet anyone. (Female respondent, 24, Czech Republic)

Although several aspects of live-in and live-out domestic work are similar, there are also important differences, as will be shown in the next section. 


\subsubsection{Live-out domestic work: Switching between sectors}

As has been mentioned before, live-in domestic work is generally followed by live-out domestic work (Anderson 2000). In our sample, after their first live-in experience, several (five) live-ins found a live-out arrangement. They were either working full-time (up to 45 hours per week) for a single employing family or for several employers at the same time. The domestic workers prefer this work situation in the first place because they have their own living space. In this way, they get not only more privacy, but more control over their working hours and generally have a higher monthly income. In the case of the following respondent however, although she had been working in a live-out arrangement for four years, she had to be available in the evenings as well.

Now that I have finished my education, I also work there in the mornings. This family found me an apartment close to where they live. I only pay I70 euro per month for the rent and a bit more for heating. But she can call me anytime in the evenings, if she wants to go meet some friends in town, then I take care of the kids.' (Female respondent, 28, Poland)

Therefore, having one's own apartment does not always mean clear working hours. Instead, it seems that live-out domestic workers who reside close to their employers or in an apartment their employers own are confronted with the same problems facing live-ins - such as no clear working hours and no defined tasks.

In contrast to the situation described above, working as a live-out generally means working for several employers on an hourly basis and is more task-oriented. Sometimes, the migrant workers are hired exclusively to clean the windows or to do the laundry, but in most cases they clean the whole house in a limited timeframe. Working for several employers implies not only great flexibility, but requires organisational and coordinative management capabilities.

I work every day from Mondays to Fridays in the mornings three to four hours and in the afternoon three or four hours as well. Sometimes, I also clean on the weekends, or I do some babysitting when they call me. In total I work for five families, and in each family I'm there once a week. Then there's also this elderly woman I go to only once a month. Sometimes I get extra work when my employers give a party and they need someone to help them out. [...] Generally I only clean, and sometimes I baby-sit 
as well. But most of the time I only do cleaning work. (Female respondent, Belarus)

Although at first glance live-out work would appear to give the domestic workers more freedom, some women also described physical stress and pain arising from their working conditions.

Every week I worked for the same families. So every day I was in a different household. I had to travel back and forth. [...] This situation was really quite stressful for me. [...] And from all this cleaning - washing the floors, you always have to bend down and your hands are always wet - I got problems with my joints. I went to the doctor in Poland and he told me not to work with lots of water anymore, but how was I supposed to avoid this as a cleaning lady? (Female respondent, 45, Poland)

A characteristic feature of live-out domestic work is the high flexibility of the employees switching between different kinds of employers on the one side and between the private and the public spheres on the other. None of the women worked exclusively in private households, but they all cleaned in restaurants, offices, bars, medical centres, pharmacies or hotels - wherever they found additional work. In the case of one Ukrainian woman, cleaning in the public sector did influence her working conditions for the worse. Although she had two families for whom she managed the household a couple of hours per week, she searched for additional income sources. During the summer, she found a hotel that was in search for additional staff.

Sometimes a hotel would only hire you for a trial period. They would tell you to come and work for two days and in the end they told you, 'Oh sorry, we don't need you, we can't hire you, you don't work fast enough,' or something like that. And once I even signed a piece of paper, without knowing what it meant, stating that I would work for a trial period of two days without payment. [...] I think there are lots of hotels or bars that play tricks like that, only to exploit you. (Female respondent, 28, Ukraine)

In this case, providing cleaning services in the public sphere was different from working in private households. It seems that the strongly personal and intimate employer-employee relationship that dominates the domestic sector does not only influence the working conditions - extension of working hours, no fixed duties - but in some cases prevents the employers from cheating the workers. In the private sphere, exploi- 
tation remains a more subtle phenomenon, although severe mistreatment and even sexual abuse can also be an element of domestic work (Anderson 2000).

The respondents working in the live-out domestic sector did not only work in cleaning or as caregivers, but they were all engaged in other types of activities and in totally different sectors as well. Domestic work was only one part of their professional career in the informal sector. The other jobs they performed ranged from leather manufacturing, shop assistance, tutoring, harvesting and in many cases jobs in catering and tourism.

\subsubsection{Gender-specific problems}

Especially interesting in this context is to compare the gender relevance of the different sectors such as catering and tourism and domestic services. Although one might assume that working in the private, invisible sphere makes young, female domestic workers more vulnerable to sexual harassment, the experiences of a young Ukrainian woman paint a totally different picture. She had worked in many different restaurants and bars as a waitress and expressed great discomfort about the working conditions for several reasons.

I also worked in a Turkish bar. [...] But this job didn't work for me at all, I had no experience. When you want to work in a bar, you have to be the kind of person who likes to joke around with the customers and talk to them, and most of them are men, And every day you have to do the accounting, which is quite complicated as well. [...] I worked there only one week and my boss told me that customers had complained about me, that I wasn't nice to them. When the customers are men, there is always some kind of sexual harassment - they don't respect you as a woman. With the boss, it was the same thing. I also had problems with payment, because he didn't want to pay me in the end. (Female respondent, 28, Ukraine)

After her unpleasant experiences in the catering and tourism sector, this woman was very pleased to find work in domestic services.

So I left this bar. I was already fed up with this type of work in bars and restaurants, and then finally I found a family on the internet looking for a child caregiver. They paid six euro per hour and I was very happy with them. (Female respondent, 28, Ukraine) 
But problems with sexual harassment can arise even in domestic services. A 30-year-old Polish woman developed a strategy so as not to attract the attention of her male employer. To avoid giving any false signals, she dressed in old clothes and refrained from putting on any makeup.

\subsubsection{Payment and qualification}

In comparison to the construction sector, where cheating in payment is a major problem, this issue plays only a minor role in domestic services. The close and often familiar atmosphere among employers and the migrant domestic worker would seem to exert a positive influence. As long as the employers are satisfied with the work performed, the arranged payment is not a problem. (That said, in two cases women reported that they had to constantly remind their employers to pay them their weekly pocket money, a situation they perceived as very unpleasant.) In another case the worker was asked to help out on the weekends and was promised extra pay for working during her time 'off'. But this extra money was never paid, and she never dared to address this sensitive issue. Bargaining for a higher salary is also seen as rather problematic. Only one of the interviewees mentioned that her employers had proposed a higher salary to her. The others had to start the bargaining process by themselves or they did not address the issue at all, in fear of ruining the 'good relations' with the employer.

In general, the au pairs earned 360 euro per month and worked 30 to 45 hours per week (which amounts to approximately two euro or three euro per hour). This extremely low income was complemented by additional services and bonuses: room and board, birthday presents and other small gifts. Some au pairs were offered a private apartment by their employers, and in two cases this was part of the payment; in one case, the woman paid I70 euro for her flat that was just around the corner from her employer's home. In this way, her landlady could easily call her in the evenings when she needed her to take care of the children. The highest income was received by a Hungarian woman: she received 700 euro plus a private apartment that the family owned, and her employers also financed her studies in Austria (377 euro tuition fee per term).

The live-in domestic workers taking care of elderly and sick people had an income between 30-50 euro per day, although one male nurse mentioned that when he started out, his daily income was only fifteen euro. These live-in caregivers also had free room and board (generally a separate room). In the cases where the migrants travelled back and forth between their country of origin and Austria every two or three weeks, the employers also paid the travel expenses: 
When I go back home, I take a 'taxi'. There are always several women working in the same region or town, and there is a company that organises this shuttle service for us. The I6o euro travel costs are paid by the family. (Female respondent, 50, Slovakia)

The moment the domestic workers switched to live-out arrangements and worked on an hourly basis for several employers, they earned a higher salary - on average seven to nine euro per hour. And it was only in live-out jobs where the duties were clearly defined and restricted to specific tasks, such as only taking care of the children. Specific tasks are also valued differently, usually eight to nine euro for cleaning and five to six euro for babysitting. In rare cases, the women also had their public transportation paid for.

Although our sample included two men who were employed to take care of elderly and disabled people, it is women who do most of the domestic and caring work. The major qualification needed for this type of work is connected to gender - being a woman is considered a sufficient criterion to do the housework, care for children, the elderly and the sick, even in those cases where intensive medical care is needed. Only one of the six respondents in elderly care had a medical education, while none of the others had experience in care-giving before their first job in Austria. Another decisive criterion seems to be age. Whereas young women prefer to take care of children, caregivers, aged between 30 and 6o, care for elderly and disabled people. This fact was confirmed by an employer who complained about younger caregivers.

Before this [50-year-old] woman, we had other caregivers working for us but I was not pleased with them. Especially the young women. For those women, care-giving is 'just a job' and in the evening, the only thing they think of is going out. But she really is different - she takes care of my mother too percent, and she always stays in the house. (Austrian employer of female respondent)

\subsection{Sector-specific conclusions}

\subsubsection{Construction}

Construction is a very labour intensive sector that is characterised by international competition and a growing participation of international players. Projects are granted to those who can do the work for the 'best price', not only on the level of the principal company, but also on the subsequent levels of subcontractors and sub-subcontractors hired to 
carry out portions of the work. This non-transparent structure of carrying out work as well as the 'need' for cheap labour results in a considerable number of construction workers who are employed irregularly. Still, there are also many private persons who employ migrants irregularly to perform construction activities in their houses, restaurants, gardens, etc.

Those two different spheres have resulted in the appearance of different actors and types of irregular employment. The system of public projects involves a long chain of employers, ranging from the initial principal to the labourer who does the job. Irregularly employed migrants can be found on all of those levels, either as 'ordinary' employees working for a company, as 'mediators' who look for workers on behalf of their own employers or by directly contacting clients and acting as employers themselves. They are either not registered at all, registered insufficiently or are in possession of a fake trade licence.

Equipping employees with a trade licence seems to be a common practice, especially for those who are involved in public projects, in order to produce the appearance of legality. As reported for other sectors, but especially for catering and tourism and in domestic services, also the construction sector involves 'visible' and 'invisible' activities irrespective of whether carried out in public or informal projects. 'As soon as there is a door installed', we also find that fully unregistered workers are employed, as the risk of worksite inspections is lower in such 'closed locations'. The same can generally be stated for work on behalf of private employers. Conversely, the need to employ migrants at least semi-legally is higher on open construction sites and when working for bigger companies. Hence, in these areas there has been a shift from non-registration to pseudo-forms of self-employment.

Migrants doing informal jobs for private employers are not involved in a chain from principal to worker, but have to get into contact with their employers directly. They also have to organise their jobs for themselves again and again. For them, registering a trade licence often seems to be unprofitable, as their own labour costs would increase as a result.

Common to migrants hired irregularly for both public and private projects is that they only have a 'word of mouth' contract with their employers. This does not give them any guarantee of keeping their job, nor does it enforce compliance with agreed upon working conditions. While people working 'on their own' are more autonomous with respect to working hours and less dependent on an employer in regard to payment, they constantly have to invest in their social networks to sustain a profitable amount of work.

On the other hand, those who work irregularly for an employer or mediator face different risks, the most important of which is not being 
paid. Often, there is no direct or close link between the employer who pays and the employee who receives the money.

To get a job in the irregular construction sector, migrants generally do not need to have a good knowledge of the German language or certificates of professional skills. 'You can always find something', as one Polish worker indicated. To make a career within the construction sector, however, versatility improves the negotiation position of employees, while working arrangements for the most part remain unregistered. Language skills become a key to getting better positions as well as to changing to regular employment - in other words, getting a formal contract. In order to achieve this, contacts to employers, especially Austrian ones, are an essential resource for the migrant's career.

In sum, the construction sector offers possibilities for an occupational career within irregularity (becoming a specialist and thus being better paid, becoming a translator and thus not having to do much manual labour, becoming a mediator and retaining fees for mediation, etc.) and, even if very restricted, outside of irregularity as well (working as a 'real' self-employed person, offering services as a foreign entrepreneur). Nevertheless, even the latter only very rarely implies working with formal contracts.

In contrast to other sectors, employment in the construction sector does not allow for parallel activities alongside work (such as education or training) or supplemental work in other sectors. On the other hand, construction work is often used as a supplementary source of income when the migrants' main activities are in another sector, as it was reported by agricultural seasonal workers. Besides, changes from one sector to another are only taken into consideration when somebody wants to get a regular job.

While all of the respondents intended to work irregularly only for a limited period of time (see Section I0.3 on irregular employment as a 'temporary project'), the biographies of migrants also show that one can easily get stuck in irregular employment. The national legal framework restricting access to the labour market for most non-nationals is primarily responsible for the lacking career perspectives. Limited access to the labour market in the course of transitional regulations facilitates and enforces irregular employment, as EU-8 citizens currently have the right to settle and to look for work in Austria but at the same time have no free access to the labour market. The increase in pseudoforms of self-employment is also a result of making use of EU regulations to circumvent national regulations. As these emerging forms of pseudo-regularity are very profitable for employers, they are likely to reinforce irregular employment structures even after the end of transitional regulations and will influence the irregular status of migrants in the long run. 


\subsubsection{Catering and tourism}

As in other sectors, employers in catering and tourism can draw on certain 'traditions' when employing irregularly. Especially with regard to the immigrant workforce, insufficient registration or registration of workers below the social security threshold can occur in all employment arrangements permitted under Foreign Employment Law: employment according to the general working regulations, seasonal work arrangements and student employment based on the specific work regulations for students from non-EU countries.

Besides the enormous number of potential small- and medium-sized workplaces, the major characteristic of the sector (with the exception of seasonal work arrangements) is that working in restaurants or bars is easily compatible with other jobs or other obligations and interests, as was demonstrated in our sample (e.g. studying). Working hours are usually flexible and organised in shifts with a tendency towards night work, which makes it easier for employees to adjust other obligations and interests to their working schedule. Salaries or at least tips are often paid in cash after the respective shifts.

This explains why some employees can cope easily with arrangements of non-registration or registration below the social security threshold, as they may be registered with another employer, either within catering or in another sector. Therefore, working in a restaurant or bar for many people is a typical side job. This is specifically true for national as well as non-national students who, according to the specific work legislation, should devote themselves to studying rather than working in the margins of the law in order to earn a living. Many prefer to work unregistered so as to prevent the potential loss of their residence permit.

While some people - especially those who are young and single - appreciate this situation, others characterise the branch as a burden. This latter group includes people who cannot rely on a primary job or those with no other obligations. In order to make a living in catering and tourism, workers need to manage several jobs at the same time. Especially those with familial responsibilities face problems, whether their families are in their country of origin or in Austria. Coping with the requirements of high flexibility was especially difficult for those who wanted to lead a family life. In our sample, this was specifically highlighted by mothers with younger children.

Another characteristic of catering and tourism is the division into 'invisible' jobs such as kitchen staff and chambermaids and 'visible' jobs such as waiters and waitresses, receptionists, etc. The more visible jobs were described as jobs where persons are at least registered as students or otherwise as workers under the social security threshold, 
where a certain appearance and German language skills are required, and which are therefore usually reserved for Austrian citizens. For the invisible jobs, all of this was secondary.

Another aspect highlighted by respondents was the fact that this structure also has consequences for worksite controls, especially concerning the more 'visible' jobs. Employees can always be presented as being employed on a trial basis and therefore not fully registered yet, or as being part-time workers yet in reality working full-time.

Moving up in the branch may be the promotion from an 'invisible' job to a 'visible' job, provided that any kind of registration is legally possible or envisaged by the employer. After all, good conduct and a close relationship with the employer also help in keeping the job, or ensuring that one day, if the status is regularised, one could also come back. Otherwise, working in catering and tourism was assessed as a good opportunity to acquire skills that could be useful in possible future work arrangements in Austria or in another country.

In cases where workers were employed in one hotel or restaurant only (as in seasonal work arrangements, for example), the high flexibility was mirrored by the fact that staff should take over several occupations within the business and act as 'jacks of all trades'. As accommodation is usually provided on the worksite in such arrangements, workers are always onsite and therefore run the risk of working much more than actually agreed.

Finally, the temporary nature of the sector, the high flexibility demanded and the different type of payment arrangements (on a daily or an hourly basis) provide fertile ground for defrauding employees on their agreed compensation.

\subsubsection{Agriculture}

In Austria, it is mainly small-scale producers who shape the domestic agricultural sector and who try to compete with others across the EU. In order to stay competitive, the seasonal employment model was introduced by Austrian politicians to provide flexible and cheap labour to a sector characterised by unsteady working hours, hard working conditions and the need for intensive labour input.

The statements of our expert and migrant respondents indicate that the complete non-registration of workers in this sector has diminished in recent years. Irregular employment is now mainly associated with the system of seasonal employment that facilitates irregularities concerning working hours, working between seasons and other violations of workers' rights.

Temporarily restricted work permits are the most striking feature of seasonal employment.,They make seasonal work attractive to commu- 
ters, students, mothers, fathers, etc., who want or need to work abroad and at the same time hope to keep close connections to the home country. The seasonal employment model per se contains this 'return perspective', as the restriction of work permits to six months and the low wage level indicate. Nonetheless, as soon as this intention to return is given up and migrants want to settle in Austria, seasonal wages are no longer sufficient to sustain a living.

Another feature of agricultural work is the close relationship between employers and employees that arises from the provision of accommodation by the farmers. Often, farmers and their workers live together in the same farmhouse. This close relationship with mostly one employer and the need to be available at all times reduce opportunities to change the job or sector, as migrants hardly have any chance to establish contacts with other potential employers. This is especially true for seasonal workers, as their work permits are bound to one employer.

In contrast to other sectors, workplaces in this sector cannot be found everywhere, as is the case for construction sites, households or restaurants. Farms are mostly situated in rural and remote areas that do not allow for the pursuit of other interests in the migrants' spare time, the use of resources of established ethnic communities or the establishment of contacts to employers other than farmers.

This all affects the career perspectives of agricultural workers, but the possibility of making a career in the agricultural sector is virtually nonexistent as well. While migrants in our sample reported that they got progressively more responsible positions or shifted from hard fieldwork to in-house activities over time, improved working conditions are only rarely bound to an increase in salaries. Thus, migrants who want to get ahead in their occupational career have to change their job as well as the sector. Especially for those who have settled in Austria, it is indispensable to have other jobs alongside their agricultural activities, to supplement their income and to bridge seasonal work breaks.

The end of the transitional regulations on the Austrian labour market and further EU enlargement thus will show whether seasonal employment stays attractive for those who have the right to settle and work in Austria, or if it is only appealing for those migrants that have no right to reside or work in the country.

\subsubsection{Domestic services}

The rapidly growing informal domestic care sector can partly be explained as a result of the re-privatisation of care work, on the one hand, and the possibility to employ a migrant caregiver, on the other. The specific work situation in the private household is the main reason for many problems domestic workers and care workers have to cope with. 
First, the fact that the job takes place in a household, the private domain of the employer, gives the employer the power to structure the work situation as he or she sees fit; second, the permanent presence and availability of the worker in a live-in arrangement - both day and night - clearly clashes with defined working hours; thirdly, because of its closeness to unpaid reproductive activities, paid domestic work lacks the recognition of 'productive work'. The ambiguities the private sector faces can be illustrated in the expression 'part of the family', which is used by the employers as well as the domestic workers themselves to describe their employer/employee relationship.

The general trend in paid domestic work can be summarised as a transition from live-in to live-out employment (Anderson 2000). Only two of our interviewed au pairs were still working as live-in domestic workers when we completed the study, whereas all the others had changed their live-in employment to a live-out arrangement. Four respondents taking care of older and disabled people also worked as liveins, but in two of these cases they were women in their fifties whose centre of interest was in their country of origin. Therefore, a change to a live-out employment situation did not make any sense for them. The change from a live-in to a live-out job affects fundamental working conditions: first, the workers enjoy greater personal freedom and privacy when they rent their own living space. Second, they have control over working hours. Third, the income level in live-out employment is generally higher. Fourth, the work tasks and duties are more clearly defined.

Central to the improvement of the working situation in the private sector, especially of live-in care work, is the recognition of the importance of this traditionally unpaid women's work:

If immigration policies recognised the need for immigrant labour in these types of work, providing work visas for such workers, workers would be more effectively protected by labour laws, including minimum wage laws, protection on hours worked, and right to privacy (Misra, Woodring \& Merz 2004: 8).

Employing a caregiver on a 24-hour basis for a handicapped or elderly family member is still not compatible with labour standards and foreign employment laws in Austria, although the government has attempted to introduce a legal basis for affordable care work and has twice prolonged a temporary amnesty programme for irregular care workers until the summer of 2008. While only a few irregular care workers have taken the offer so far, politicians are recognising the need for such types of feminised work, and the heightened awareness of ir- 
regular working conditions in this sector has led to an intense, if politically difficult, search for solutions.

\subsection{Career planning in irregular versus regular work}

\subsubsection{Decision-making processes in an irregular work situation}

Given all the uncertainties that have to be taken into account in an irregular work situation, making decisions is no easy matter. How migrants navigate through irregular employment depends on their initial intentions to work abroad, their individual resources such as language, professional skills and networks as well as the legal framework that surrounds them. While every person has to make decisions on his or her occupational career and future perspectives every now and then, the difference for irregularly employed persons is that they cannot plan on a long-term basis. Nothing is set in stone, and unpredictable events can suddenly change all plans that were made beforehand. This insecurity is a direct result of irregularity. As was shown in the description of working conditions, irregularly working migrants have no secured rights, no guarantees of being financially secured in the immediate future, etc.

Thus, migrant workers are not able to make plans in the long term. Plans are made for the moment and can be changed as soon as new perspectives arise. For this reason, answers to questions about future perspectives are usually elusive.

In sum, I've tried not to plan too much, only to put as much money aside as I can. But any big plans, such as saying this year I have to achieve this and that, I've never made plans like that. I know that when you plan too much, you won't succeed. (Male respondent, Poland, construction)

Another comment very impressively illustrates how pragmatic and quickly decisions are made. After complaining about deceitful employers and bad working conditions for quite some time, saying he would definitely return to Poland in the near future, a Polish construction worker comes to the following conclusion:

If there would at least be the money, this would be something, but now, when I can't even send home money, then it makes no sense anymore to stay here. [...] In case something special comes up in the next two months, then I will probably stay. (Male respondent, Poland, construction) 
On this uncertain basis, migrants have to navigate through irregular employment, taking into consideration factors in both the country they work in and their home country. Decisions to continue with or quit irregular employment or to change within irregular employment to another employer or even another sector largely depend on the initial objectives that were connected with working abroad. As shown above, these motives differ between people of different ages and family status. In addition, sector-specific working conditions and working possibilities also influence those decisions.

\subsection{2 'Profiting' from irregular employment}

The migrants in our sample are very conscious about the advantages and disadvantages of regular and irregular work; some deliberately decided to work irregularly, while others entered irregular employment because of a lack of alternatives. Being able to get any 'profit' out of the current working situation is a decisive factor in keeping or quitting one's job, returning home or looking for another job abroad. 'Profit' can be associated with the fulfilment of financial aims as well as educational aims, acquiring new skills or family-related aspects.

I could save something and give it to my family as a present, but I'm not talking about big sums, it was always tight. (Male respondent, Slovakia)

Irregular employment is often assessed as a good starting point in the beginning of the migratory project, as long as the overall working and living conditions are acceptable and the work situation is compatible with future plans.

For most respondents, earning or saving as much money as possible, making investments in the country of origin and caring for family members at home were important motives for working in Austria, and were thus also decisive in their evaluation of the current work situation.

My only aim is to earn more money; the means don't interest me. I have achieved my goals: I can care for my family very well, my children get everything they want, and with better education, they have better chances in their future lives. (Male respondent, Hungary, construction)

Yes, I'm very satisfied, I've already bought a car, in Poland I would have to work eight years for that. (...) At the moment, I'm 
content with my work because there's money, that's the only thing that counts. (Male respondent, Poland, construction)

For others, the principal goal was to overcome insufficient educational opportunities and inadequate job opportunities in the country of origin by internationalising, professionalising and acquiring additional knowledge in Austria. This attitude was especially pronounced by students responding to the current European promotion of student mobility. As a good example, the summary conclusion of a Slovak student can be presented. Talking about her future plans and career opportunities, she stated that moving up in her position 'is only possible in Slovakia because that's where I can utilise my acquired German language skills, which do not help me any further in Austria'. Several persons currently in training in Austria mentioned acquiring certain skills, which subsequently should improve their long-time earning potential in their countries of origin.

Nevertheless, many circumstances can upset migrants' plans and goals and render getting profit from irregular employment very hard, as we have seen with the irregularities on payment. Still, especially for those who work on their own, working irregularly is sometimes preferred to registering a trade as a self-employed person. First, getting a trade licence is very cost-intensive. Second, people have to keep their labour costs low in order to remain competitive. According to one construction worker: 'When you charge legitimate prices, nobody will hire you'. Paying taxes is thus considered a disadvantage, because it would result in an increase of labour costs.

In contrast to those persons, working as a self-employed individual with a trade licence seems to be very profitable for 'mediators' who employ other migrant workers irregularly. A precondition to become an 'employer' is to have as many contacts with potential clients as possible:

I collected my connections while working for an AustrianHungarian company from I998 to 200I. I then realised I could earn more working for myself. (Male respondent, Hungary, construction)

As we mentioned earlier, the other example is students. Because the legal provision is not specific on their possible engagement in the formal labour market, students may actually prefer to work unregistered in order to prevent the eventual loss of their residence permit.

Those respondents who had planned to settle in Austria faced additional difficulties in irregular job arrangements, as their aim to integrate into Austrian society and establish a life in Austria requires higher costs, such as expenses for living costs, consumer products, etc. This 
became most obvious in seasonal work, as the legal framework for seasonal work is designed for temporary work arrangements and has specific regulations for low wages. For people who agreed to settle in Austria for a full year, for two seasons or more, it is impossible to cover their costs of living exclusively with seasonal labour. The employment break in between two seasons makes seasonal work incompatible with an actual regular life in Austria, especially for those who also have to care for a family.

As a consequence, migrants have to engage in other irregular activities as a supplement to their seasonal wages or must try to change to another sector completely. A Polish respondent worked as a harvester during the seasons and as a construction worker in between seasons. Because of family reasons, he finally decided to settle in Austria permanently. This made it necessary to quit his job as a farm worker:

Q: What do you think about the hourly wage of 3.80 euro?

A: Well, let's say it like this: with the money I earned at the farm, I could live happily in Poland. But as it is now, I want to live in Austria [...] With this money, this is not possible, I cannot make a living. You have to earn more, that's it. (Male respondent, Poland, agriculture and construction)

Due to the fact that employment in domestic services is regarded as a temporary project, satisfaction with the overall work situation is largely related to whether the domestic worker is able to pursue other interests (e.g. attend university) alongside their employment. This is especially true for young, highly qualified, single females. Furthermore, live-in working conditions solve problems of employment and accommodation simultaneously. For undocumented migrants, the 'invisible' workplace - the private household - protects employees from inspections and consequently from expulsions. In a live-in arrangement, the migrants save as much money as possible and minimise their expenses. Therefore, several young and especially single respondents saw employment in domestic services as a good way to combine living, studying and financing their studies, as well as improving their knowledge of German. After some time, they generally change to a live-out occupation rather than another sector.

The main goal of my trip was to improve my German, and I'm sure that I succeeded. I'm also sure I learned a lot about Austria. I didn't expect any financial successes, so in this sense nothing really surprised me. [...] I can study while working, and I always have contact to German-speaking people. I also like to 
work with children, so my working situation isn't too bad. (Female respondent, 22, Czech Republic, domestic worker)

If a job was not compatible with one's aims anymore, migrants considered changing their job. Reasons included monetary issues (low or unpaid salaries, etc.), but at the same time also difficulties in the relationship with their employers and questions of respect. Respondents who felt disrespected by employers, who cheated them out of their wages or exploited a position of power by insulting their integrity in any other way, were often motives for leaving the job.

I left because the employer was an idiot, or because he had too high expectations, or because he did not pay well, or did not pay more for working at night, or because the work was boring. (Male respondent, Poland, construction)

Nevertheless, a good relationship with the employer can also compel a migrant to keep the job, even of it is irregular and they do not like the work very much. This is true especially in the domestic sector, where a trusted relationship between employer and employee is of significant importance. Employers sometimes undertake efforts to keep their au pair, cleaning lady or caregiver and try to improve the working and living conditions.

Keeping the au pair even after the contract has run out can be of major interest to the host family, because all family members and especially the children - the main care recipients - are already familiar with this caregiver and the daily routines in the household are already well developed. After three months, the employers of a Hungarian woman decided that they wanted her to stay so they increased her monthly income from 600 euro to 700 euro. After the au pair contract had run out, they supported and financed her university education.

After the first year, I thought I'd finish with the job, because I don't really want to work as a babysitter. [...] But I get along really well with the family, so I decided to stay, even though the only reason I'm still in Austria is my university education. To start with a university degree was their idea. My employers suggested that I study in Austria, because they knew that otherwise I would leave. (Female respondent, 26, Hungary, au pair)

Several of the domestic workers who were employed for some time with a single employer had the opportunity to live-out in a private apartment, often rented or even owned by their employers, while working full or part-time for this family. In general, the women preferred 
living-out because of greater freedom, privacy and control over working hours. One 23-year-old respondent from Ukraine, who had worked as a live-in caregiver for two years and recently switched to live-out employment for several employers, commented on her situation:

Yes, I am satisfied with my current working situation, because I work and I also have enough time to study, go out and meet friends. Now that I don't work as an au pair anymore, I have much more time to myself, although I earn the same money as before. (Female respondent, 23, Ukraine)

But even in cases where the migrant workers are not satisfied with their working conditions and their boss is unfair, they do not always have the opportunity to improve their working conditions or change their job. For example, a Polish man who came to Austria in I997 does not want to give up the level of stability he has reached with his work. As he has never changed his job since his arrival in Austria, he is very dependent on his current employment. For him, a bad job is better than no job:

Sometimes I thought about changing my job, but I never had an offer that would have motivated me to leave behind all I have now. Nobody would guarantee me that I'd have worked non-stop there. Everything else [other offers] was like it is here, but I have this job. It's a steady job. (Male respondent, Poland, construction)

\subsubsection{Irregular employment as a temporary project}

Irregular employment was seen as a temporary project by respondents irrespective of age, high or low skill levels, working in the public or private spheres, on a contract basis or fully unregistered. Most often, people agree to work irregularly only until they have accomplished their aims, for example, building a house back home, finishing university or earning a supplement to their pension. Nonetheless, as was shown above, decision-making processes are related to the moment and decisions can be changed according to circumstances. Hence, irregular employment often becomes a permanent 'temporary' project, as the biographies of those whose aims are strongly connected to projects in their country of origin demonstrate.

For example, most of the respondents in the construction sector aim at getting a regular job after the end of the transitional regulations. Young women working in domestic services - on an hourly basis for several households, for a single employer as live-out domestic workers or as live-in caregivers - all defined their current work situation as a 
'temporary project'. As one respondent observed, the overall aim is to find a 'normal job' afterwards, 'because I don't want to do this kind of work - cleaning and childcare - all my life!' (Female respondent, 23, Ukraine). The young and highly-qualified domestic workers want to keep on working in the private sector until they finish their university education or find access to a 'better job that is legal and related to my education' (Female respondent, 23, Ukraine).

Similar to the young women primarily taking care of children, irregular employment also had a temporary character for the two male caregivers from Slovakia (30 and 35). They had both already taken actions to leave the private sphere. One had his foreign diploma in health care recognised and worked in a domiciliary care service, while the other planned to migrate to London and find work in another sector.

In contrast to the perspectives of the young domestic workers for whom work in a private household has no future, the elderly caregivers, aged between 40 and 6o, wanted to continue their care-giving activities until their retirement. For elderly women, especially those with low qualifications, employment in domestic services means a reasonable income and a possibility to finance their life back in their home countries.

In Slovakia, women over 45 can't find any work, they are already too old. So old women like us have to search for work abroad. (Female respondent, Slovakia, 50)

As a consequence, this Slovak woman plans to work as a caregiver for another decade, although she would also prefer regular employment:

I have to work some ten or twelve years more. Then I can finally retire. As long as Sonja [the care recipient] is healthy, I'll stay here and take care of her. When she dies, I'll have to find work somewhere else. But I can't stay at home because I can't retire yet, I still have to work and I hope that I can stay in Austria. [...] But I'd appreciate it if we could register this work I'm doing, so I could pay some money into the social insurance system. (Female respondent, Slovakia, 50)

\subsubsection{Advantages and disadvantages of an irregular employment situation}

The advantages that are connected to regular employment (meaning having a 'normal' employment contract) in contrast to irregular employment (not having any employment contract) are well appreciated. But only when the disadvantages in an irregular employment situation start to outweigh the advantages do people consider quitting irregular 
employment. However, this is often easier said than done, as will be discussed in Section 3.I0.5, Attempts to get a formal contract.

By weighing the costs against the benefits of irregular employment, most respondents would opt for any type of formal, contract-based employment. Respondents specifically highlighted the rights associated with formal, contract-based employment as among the most important potential improvements, as well as the fact that regular employees have the right to complain in the event of an exploitative situation.

If you work unregistered, you cannot go and complain anywhere, you just have to accept it, live with it or look for something else. But if you have a contract, you can go and officially report it. (Female respondent, Serbia)

Another major advantage of contract-based employment was seen in social security. First, formally employed workers are covered in case of an accident in the workplace. For those working irregularly, having an accident means an interruption of income as well as problems in getting medical treatment. Without social insurance, medical treatment is de facto not affordable, so many people return to their home country to see a doctor. Since EU enlargement, possibilities of private insurance have improved and an increasing number of unregistered migrant workers choose this option. But generally speaking, an accident means a serious problem.

As soon as somebody offers me a formal job, I'll accept immediately. Like with the accident I had: if I had worked legally, I would have got compensation, and would have been insured. Then you can live quietly without fear of what the next day may bring, how to survive. And you don't have to go to work on crutches to earn some money because your resources are all used up. (Male respondent, Poland, construction)

This interviewee also addressed the feeling of security that is connected to having a contract. Permanently being stressed and uncertain about one's immediate future and only being able to plan from one day to the other are considered to be very negative aspects of irregular employment. This uncertainty also affects the core family, partners and children. Irregular employment can meet the expectations to care for the family, but only with difficulties. In the absence of a contract, there is no guarantee of regularly transferring money to the family. Furthermore, by not having social insurance oneself, it is impossible to provide it to spouses and children. Therefore, social insurance is often organised in the country of origin: migrants are co-insured through their 
parents or have taken out a basic insurance policy with minimal contributions in their country of origin. Nonetheless, those arrangements require investments and are not affordable for everybody:

I don't have money, so I don't have insurance, either. For some time I had it in Poland. My children are insured through my wife because she worked in the past. (Male respondent, Poland, construction)

Being separated from the family is another substantial disadvantage for those who are married or in a long-term partnership. While it would be less of a problem for the entire family to migrate to Austria with a regular contract, irregular work in many cases does not even enable visits by family members because living conditions are not appropriate, for example, when migrants share an apartment with several others. Consequently, most people with a family plan to return home sometime in the future, but this contrasts with the need or wish to earn more money.

I'm satisfied with my work, but I'm not satisfied that I live without my family. [...] We talk every evening, but that's not what I want. There are two possibilities: either I return home, or I stay here. (Male respondent, Poland, construction)

The lack of social security is also a concern in the long-term future of migrants. The right to a pension is bound to a regular job. This also includes pension claims in the country of origin that can be accumulated with regular working hours abroad (within EU countries, for example). Therefore, irregular work over a longer period of time means getting only the minimum pension upon retirement.

Additional social aspects were laid down especially by third-country nationals who sense difficulties on two sides: legal residence and access to the labour market. As a Serbian woman explained:

Contract-based employment is much better! Everything is better. You earn less but you have certain benefits to safeguard the future. I could see my child, as he could come to Austria regularly. But now I don't have this possibility. Now my aunt or my cousin living in Austria has to invite my child to make it possible for us to see each other. My child also needs a formal invitation to get a tourist visa. In order to file for a formal invitation, you have to have a pay slip and a tenancy agreement of three or four months. I cannot provide these things. (Female respondent, Serbia, cleaning, catering and tourism) 
The well-being and general feeling of security of migrants is also diminished by the permanent, if suppressed, fear of worksite inspections and their related consequences. On the other hand, this fear has diminished with EU enlargement and the associated freedom of residence for all new EU citizens, as will be shown in the next chapter.

\subsubsection{Attempts to get a formal contract}

Making a career within irregular employment is fraught with constraints and is seen as desirable only when the current working and living conditions do not clash with other aims migrants have (e.g. living together with one's family).So under specific circumstances, irregularly working migrants undertake efforts to get a regular job during the course of their employment. In sum, almost all of the workers would prefer to have regular work, although some fear not to profit from their work anymore. At the same time, irregularity generally is considered to be a 'temporary' project.

Nevertheless, there is often an intention to continue to work irregularly at least 'in the near future' - which could mean up to 'the next few years' - but still not in the long run. Especially those who plan to settle in Austria would prefer to regularise their status, while those who plan to return 'soon' or are commuting anyway do not see the need to get a regular job: here, the principle goal is to 'come to work in Austria'.

On the other hand, most respondents in our sample wished to enter the formal Austrian labour market for the reasons that were already mentioned above: having social insurance, being secured for a longer period of time, being able to care for the family in the country of origin, etc.

However, most of the labourers got stuck in irregularity and worked much longer in an irregular setting than expected. Still, the state of irregularity is not necessarily a permanent one, but people may shift in and out of irregularity or may be in both situations at the same time, similar to what is generally known as moonlighting and is equally applicable to the non-immigrant workforce. But for some immigrant employees, this is not voluntary in the least. Take immigrant students, for example: due to the specific restrictions in accessing the formal labour market, they are not allowed to have two jobs above the social security threshold, as the following example of a Polish student illustrates:

Now I have a part-time contract and I earn approximately 280 euro a month. Based on this contract, I also have accident insurance covering accidents on the job. It was not easy to get this, but my employer, the lady in the hotel, helped me a lot. Generally everything is fine now. The only thing that makes me angry 
is that for a second small employment, I was told that as a foreign student I'm not allowed to have a second employment. (Female respondent, Poland)

When presenting oneself to a possible employer, insufficient language skills severely obstruct negotiations with employers from the very beginning.

It took quite some time until I found a job, most probably because of my bad German. Then I found a Polish pub on the Internet. I called and had the interview, presented myself and it went fine. (Female respondent, Poland, catering and tourism)

...I also speak German quite well. Now it's no problem anymore to look for work. Thank God it now works with the language, without language it's difficult to find work. You have to speak well. No language always means problems. (Male respondent, Poland, agriculture and construction)

With the exception of employment in ethnic businesses, where the insufficiencies of the language skills would not be as significant, this was often the case when trying to enter employment based on a legal contract or with an Austrian employer.

Nevertheless, language skills may facilitate getting a regular contract but are by far no guarantee. Interviewed migrants stated that regular and 'skilled' positions are still restricted to Austrians or long-term immigrants such as already established Turks or Yugoslavians.

Still, sound knowledge of the German language was considered a key competence to get out of short-lasting, low-skilled, badly paid positions. In catering and tourism, this took the form of changing from an invisible position (e.g. as an assistant in the kitchen) to a waiter or waitress dealing directly with customers.

In the construction sector, German language skills were considered helpful in developing from a manual labourer to an employee assuming certain responsibilities. This could be translating between colleagues with little knowledge of German and employers, or getting in contact with clients and thus developing one's own recruitment networks. In short, German language skills allow for advanced responsibilities and coordinative and administrative tasks.

After a few hours, I noticed that the other Hungarian workers who were employed illegally there could not speak German that well. So I had to help with translation everywhere, and I didn't 
have to do so much manual labour. (Male respondent, Hungary, construction entrepreneur)

Moreover, in the construction sector, German language skills were also presented as a precondition to become a mediator or 'employer' oneself and thus profit by organising and distributing work. To be able to deal with architects, real estate owners, etc., one has to have sound knowledge of the German language.

Although in domestic services women can find work with no or very low language proficiency, finding work in the formal health and nursing sector also requires good language skills, even in those cases where caretaking activities predominate.

Employers are important players in regard to regularisation efforts under current foreign employment laws. Some migrants reported very positive experiences with their Austrian employers. In other cases, especially in seasonal work, employees explained that the employers' hands were tied to the seasonal workers regulations, awarding only a limited number of seasonal workers to every employer. If the quota was already exploited, there was nothing to be done.

Yet others stated that although their employers often have the possibility to register them in a regular way, they are not willing to do so.

If you're an ordinary Polish citizen and would like to find a regular job, this is very hard, because nobody really wants to apply for your registration. (Male respondent, Poland, construction)

The very weak legal position of irregularly working migrants makes them vulnerable to exploitation by their employers, who take advantage of their employees' marginal position.

I think the boss could employ us legally if he wanted to. You hear about that. But he doesn't want to, because why should he pay more taxes? Besides, he's afraid that we'd run away and get a new job as soon as he'd registered us. (Male respondent, Poland, construction)

To avoid this, employers often feed the employees they hire irregularly with hope, saying that they would register them officially if they had a work permit: 'Many employers tell me that they would immediately register me if I had a work permit' (Male respondent, Poland, construction). Unfortunately, in most cases this is a false promise. For the most part, employers try to shift their responsibility for regular working conditions to someone else. 
Another paradoxical situation that emerged from the migrants' attempts to regularise their working status was that employers asked for working experience in Austria as a precondition for registering them. But even when a migrant has worked in Austria for years, he or she cannot prove this experience because irregular employment is not registered.

The absence of working papers also poses difficulties to women working in domestic services, as it binds them to a specific employer and makes it even more difficult to find regular employment.

I don't want to work illegally forever, as this is a great insecurity for me. If my family would register me, even for a couple of hours, I would already have proof that I cared for a handicapped person, and that would prove my work experience when I'd begin my studies. With papers, it'd be easier to find a regular job. But they won't even bother, although I talked to them about it several times. (Female respondent, 24, Poland)

Although a regular contract is generally a hot commodity, specific circumstances can cause migrants to reject the offer for a regular job. In one case, a Polish construction worker got a regular job offer in the I990s, but he rejected it because he intended to return to Poland very soon. When he ended up getting divorced, his plans changed and he regretted this missed chance.

I was asked twice whether I wanted to have a regular job, to be registered. I always thought, why do I need that? I'll stay here for another half a year and then go back, because I had my family in Poland and a small child. I really regretted having declined this offer, as it has become increasingly difficult to get a work permit over the course of time. (Male respondent, Poland, construction)

\subsubsection{The case of the domestic service sector}

Due to the restrictive labour migration policies in Austria, work in the domestic service sector rarely allows for a regular career. It is interesting to note that all female childcare-giving respondents in their midtwenties except for one had pursued a university degree or higher education in Austria. Due to their status as students, they met the conditions to get a limited work permit. Taking into account that the interviewed caregivers had the right to work legally at least for several hours a week, none of the women was offered regular employment in the domestic sector. At the same time, except for one case mentioned below, 
none of the other women claimed to be employed regularly in the domestic sector. This fact has to be analysed in connection with the low status of domestic work. Domestic work is rarely part of the women's self-definition, but rather they see it as a temporary work project and not a desirable occupation (see also Caixeta et al. 2004). When domestic workers tried to find regular employment, it was mostly in other sectors 'outside' the private sphere.

The only exception in our sample concerns a Polish woman who worked as a live-out for several employers and registered a trade licence for a 'cleaning company' after May 2004, semi-legalising her working status in the process. As we have seen above, this practice is generally more widespread in the construction sector.

\subsubsection{The case of students and seasonal workers}

Irregular employment of students and seasonal workers, but also of part-time employees, differs from other forms of irregular employment as those persons in principle have formal, if limited, access to the labour market.

Although there are many cases in which employees gained legal access by registering at an Austrian university, their working situations did not change all that much. Still, this regularisation was for the benefit of both sides. First, third-country nationals could legalise their residence status by means of a student residence permit. Second, health insurance was covered at relatively low costs. In the care sector, some of the employers would even pay the insurance fee. Third, the future perspective of acquiring a higher education that would pave the way for a better-paid, high-status job, either in Austria or elsewhere, increased the workers satisfaction with their current situation. And yet, and most importantly for the care sector, the employers could be more or less sure that their caregiver would stay in Austria as long as the university education would last, and would most likely continue working in their household.

For seasonal work, too, the central 'plus' is the basis of regular registration. Although seasonal work is considered poorly paid, in the end most seasonal employees are registered and insured and do not have to fear inspections. Despite the low wage level, migrants keep their seasonal contracts in order to have access to the formal labour market (albeit limited access), a regular residence status and social insurance. One seasonal worker who is also employed irregularly in the construction sector as a supplement to seasonal work stresses the importance of being registered: 
I don't want to work unregistered permanently. It's just temporary, until the season starts again. [...] I'm also afraid that my family and I would be deported to Ukraine again in the case of an inspection. You risk too much, even if you can earn more this way. (Male respondent, Ukraine, agriculture and construction)

For people without access to the formal labour market, seasonal labour is often the only way to get a regular contract. Thus, it seems paradoxical that this regular job does not suffice to sustain a life in Austria. 'It is hard sometimes; one has to work longer; there is much work to do. Nonetheless, you are not able to make any savings' (Male respondent, Ukraine).

Even for those who are exclusively engaged in seasonal work and return to their country of origin afterwards, seasonality does not only imply advantages. Especially those who have a family appreciate the seasonal break in order to see their families and take care of matters in their countries of origin. Nonetheless, no one can get a definite commitment to be able to return the following season. Recruitment for the next season sometimes happens on very short notice, so migrants have to leave their families behind and return to Austria with almost no warning.

[...] my boss needed somebody to clean the house for the personnel. She called and asked, 'Can you come? We need somebody for the cleaning.' So I had to come again in February, while I'd only returned home in December. (Female respondent, Romania, agriculture)

Regular access to the labour market is a precondition for occupational mobility and the changing of jobs. As a construction worker states, 'Everything has to be able to advance.' People working as students in catering and tourism or in other sectors can make use of this regular basis, but the seasonal employment model excludes such an advance. Seasonal employment does not result in further access to the formal labour market as it is excluded from the ordinary regulations on the employment of foreigners. Thus, the expectations of a Bulgarian seasonal worker of getting a better job upon losing seasonal work will not be fulfilled:

I'd try to find something else in Austria. I think I have a visa and I'm registered at the employment agency. That's why I can find another job easily. (Male respondent, Bulgaria, agriculture) 


\subsection{EU enlargement and its impact on irregular employment of migrants}

Ahead of enlargement of the EU in 2004, politicians and the media predicted dramatic impacts of this development on the Austrian labour market. Prognoses like the 'flooding of the labour market' dominated the reporting on the new states joining the EU. Therefore, transitional regulations for protecting the Austrian labour market were put in place, restricting the rights of new EU members to enter the labour market. As EU enlargement has not brought access to the labour market for all our interviewees so far, this report now asks what EU enlargement has really changed for irregular workers from new EU Member States as well as for third-country nationals who are irregularly employed in Austria.

\subsubsection{Irregular employment before EU enlargement}

Many of the interviewed migrants came to Austria in the I990s, long before becoming EU citizens, and before being granted privileged access in relation to other foreigners when applying for a work permit. Migrants from neighbouring countries were all third-country nationals and thus were not only obliged to have a work permit for employment in Austria, but also a residence permit to be able to reside in Austria and move freely in and out of the country.

Regulations on residence differ for each country of origin. While most non-EU citizens need a visa to come to Austria, some countries are excluded from this requirement; at the same time, their period of stay is limited to three months. This variety of regulations makes it very difficult for migrants to comply with regulations and also for police to inspect the compliance.

In the I990s, regularly entering Austria on the basis of a tourist or seasonal employment visa was a common practice for irregularly working migrants from the neighbouring countries. Although it was reported to us that the likelihood of getting checked at the borders was rather small, persons who did not risk overstaying their visa would return before their visa had expired (or before the three-month period was over), in order to get the exit stamp and apply for another visa. Nonetheless, as this became more and more common practice, a solution to the entering and exiting issue arose in the form of a market for falsified stamps, sold informally inside the country for about 200 Schillings (about fourteen euro in today's currency).

It wasn't easy. In the beginning, I also returned every three months. Later on, as the relationship with my wife deteriorated, 
I stopped going back. I got a false stamp twice, for 200 or 300 Shillings. In the case of inspections, I could've proven that I'd just arrived. (Male respondent, Poland, construction)

To explain how common this practice actually was, respondents referred to the fact that even foreign enterprises sending their workers to Austria would make use of such practices for all workers without a permit.

In Hungary, we had a contract with a Hungarian enterprise. But we had to hide it when crossing the border and immigrate as tourists. (Male respondent, Hungary, construction)

As tourist visas may be issued rather quickly and in succession, migrants often became 'permanent tourists'. Today, the following recommendation can be found on the homepage of the Federal Ministry of Internal Affairs: 'The Ministry strongly advises against the frequently used practice of leaving the country at the end of three months and reentering the country a few days later'. ${ }^{\text {? }}$

If there were any border controls at all, border they were described as rather lax harassments, as one Polish worker remembered entering the country in a bus full of male Polish 'tourists':

Upon leaving the country, they often checked the stamps in our passports that showed how long we'd been in Austria. And when we came back, they asked, 'Where are you going?' Such silly inquiries, because it was pretty logical that 50 men wouldn't come to Austria to visit someone, but to work. (Male respondent, Poland, construction)

Especially for younger persons, another way of extending the right to residence was by applying for a student visa. If the visa was granted, however, this meant additional obligations, namely the successful completion of a minimum number of courses.

The first time I had a visa for six months, the second time again for six months, and then I applied for my student visa. At first this was only for six months, but then I extended it up to one year. (Female respondent, Ukraine, catering and tourism)

Another regulation makes it difficult to uphold the legality of one's residence status, or at least the resemblance of it. Everybody who stays in Austria is obliged to appear at the local registration office after three days of their stay. Thus, not being registered could result in expulsion 
for most migrant workers. Today, this still applies to third-country nationals in some cases. As registration documents were primarily checked in the public sphere (e.g. at street inspections), migrants highlighted that having a registration document was of specific importance and in some cases even more important than a visa. Thus, many migrants were looking for ways to register themselves, even if they did not have a long-term residence permit. For example, an easy way to get registered was to list one's accommodations as one of the mass dwellings, even when one did not actually live there.

'It is not that expensive [to live in a mass dwelling], and you can also register here. For those who work legally, this is very important, because you need it [a registration certificate] to get a bank account. (Male respondent, Poland)

Thus, even today, the registration of one's place of residence is important for migrants from EU countries. First, it is a precondition for getting a regular job or to register a trade licence. Second, it is necessary for administrative issues, such as opening a bank account or registering a mobile telephone.

In live-in care in the domestic sector, migrants and agencies found a specific way to handle the restrictions in residence legislation: transnational care circuits. Workers would enter Austria as tourists and only then contact the Austrian family in need of long-term care. Two persons sharing a workplace could solve the problem of periodic absences after the visa had expired. While one caregiver would stay in Austria with the patient, his or her exchange partner returned to the country of origin and took his or her time 'off'. After several weeks, or a maximum of three months, and well before the expiry of the tourist visa, the exchange person would regularly enter and resume work. This organisational pattern was encouraged by placement agencies as well as by informal networks. The advantages of this arrangement are quite obvious: the workers had a temporary but secure residence status as tourists; while working in the private sphere, they barely had to fear inspections; returning home regularly allowed the caregivers to uphold contact with family and friends and relax after an intense and exhausting working cycle. (For further details, see Section 3.8.2 on specific actors in domestic services).

\subsubsection{Impact of EU enlargement on the situation of irregularly employed migrants}

Although regulations on access to the labour market substantially stayed the same for new EU citizens, EU enlargement and the asso- 
ciated freedom of residence significantly changed the circumstances of an irregular employment situation. First, it presented the possibility to freely move (coming, returning, visiting, receiving visits) whenever one wished; second, the consequences of worksite inspections changed substantially for EU citizens, as they cannot lose their residence permit anymore.

While most of the migrants managed to find their way through regulations on residence and employment in some way or other, the story of a Polish worker is characterised by the results of non-compliance with residence regulations and their consequences. While he came from Poland as a refugee in 1989 and even got a regular job in the beginning of his stay, he lost all his residence and work permits through adverse circumstances. He was deported sixteen times since then, always returning to Austria immediately thereafter. For him, EU enlargement is a valuable relief.

I was deported sixteen times. I always slept in parks. No money, no documents, nothing to eat. Every three months, you had to get a new stamp [to renew the tourist visa]. Police often came to check on it. And I didn't have one. I was deported on 7 April I995, and I haven't forgotten it. I was forbidden to enter Austria for the next five years. I then came back over the 'green border'. Four times, five times. In one year, I was deported three times. The police just laughed, they already knew me. (Male respondent, Poland, construction)

EU-8 citizens can now travel within the EU as they like and can only be deported for criminal activities. As a result, they do not have to fear police inspections on the streets anymore, and border controls are no longer a threat, either. Therefore, although hopes of getting a regular job were not fulfilled, EU-8 citizens state that EU enlargement has made their lives easier.

On the day of accession, I thought that everything would be better, that there would be some chances of getting a legal job. In the end, there are no prospects for legal working possibilities. But at least we feel better here. (Male respondent, Poland, construction)

Almost all interviewees mentioned this 'feeling better' as a result of their legal residence status as the most crucial change in the course of EU enlargement. 
Maybe there is less fear, although I'm still working illegally. (Male respondent, Poland, construction)

What has changed certainly is the situation at the borders. Also here in Vienna, because you used to have to worry about street controls. This doesn't happen anymore. (Male respondent, Poland, construction)

There used to be lots of problems at the border - they always checked and searched the car. But thank God this has changed. There are no controls anymore. Now everything is easier. (Male respondent, Poland, agriculture and construction)

While EU citizens are still not treated equally, mobility rights may help in feeling safe and at home also in Austria.

It was rather comfortable, because I could feel like I was at home. Before accession, there was a strict border, which was feared. [...] We then felt like second- or third-class citizens. And now, of course we're not like Austrians, but it's much better. (Male respondent, Slovakia, caregiver)

Before EU enlargement, travelling between Austria and the country of origin was not easily undertaken. It was a rather risky endeavour, as border crossings could always mean the loss of one's residence rights or being detected as working irregularly. People had to plan their visits according to visa regulations, not leaving the country too late though still just in time not to exhaust the maximum period of stay.

In emergency situations, such as a family member falling ill or having an accident, one could not just return to the home country without putting one's right to return at risk. The need to return after a threemonth stay could also come into conflict with ongoing work contracts, which could quickly be lost during one's absence.

Now it's different. You can travel as you like. A lot has changed since EU enlargement. I'm not afraid anymore. I often go around in my work clothes and I'm not afraid. I'm not a criminal because I work. (Male respondent, Poland, construction)

Thus, irregularly employed migrants of the new EU Member States do not have to fear inspections anymore: border controls and street inspections are no longer a threat to EU citizens. Since EU enlargement, people can feel more secure, also in their daily life on the streets. In the case of a police check, they just show their registration certificate or 
say they have just arrived to visit somebody, and no further troubles arise. Also, perspectives of shifting one's centre of vital interests to Austria open up.

When I cross the border, it's easier for me now. He asks what I am going to do here, and I say that I live here, it's that simple. I used to pretend I was only crossing through Austria. I've already been stopped by the police, and I just said, 'I live here in G.,' showed them the registration certificate, and they didn't ask any further questions. (Male respondent, Poland, construction)

However, the transitional regulations and the ongoing restrictions on the Austrian labour market are assessed very negatively. As one migrant commented: 'I think EU enlargement has not brought about any advantages for us' (Male respondent, Poland). At the same time, there are concerns that it has become more difficult to find regular employment since EU enlargement. While some connect registration difficulties directly to EU enlargement, others see this trend as embedded in a longer process of EU-wide integration and migration policies.

The situation has surely changed in Ireland, Great Britain, France, Spain, et cetera. where it is allowed for the 'new members of the EU' to work without a work permit. But otherwise I'd say that in Austria and Germany, the situation has gotten even worse than it was before. I think it's nearly impossible to get a work permit nowadays. (Female respondent, 22, Czech Republic, au pair)

The forthcoming accession helped people to hang on and wait for better times. In the words of a Slovak woman:

I didn't like my situation at all. But I knew I just had to hang on for some time until I'd get free access to the Austrian labour market, as I was already registered for one year. Then I would have the right to choose a job and say, 'Now this I don't like.' (Female respondent, Slovakia, catering and tourism)

\subsubsection{Shifting working opportunities through EU enlargement}

Several migrants reported that especially in seasonal work, fully unregistered employment was not as easily found anymore as before EU enlargement. Nevertheless, those changes were referred to not only in the context of EU enlargement, but as developments of the last years 
in general. In his reflections about changes after the EU accession of his country, a Czech migrant who had already regularly worked in Austria long before EU accession most clearly summarised:

Before, non-registration was almost not an issue at all. It was just the common practice. (...) It has become much more difficult to arrange, to organise and to find fully unregistered work. I always found it, but now you really have to try, in the remote areas somewhere up in the mountains. Employers probably feel safer there now. (Male respondent, Czech Republic, catering and tourism)

Moreover, some respondents, but especially third-country nationals from the 'traditional' sending countries (former Yugoslavia, Turkey) who already had established working relations in Austria or who were even holding temporary work permits before EU enlargement, also sensed an enhanced level of competition.

Now they all ask for a seasonal permit. But I don't have this document, this seasonal permit and all that. Many employers now say, 'No, there are too many unemployed Austrians,' so many natives. First they have the chance to work, then the EU nationals, then me! (Female respondent, Serbia)

So now, Austrians come first, then people from Poland, the Czech Republic, et cetera. All of a sudden, so many people have EU rights and get the chance to work before I do - just because I'm Serbian, just because of that! I tried to get a temporary work permit three times, but I was rejected every time. (Female respondent, Serbia, catering and tourism)

Although some employers apply for the registration of their employees, this is now often rejected by the labour market service due to the preferential treatment of domestic and EU workers.

The company would've liked to register me, but the regional labour market agency didn't issue the authorisation. My boss would've liked to register me as an 'intern' because I did tourism school before. But they knew that I'd most probably work much more than twenty hours, and they didn't want to allow it. The regional labour agency informed me of this 'no continuation decision' saying that there's no good reason why I should work in Austria, as there are enough unemployed Austrians who could do this job. (Female respondent, Poland, catering and tourism) 
Conversely, some respondents from the new EU Member States finally achieved what had always been hoped for: a formal employment contract. In the words of an emotional Slovak woman who had worked only unregistered in private households before:

I was cleaning in their home. One day they told me, 'We're looking for someone for our catering company, someone from an EU Member State.' They told me I should go to the lady who knows everything about the law and how it works. Then I started to work. This was the first time I worked legally, and I had a contract! (Female respondent, Slovakia)

The implications of a formal employment contract were highlighted by another Slovak woman, who had been registered in a bar and was regularly cheated out of her salary in the past.

After one year of permanent registration before accession, I would get a work permit. And I got it last week. For me, this means that I have much better chances now: I can pay for my studies and my rent without being scared I'll end up in a miserable situation, like when I had to ask friends to help out with cleaning, et cetera. The things you do when you can't get registered. Now I really feel safe, also in regard to the border control - it's just enjoyable now. (Female respondent, Slovakia).

The 2004 EU enlargement also changed some perspectives with regard to the labour market in the UK and Ireland: 'If I can't make it here, I can always try it in Ireland or Great Britain' is a common statement migrants make. Even workers in the domestic sphere can now use the possibility to register for a trade licence - as in the construction sector - in order to work in private households as a self-employed person. This is the case of a 30-year-old Polish woman. For her, the trade licence is a possibility to partly legalise her status, and at least, as she put it: 'I can now pay my own social security and health insurance'.

In contrast to some expert and media predictions of a 'flooding of the labour market', most of our respondents stated that there would not be any major changes in regard to who comes to Austria and how many people would come: 'The people who want to work here are already here' is another frequent statement heard. In addition, the current transitional regulations are thought to render countries like Germany and Austria unattractive for new, young immigrants, who would prefer to work in an EU country with regular working possibilities. 
Regular employment possibilities in other EU countries also open up perspectives for those who see no perspective on regularising their job in Austria.

I'm already older now and have to start to work regularly. Before that didn't interest me much, but now it does. I also thought about going to Great Britain, because you can already work legally there. (Male respondent, Poland)

Furthermore, some students in our sample started to exploit their mobility rights after EU accession and found new ways of escaping the restrictive regulations concerning the labour market access for non-national students in Austria. During their semester breaks, they would go and work abroad in a third country (preferably an English-speaking country such as the UK or the United States, in order to improve their English language skills), using extended networks to find a job. In doing so, they could save money to finance their studies in Austria.

During my semester break in the summer, I could go to the United States and Great Britain, where I also worked as a chambermaid. That way, I didn't have to work in Austria until January. Then my parents helped me out a bit and I started to distribute flyers again, et cetera. (Female Polish student)

During my semester break in the summer, I went to work in England for all three months. As Poland was already a member of the European Union, I didn't need a visa or even a work permit for Great Britain. I could work in a factory and as a cleaning lady in an office. (...) Because I'd earned enough in England to survive in Vienna until the next semester break, I didn't have to go back to that bar, which actually made me very happy! (Female respondent, Poland)

In sum, restrictions on access to the labour market connected with the freedom of residence are often directly related to irregular employment as such. Irregular employment is thus seen to be facilitated by state regulations.

It'd be better if the labour market were already open. Then they'd have all the people together under one umbrella and they'd know what they're doing here and who they are. Nobody would be able to circumvent that anymore. (Male respondent, Slovakia) 


\subsubsection{Impact of EU enlargement on the inspection situation}

Since EU enlargement, the inspection situation for EU citizens has changed completely, reducing the general risk associated with irregular work in Austria for many. This not only refers to street inspections or border controls, but also to worksite inspections that are now directed at the employer and no longer result in the expulsion of irregularly working migrants. On the other hand, such inspections can still result in the loss of one's job, as employers find themselves in trouble with the law. Hence, inspections can still mean the loss of one's livelihood. In whatever case, what migrant workers had to say about inspections on construction sites before EU enlargement reveals a great deal about how risky and frightening the atmosphere in irregular construction work must have been back then:

I was working illegally around I995 and I got caught. We were working in Floridsdorf. They had dogs, so we couldn't run away. First they put us in jail, then we were brought back to Poland by bus, in the beginning they even did this by plane [laughs]. (Male respondent, Poland, construction)

There were cases before where we had to flee on the roofs or we always had to have a hiding place somewhere. (Male respondent, Poland, construction)

The secure legal residence status of EU citizens now facilitates the enforcement of workers' rights, which theoretically also exist for employees hiring irregularly. One Polish man tells about a situation in which, during the course of a worksite inspection, he charged his employer with cheating him in wages.

Two years ago, there was an inspection by the tax office. That was when I worked for the guy who owed me I,400 euro. When he saw the inspectors, he disappeared immediately. So I betrayed him, I told them everything: that I should get nine euro per hour and had worked for three months. I also said that he owed me money and I gave them his address, everything. If he'd treated me all right, I wouldn't have done this. But so, then he had to declare bankruptcy. That was exactly around the time of accession. And I had no difficulties at all. (Male respondent, Poland, construction)

Employers and workers are increasingly mutually dependent on each other, although most employers try to undermine this recently 
strengthened position of workers by prompting them to get a trade licence. Some interviewees stated that activities of inspection bodies have increased, making it more dangerous for employers to employ people without any papers. One works for an employer, but is formally 'self-employed':

During inspections, there's always the question about who gave the assignment and who the employer is. Our boss has explained to us several times what to do in the event of an inspection, where we could hide. That when they catch us, it is over for both of us, us and him. (Male respondent, Poland, construction)

In catering and tourism and, more generally, in seasonal work, respondents explained that since EU enlargement, employers regularly ask for seasonal documents as a precondition to being employed. Regarding the worksite inspections, some things have still remained the same. This was also reported for the construction sector in respect to trade licences. Those working 'visibly' would be registered at least parttime (under the social security threshold), while those working completely 'unregistered' would be carefully hidden and work in less visible places. Nonetheless, other respondents explained that they were dismissed after a worksite control, as employers got increasingly scared of being punished. They added that unregistered employment is easier to find in remote rural areas where worksite controls are not to be expected.

In contrast, people working in private households still feel rather secure (in respect to being inspected) and thus do not consider it necessary to get regular access to the labour market, as one Polish worker suggests: 'If you are working privately, how will they find out? Only if someone denounces you' (Male respondent, Poland). Private persons who hire workers for informal jobs in their homes and gardens do not care about inspections and their consequences, either. According to the same migrant, he was never even asked by his employers whether he had a work permit or not.

\section{Notes}

I A rough overview of the most notorious branches and sectors has been obtained through the preceding Delphi survey. Note: illicit or criminal activities (e.g. prostitution, drug trafficking and illegal trading activities) were not targeted by the interviewers for reasons of their own personal safety and the special difficulties of access.

2 See Section I.9 in Part I of this report on the regulation of migration and foreign employment in Austria. In order to qualify as 'key personnel' under the annual immigration quota, the prospective immigrant has to demonstrate to the Employment 
Service earnings of at least 60 per cent of the upper threshold for social security contributions, which in 2007 amounted to a 2,304 euro gross monthly salary, fourteen times a year (Beratungszentrum 2007).

3 Means of proof can include a sufficient balance on a personal account at an Austrian bank, traveller's cheques, or indication that a scholarship has been granted.

4 See also Fassmann et al. (2004).

5 We chose to call people who mediate jobs for a return payment 'mediators', seeing as the term 'client' is often associated with criminal activities, and other expressions such as 'organiser' are not used in the literature.

6 The social security threshold is the amount below which no social security contributions have to be paid, except accident insurance, about 333 euro per month. At this income level, no income taxes are due, either.

7 Source: www.bmi.gv.at/einreise (last accessed on i9 March 2007). 


\section{Conclusions}

\subsection{Integrating research approaches and results}

As stated in the introduction, our research project has aimed to contribute to improving the knowledge base in two disciplines: migration as well as labour market research. More specifically, the main objectives of the project have been as follows: to fill a major gap in Austrian migration research; to identify the main underlying factors driving and sustaining irregular migrant work; to discover fundamental patterns and structural characteristics of irregular migrant work; to identify shifts and changes in these patterns and characteristics resulting from major socioeconomic trends; to determine the impact of successive rounds of EU enlargement on irregular migrant work in Austria; and to compare and contrast our findings with the regulatory intentions of state policies and control mechanisms.

To guide our theoretical interest and the development of our research project, we started off by putting forward a number of hypotheses that constitute something like a guiding principle throughout this report and the various research methods we employed. We will now try to assess each of these hypotheses against the theoretical and empirical insights generated by our research.

1. Due to high income differentials, there is a large potential supply of regular and irregularly working migrants in Austria from lower-income countries in Central, Eastern and South-Eastern Europe.

In its simplest form, this widely held, almost common-sense view on migration argues that migration flows are generally from low-income to high-income countries, and that the income differentials between Austria and its neighbouring countries are thus a necessary and sufficient condition for regular and irregular labour migration to the country. This basic argument has been refined in several strands of migration theories, such as push-pull theories (Lee 1966) and microeconomic and macroeconomic theories of migration (Lewis I954; Harris \& Todaro I970; Sjastaad I962; Borjas I989). It was later complemented 
by more sophisticated approaches (Stark I99I) and the migration-sustaining network theories of migration (Massey I989).

Against this general theoretical framework, there is much empirical evidence that confirms the importance of income differentials as well as short geographical distances for migration flows, and for irregular labour migration flows in particular. For example, while the larger part of migrants in Germany still stem from traditional 'guest worker' recruitment countries such as Turkey and former Yugoslavia (indicating the importance of state policies and ensuing network effects), migrants from the neighbouring Central and Eastern European countries account for the largest share of irregularly working migrants in Germany today (cf. Alt 2003; Cyrus 2004; Schönwälder et al. 2004; and others). The same has been argued for Austria, where around two-thirds of all migrants originate from the erstwhile labour recruitment countries, the successor states of former Yugoslavia and Turkey (Fassmann \& Stacher 2003; Biffl 2005). And while migrants from the new EU Member States still make up only a minor part of the foreign population, it has been suggested that their share is likely to be much higher in irregular migrant work (Biffl 200I; Jandl \& Hofmann 2004).

These views were also shared by the majority of our experts in the Delphi survey. There was widespread agreement on the following: that irregular migrant work in Austria has assumed a considerable magnitude; that it has significantly grown over the past fifteen years and in particular since 2004; that it has the potential to further grow due to EU enlargement and the lifting of transitional regulations on the labour market; and that the majority of irregularly working migrants in Austria originate from the new EU Member States.

How do these theories, empirical studies and expert assessments compare to our empirical findings through interviews with irregularly working migrants? We can say that our results largely confirm the rough outlines of the theories and evidence sketched above. However, when it comes to the details, we often found contradictory and sometimes surprising evidence. Our sample selection was deliberately focused on irregularly working migrants from the new (2004 and 2007) EU Member States and former Yugoslavia, so the sample composition does not in itself provide evidence on the geographical origins of the wider population. Nonetheless, the accounts of our interviewees on who they work with and which irregular branches are dominated by which nationalities do provide this evidence - again, largely in concurrence with the theory and expert assessments above.

Moreover, the description and analysis of the functioning of migrant networks provides a central message on the question of the "potential supply' of irregularly working migrants. This supply (at least from the new EU-8 countries) is highly 'elastic', meaning that new, yet unfilled 
potential job opportunities are quickly communicated along established migrant networks and are consequently quickly filled by either already present or newly arriving migrants. To put it differently, there would be no supply independent of a demand for irregular migrant work. This brings us to the next hypothesis put forward at the beginning.

\section{In certain sectors and branches of the Austrian economy, there is a considerable demand for irregular foreign labour.}

Returning again to the theoretical underpinnings of migration research, there are several influential authors who have argued that irregular labour migration is fundamentally determined by a permanent demand for cheap labour in industrialised countries. On a general level, the dual labour market theory (Piore I979) in its classical (Portes I997) and modern (Arango 2004) interpretations, as well as the global city hypothesis (Sassen I99I) and its extension by ethnic economies (Light 2004) all argue that because the demand for low-skilled, lowpaying and precarious jobs cannot be satisfied by native workers, it is increasingly satisfied by irregularly working migrants. These migration theories are complemented by a number of theoretical discussions on informal labour markets that attribute the demand for irregular foreign work to certain structural characteristics of labour markets, such as over-regulation (Williams \& Windebank I998), de-regulation (Talbot 2004), flexibilisation (Overbeek 2002) or globalisation, increasing cost pressures and other factors (cf. Samers 2005).

These theoretical arguments are too abstract to lend themselves to operationalisation and evidence-based testing. Empirical studies on irregular foreign employment in other European countries, however, have produced valuable evidence and have identified a number of sectors and working conditions as conducive to the irregular employment of migrant workers. For Germany, the sectors and branches most often mentioned are construction, agriculture, tourism and domestic services (AKI 2003; Cyrus 2004; Lederer \& Nickel I997; Sinn et al. 2005; and others). Specific conditions and characteristics conducive to irregular migrant work are often seen in labour-intensive, physically demanding and low-qualified work, with a low risk of detection, high seasonal variability, and tasks that are generally impossible to mechanise or outsource (Alscher et al. 200I; Alt 2003; and others).

In our Delphi survey, we collected a number of expert assessments on the most notorious sectors and branches and provided a tentative quantification of the extent of irregular migrant work for Austria. In these assessments, construction, catering and tourism and agriculture surfaced as the most affected branches in the public sphere, while do- 
mestic services (cleaning and home care) were seen as being dominated by irregularly working migrants.

Building our interview sample on these assessments, we were able to learn a great deal on work opportunities and the demand for migrant workers in these sectors. As our in-depth narrative interviews went deep into the reasons and motives of workers and their employers to engage in irregular migrant work, we were able to trace patterns, structures, forms, characteristics and other previously unavailable insights. One general conclusion from this research is that there is indeed a considerable and permanent (if seasonally fluctuating) demand for irregularly working migrants in a number of sectors and branches of the Austrian economy. Moreover,the single most important reason for this demand is the high level of taxes and social security contributions associated with regular employment (the so-called 'tax-wedge') and, thus, the cost savings associated with irregular migrant work.

As this permanent demand for cheaper irregular labour is the main driving force behind irregular migrant work in Austria, other factors and developments assume only secondary importance. Thus, while our research traces the influence of EU enlargement in 2004 on irregular migrant work and demonstrates the influence of it on forms, patterns and employment arrangements, we found little evidence that the overall extent of irregular migrant work has fundamentally changed. We ascribe this to the observation that - while opportunities have expanded for many irregularly working migrants and the forms of irregular migrant work have become more complex over the past decade as described in this report - the demand side changes only gradually and is driven by other socioeconomic factors.

To sum up this discussion on the supply and demand of irregular foreign employment and to assuage fears of a sudden flooding of the Austrian labour market by irregularly working migrants (whether after EU enlargement, the lifting of transitional regulations, the lifting of border controls and so on), we wish to reformulate the two hypotheses above. We propose to do so with the following statement: rather than by the supply of irregularly working migrants alone, the structure and dynamics of irregular migrant work in Austria are equally shaped by a considerable and permanent demand for irregular migrant work in certain sectors and branches of the Austrian economy.

\section{Irregular migrant work is in most cases accompanied by a de- qualification of the migrant workers accepting low-skilled work.}

There is a wide spectrum of opinions concerning the de-qualification of migrant workers and especially those involved in irregular work. In the theoretical literature, one can generally distinguish two positions in 
this respect. While many authors draw attention to the low-skilled migrants working in the informal economy (Bundesregierung 2005), others (Lederer \& Nickel 1997; Stobbe 2004) see them as being aboveaverage skilled and resourceful and, by necessity, having to accept unskilled, low-paid irregular jobs that sacrifice their skills. This process is seen by Cyrus (2004) and other authors as 'brain waste', 'brain loss', 'skill waste', declassification, depreciation of skills or downward mobility. Veiga (I999) speaks about 'domestification' of migrant skills on the irregular Spanish labour market. Many of the irregular migrants mostly concentrated in domestic, agricultural, construction and trade work lose their previous qualifications and skills and become generalists.

A similar opinion was shared by the experts involved in our Delphi survey and many of the migrant workers we interviewed. Before taking this assessment/phenomenon for granted, however, it is interesting to look at it carefully from different perspectives. In many cases, due to the restricted foreign employment and migration regulations, migrants do not have any other choice but to accept work below their qualifications. This is also a distinctive feature of irregular migrant work. And yet, the skills they brought from abroad have to be seen in the new social context. As our migrant interviews showed, some qualifications had nothing in common with the job performed and, in some cases, the qualifications were not even practiced in the country of origin, making it difficult to speak about de-qualification through irregular migrant work.

Nevertheless, irregular migrant work is in most cases accompanied by a de-qualification, as in most cases it is simply a characteristic feature of irregular work in general, no matter if performed by migrants or natives. In a modern interpretation of the dual labour market theory, economic globalisation does not only create opportunities for highly qualified labour, but it also generates opportunities for poorly qualified and unskilled workers. In post-Fordist economies, employers find it beneficial to use cheaper, irregular labour, and the demand for it is high. On the other hand, due to the restrictive nature of immigration and labour market policies, this affects migrants the most of all. They are a particularly vulnerable group, also because they have insufficient language skills, lack specific knowledge of alternative opportunities, cannot get their foreign education recognised, etc. Furthermore, this trend is stronger in respect to migrants with an irregular resident status or asylum seekers, where the level of uncertainty and risk are much higher. Especially regulations regarding the admission of low-skilled migrants have become more restrictive - hence the demand for irregular migrants. Local workers may accept such low-paid jobs for a short time, whereas the differentiating characteristic of migrants is that they 
accept these conditions for a longer period of time (Quassoli I999), even if they intended only a temporary migration project at the beginning. This is also an opportunity for low-skilled or unskilled migrant workers.

Furthermore, there are certain characteristics that make specific branches and economic activities particularly susceptible to irregular migrant work - such as a standardised qualification profile in many low-skilled labour intensive jobs or a seasonal or generally high fluctuation of workers.

In addition, different branches are entered by different groups of migrants for different reasons and with certain distinctive characteristics. The concentration of migrant workers in particular sectors increases pressure on both wages and vacancies, especially when unscrupulous employers exploit the vulnerabilities of migrant workers to drive down wages and offer worse working conditions. This not only exacerbates a process of 'regressive flexibilisation' within the local labour market, but it also seems to discourage some employers from investing in workforce employment. The majority of experts shared the view that the qualification profile of migrant workers is higher than the nature of their work in all sectors except private home care, where qualified personnel perform skilled work even if the employment relationship is mostly irregular. The strongest contrast between the unskilled nature of work and the migrants' qualification was seen in agriculture, household and cleaning and catering and tourism - thus suggesting a strong de-qualification effect. Interestingly, the career opportunities are very much influenced by the sector one is in. Young migrants in domestic work or catering and tourism have more possibilities for upward mobility through wider networks and contacts with nationals, as well as greater opportunities to acquire new skills (sometimes improving career potential in the country of origin) than those in the construction or agriculture sectors.

Another important point worth stressing is the temporary character of irregular employment, which is often seen as an entry strategy. Regular jobs are preferred in general, but this is not always the case. Thus, one could say that the generally observed de-qualification takes place in a time-limited way, and it is only a part of a migration plan or career development that fits well with the migrants' goals. Thus the observed 'skill waste' is often temporary, ${ }^{\mathrm{I}}$ though in some cases it can also become of a more permanent nature. This opinion was often shared by our migrant respondents and is particularly true for young persons who are still studying when they come to Austria or take up studies during their stay in Austria. A similar situation is in the agriculture sector, where the character of work is temporary in itself, even if repeated each season over a number of years. In addition, some experts 
pointed out that even when migrants had formally low-skilled jobs, they sometimes still used their qualifications in their daily work.

In many cases, there is thus not a 'brain waste', but rather a 'brain change'. Migrants counted the irregularity and official de-qualification in, while having another motive such as 'improving German language skills' or 'gaining work experience'. The de-qualification was thus expected to last only for a short or limited period of time, with the eventual goal of improving qualifications and developing professionally. In many migrant biographies, the advancing in hierarchical structures was remarkable. The problem with the de-qualification started, however, in cases when the 'temporary' project took on a permanent character. And migrants almost always believe that return is just a matter of time. Young migrants, especially, also thus believe it will only be a matter of time until they gain a better socioeconomic position. They believe they will achieve this by improving their language skills and getting additional education, occupational skills and experience.

One more important aspect concerning migrant skills in general is often missed in the theoretical discussions. In a migratory context, the recognition of qualifications and credentials is more complex due to the internationality that is at the heart of cross-border mobility (Csedo 2007). In general, migrants' qualifications and skills are different in their national context and the new context of the host country. Zulauf (200I) acknowledges the employment mismatch originating from partial or non-recognition of foreign credentials on the host labour market. Others such as Salt (I992) are of the opinion that migrants' overall human capital is the object of transfer during the process of migration, hence employers are concerned with the recognition of the migrants 'brains' rather than their qualifications. Significantly, as Csedo (2007) notices in the case of the UK and what can also be observed in the case of Austria, employers are skill-based recruiters and job-relevant specific skills have a higher labour market value than generic educational skills. Thus, skills in the migratory context are not individual givens, fully transferable across borders, but they are rather outcomes of negotiations between employer and migrant (Csedo 2007). Therefore, skills have different values in different places and times, and 'de-qualification' is a normal phenomenon for many cases in the migration process.

\section{Irregularly working migrants in Austria strongly depend on the existence and functioning of social and family networks and increasingly on professional networks of illegal job providers as well.}

As in most labour migrations, networks play a crucial role in facilitating the irregular labour migration at many different stages. Networks 
are powerful intermediaries, not only offering migrants-to-be information on the opportunities of migration destinations, labour market needs and housing offers, but also on views, ideas, values and behaviours in destination countries. In all these functions, networks can help to reduce the social, economic and emotional costs of migration, as argued by the proponents of migration network theory (Faist 1997; Light \& Bhachu I993; Massey I989). Sociologists use the term 'exchange theory' to describe how people engage in social relationships in order to benefit from them. Based on kinship and trust, networks of family and friends constitute the core of migrant networks, in general, though especially for those in an irregular situation. They are characterised by strong ties of interpersonal relationships, while ethnic networks are based on weak ties of common heritage. This opinion is shared by our experts as well as our interviewed migrants, and is also prevalent in the theoretical debate. Irregularly working migrants in Austria depend on the existence of these networks with varying intensity over the course of their migration experience. Thus, networks play a particularly strong role at the beginning of the migration project: for recruitment and finding housing, for acquiring both general and specific information and for help in emergency situations. They provide inspiration, create 'fashions' of behaviour on the labour market and also shape return perspectives. In general, although most interviewees did rely on various networks, the most important ones consisted of individuals they had known from their country of origin prior to departure and, less importantly, of individuals from the same country of origin (via kinship and friendship networks) they got to know later on. These findings are in line with other research. For example, Parrẽnas (200I) speaks about the 'dislocation of emotional relations' as the result of migration and globalisation. Family and friends often serve as role models who can have both positive and negative influences on the situation of irregularly working persons in Austria, supporting but also hindering their professional development. When it comes to professional development, however, it is more often ethnic and linguistic networks - who enable access to particular job opportunities - that manage to 'trap' irregular migrants within their own ethnic and linguistic communities.

In whatever form, the irregularity magnifies the strong dependence on migrant networks. Where the access to irregular work cannot be communicated officially, the importance of networks is growing. Thus, the communication and information strategies take place in an informal way and depend on them to a very high degree. The insecurity and the 'illusionist' temporariness of the situation require a high mobility and flexibility, for which network support is of particular importance. After all, access to irregular work information about job opportunities is usually communicated within established networks, rather 
than advertised freely in front of law enforcement agencies (cf. Doomernik et al. 1997). Besides informal networks of family, friends and ethnic compatriots, professional networks of labour brokers and people smugglers also act on the intermediary 'meso-' level of migration actors (Faist 1995, I997; Heckmann 2004; Jandl 2007; Kyle \& Koslowski 200I; Mavris 2002; Salt \& Stein I997).

Commercial networks are generally based on weak ties of common interest, as well as criminal networks that involve the exploitation of irregular migrants. Alt (2003a) observed that for certain forms of irregular migration (e.g. irregular circular migration), the significance of professional networks has declined as migrants have accumulated their own migration-specific knowledge and personal contacts. This observation was also supported by our migrant interviews. Professional networks of illegal job providers or job mediators often overlapped with ethnic networks and were more commonly used for finding irregular employment in seasonal branches such as agriculture or tourism, as well as in the care and construction sectors. Several experts in our Delphi survey shared this view. Significantly, ethnic and linguistic community networks are not equally available in all regions, but are concentrated especially in the bigger agglomerations (Vienna, Innsbruck). This also creates an initially favourable situation for more professional networks of irregularly acting job providers. Nevertheless, as soon as migrants have established their own networks, also with or through their employers, the importance of professional agencies providing access to irregular jobs declines. Thus, we can say that professional networks of illegal job providers often play an important role for irregularly working migrants at the beginning of their stay in Austria. They are often used as an entry strategy by new migrants or by those with very limited opportunities to build up their own social networks. At the same time, professional agencies providing access to irregular jobs are also very flexible and can change over time in reaction to the fluctuating demand for irregular work in particular sectors.

\section{Access to irregular labour markets varies considerably according to the impact of specifically targeted policies (migration policy, labour market policy, enforcement measures, etc.) and the amount of administrative and 'social' control.}

Generally it can be stated that most policies structuring access to irregular employment are not specifically targeted towards irregular employment or the irregular employment of migrants. It is rather a wider framework of national and EU-wide regulations that structures access to irregular employment. Moreover, as also experts stressed in the Delphi survey, irregular employment of migrants (non-nationals) is only a 
small part of irregular employment in general. For Austria, this framework structuring the access of migrants to regular and irregular labour markets consists of regulations defining access of foreigners to employment and residence in general (Foreign Employment Law and Residence Law), as well as more specific regulations for certain trades or groups of people, such as regulations on self-employment, student employment, au pair or seasonal employment. Those regulations define what is considered to be legal or illegal employment. (Regulations impacting the situation of irregular employment of EU citizens will be treated in the next section). Therefore, our experts underlined that in order to reduce irregular employment, more comprehensive political measures must be found that go beyond a pure "cure for the symptoms'. Nonetheless, most of the strategies pursued to reduce irregular employment of nationals and non-nationals hardly cross this line.

Thus, for example, both our experts and migrants indicated that the Austrian regulation on seasonal employment, on the one hand, did reduce completely unregistered employment in agriculture. On the other hand, however, it has facilitated irregular employment by providing migrant workers only with a minimum of labour rights and an extremely low income, making it impossible to sustain a living for those who want to settle in Austria.

In contrast, employment in the domestic sphere was completely unregulated until recently, leaving childcare, care for the elderly and disabled as well as cleaning services almost entirely to irregular employment. Irregular employment in domestic services, generally not considered as 'labour', only attracted the interest of politicians as migrant workers were seen as competitors to domestic workers. Political interest in the provision of irregular care services by migrant workers only increased when the issue 'exploded' in the mass media during the 2006 national election campaign, bringing some embarrassing revelations on the use of irregular migrant care workers by prominent politicians along with it. In an intense political debate, neither criminalising nor permanently legalising irregular care work were seen as political options, so the government decided to buy time for reflection by establishing a commission that would come up with sustainable solutions. For the meantime, a general amnesty until June 2007 for irregular care workers and their employers (the patients and/or their relatives) was announced by the Minister for the Economy and Labour, which at the time of writing - still lacking any comprehensive political and financially sustainable solutions - has been extended twice for six months, first until the end of 2007 and then until June 2008. Despite this sudden outburst of attention and the various draft laws debated, in reality not much has changed in the situation of irregularly working caregivers in Austria so far. 
Besides setting the legal and policy framework, stepping up control efforts and increasing the level of penalties for irregularly hiring employers (i.e. employer sanctions) are another strategy to contain and reduce irregular employment. While experts and migrants both confirmed that increased inspection measures (worksite inspections) increase the risk of irregular employment for employers and employees, the available evidence indicates that this does not automatically mean a reduction of irregular employment. Rather, ways of circumventing legal regulations via semi-legal arrangements are sought out and implemented. As the many examples of 'pseudo-self-employment' in our research show, despite new legal enactments to clearly distinguish between regular and pseudo-regular forms of employment, the latter are in reality very hard to control.

Thus, while the above-mentioned examples show that specific reactive policies and control measures influence the way irregular work is structured and organised, they do not seem to have a decisive impact on the extent of irregular migrant work as such. One reason for this is the simple observation that repressive control measures are quickly circumvented by employers hiring irregularly and their employees, as long as the gains of doing so exceed the expected losses. Another reason seems to be the widespread conviction among policymakers that irregular migrant work in many cases solves more problems than it creates (e.g. in the care sector) and thus deserves a certain tolerance. If this is so, it might be better to state it clearly rather than spending time and money on symbolic policies and ineffective control efforts.

\section{The 2004 enlargement of the EU had a profound impact on the structure and dynamics of irregular migrant work in Austria.}

The 2004 enlargement of the EU is only one point in a longer process of economic internationalisation, as well as in the development of the legal and economic framework within the EU. As explained, the latest EU enlargement in 2004 introduced various levels of access to the Austrian labour market, but basically kept the dichotomy between EU and non-EU citizens. In addition, transition periods with their multitude of inscrutable regulations and exemption clauses for 'new' EU-8 citizens render a simple legality-illegality dichotomy insufficient for describing irregular work (see also Anderson \& Ruhs 2006).

Already in an early stage of our research project, several experts participating in our Delphi study suggested that over the past few years, the irregular employment of migrants has occurred in greater heterogeneity and that this is related to the enlargement processes. It was stated that de-regulation processes, outsourcing to sub-companies and the ongoing liberalisation of the labour market promote irregular migrant 
employment, while at the same time the boundaries between 'irregular' and 'regular' work become more and more blurred. Employers and 'employees' try to make use of the broad range of legal regulations or search for ways to circumvent them. Our experts stated that especially 'grey' forms of employment such as pseudo-self-employment and the violation of trade regulations have increased since 2004, mostly so in the construction sector, which is characterised by internationally competing companies and sub-companies.

This development was also clearly confirmed by statements of irregularly employed construction workers themselves, stating that owning a trade licence has almost become a precondition to being 'employed' irregularly at a company. In seasonal sectors, it was also stated that completely illegal forms of employment have been replaced by 'grey' forms of irregularity, such as by issuing 'pseudo-contracts'.

The facilitated access of EU citizens to self-employment and their preferential treatment has clearly contributed to this development. The increase of pseudo-forms of regularity or irregularity also corresponds to another assessment of experts, judging that the main motive of employers to employ irregularly is to save on non-wage labour costs. Pseudo- self-employment and insufficient registration of employees passes those costs along to migrants and relieves employers of their legally defined duties.

In addition, several of our experts stated that the increased availability of migrant labour, due to the right for EU citizens to freely reside and travel within the EU, coupled with the restricted access to the labour market for EU-8 citizens, has led both to a higher supply and a higher demand (due to decreased risks) of irregular migrant labour in certain sectors. Generally speaking, our experts assessed that the amount of irregular migrant work, especially in self-employment, has increased since enlargement in 2004, except for in the agriculture and industrial sector. While these claims are not directly verifiable through our migrant interviews, many migrants reported that they did not notice any significant changes in the amount of irregular work among their own networks and certainly no big increases or decreases around the time of EU enlargement in 2004. The general conclusion on the above hypothesis is thus that the 2004 EU enlargement certainly had a profound impact on the structure of irregular migrant work in Austria but little, if any, impact on its dynamics. 


\section{The ongoing process of EU enlargement has noticeable (substitution) effects on already-established migrants working both regularly and irregularly in Austria.}

The 2004 and 2007 EU enlargements have brought new divisions within the non-national labour force, privileging 'new' EU citizens over third-country nationals, even if access to the labour market for both is currently restricted. For these two groups, changes associated with enlargement are of a different nature: for EU-8 citizens, EU enlargement is associated with freedom of residence and movement, while access to the EU labour markets has become arguably more difficult for thirdcountry nationals.

Thus, interviewees coming from the 'new' EU countries stated that EU enlargement has profoundly changed their life. They can now move freely between their countries of origin and Austria, not having to fear border controls or the consequences of police inspections (expulsion) anymore. Furthermore, they no longer have to invent strategies to keep their residence status legal, such as through becoming permanent commuters travelling back and forth every three months or using falsified stamps. Overstaying is no longer a problem. This right to stay has resulted at least in a 'better feeling' as stated by many new EU citizens in our interviews, even if nothing has changed in respect to their access to the labour market. As our experts in the Delphi study suggested, the risk connected to irregular employment has also subjectively diminished for the EU-8 citizens. Most were conscious of the fact that, first of all, they cannot be deported anymore and, second, in the event of worksite inspections, their legal residence status provides them with better means to take legal steps against their employers. Still, worksite inspections can result in the loss of one's (irregular) job and thus in the loss of one's livelihood.

We also noticed that the right to move and settle within the EU has apparently resulted in an increase of more or less spontaneous arrivals and stays of younger persons or students, in order to earn some money for a limited period. On the other hand, for some 'new' EU citizens, the perspective to permanently settle in Austria has opened up. While the latter project is not bound to a regular job, those who plan to settle in Austria face additional difficulties in irregular job arrangements, as their aim to integrate into Austrian society and to establish life locally implies a higher cost of living.

At the same time, EU enlargement has also resulted in increased possibilities to work within the EU and thus in other countries than Austria - in countries not protected by transitional regulations even in regular job arrangements. Especially students and younger, better qualified persons are reported to make increasingly frequent use of these 
more attractive working alternatives. In addition, possibilities of transnational insurance have improved and many of our interviewed workers now have at least basic health insurance, whereas they were working without any insurance coverage at all for most of the I990s.

On the other hand, within this ongoing process of EU enlargement, third-country nationals face increasing difficulties regarding their access to the labour market and to the EU in general. Reinforced EU border controls affect the entry of third-country nationals to the EU, while they no longer have consequences for EU citizens. Thus, in contrast to the assessment of our experts, third-country nationals who are still subject to visa regulations cannot profit from the flexibility implied in irregular working arrangements. In order to keep their right to return to their home countries or back to Austria, they cannot flexibly travel back and forth as they wish, even in cases of emergency.

As EU citizens enjoy preferential treatment in almost all areas of foreign employment, third-country nationals have almost no chance of getting a regular or pseudo-regular job anymore. This is especially true for seasonal labour contracts, which are no longer issued to newly arriving third-country nationals.

Although experts declared EU-8 citizens to be 'potentially competitive' with natives and saw them in direct competition with already integrated (legally employed) third-country nationals, this was not directly confirmed by our migrant interviews. Competition between natives and EU-8 citizens seems to be marginal and, among EU-8 citizens, third-country nationals and the additional group of future EU citizens (i.e. those of accession countries), it seems to occur mostly between newcomers and in the lowest-skilled segments. Nonetheless, the first argument appears to be at least indirectly true, as dependent forms of employment are more and more substituted by often irregular self-employment arrangements by outsourcing tasks to sub-companies.

For both EU-8 citizens and other migrant workers, however, EU enlargement has not changed the relatively low chances of making a career in a regular or irregular employment situation. EU-8 citizens can at least wait for the end of the transitional periods on the labour market, expecting to then have the possibility to choose and not having to accept just any job. In this sense, many of our interviewed migrant workers from the EU-8 expected some future upward mobility over the course of their stay in Austria and were less willing to accept ill-paid job offers. Some also complained about workers from other countries (e.g. Romania, Bulgaria, Ukraine, Moldova), who would work for less money and could not afford to be so picky. In certain sectors, most clearly in agriculture and domestic work, there was already a noticeable shift in irregular workers from EU-8 countries towards irregular work- 
ers from Romania, Bulgaria and non-EU countries, a process that can be expected to accelerate in the coming years.

Thus, the end of transition periods on the labour market for the EU8 citizens (whether they will come in 2009 or 20II) will not necessarily mean that irregular migrant work will decrease in general, as a relatively constant demand for IMW is met by new sources of supply. Since 2007 , there are already two new groups (Romanians and Bulgarians) that face restrictions on the labour market while enjoying free movement and residency rights within the EU. Other countries already enjoy visa-free travel and face few restrictions on entry to Austria. Nor do EU enlargement and the eventual end of transition periods for 'new' EU citizens imply that most irregularly working migrants will shift from irregular to regular work, even if theoretically they could do so. After all, this would make them more expensive for employers and hence negate their main competitive advantage over regular workers. Hence, for the foreseeable future, many irregularly working migrants from the EU-8 will remain in an irregular situation while others will return, become self-employed or get a regular job, in which case they will quickly be replaced by others irregularly working from more distant countries.

\subsection{Concluding remarks}

At the end of this research report, we hope to have drawn attention to some of the implications of our findings for public policies - especially those relating to migration and the labour market - for migration research in Austria and elsewhere and for the public debate shaping attitudes on irregular migration and irregularly working migrants.

As we have seen throughout this report, there are many underlying reasons for the occurrence of irregular migrant work that together account for the significant extent of the phenomenon in Austria. Nevertheless, while an adequate supply of foreign workers willing to work in Austria irregularly, often under difficult, unpleasant and physically demanding conditions for low wages, is a necessary condition for irregular migrant work to occur, it is not a sufficient condition. For irregular migrant work to occur, a demand for the services of irregularly working migrants is also necessary. Both elements are currently present in Austria to a considerable extent.

Both the supply side and the demand side are in turn determined by a number of factors, and we have encountered many throughout our research project. On the supply side, migrants bring with them a mix of motives that together account for their mobility and activity decisions - the wish to earn a higher income, generate savings, support 
their families, have new experiences, learn foreign languages or get an education abroad. On the demand side, there are at first sight also a number of determining factors - the non-availability of native workers in certain occupations, the need for flexible workers on short notice, the non-affordability of regular personnel, etc. In the end, however, all these factors boil down to one central factor: irregularly working migrants are simply less costly to hire for their employers than regular (native or migrant) employees. And the main reason for this cost advantage of irregularly working migrants is not necessarily their lower wages (as we have seen, skilled irregularly working migrants can earn net wages comparable to those of regular workers), but the fact that their wages are not subject to taxes and social security contributions, two factors that enormously increase the wage costs for employers.

We do not wish to go into an argument about formal exclusion and exploitation here, and we recognise that to a certain extent non-wage labour costs are a necessary contribution to the maintenance of the social welfare system in our market economy. Still, this is the evidence: employers do not irregularly hire migrant workers because they are available, more pliable, more dependent, more flexible, more versatile or harder working (they usually possess all these traits, too), but because they are cheaper to hire than regular employees. Nonetheless, before rushing to premature conclusions, we should take a closer look at who the employers are. Certainly there are many among them who are criminal entrepreneurs and use irregular migrant labour to increase their tax-free profits (especially in branches such as construction and industry). Then there are many small- and medium-sized entrepreneurs (e.g. in agriculture, catering and tourism), who feel strong cost pressures and hence the need to opportunistically use flexible and less costly irregularly working migrants. But there are also a great number of private households that benefit from irregularly working migrants, in areas such as home renovation, cleaning, childcare or care for the elderly. When irregularly working migrants provide services such as childcare and health or elderly care in private homes, they also help to alleviate the shortcomings in the public provision of these services (e.g. nursing homes for the elderly or nursery schools) in Austria. This irony - irregularly working migrants as both supporting and undermining social welfare systems - illustrates the complexity of the issue and the difficulties of designing sensible policy interventions in this area.

When talking about irregular migration, ten to fifteen years ago the most pressing issue was the overburdening of asylum systems across Europe and - though it certainly existed - there was less concern about irregular migrant work. The concerns and problems surrounding asylum seekers have since been substantially reduced, and the next big issue (at least in many Western European countries, including Austria) 
was the enlargement of the EU to the East and the resulting implications for East-West migration and labour markets. To alleviate pressures on native workers, temporary restrictions on the access to labour markets were put in place in twelve of the EU-I5 countries in 2004, and Austria (as well as Germany) has been one of the countries determined to prolong these transitional regulations as long as there is a serious risk of labour market disturbance.

At the same time, the 2004 EU enlargement also had consequences for irregular labour markets in Austria (and elsewhere in Western European countries), which has raised new concerns among the public. As we have seen, however, it is not so much the extent of irregular migrant work that has experienced fundamental changes since 2004, but rather the forms it takes on. Thus, both migrants and employers have used emerging opportunities to circumvent legal regulations and policy intentions, and a number of semi-legal or quasi-regular forms of irregular migrant work have gained prominence. This should not be surprising: both migrants and employers are innovative human actors and are constantly searching for ways to adapt to changing economic, legal and institutional circumstances to achieve their respective goals.

But while the forms and organisational arrangements of irregular migrant work have changed, its basic determinants have remained fairly stable. We do not know how irregular migrant work will look ten to fifteen years from now (it will very likely appear in very different forms yet again), but we know that it will exist as long as there is a demand for it. And from all we have learned in our research, we are convinced that the uses of irregularly working migrants are by now so deeply ingrained in various areas, branches and sectors that this demand is very likely to persist over the coming decade. But what if the current workers from Austria's neighbouring countries are no longer coming to Austria because they find better opportunities at home or elsewhere? Then again, we expect the market mechanisms to do their work by replacing current workers from Central European countries with workers coming from countries further East, a development already visible in some segments of irregular labour markets.

All of this, of course, raises the question as to what policymakers can reasonably do in order to address irregular migrant work. Above all, they should carefully consider all possible consequences of their policy interventions before publicising or promoting them, as the measures they adopt will eventually lead to direct as well as indirect and, very often, unintended consequences. This is all the more so, as both irregularly working migrants and their employers will certainly react to restrictive or inconvenient measures and develop new ways and means to circumvent them. At the same time, both can be expected to use new legal opportunities and favourable options to their advantage. The 
challenge is thus to design policy measures that use this active capacity of their target groups by aligning expected behaviours with motives and incentive systems (incentive-aligned policies).

To design policy measures that are effective as well as incentivealigned is not an easy task, especially in such a complex and largely hidden area as irregular migrant work. Using the insights and evidence collected in this research project is only a first step. The next step is to develop concrete evidence-based policies that are flexible enough to adapt to a frequently changing phenomenon. Finally, the real challenge is to implement them.

What could such policies look like? Without going into detail, it is unlikely that extreme policy measures will reach their goals in an area as complex as this one. For example, throughout this report we have seen that inspection measures alone have only limited effectiveness. Thus it is unlikely that multiplying inspection measures by a factor of $\mathrm{x}$ (whether $\mathrm{x}$ times more worksite inspections, more internal controls, stricter border controls, the introduction of more generalised biometrics, etc.) will decrease the extent of irregular migrant work accordingly, as both migrants and their employers will invent new ways of evasion. The same, of course, is true also of extreme policy measures on the converse side. For example, simply regularising all irregularly working migrants is unlikely to solve the problem, as this does not remove the underlying reasons for the demand for irregular rather than regular workers; quite simply, the latter are less expensive. We may thus expect that regularised migrant workers would become too expensive for many employers and would be laid off and then replaced by other irregularly working migrants.

Likewise, from what we have learned from our own research, we can also expect that isolated or one-sided policy measures will not be effective and may even be counterproductive. To take up the example of the recent policy proposal of the European Commission cited in the introduction, the explicitly stated rationale of this proposal is to reduce the pull factor of irregular work for illegal migration by 'targeting the employment of third-country nationals who are illegally staying in the EU' (Commission of the European Communities 2007a: 2). To do so, the Commission proposes mainly to harmonise (i.e. presumably increase) employer sanctions (including the adoption of criminal sanctions for certain infringements), increase employers' responsibility for checking work documents and dramatically step up inspections of worksites. Nevertheless, while it is doubtful if these measures, which are likely to cost billions of euros to implement, will reach their desired goals, there are no indications in the policy proposal that thought has been given to any unintended consequences that the planned interventions are likely to engender. This is unfortunate, as we have shown time and 
again in this research report that irregular employers and employees (and migrant workers are no different in this respect) are likely to react to stronger control measures and harsher sanctions in all kinds of evasive ways, thus counteracting the effect of the control measures and sanction regimes. Moreover, our case study has also shown that thirdcountry nationals are not a major factor in overall irregular migrant work in Austria (and the situation is likely to be similar in most EU countries), thus targeting only third-country nationals is too one-sided and isolated a measure to say the least. It would be better to take a comprehensive approach towards irregular migrant work as an integral part of the informal or 'shadow' economy of many states, rather than a single-issue approach. At the same time, broader policy measures that consider the full structure of the economic and regulatory system are called for, ones that are appropriate to address the underlying forces of supply and demand for irregular (migrant) work. ${ }^{2}$

If extreme policies to address irregular migrant work are unlikely to be effective, we should look for a number of medium-range policy instruments that together can make an impact on policy outcomes. In our Delphi study, we discussed a number of proposed policy measures as seen by our experts, so we will thus not repeat them here. Rather, we wish to add one final observation on the nature of the policy mix available to policymakers: policies aiming to reduce irregular migrant work can address either the supply, demand or repression side of the equation, but up to now the focus was almost exclusively on repression. While there is not much within the sphere of Austrian policymakers that can be done on the supply side, more efforts should be devoted to the demand side. What, if anything, can be done to reduce the demand for irregular migrant work? The answers could be conventional (employer sanctions, fines) progressive (more nursery schools, public nursing homes for the elderly, innovative (tax breaks, so-called household service cheques) or even futuristic (tele-home care), but they will all have to deal with one fundamental issue - the different and often opposing interests of various groups in society affected by such policy measures.

In this sense, effectively addressing irregular migrant work is not only an issue concerning the interests of 'those' irregularly working migrants. It is an issue that reaches deep into the interests and political stakes of various groups in Austrian society itself. 


\section{Notes}

I See also Fassmann et al. (I995).

2 The European Commission itself recognises this in another recent communication on policy measures against 'undeclared work'. In this communication, which is not concerned with migration but the economic and fiscal systems, alternative approaches such as 'reducing the financial attractiveness of undeclared work stemming from the design of tax and benefit systems' and 'administrative reform and simplification, with a view to reducing the cost of compliance with regulations' are emphasised (Commission of the European Communities 2007c). 


\section{Annex}

Annex Political measures to reduce irregular migrant work: Expert evaluations in Delphi 2

\begin{tabular}{|c|c|c|c|c|c|c|}
\hline \multicolumn{2}{|c|}{ Policy option } & \multirow{2}{*}{$\begin{array}{l}\text { Feasibility } \\
\text { Desirability } \\
\text { Feasibility }\end{array}$} & \multirow{2}{*}{$\begin{array}{l}\text { Yes } \\
\text { Yes } \\
16\end{array}$} & \multirow{2}{*}{$\begin{array}{l}\text { No } \\
\text { No } \\
4\end{array}$} & \multirow{2}{*}{$\begin{array}{l}\text { Don't know } \\
\text { Don't know } \\
2\end{array}$} & \multirow{2}{*}{$\begin{array}{l}\text { Total } \\
\text { Total } \\
22\end{array}$} \\
\hline \multirow[t]{2}{*}{1} & \multirow{2}{*}{$\begin{array}{l}\text { Opening of the labour market for certain } \\
\text { occupations }\end{array}$} & & & & & \\
\hline & & Desirability & 15 & 5 & 2 & 22 \\
\hline \multirow[t]{2}{*}{2} & \multirow{2}{*}{$\begin{array}{l}\text { Opening of the labour market for certain } \\
\text { groups }\end{array}$} & Feasibility & 21 & 1 & 0 & 22 \\
\hline & & Desirability & 16 & 3 & 3 & 22 \\
\hline \multirow[t]{2}{*}{3} & \multirow{2}{*}{$\begin{array}{l}\text { Regional opening of LM by branches and } \\
\text { occupations }\end{array}$} & Feasibility & 14 & 6 & 2 & 22 \\
\hline & & Desirability & 10 & 11 & 1 & 22 \\
\hline \multirow[t]{2}{*}{4} & \multirow[t]{2}{*}{ Early phase-out of transitional rules } & Feasibility & 9 & 12 & 1 & 22 \\
\hline & & Desirability & 10 & 12 & 0 & 22 \\
\hline \multirow[t]{2}{*}{5} & \multirow[t]{2}{*}{ Liberalisation of current labour standards } & Feasibility & 14 & 5 & 3 & 22 \\
\hline & & Desirability & 2 & 17 & 3 & 22 \\
\hline \multirow[t]{2}{*}{6} & \multirow[t]{2}{*}{ Adjusting minimum wages downwards } & Feasibility & 6 & 13 & 3 & 22 \\
\hline & & Desirability & 0 & 20 & 2 & 22 \\
\hline \multirow[t]{2}{*}{7} & \multirow{2}{*}{$\begin{array}{l}\text { Merging of the right to reside and the right } \\
\text { to work }\end{array}$} & Feasibility & 18 & 4 & 0 & 22 \\
\hline & & Desirability & 16 & 4 & 2 & 22 \\
\hline \multirow[t]{2}{*}{8} & \multirow[t]{2}{*}{ Increasing state-funded care allowances } & Feasibility & 7 & 14 & 1 & 22 \\
\hline & & Desirability & 17 & 3 & 2 & 22 \\
\hline \multirow[t]{2}{*}{9} & \multirow{2}{*}{$\begin{array}{l}\text { Switching from cash to in-kind care } \\
\text { allowances }\end{array}$} & Feasibility & 14 & 7 & 1 & 22 \\
\hline & & Desirability & 20 & 2 & 0 & 22 \\
\hline \multirow[t]{2}{*}{10} & \multirow{2}{*}{$\begin{array}{l}\text { Providing access to the LM for foreign } \\
\text { household helpers }\end{array}$} & Feasibility & 14 & 3 & 5 & 22 \\
\hline & & Desirability & 17 & 1 & 4 & 22 \\
\hline \multirow[t]{2}{*}{11} & Combination wage for low-wage jobs & Feasibility & 15 & 4 & 3 & 22 \\
\hline & & Desirability & 8 & 11 & 3 & 22 \\
\hline 12 & Sanctions or fines against irregular & Feasibility & 16 & 4 & 2 & 22 \\
\hline & migrant workers & Desirability & 5 & 16 & 1 & 22 \\
\hline 13 & Strengthen legal support for irregular & Feasibility & 16 & 5 & 1 & 22 \\
\hline & migrant workers & Desirability & 18 & 3 & 1 & 22 \\
\hline 14 & Creation of specialised advisory services & Feasibility & 18 & 2 & 2 & 22 \\
\hline & & Desirability & 18 & 3 & 1 & 22 \\
\hline 15 & Mandatory role for trade unions in legal & Feasibility & 11 & 10 & 1 & 22 \\
\hline & proceedings & Desirability & 15 & 6 & 1 & 22 \\
\hline 16 & Skimming off profits & Feasibility & 8 & 12 & 2 & 22 \\
\hline & & Desirability & 17 & 3 & 2 & 22 \\
\hline 17 & Exclude offenders from public work & Feasibility & 14 & 4 & 4 & 22 \\
\hline & contracts & Desirability & 14 & 4 & 4 & 22 \\
\hline 18 & Common EU framework for combating & Feasibility & 12 & 6 & 4 & 22 \\
\hline & irregular work & Desirability & 16 & 3 & 3 & 22 \\
\hline
\end{tabular}


Annex Political measures to reduce irregular migrant work: Expert evaluations in Delphi 2 (continued from previous page)

\begin{tabular}{llllll}
\hline Policy option & Feasibility & Yes & No & Don't know & Total \\
& Desirability & Yes & No & Don't know & Total \\
\hline 19 Approximation of economic framework & Feasibility & 10 & 9 & 3 & 22 \\
$\quad \begin{array}{l}\text { conditions } \\
20 \text { Raising awareness among irregular }\end{array}$ & Desirability & 14 & 6 & 2 & 22 \\
$\quad$ employers & Feasibility & 11 & 7 & 4 & 22 \\
21 Strengthen control systems through & Desirability & 16 & 3 & 3 & 22 \\
modern technologies & Feasibility & 12 & 7 & 3 & 22 \\
22 Faster recognition of foreign diplomas & Desirability & 3 & 18 & 1 & 22 \\
& Feasibility & 18 & 2 & 2 & 22 \\
23 Legalisation of irregular migrant workers & Desirability & 16 & 5 & 1 & 22 \\
& Feasibility & 14 & 7 & 1 & 22 \\
24 Better networking of labour market & Desirability & 14 & 6 & 2 & 22 \\
& Feasibility & 18 & 1 & 3 & 22
\end{tabular}
institutions 


\section{References}

Abella, M. (2002), 'Migration and Employment of Undocumented Workers: Do Sanctions Work?', in Cinar, D., Gächter, A. \& Waldrauch, H. (eds.), Irregular Migration: DYnamics, Impact, Policy Options, 205-235. Vienna: European Centre for Social Welfare Policy and Research.

Alscher, S., Münz, R. \& Özcan, V. (200I), 'Illegal anwesende und illegal beschäftigte Ausländerinnen und Ausländer in Berlin. Lebensverhältnisse, Problemlagen, Empfehlungen' (Illegally resident and illegally employed foreigners in Berlin: Living conditions, problems, recommendations), in Demographie aktuell, Vorträge - Aufsätze - Forschungsberichte. Berlin.

Alt, J. (I999a), 'Illegal in Deutschland. Forschungsprojekt zur Lebenssituation "illegaler" Migranten in Leipzig' (Illegal in Germany: Research project on the living situation of "illegal" migrants in Germany). Karlsruhe: Loeper Literaturverlag.

Alt, J. (I999b), 'Illegal in Germany: Summary of results of the research project on the living situation of "illegal" migrants in Leipzig'. Commissioned by Jesuit Refugee Service (Europe). Munich: Institut für Gesellschaftspolitik, Munich Hochschule für Philosophie.

Alt, J. (2003a), Leben in der Schattenwelt. Problemkomplexe Illegale Migration. Neue Erkenntnisse zur Lebenssituation, illegaler' Migranten aus München und anderen Orten Deutschlands (Life in the world of shadows, the problematic of illegal migration: A new look at the living situation of "illegal" migrants in Munich and other places in Germany). Karlsruhe.

Alt, J. (2003b), 'Anlage 5: Zusammensetzung der "Illegalenpopulation" in Deutschland'. Available at www.joerg-alt.de.

Alt, J. (2004), 'Illegale private Ausländerbeschäftigung' (Illegal private foreign employment), in Cyrus, Norbert (ed.), Zwischen dosierter Öffnung und verschärfter Kontrolle. Arbeitsmöglichkeiten für Migrantinnen und Migranten in Deutschland, 53-55. Dokumentation der Fachtagung der Friedrich-Ebert-Stiftung Berlin in Kooperation mit dem Institut für Bildung und Kommunikation in Migrationsprozessen (IBKM) der Universität Oldenburg, EU-Forschungsprojekt IAPASIS. Berlin Friedrich-Ebert-Stiftung.

Anderson, B. (2000), Doing the Dirty Work? The global politics of domestic labour. London: Zed Books.

Anderson, B. (200I), 'Why madam has so many bathrobes: Demand for migrant domestic workers in the EU', Tijdschrift voor Economische en Sociale Geografie 92 (I): I8-26.

Anderson B. \& Rogaly, B. (2005), 'Forced Labour and Migration to the UK', paper presented at the Trades Union Congress (COMPAS), London.

Anderson, B. \& Ruhs, M. (2006), 'Semi-compliance in the migrant labour market'. Working Paper No. 30, Centre on Migration, Policy and Society (COMPAS), University of Oxford.

Anderson, P. (1999), 'From the Wailing Wall to the "Dignified Juggler”: Making a Living as an Undocumented Migrant in the UK', in Eichenhofer, E. (ed.), Migration und Illegalität (Migration and Illegality), I57-76. Osnabrück: Universitätsverlag Rasch. 
Andrees, B. (2004), 'International Labour Organization research on the forced labour outcomes of human trafficking and irregular migration', paper presented at the IOM International Expert Meeting, ILO, Rome, May 2004.

Angenendt, S. (2002), 'Entwicklung und Perspektiven der europäischen Migrations- und Asylpolitik', Die Friedens-Warte 77 (I-2): I43-I72.

Arango, J. (2004), 'Theories of International Migration', in Joly, D. (2004), International Migration in the New Millennium: Global Movement and Settlement, I5-35. Ashgate.

'Arbeitsstelle Interkulturelle Konflikte und gesellschaftliche Integration (AKI)' (2003), Working paper presented at the workshop 'Migration and Illegality: Key Problems and Possible Interventions', November 200. Available at www.wzberlin.de/zkd/aki/ files/berlinworkshopthesen.pdf.

Bauböck, R. (I994), Transnational citizenship: Membership and rights in international migration. Aldershot: Edward Elgar.

Behr, D. (2004), Was hat Gemüse mit Migration zu tun? Landschaftsplanerische Reflexion zur Arbeitsmigration in der Landwirtschaft. Dargestellt an Gemüse- und Obstbetrieben im niederösterreichischen Marchfeld (Landscape planning thoughts about the migration of work forces within state agriculture, described by showing the impact of migration on vegetable and fruit producing companies in the Marchfeld of Lower Austria). Undergraduate thesis, Institut für Landschaftsplanung und Ingenieurbiologie, Universität für Bodenkultur, Vienna.

'Beratungszentrum für Migranten und Migrantinnen' (Employment of Foreigners in Austria) (2007). www.migrant.at.

Biffl, G. (ed.) (200I), Arbeitsmarktrelevante Effekte der Ausländerintegration in Österreich (Labour market relevant effects of the integration of foreigners in Austria). Vienna: WIFO (Austrian Institute of Economic Research).

Biffl G. (2003), 'Mobilitäts- und Verdrängungsprozesse auf dem österreichischen Arbeitsmarkt: Die Situation der unselbständig beschäftigten AusländerInnen' (Mobility and substitution processes on the Austrian labour market: The situation of foreign employees), in Heinz Fassmann, Irene Stacher (eds.) (2003), 62-77.

Biffl, G. (2005), Zur Niederlassung von Ausländerinnen und Ausländern in Österreich (Study on the settlement of foreigners in Austria). Studie des Österreichischen Instituts für Wirtschaftsforschung im Auftrag des Bundesministerium für Inneres. Vienna. www. bmi.gv.at/publikationen.

Bilger, V., Gendera, S., Hollomey, C., Jandl, M. \& Stepien, A. (2006), Migration und Irreguläre Beschäftigung in Österreich: Ergebnisse einer Delphi-Studie. Vienna: International Centre for Migration Policy Development (ICMPD).

Bilger, V., Hofmann, M. \& Jandl, M. (2006), 'Human Smuggling as a Transnational Service Industry: Evidence from Austria', International Migration 44 (4): 59-93.

Bock-Schappelwein, J. (2004), 'Ausländer in Österreich - vier Fragen zu ihrer Integration' (Foreigners in Austria - four questions on their integration). Vienna: WIFO.

Bogner, A. \& Menz, W. (2005), 'Expertenwissen und Forschungspraxis: die modernisierungstheoretische und die methodische Debatte um die Experten. Zur Einführung in ein unübersichtliches Problemfeld', in Bogern A., Littig, B. \& Menz, W. (eds.), Das Experteninterview. Theorie, Methode, Anwendung, 7-30. Wiesbaden: VS Verlag für Sozialwissenschaften.

Bolyos, L. \& Behr, D. (2007), 'Ensemble on ne se laisse pas faire... - Migration, Ausbeutung und Widerstand in der industriellen Landwirtschaft am Beispiel El Ejido', in Reader des Aktionsbündnisses Globale Landwirtschaft (ed.), Analysen und Perspektiven für eine nicht-kapitalistische Landwirtschaft - Widerstand ist fruchtbar, 2I-25. Göttingen: AktivDruck \& Verlag GmbH.

Borjas G. J. (I989), 'Economic Theory and International Migration', International Migration Review 23 (3): 457-485. 
Borowski, A. et al. (I997), 'The International Movements of People', in Adelman, H. et al. (eds.) (I997), Immigration and Refugee Policy. Australia and Canada Compared, Volume 1, 3I-62. Toronto, Buffalo: University of Toronto Press.

Boswell, C. \& Straubhaar, T. (2004), 'The Illegal Employment of Foreigners in Europe', Intereconomics, January/February 2004: 4-7.

Brochmann, G. (I999), 'The Mechanisms of Control', in Brochmann, G. \& Hammar, T. (eds.), Mechanisms of Immigration Control: A Comparative Analysis of European Regulation Policies, I-27. Berg: Oxford International Publishers.

Bundesministerium für Finanzen (BMF) (2004a), Betrugsbekämpfung Aktiv und Offensiv, BMF. Vienna.

Bundesministerium für Finanzen (BMF) (2004b), Betrugsbekämpfung. Sicherung des Wirtschaftsstandorts, BMF. Vienna.

Bundesministerium für Wirtschaft und Arbeit (BMWA), (2005), 'Informationsblatt zur Ausländerbeschäftigung Stand: April 2005’ (Information Sheet from April 2005). Vienna.

Bundesministerium für Wirtschaft und Arbeit (BMWA), (2006), Ausländerbeschäftigung. Informationsblatt Stand Mai 2006 (Employment of Foreigners. Information Sheet from May 2006), Vienna.

Bundesregierung, (2000), Neunter Bericht der Bundesregierung über Erfahrungen bei der Anwendung des Arbeitnehmerüberlassungsgesetzes - AÜG - sowie über die Auswirkungen des Gesetzes zur Bekämpfung der illegalen Beschäftigung - BillBG. (Deutscher Bundestag, Drucksache I4/4220).

Bundesregierung (2005): Zehnter Bericht der Bundesregierung über die Auswirkungen des Gesetzes zur Bekämpfung der illegalen Beschäftigung - BillBG. (Deutscher Bundestag, Drucksache 15/5934). Berlin.

Castles, S. \& Miller, M. (2003), The Age of Migration: International population movements in the modern world, third edition. Basingstoke: Macmillan.

Caixeta, L., Haas, B., Haidinger, B., Rappold, S., Rechling, D. \& Ripota, P. (2004), 'Housework and Caretaking: Part: Austria - Migrantinnen in Privathaushalten'. Linz: MAIZ Autonomes Integrationszentrum von \& für Migrantinnen. www.maiz.at.

Chahrokh, H., Hofmann, M., Kraler, A., Jandl, M. \& Lundström, C. (2005), 'The Implications of The Hague Programme for European Asylum and Migration Policies'. Vienna: International Centre for Migration Policy Development.

Chelimsky, E. (I99I), 'Politics, Policy Making, Data and the Homeless', Housing Policy Debate 2 (3): 683-697.

Chimienti, M., Efionayi-Mäder, D. \& Farquet, R. (2003), 'La répression du travail clandestin à Genève. Application des sanctions et conséquences pour les personnes concernées' (The suppression of illegal work in Geneva: Implementation of sanctions and consequences for the persons involved), Research Report No. 27/2003. Neuchatel: Swiss Forum for Migration Studies.

Chiswick, B. R. (I978), 'The Effect of Americanisation on the Earnings of Foreign-Born Men', Journal of Political Economy 85 (5): 897-921.

Chiswick, B. R. (I999), 'Are Immigrants Favorably Self-Selected?' American Economic Review 89 (2): I8I-I85.

Çinar, D., Waldrauch, H. \& Gächter, A. (2000), Irregular Migration: Dynamics, Impact, Policy Options. Vienna: European Centre for Social Welfare Policy and Research.

Collyer, M. (2005), 'Transnationalism', in Fassmann, H., Kohlbacher, J., Reeger, U. \& Sievers, W. (eds.), International Migration and its Regulation. Available at www.imiscoe. org.

Commission of the European Communities (2003): 'Potential Migration from Central and Eastern Europe into the EU-I5: An update.' Report for the European Commission DG Employment and Social Affairs, October 2003. 
Commission of the European Communities (2006), 'Communication from the Commission - Report on the Functioning of the Transitional Arrangements set out in the 2003 Accession Treaty (period I May 2004-30 April 2006)', COM (2006)48 final, Brussels.

Commission of the European Communities, (2006), 'Communication from the Commission on policy priorities in the fight against illegal immigration of third-country nationals', COM (2006)402 final, Brussels.

Commission of the European Communities, (2007a), 'Proposal for a Directive of the European Parliament and of the Council providing for sanctions against employers of illegally staying third-country nationals', COM (2007)249final, Brussels.

Commission of the European Communities (2007b). 'Accompanying document to the Proposal for a Directive of the European Parliament and of the Council providing for sanctions against employers of illegally staying third-country nationals', Commission Staff Working Paper, SEC (2007)604, Brussels.

Commission of the European Communities (2007c). 'Communication from the Commission to the Council, the European Parliament, the European Economic and Social Committee and the Committee of the Regions. Stepping up the fight against undeclared work', COM (2007) 628final, Brussels.

Cornelius, W. A., Takeyuki T., Martin, P.L. \& Hollifield, J. F. (eds.) (2004), Controlling Immigration: A Global Perspective, second edition. Stanford University Press.

Csedo, K (2007), 'Migrants or Professionals? University Educated East Europeans' Employment in London', paper presented at the IMISCOE A2 Conference on EU Enlargement and Labour Migration within the EU', Warsaw University, 23-24 April 2007.

Cyrus, N. (2004), 'Aufenthaltsrechtliche Illegalität in Deutschland. Sozialstrukturbildung - Wechselwirkungen - Politische Optionen.' Bericht für den Sachverständigenrat für Zuwanderung und Integration, Nürnberg. Oldenburg. Available at www.forum-illegalitaet.de/Materialien/04_Expertise_Sachverst_ndigenrat_Cyrus.doc.

Cyrus, N. (2005), Menschenhandel und Arbeitsausbeutung in Deutschland. Geneva: Internationale Arbeitsorganisation. Available at www.ilo.org/public/german/region/eurpro/ bonn/download/menschenhandelendfassung.pdf.

Cyrus, N. (2007), 'Menchen mit Migrationshintergrund in prekärer Beschäftigung - legale und illegale Beschäftigung', in Pape, K. (ed.), Arbeiten ohne Netz. Prekäre Arbeit und ihre Auswirkungen, 7I-88. Hannover: Offizin.

Cyrus, N. (2008), 'Being Illegal in Europe: Strategies and Policies for Fairer Treatment of Migrant Domestic Workers', in Lutz, H. (ed.), Migration and Domestic Work: A European Perspective in a Global Theme, I77-I94. Aldershot: Ashgate.

Cyrus, N., Düvell, F. \& Vogel, D. (2004), 'Illegale Zuwanderung in Großbritannien und Deutschland: Ein Vergleich', in IMIS-Beiträge Issue, July 2004: 45-74. Available at www.imis.uni-osnabrueck.de/pdffiles/imis24.pdf.

Demel, K., Fassmann, H., Kohlbacher, J., Reeger U. \& Stacher, I. (200I), 'Die soziale Mobilität der AusländerInnen - Ein Beitrag zur Arbeitsmarkt- und Sozialstruktur-analyse der Großstadt' (The social and occupational mobility of the foreign workforce in the metropolitan labour market in Austria), final report prepared by ICMPD/AFM and the Austrian Academy of Science, Institute for Urban and Regional Research for the Federal Ministry for Education, Science and Culture, Vienna.

Djajic, S. (1989), 'Migrants in a Guest-Worker System: A Utility Maximising Approach', Journal of Development Economics 31: 327-339.

Doomernik, J. \& Jandl, M. (forthcoming), 'Modes of Migration Regulation', in IMISCOE Research Series. Amsterdam University Press.

Doomernik, J., Penninx, R. \& Van Amersfoort, H. (1997), A Migration Policy for the Future: Possibilities and Limitations, Brussels: Migration Policy Group. 
Durand, J. \& D. Massey (2004) 'Appendix: The Mexican Migration Project', in Durand, J. \& Massey, D. (eds.), Crossing the Border. Research from the Mexican Migration Project, 32I-336. New York: Russell Sage Foundation.

Düvell, F. (2006), 'Undocumented Migration: A Global, Historical and Economic Perspective', in Illegal Immigration in Europe. Beyond Control?, I4-3I. England/New York: Palgrave/Macmillan.

EBF/CEDRI (eds.) (2004), 'Bittere Ernte - Die moderne Sklaverei in der industriellen Landwirtschaft Europas’. Verlag Europäisches Bürgerforum/CEDRI.

Elwert, G. (2002), 'Unternehmerische Illegale. Ziele und Organisationen eines unterschätzten Typs illegaler Einwanderer' (Entrepreneurial Illegals: Goals and Organisation of an Underestimated Type of Illegal Immigrants), IMIS Beiträge Issue I9/ 2002. Osnabrück: Vorstand des Instituts für Migrationsforschung und Interkulturelle Studien (IMIS) an der Universität Osnabrück.

Engbersen, G. (I999a), 'The undocumented outsider class: Illegal immigrants in Rotterdam', in Eichenhofer, E. (ed.), Migration und Illegalität (Migration and Illegality), 2I3233. IMIS-Schriften 7 , Osnabrück.

Engbersen, G. (I999b), 'Sans-papiers. Les strategies de sejour des immigres clandestins', in Actes de la recherché en sciences sociales I29 (9): 25-38.

Engbersen, G. (200I), 'The Unanticipated Consequences of Panopticon Europe: Residence Strategies of Illegal Immigrants', in Guiraudon V. \& Joppke C. (ed.), Controlling a New Migration World - EUI Studies in Political Economy, 222-246. London: Routledge.

Engbersen, G., Van San, M. \& Leerkes, A. (2006), 'A room with a view: Irregular migrants in the legal capital of the world', Ethnography 7 (2): 205-238.

Esser, H. (I999), 'Die Wert-Erwartungstheorie', in Soziologie, Band 1: Situationslogik und Handeln, 247-293. Frankfurt, New York: Campus.

Faist, Th. (I995), 'Sociological Theories of International Migration: The Missing MesoLink', paper presented at the Meeting of the Theory Group of Migration and Development (MAD) Project, Hamburg. ZeS-Arbeitspapier I7.

Faist, Th. (I997), 'The crucial meso-level', in Hammar, T., Brochmann, G., Tamas, K. \& Faist, Th. (eds.), International migration, immobility and development: Multidisciplinary perspective, I87-2I7. New York: Berg Publishers.

Faist, T. (2000), The volume and dynamics of international migration and transnational social spaces. Oxford: Clarendon.

Fassman, H., Kohlbacher J. \& Reeger U. (I995), 'Die “neue Zuwanderung” aus Ostmitteleuropa - eine empirische Analyse am Beispiel der Polen in Wien', ISR Forschungsberichte, Issue I3. Vienna: Verlag der Österreichischen Akademie der Wissenschaften.

Fassmann, H. \& Münz, R. (2002), 'EU enlargement and future East-West migration', in Laczko, F., Stacher, I. \& Klekowski von Koppenfels, A. (eds.), New Challenges for Migration Policy in Central and Eastern Europe. Vienna: ICMPD/IOM.

Fassmann, H. \& Stacher, I. (2003), Österreichischer Migrations- und Integrationsbericht (Austrian Migration and Integration Report), 62-77. Klagenfurt: Drava Verlag.

Fassmann, H., Kohlbacher, J. \& Reeger, U. (2004), 'Polen in Wien: Entwicklung, Strukturmerkmale und Interaktionsmuster', ISR-Forschungsberichte (Hg.) Institut für Stadtund Regionalforschung, Issue 30. Vienna: Verlag der Österreichischen Akademie der Wissenschaften.

Favell, A. (2006), 'After Enlargement: Europe's New Migration System', D2S Brief. Copenhagen: Danish Institute for International Studies.

Flick, U. (I995), Qualitative Forschung. Hamburg: Rowohlts.

Flick, U. (2007): 'Triangulation in der qualitativen Forschung', in Flick, Kardorff \& Steinke (eds.), Qualitative Forschung. Reinbek bei Hamburg: Rowohlts. 
FORBA, (2007), Austria Country Report. Deliverable of the project 'Undocumented Worker Transitions'. Available at www.londonmet.ac.uk/research-units/\$-workinglives/projects/uwt/country/country_home.cfm.

Fronek, H. (2000), 'Illegalisierung in Österreich' (Illegalisation in Austria), SWSRundschau, Issue I: 89-99.

Gendera, S. (2007) Transnational Care Space Zentraleuropa. Arbeits- und Lebensbedingungen von irregulär beschäftigten Migrantinnen in der häuslichen Pflege (Transnational Care Space Central Europe: Working and Living Conditions of Irregular Migrants in Domestic Care Provision). Undergraduate thesis, University of Vienna.

Gendera, S. (forthcoming), 'Gaining Insight into the Transnational Care Space: Recruitment of Migrant Live-In Carers in Austria', in Bommes, M. \& G. Sciortino (eds.), Foggy Social Structures: Irregular Migration and Informal Economy in Western Europe. Amsterdam University Press.

Gendera, S. \& Haidinger, B. (2007) 'Ich kann in Österreich als Putzfrau arbeiten. Vielen Dank, ja. Bedingungen der bezahlten Haushalts- und Pflegearbeit von Migrantinnen', Grundrisse, Zeitschrift für linke Theorie und Debatte 23: 28-40. See www.linksnet.de/ artikel.php?id=3306.

Gläser, J. \& Laudel, G. (2004), Experteninterviews und qualitative Inhaltsanalyse. Wiesbaden: VS Verlag für Sozialwissenschaften.

Glaser, B.G. (1978), Theoretical Sensitivity. Mill Valley, California: Sociology Press.

Glaser, B.G., Strauss , A. (1967), The Discovery of Grounded Theory: Strategies for Qualitative Research. New York: Aldine Publishing Company.

Gordon, T. J. (I994), The Dephi Method. AC/UNU Millennium Project, Futures Research Methodology. Available at www.futurovenezuela.org/_curso/5-delphi.pdf.

Hahn, K., Behr, D. \& Dinhof, D. (2007), 'Kampagnenbericht 2006: Bildungs- und Solidaritätsarbeit zur Unterstützung der LandarbeiterInnengewerkschaft SOC im "Plastikmeer von Almería”/Südspanien (Österreich, Deutschland und Italien-Südtirol)'. Available at www.forumcivique.org/index.php?lang=DE\&site=MIGRATION\&article=922 .

Haidinger, B. (2004), She sweeps for money! Beschäftigungsverhältnisse und Strukturelle Bedingungen bezahlter Haushaltsarbeit von Migrantinnen in Österreich. Undergraduate thesis, Vienna University of Economics and Business Administration.

Hammar, T, Brochmann, G., Tamas, K. \& Faist, T. (eds.) (I997), International migration, immobility and development: Multidisciplinary perspective. New York: Berg Publishers.

Harris, J.R. \& Todaro, M.P. (I970), Migration, Unemployment and Development: A TwoSector Analysis, American Economic Review 6o: I26-I42.

Heckmann, F. (1995), 'Is There a Migration Policy in Germany?', in Heckmann, F. \& Bosswick, W. (eds.), Migration Policies: a Comparative Perspective, I57-I72. Stuttgart: Enke Verlag.

Heckmann, F. (2004), 'Illegal Migration: What Can We Know and What Can We Explain? The Case of Germany', International Migration Review 38 (3): IIO3-II25.

Hess, S. (200I), 'Transnationale Überlebensstrategien von Frauen - Geschlecht und neuere Konzepte der Transkulturalität, in Hobuß, S.(ed.), Die andere Hälfte der Globalisierung: Menschenrechte, Ökonomie und Medialität aus feministischer Sicht, 197-225. Frankfurt/New York: Campus.

Hofer, K. (I993), Arbeitsstrich. Unter polnischen Schwarzarbeitern (Black Labour Market. Among Polish Moonlighters). Vienna.

Hoffman-Nowotny, H.-J. (I993), 'Weltmigration - eine soziologische Analyse', in Kälin, W. \& Moser, R. (eds.), Migration aus der Dritten Welt: Ursachen, Wirkungen, Handlungsmöglichkeiten, 57-68. Bern, Stuttgart, Vienna: Haupt Verlag.

Huber, P. \& Brücker, H. (2003), 'Auswirkungen und Ausnutzung von Übergangsfristen für die Freizügigkeit der Arbeitskräfte nach der EU-Erweiterung' (Consequences and 
Usage of Transitional Periods for the Freedom of Movement of Workers after EU Enlargement). Vienna: WIFO.

Hudler-Seitzberger, M. \& Bittner, M. (2005), 'Arbeitsmarktmonitoring. Zusammenfassende Projektdarstellung' (Labour Market Monitoring: A Project Summary). Vienna. Available at www.arbeitsmarktmonitoring.at/pdf/LAMO_Projektbericht.pdf.

Iskander, N. (2000), 'Immigrant workers in an irregular situation: The case of the garment industry in Paris and its suburbs', in OECD (ed.), Combating the illegal employment of foreign workers, 45-69. Paris: OECD Publications.

Itzigsohn, J., Cabral, C.D., Medina, E.H. \& Vazquez, O. (I999), Mapping Dominican transnationalism: Narrow and broad transnational practices, Ethnic and Racial Studies $22(2):$ 316-339.

Jahn, A. \& Straubhaar, Th. (2000), 'A Survey on the Economics of Illegal Migration', working paper presented at the workshop 'Managing Migration in the 2Ist Century", Comparative Immigration and Integration Program, Institute on Global Conflict and Cooperation, University of California, San Diego, I9-20 February I998. Available at http://migration.uni-konstanz.de/content/center/events/de/events/mm2I/StraubhaarIllegalImmig.html.

Jandl, M. (I994), 'Is Migration Supply or Demand-determined? Some remarks on the ideological use of economic language', International Migration, Quarterly Review $\mathrm{XXX}_{2}(3)$.

Jandl, M. (2004), 'The Estimation of Illegal Migration in Europe', Studi Emigrazione/Migration Studies XLI (I53): I4I-I55.

Jandl, M. (2007), 'Irregular Migration, Human Smuggling and the Eastern Enlargement of the European Union', International Migration Review (IMR) 4I (2): 29I-3I5.

Jandl, M. \& Hofmann, M. (2004), 'Expected Short-Term Effects of EU Enlargement on Migration - The Case of Austria', in Der Donauraum 4/2003: 37-43.

Jandl, M. \& Kraler, A. (2003), 'Austria: A Country of Immigration?', Migration Information Source. Available at www.migrationinformation.org/Profiles/display.cfm?ID=I05.

Jandl, M. \& Kraler, A. (2006), 'Links between Legal and Illegal Migration', in Poulain, M., Perrin, N. \& Singleton, A. (2006), THESIM - Towards Harmonised European Statistics on International Migration. Louvain-La-Neuve: UCL Presses.

Jandl, M., Hollomey, C. \& Stepien, A. (2007), 'Migration and Irregular Work in Austria: Results of a Delphi Study', International Migration Papers 90. Geneva: International Labour Office.

Joly, D. (2000), 'Some structural effects of migration on receiving and sending countries, International Migration 38 (5): 25-40.

Jordan, B. \& Düvell, F. (2002), Irregular Migration. The Dilemmas of Transnational Mobility. Cheltenham.

Jordan, B. \& Vogel, D. (1997), "Which policies influence migration decisions? A comparative analysis of qualitative interviews with undocumented Brazilian immigrants in London and Berlin as a contribution to economic reasoning', ZeS-Arbeitspapier I4/97, Centre for Social Policy Research.

Kindler, M. (2005), 'Irregular Migration in Central and Eastern Europe: The case of Ukrainian workers in Poland', paper presented at the conference 'Irregular Migration Research, Policy and Practice', organised by the Centre on Migration, Policy and Society, University of Oxford, 8-9 July 2005.

Klosterman, R. \& Rath, J. (2003), Immigrant Entrepreneurs: Venturing abroad in the age of globalisation. Oxford.

Kofman, E., Phizacklea, A., Raghuram, P. \& Sales, R. (2000) Gender and International Migration in Europe: Employment, Welfare and Politics. London: Routledge. 
König, K. \& Perchinig, B. (2003), 'Austria', in Niessen, J., Schibel, Y. \& Magoni., R. (eds.) (2003), EU and US approaches to the management of immigration. Brussels/Vienna: Migration Policy Group.

König, K. \& Perchinig, B. (2005), 'Austria', in Niessen, J., Schibel, Y. \& Thompson, C. (eds.) (2005), Current Immigration Debates in Europe: A publication of the European Migration Dialogue. Brussels/Vienna: Migration Policy Group.

König, K. \& Stadler, B. (2003), 'Entwicklungstendenzen im öffentlich-rechtlichen und demokratiepolitischen Bereich', in Fassmann, H. \& Stacher, I. (eds.), Österreichischer Migrations- und Integrationsbericht. Demographische Entwicklungen, sozioökonomische Strukturen, rechtliche Rahmenbedingungen, 226-26o. Klagenfurt/Celovec: Drava.

Kyle, D. \& Koslowski, R. (eds.) (200I), Global Human Smuggling: Comparative Perspectives. Baltimore.

Lazaridis, G. (2007), 'Les Infirmieres Exclusives and Migrant Quasi-Nurses in Greece', European Journal of Women's Studies I4 (3): 227-245. Available at http://ejw.sagepub. $\mathrm{com} /$ cgi/content/abstract/14/3/227.

Leibetseder, B. (2004), 'Gesundheits- und Sozialdienste in Tschechien', in EQUAL Modul I: Rechtliche und gesellschaftspolitische Rahmenbedingungen, Teilbericht VI, University of Linz.

LeVoy, M., Verbruggen, N. \& Wets, J. (2003), 'Undocumented Migrant Workers in Europe'. Brussels: HIVER, PICUM.

Lutz, H. (2006), Vom Weltmarkt in den Privathaushalt. Die neuen Dienstmädchen im Zeitalter der Globalisierung. Verlag Barbara Budrich.

Lutz, H. (ed.) (2008), Migration and Domestic Work: A European Perspective in a Global Theme. Aldershot: Ashgate.

Lachmanová, L. \& Drbohlav, D. (2004), 'The Probable Future Development of European East- West Migration (The Dephi Method Revived)', European Spatial Research and Policy II (I): I35-I55.

Laczko, F., Stacher, I. \& Klekowski von Koppenfels, A. (eds.) (2002), New Challenges for Migration Policy in Central and Eastern Europe. Vienna: ICMPD/IOM.

Lebhart, G. (2002), 'Internationale Migration - Hypothesen, Perspektiven und Theorien', Demographie aktuell I9. Available at www.demographie.de/demographieaktuell/darg. pdf.

Lederer, H. \& Nickel, A. (I997), 'Illegale Ausländerbeschäftigung in der Bundesrepublik Deutschland' (Illegal Employment of Foreigners in the Federal Republic of Germany), Electronic ed.: Bonn: Friedrich-Ebert-Stiftung, FES Library 2000. Available at http://library.fes.de/fulltext/asfo/oo763toc.htm.

Lee, E.S. (I966), 'A Theory of Migration', Demography 3: 47-57.

Leibetseder, B. (2004), 'Gesundheits- und Sozialdienste in Tschechien', in EQUAL Modul I: Rechtliche und gesellschaftspolitische Rahmenbedingungen, Teilbericht VI, University of Linz.

Light, I. (1972), Ethnic Enterprise in America. Berkeley: University of California Press.

Light, I. (2004), 'Immigration and Ethnic Economies in Giant Cities', in Dogan, M. (ed.), 181-Mega-Cities, 385-398. UNESCO, Blackwell Publishing.

Light, I. \& Bhachu, P. (I993), Immigration and entrepreneurship: Culture, capital and ethnic networks. New Brunswick: Transaction Publishers.

Linstone, H. \& Turoff, M. (eds.) (I975), The Dephi Method: Techniques and Applications. Reading, Massachusetts: Addison-Wesley Publishing Company.

Longchamp, C., Aebersold, M., Rousselot, B. \& Ratelband-Pally, S. (2005), 'Sans Papiers in der Schweiz: Arbeitsmarkt, nicht Asylpolitik ist entscheidend. Schlussbericht im Auftrag des Bundesamtes für Migration' (Undocumented in Switzerland: Labour Market, Not Asylum Policy Is Decisive'. Final Report commissioned by the Federal Office for Migration, Bern. 
Łukowski, W. (2004), 'Polscy pracownicy na rynku Un2 Europejskiej na przełomie wieków' (Polish workers on the EU market at the turn of the century), Working Papers 57. Warsaw: Instytut Studiów Społecznych, Uniwersytet Warszawski. Available at www.iss.uw.edu.pl.

Marcelli, E. A. (2004), 'Unauthorised Mexican immigration, day labour and other lowwage informal employment in California', Regional Studies 38 (I): I-I3.

Martin, P. \& Miller M. (2000), 'Employer Sanctions: French, German and US Experiences', International Migration Papers 36. Geneva: International Labour Organization.

Masser, I. and Foley, P. (I987), 'Delphi Revisited: Expert Opinion in Urban Analyses', Urban Studies 24: 2I7-225.

Massey, D. S. (I988), 'Economic Development and International Migration in Comparative Perspective', Population and Development Review I4: 383-4I3.

Massey, D. S. (1989), 'Social structure, household strategies, and the cumulative causation of migration', paper presented at the 'annual meeting of the American Sociological Association, San Francisco Hilton Hotel, i3 August i989.

Massey, D.S. (2004), 'Measuring Undocumented Migration', International Migration Review 38 (3): IO75-IIO2.

Massey, D. S., Arango, J., Hugo G., Kouaouci, A., Pellegrino, A. \& Taylor, J.E. (I993), 'Theories of international migration: A review and appraisal', Population and Development Review I9 (3): 43I-466.

Massey, D. S., Arango, J., Hugo G., Kouaouci, A., Pellegrino, A. \& Taylor, J.E. (I998), Worlds in Motion: Understanding International Migration at the End of the Millenium. Oxford.

Massey, D. S. \& Zenteno, R. (2000), 'A validation of the ethnosurvey: The case of MexicoUS migration', International Migration Review 34 (3): $766-793$.

Mavris, L. (2002), 'Human smugglers and social networks: Transit migration through the states of former Yugoslavia', New Issues In Refugee Research Working Paper No. 72, Evaluation and Policy Analysis Unit, UNHCR, Geneva.

Meuser, M. \& Nagel, U. (2002), 'Experteninterviews - vielfach erprobt, wenig bedacht. Ein Beitrag zur qualitativen Methodendiskussion', in Bogner, A., Littig, B. \& Menz, W. (eds.), Das Experteninterview. Theorie, Methode, Anwendung, 7I-93. Opladen: Leske $\&$ Budrich.

Mingione, E. (I999), 'Introduction: Immigrants and the informal economy in European cities', International Journal of Urban and Regional Research 23 (2): 209-2II.

Misra, J., Woodring, J. \& Merz, S. (2004), 'The Globalisation of Carework: Immigration, Economic Restructuring, and the World-System'. Available at http://masspolicy.org/ pdf/working/WP2005_I.pdf.

Müller-Schneider, Th. (2003), 'Wertintegration und neue Mobilität. Theorie der Migration in modernen Gesellschaften'. Bamberg: efms.

Morkvasic, M. (2003) 'Transnational mobility and gender: A view from post-wall Europe', in Morokvasic, M., Erel, U. \& Shinozaki, K. (eds.), Crossing Borders and Shifting Boundaries: Volume 1, Gender on the move, IOI-I33. Opladen: Leske \& Budrich.

OECD (ed.) (2000), Combating the illegal employment of foreign workers. Paris: OECD Publications.

Overbeek, H. (2002), 'Globalisation and Governance: Contradictions of Neo-Liberal Migration Management', HWWA Discussion Paper I74, Hamburg.

Parreñas, R. S. (200I), Servants of Globalisation: Women, Migration and Domestic Work. Stanford: Stanford University Press.

Parnreiter, C. (I994), Migration und Arbeitsteilung. AusländerInnenbeschäftigung in der Weltwirtschaftskrise. Vienna: Promedia. 
Pastore, F. (forthcoming), 'Modes of Migration Regulation in Italy', in Doomernik, J. \& Jandl, M. (eds.), Modes of Migration Regulation, IMISCOE Research Series. Amsterdam University Press.

Paul Lazarsfeld Gesellschaft für Sozialforschung (2004), 'Analyse der leitfadenorientierten ExpertInneninterviews zur Abschätzung der Veränderungen am Arbeitsmarkt im Zuge der EU-Erweiterung' (Analysis of expert interviews to evaluate changes on the labour market in the course of EU enlargement). Vienna. Available at www.arbeitsmarktmonitoring.at/expertinneninterviews.pdf.

Pichelmann, K. (I994): 'Arbeitsmarktkonsequenzen der Ostöffnung.' (Consequences for the labour market as a result of opening to the east), ARBEITS-LOS 8: Informationen zur politischen Bildung. Vienna.

PICUM (2007), 'Access to Health Care for Undocumented Migrants in Europe'. Brussels: PICUM.

Pinkerton, C., McLaughlan, G. \& Salt, J. (2004), 'Sizing the illegally resident population in the UK'. Home Office Online Report 58/04. Available at www.homeoffice.gov.uk/ rds/pdfso 4/rdsolr5804.pdf.

Piore, M.J. (1979), Birds of Passage: Migrant Labor and Industrial Societies, New York: Cambridge University Press.

Portes, A. (I995), 'Economic sociology and the sociology of immigration: A conceptual overview', in Portes, A. (ed.), The economic sociology of immigration: Essays on networks, ethnicity and entrepreneurship, I-4I. New York: Russell Sage Foundation.

Portes, A. (1997), Globalisation from Below: The Rise of Transnational Communities. Princeton University. Available at www.transcomm.ox.ac.uk/working per cent2opapers/ portes.pdf.

Portes, A. \& Sensenbrenner, J. (I993), 'Embeddedness and Immigration: Notes on the Social Determinants of Economic Action', American Journal of Sociology 98 (6): I320I350.

Pries, Ludger (ed.) (I999), Migration and Transnational Social Spaces. Aldershot.

Quassoli, F. (I999), 'Migrants in the Italian Underground Economy', International Journal of Urban and Regional Research 23 (2): 212-23I.

Rath, J. (I999), 'The Informal Economy as Bastard Sphere of Social Integration: The Case of Amsterdam', in Eichenhofer, E. (ed.), Migration und Illegalität (Migration and Illegality), II7-I36. Osnabrück: IMIS-Schriften 7.

Rechling, D. (2004), Bezahlte Haushaltsarbeit. Aspekte der Lebenswelten von illegalisierten Migrantinnen. Strukturelle Rahmenbedingungen. Undergraduate thesis, University of Vienna.

Reyneri, E. (I998), 'The Role of the Underground Economy in Irregular Migration to Italy. Cause or Effect?', Journal of Ethnic and Migration Studies 24 (2): 3I3-33I.

Reyneri, E. (200I), 'Migrants' involvement in the underground economy in the Mediterranean countries of the European Union', International Migration Papers 4I. Geneva: International Labour Organization.

Riedel, V. (2000), 'Measures Undertaken to Combat the Employment of Foreigners in an Irregular Situation in Austria', in OECD (ed.), Combating the illegal employment of foreign workers, I39-I42. Paris: OECD Publications.

Rodríguez, E.G. (2007), "The "hidden side" of the new economy: On transnational migration, domestic work, and unprecedented intimacy, Frontiers: A Journal of Women's Studies 26 (3).

Rowe, G., Wright, G. \& Fergus, B. (I99I), 'Delphi: A Re-evaluation of Research and Theory', Technological Forecasting and Social Change 39: 235-25I.

Rubin, H.J. \& Rubin, I. (2005), Qualitative interviewing: The art of hearing data, second edition, Thousand Oaks, California: Sage. 
Salt, J. (I992), 'Migration process among the highly skilled in Europe', International Migration Review 26 (2): 484-505.

Samers, M. (2002), 'Immigration and the global city hypothesis: Towards an alternative research agenda', International Journal of Urban and Regional Research 26: 389-402.

Samers, M. (2003), 'Invisible capitalism: Political economy and the regulation of undocumented immigration in France', Economy and Society 32: 555-583.

Samers, M. (2005), "The "underground economy" - Immigration and economic development in the European Union: An agnostic-sceptic perspective', International Journal of Economic Development 6 (2): I99-272.

Sandelowski M., Holditch-Davis D. \& Harris B.G. (I992), 'Using qualitative and quantitative methods: The transition to parenthood of infertile couples', in Gilgun J.F., Daly K. \& Handel G. (eds.), Qualitative Methods in Family Research, 30I-323. Newbury Park, California: Sage.

Salt, J. \& Stein, J. (I997), 'Migration as a business: The case of trafficking', International Migration 35 (4): $467-494$.

Sassen, S. (1988), The mobility of labor and capital, New York: Cambridge University Press.

Sassen, S. (I99I), The Global City, New York, London, Tokyo: Princeton University Press.

Schatzman L. \& Strauss A.L. (I973), Field Research: Strategies for a Natural Sociology. Englewood Cliffs, New Jersey: Prentice Hall.

Schmid, T. \& Prochazkova, L. (2004), 'Pflege im Spannungsfeld zwischen Angehörigen und Beschäftigung’. Vienna: Kurzfassung, Sozialökonomische Forschungsstelle.

Schneider, F. (2002), 'Die Entwicklung der Schattenwirtschaft (Pfusch) in Österreich und in den Bundesländern Niederösterreich, Oberösterreich, Steiermark und Tirol in den Jahren I990 bis 2002' (The development of the informal sector in Austria and in the federal provinces of Lower Austria, Upper Austria, Styria and the Tyrol from I990 to 2002). Linz: University of Linz.

Schneider, F. (2003), 'Der Umfang der Schattenwirtschaft des Jahres 2003 in Deutschland, Österreich und der Schweiz - Weiteres Anwachsen der Schattenwirtschaft'. Linz: University of Linz.

Schneider, F. (2005), 'Noch rückläufige Schattenwirtschaft in Deutschland - Fluch oder Segen?’. Linz: University of Linz.

Schneider, F. (2006), 'Nur noch leicht sinkende Schattenwirtschaft in Deutschland im Gegensatz zu anderen OECD-Ländern im Jahr 2006: Fluch oder Segen?’. Linz: University of Linz.

Schneider, F. \& Enste, D. (I999), 'Shadow Economies around the World: Size, Causes, and Consequences'. IMF Working Paper WP/oo/26. Available at www.imf.org/external/pubs/ft/wp/2000/wpoo26.pdf.

Schneider, F. \& Enste, D. (2000), 'Schattenwirtschaft und Schwarzarbeit: Umfang, Ursachen, Wirkungen und wirtschaftspolitische Empfehlungen' (Shadow economy and black labour: Extent, reasons, impact and economic policy implications), Forum Wirtschaft und Soziales (FWS). Munich/Vienna: R. Oldenbourg Verlag.

Schneider, F. \& Klinglmair, R. (2004), 'Shadow Economies around the World: What do We Know?'. Working Paper 0403, Department of Economics, University of Linz.

Schönwälder, K., Vogel, D. \& Sciortino G. (2004), 'Migration und Illegalität in Deutschland' (Migration and Illegality in Germany), AKI-Forschungsbilanz I, Arbeitsstelle Interkulturelle Konflikte und gesellschaftliche Integration (AKI), Wissenschaftszentrum Berlin für Sozialforschung (WZB).

Sciortino, G. (2004a), 'Immigration in a Mediterranean Welfare State: The Italian Experience in Comparative Perspective', Journal of Comparative Policy Analysis 6 (2): IIII29. 
Sciortino, G. (2004b), 'Between Phantoms and Necessary Evils: Some Critical Points in the Study of Irregular Migrations to Western Europe', IMIS Beiträge 24: I7-43. Osnabrück: Vorstand des Instituts für Migrationsforschung und Interkulturelle Studien (IMIS) an der Universität Osnabrück.

Sheldon, G. (2002), 'Forschungsdesign zur Bestimmung des Ausmasses und der Struktur der Schwarzarbeit in der Schweiz, Forschungsstelle für Arbeitsmarkt- und Industrieökonomik'. Basel: University of Basel.

Sinn, A., Kreienbrink, A., von Loeffelholz, H.D. \& Wolf M. (2005), 'Illegally resident third-country nationals in Germany: Policy approaches, profile and social situation'. Nuremberg: German National Contact Point of the European Migration Network, Federal Office for Migration and Refugees. Available at www.bamf.de/SharedDocs/ Anlagen/DE/Migration/Downloads/EMN/2research-2-2005-illegals,templateId=raw, property=publicationFile.pdf/2research-2-2005-illegals.pdf.

Sjaastad, L. A. (I962), 'The costs and returns of human migration', Journal of Political Economy 705: 80-93.

Snel, E., Engbersen, G. \& Leerkes, A. (2006), 'Transnational involvement and social integration, Global Networks 6 (3): 265-284.

Social Impact (2000), Zur Situation illegaler ausländischer Putzfrauen (On the Situation of Illegal Foreign Cleaning Women). Vienna.

Stark, O. (I99I), The Migration of Labor. Cambridge, Massachusetts: Basic Blackwell.

Stark, O. \& Bloom, D. (I985), 'The New Economics of Labor Migration, American Economic Review 75 (2): I73-I78.

Stark, O. \& Taylor, E. (I989), 'Relative deprivation and international migration', Demography 26 (I): I-I4.

Staudinger, F. (I992), Illegale Beschäftigung und Schwarzarbeit von Ausländern (Illegal Employment and Moonlighting of Foreigners). Undergraduate thesis, Institut für Soziologie, University of Linz.

Steineck, A. (I994), Ökonomische Anforderungen an eine europäische Zuwanderungspolitik. Baden-Baden: Nomos Verlagsgesellschaft.

Stobbe, H. (2004), Undokumentierte Migration in Deutschland und den Vereinigten Staaten. Interne Migrationskontrollen und die Handlungsspielräume von Sans Papiers (Undocumented Migration in Germany and the US: Internal Migration Controls and the Room for Manoeuvre for Undocumented Migrants). Göttingen: Universitätsverlag Göttingen.

Talbot, C. (2004), 'The Invisible Hand's Shadow', a conference on the policy implications of the shadow economy, Nottingham Policy Centre, University of Nottingham, Nottingham, 25 May 2004 .

Tamas, K. (2004), 'Mapping Study on International Migration', Institute for Futures Studies, Stockholm. Available at www.framtidsstudier.se/filebank/files/2005ı206 \$I64548\$fil\$6oIlJ56KrbCJu2u9U5u5.pdf.

Tamas, K. \& Münz, R. (2006), 'Labour Migrants Unbound? EU Enlargement, Transitional Measures and Labour Market Effects', Institute for Futures Studies, Stockholm.

Tapinos, Georges (I999): 'Clandestine Immigration: Economic and Political Issues', in OECD/Sopemi (eds.), Trends in International Migration, 229-25I. Paris: OECD Publications.

Todaro, M. P. (I976), 'Internal migration in developing countries'. Geneva: International Labour Organization.

Treibel, A. (I990), Migration in modernen Gesellschaften. Soziale Folgen von Einwanderung und Gastarbeit. Weinheim/Munich: Juventa Verlag.

Veiga, U. M. (I999), 'Immigrants in the Spanish Labour Market', in Baldwin-Ewards, M. \& Arango , J. (eds.), Immigrants in the Informal Economy in Southern Europe, I05-I28. 
Vertovec, S. (I999), Conceiving and Researching Transnationalism, Ethnic and Racial Studies 22 (2): 447-462.

Vertovec, Steven (200I), 'Transnational Social Formations: Towards Conceptual Cross-Fertilisation'. WPTC-OI-I6 - ESRC Research Programme on Transnational Communities, Oxford.

Vertovec, S. (2004), Trends and impacts of migrant transnationalism. Oxford: Compas.

Vogel, D. (2003), 'Illegaler Aufenthalt. Konzepte, Forschungszugänge, Realitäten, Optionen’ (Illegal Residence: Concepts, Research Approaches, Realities, Options), in Thränhardt, D. \& Hunger, U. (eds.), Migration im Spannungsfeld von Globalisierung und Nationalstaat (Migration in the Tension between Globalisation and Nation State), I6II79. Wiesbladen: Westdeutscher Verlag.

Wallace, C. (2002), 'Opening and Closing Borders: Migration and Mobility in East-Central Europe', Journal of Ethnic and Migration Studies 28 (4): 603-625.

Wallerstein, I. (I974), The modern world system: Capitalist agriculture and the origins of the European world economy in the sixteenth century. New York: Academic Press.

Witzel, A. (2000), 'The problem-centred interview' [27 paragraphs]. Forum Qualitative Social Research [Online Journal] I (I). Available at www.qualitative-research.net/fqstexte/I-oo/I-oowitzel-e.htm.

Williams, C. C. \& Windebank, J. (I998), Informal Employment in the Advanced Economies: Implications for Work and Welfare. London/New York: Routledge.

Yeats, N. (2006), 'Changing Places: Ireland in the International Division of Reproductive Labour, Translocations', The Irish Migration, Race and Social Transformation Review I (I): 5-2I.

Zulauf, M. (200I), Migrant women professionals in the European Union. New York: Palgrave. 
Other IMISCOE titles

IMISCOE Research

Rinus Penninx, Maria Berger, Karen Kraal, Eds.

The Dynamics of International Migration and Settlement in Europe:

A State of the Art

2006 (ISBN 9789053568668 )

(originally appearing in IMISCOE Joint Studies)

Leo Lucassen, David Feldman, Jochen Oltmer, Eds.

Paths of Integration: Migrants in Western Europe (1880-2004)

2006 (ISBN 978905356883 5)

Rainer Bauböck, Eva Ersbøll, Kees Groenendijk, Harald Waldrauch, Eds. Acquisition and Loss of Nationality: Policies and Trends in 15 European Countries, Volume 1: Comparative Analyses

2006 (ISBN 978905356920 7)

Rainer Bauböck, Eva Ersbøll, Kees Groenendijk, Harald Waldrauch, Eds. Acquisition and Loss of Nationality: Policies and Trends in 15 European Countries, Volume 2: Country Analyses 2006 (ISBN 978905356 921 4)

Rainer Bauböck, Bernhard Perchinig, Wiebke Sievers, Eds.

Citizenship Policies in the New Europe

2007 (ISBN 978905356922 I)

Veit Bader

Secularism or Democracy? Associational Governance of Religious Diversity 2007 (ISBN 978905356999 3)

Holger Kolb \& Henrik Egbert, Eds.

Migrants and Markets: Perspectives from Economics and the Other Social Sciences

2008 (ISBN 9789053566848 )

Ralph Grillo, Ed.

The Family in Question: Immigrant and Ethnic Minorities in

Multicultural Europe

2008 (ISBN 978905356869 9) 
Corrado Bonifazi, Marek Okólski, Jeannette Schoorl, Patrick Simon, Eds. International Migration in Europe: New Trends and New Methods of Analysis 2008 (ISBN 978905356894 I)

Maurice Crul, Liesbeth Heering, Eds.

The Position of the Turkish and Moroccan Second Generation in Amsterdam and Rotterdam: The TIES Study in the Netherlands 2008 (ISBN 978908964 06I I)

Marlou Schrover, Joanne van der Leun, Leo Lucassen, Chris Quispel, Eds. Illegal Migration and Gender in a Global and Historical Perspective 2008 (ISBN 9789089640475 )

\section{IMISCOE Reports}

Rainer Bauböck, Ed.

Migration and Citizenship: Legal Status, Rights and Political Participation 2006 (ISBN 978905356888 o)

Michael Jandl, Ed.

Innovative Concepts for Alternative Migration Policies:

Ten Innovative Approaches to the Challenges of Migration in the 21st Century 2007 (ISBN 978905356990 0)

Jeroen Doomernik \& Michael Jandl, Eds.

Modes of Migration Regulation and Control in Europe

2008 (ISBN 978905356689 3)

\section{IMISCOE Dissertations}

Panos Arion Hatziprokopiou

Globalisation, Migration and Socio-Economic Change in Contemporary Greece: Processes of Social Incorporation of Balkan Immigrants in Thessaloniki

2006 (ISBN 9789053568736 )

Floris Vermeulen

The Immigrant Organising Process: Turkish Organisations in Amsterdam and Berlin and Surinamese Organisations in Amsterdam, 1960-2000 2006 (ISBN 978905356875 o) 
Anastasia Christou

Narratives of Place, Culture and Identity: Second-Generation

Greek-Americans Return 'Home'

2006 (ISBN 978905356878 I)

Katja Rušinović

Dynamic Entrepreneurship: First and Second-Generation Immigrant

Entrepreneurs in Dutch Cities

2006 (ISBN 9789053569726 )

Ilse van Liempt

Navigating Borders: Inside Perspectives on the Process of Human Smuggling into the Netherlands

2007 (ISBN 9789053569306 )

Myriam Cherti

Paradoxes of Social Capital: A Multi-Generational Study of Moroccans

in London

2008 (ISBN 9789053560327 )

Marc Helbling

Practising Citizenship and Heterogeneous Nationhood: Naturalisations in Swiss Municipalities

2008 (ISBN 978908964034 5)

Inge Van Nieuwenhuyze

Getting by in Europe's Urban Labour Markets: Senegambian Migrants'

Strategies for Survival, Documentation and Mobility

2009 (ISBN 978908964050 5) 